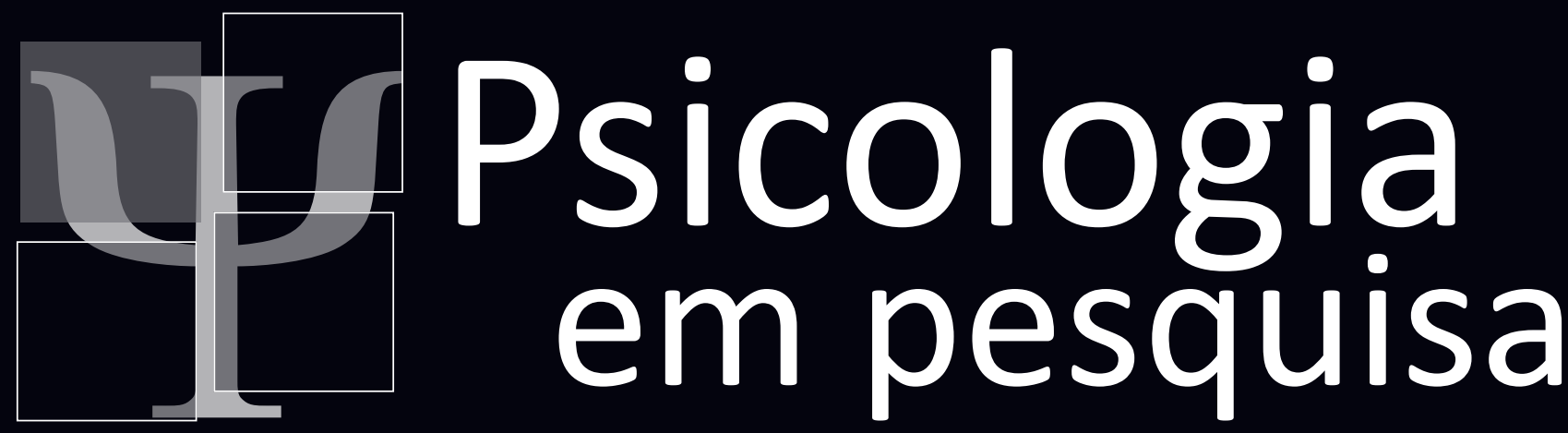

Revista do Programa de Pós-Graduação em Psicologia da UFJF

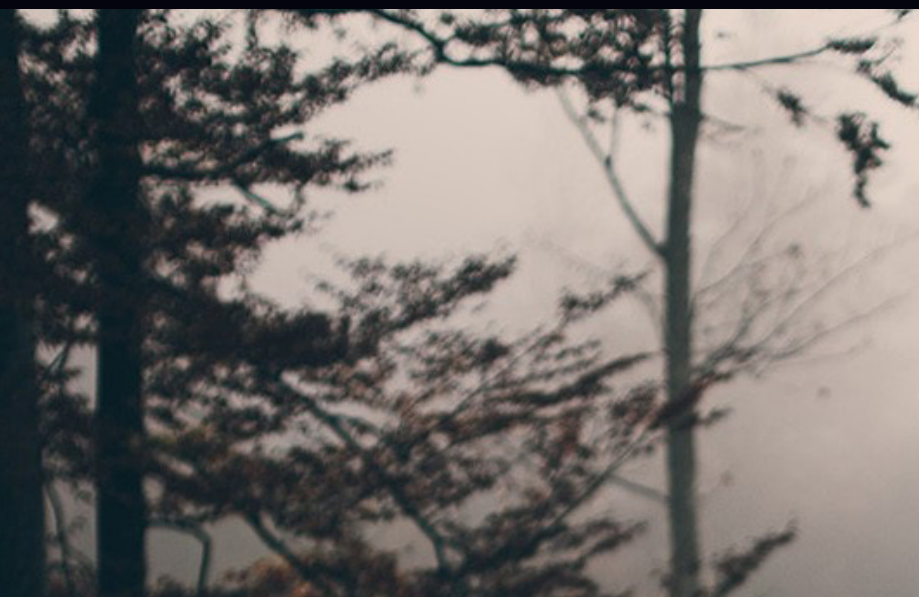

Volume 13 | Número 1 


\section{Psicologia em Pesquisa}

ISSN 1982-1247

Programa de Pós-Graduação em Psicologia da UFJF | Brasil Volume 13 Número 1

Janeiro - Abril de 2019

\section{Missão}

Psicologia em Pesquisa é uma revista quadrimestral (abril, agosto e dezembro) do Programa de Pós-Graduação em Psicologia da Universidade Federal de Juiz de Fora (UFJF) e tem como público alvo pesquisadores, docentes e profissionais de psicologia e demais áreas correlatas.

Seu objetivo principal é promover a produção e a divulgação do conhecimento científico no campo da Psicologia e de suas áreas afins. Para tanto, prioriza a publicação de artigos originais que relatam os resultados de pesquisas empíricas ou teóricas. Também são publicadas outras comunicaçóes científicas originais como, por exemplo, revisão de literatura, ensaio teórico, resenha, entrevista, relato de experiência, que tenham relevância para a Psicologia e suas áreas correlatas. Os manuscritos podem ser submetidos em português, inglês ou espanhol.

Com a meta de assegurar uma avaliação imparcial e promover um intercâmbio entre os autores e seus pares, todos os manuscritos submetidos à Psicologia em Pesquisa são avaliados segundo um processo de revisão às cegas por pares, seguindo orientaçóes do Committee on Publication Ethics (COPE) em todos os aspectos éticos e, em especial, em relação a casos de má conduta e plágio em publicaçóes acadêmicas.

\section{Editor-Chefe}

Telmo Mota Ronzani - UFJF

\section{Editores Associados}

Fernando Antônio Basile Colugnati - UFJF

Francis Ricardo dos Reis Justi - UFJF

Francisco Teixeira Portugal - UFRJ

Jorge Artur Peçanha de Miranda Coelho - UFAL

Saulo de Freitas Araujo - UFJF

\section{Comissão de Política Editorial}

Altemir José Gonçalves Barbosa - UFJF

Juliana Perucchi - UFJF

Lélio Moura Lourenço - UFJF

Marisa Consenza Rodrigues - UFJF

Saulo de Freitas Araujo - UFJF

\section{Assistentes do Editor}

Brune Coelho Brandão (UFJF)

Eduardo Cormanich - UFJF

Maira Leon Ferreira - UFJF

María Elena Iturriaga Goroso (UFJF)

\section{Equipe Técnica}

Leonardo Melo Guedes (UFJF)

Mayra Bibiano Caixeiro - UFJF

\section{Produçáo Editorial}

Traço Leal Comunicação

\section{Conselho Editorial}

Acácia Angeli Aparecida dos Santos - USF

Adelina Guisende - Universidad de Santiago de Compostela (Espanha) Adrian Daños - Universidad Nacional de Tucumán (Argentina)

Alexander Moreira-Almeida - Universidade Federal de Juiz de Fora (UFJF)
Ana Maria Jacó Vilela - Universidade Estadual do Rio de Janeiro (UERJ) Andrés Felipe Tirado - Universidad Pontificia Bolivariana (Colombia) Ann Dowker - University of Oxford

Antônio Castanheira Neves - Centro Federal de Educação Tecnológica Celso Suckow da Fonseca- (CEFET RJ)

Carla Witter - Universidade Sáo Judas Tadeu

Claudio Garcia Capitão - Universidade São Francisco

Denise De Micheli, Professora Adjunta da Disciplina de Medicina e Sociologia do Abuso de Drogas - Departamento de PsicobiologiaUniversidade Federal de São Paulo

Eduardo José Manzini - Universidade Estadual Paulista (UNESP)

Enrique Saforcada - Universidade de Buenos Aires (UBA)

Erikson Furtado - USP

Feliciano Henriques Veiga (Universidade de Lisboa, Portugal)

Fernando Vidal - Universitat Autònoma de Barcelona (Espanha)

Gerardo Pietro - Universidad de Salamanca (Espanha)

Gerson Yukio Tomanari - USP

Joana R. Silva - Universidade do Porto (Portugal)

José Antonio Damasio Abib - Ufscar

Leandro Almeida - Universidade do Minho (Portugal)

Makilim Nunes Baptista - Universidade São Francisco (USF)

Marcelo Rossal - Universidad de la República (UDELAR), Uruguai

Marcia Mota - Universidade Estadual do Rio de Janeiro (UERJ)

Marcos Emanoel Pereira - UFBA

Marcus Bentes de Carvalho - UFPA

Maria do Carmo Guedes - PUC-SP

Miguel M. O. Gonçalves - Universidade do Minho (Portugal)

Monica Sanches Yassuda - USP

Richard Saitz - Boston University (EUA)

Richard Thensen Simanke - UFJF

Rodrigo Teixeira Lopes - Universidade Católica de Petrópolis (UCP)

Sandra Regina K. Guimaraes - UFPA

Sonia Maria Gondim - UFBA

Thomas Sturm - Universitat Autònoma de Barcelona (Espanha)

Verônica Morais Ximenes - Universidade Federal do Ceará, Brasil

Willian Barbosa Gomes - UFRS

Zilda Aparecida Pereira Del Prette - Ufscar 


\section{Psicologia em Pesquisa}

ISSN 1982-1247

Programa de Pós-Graduação em Psicologia da UFJF | Brasil

Volume 13 Número 1

Janeiro - Abril de 2019

\section{Sumário}

\section{Artigos / Articles}

\section{Processos Psicossociais em Saúde}

01 Políticas sociais e subjetividade: discussóes a partir do contexto neoliberal Rafael Bianchi Silva, Ana Clara Siena Alexandre

12 Fatores de risco psicossocial relacionados ao estresse em trabalhadores terceirizados: uma revisão Marina Bernardo Mandarini, Marina Greghi Sticca

22 Estigma social de profesionales de la salud hacia personas que usan drogas Andrés Felipe Tirado Otálvaro, Gustavo Adolfo Calderón Vallejo, Sandra Milena Restrepo Escobar, Valentina Vásquez Gallón, Isabel Cristina Orozco Giraldo

33 Relaciones sociales y prácticas cotidianas del habitante de calle en Medellín, Colombia Maricelly Gómez Vargas, Gustavo Adolfo Calderón Vallejo, Lucas Dávila Cañas,

María Jimena Osorio Salazar, Emerson José Caro Cencio, Jonhatan Castaño Gómez

42 Mulheres e loucura: a (des)institucionalização e as (re)invençóes do feminino na saúde mental Thaiga Danielle Momberg Silva, Marcos Roberto Vieira Garcia

53 Transtornos Mentais Comuns entre Trabalhadores do Sistema Prisional Ana Izabel Oliveira Lima, Magda Dimenstein

64 Práticas sexuais de homens que fazem sexo com homens: adaptaçáo de questionário Raquel de Andrade Souza Ew, José Manuel Martinez, Fernanda Torres de Carvalho, Kátia Bones Rocha

Evidências de estrutura interna da Escala Baptista de Depressão - Versão Idoso (EBADEP-ID) Makilim Nunes Baptista, Felipe Augusto Cunha, Maria Andreia da Nóbrega Marques

\section{Desenvolvimento Humano e Processos Sócio-Educativos}

86 Traços frios e insensíveis no DSM-V: Implicações teóricas e clínicas para o estudo da psicopatia Guilherme Welter Wendt, Silvia Koller

97 Percepçáo de professores dos problemas de comportamento em duas amostras clínicas com TDAH: Brasil e Espanha

Ana Flávia Lima Teles da Hora, Simone Souza da Costa Silva, Concepción López Soler 



\title{
Políticas sociais e subjetividade: discussóes a partir do contexto neoliberal
}

Social policies and subjectivity: discussions from the neoliberal context

\author{
Rafael Bianchi Silva ${ }^{1}$ \\ Ana Clara Siena Alexandre ${ }^{2}$ \\ Universidade Estadual de Londrina- Brasil
}

\begin{abstract}
Resumo
O presente artigo é resultado de uma pesquisa envolvendo as questôes da subjetividade em detrimento de um recente projeto político que se desenvolve no Brasil: o neoliberalismo. A partir desses elementos, objetiva-se a discussão acerca das influências neoliberais, as quais acarretam em novos modos de gestão política e, consequentemente, propicia mudanças nas formas de gerir as políticas sociais. Além disso, discute-se sobre tais impactos nas políticas sociais, visto que o neoliberalismo visa o afastamento do Estado dos assuntos sociais e econômicos, e seus desdobramentos no que diz respeito a produção de novos modos de subjetivação neste novo cenário político que emerge.
\end{abstract}

Palavras--chave: Neoliberalismo; Subjetividade; Políticas sociais; Psicologia.

\section{Abstract}

This article is the result of a research involving the issues of subjectivity to the detriment of a recent political project that develops in Brazil: neoliberalism. It is on the basis of these elements that the discussion about neoliberal influences is carried out, which lead to new modes of political management and, consequently, to changes in the ways of managing social policies. In addition, it discusses such impacts on social policies, since neoliberalism aims at the removal of the State from social and economic affairs, and its consequences for the production of new modes of subjectivation in this emerging political scene.

Keywords: Neoliberalism; Subjectivity; Social politics; Psychology.

Este relato de pesquisa é resultado de uma investigação acerca dos novos modos de produção de subjetividade preconizada pela emergência do neoliberalismo no Brasil, que reconfigura a relação do Estado para com as políticas sociais e, consequentemente, produz efeitos nas formas de viver e se relacionar, visto que o neoliberalismo, para além de um projeto político, é uma teoria que transformou-se "(...) numa verdadeira concepção de mundo” (Gros, 2002, p.82), caracterizando-se como uma espécie de doutrina econômica, que visa a individualidade, além de, consequentemente, inviabilizar a garantia de direitos sociais e civis garantidos constitucionalmente.

Inicialmente, fez-se um breve histórico sobre o neoliberalismo, contextualizando-o enquanto doutrina econômica que se faz presente neste modelo de projeto político, o qual tem assolado o cenário político brasileiro desde a primeira eleição direta e permanece até os dias atuais, a contraposição com outros modelos de Estado (como, por exemplo, o Estado de Bem Estar Social, o qual será abordado neste trabalho) e seus desdobramentos até sua implementação no Brasil. Considerando tais aspectos e a situação política brasileira, este estudo se desdobra sobre tais acontecimentos a fim de retratar como as situaçóes sociais e políticas contribuem para a construção da subjetividade na contemporaneidade, haja vista que se vive em um período sociopolítico de crise. Após esse primeiro momento, é feita uma análise entre a relação de um Estado neoliberal com as políticas sociais e, por fim, sua influência para o surgimento de novos modos de subjetivaçáo.

Assim, a implementação e execução de políticas sociais possuem íntima relação com o papel do Estado para concretizá-las, visto que a questão social entendida como “(...) o conjunto das expressóes das desigualdades da sociedade capitalista" (Alves, Vilela \& Rodrigues, 2013, p.6), decorrentes dos acontecimentos históricos, é o que norteia o surgimento destas políticas, significando que o Estado “(...) combinou medidas de caráter social sem, contudo, perder seu caráter capitalista" (Pastor \& Brevilheri, 2009, p.141). Contudo, com as mudanças nos cenários político e

\footnotetext{
${ }^{1}$ Universidade Estadual de Londrina Brasil. Doutor em Educação (Unesp/Marília). Docente do Departamento de Psicologia Social e Institucional e do Programa de Pós-Graduação em Psicologia da Universidade Estadual de Londrina (UEL).

${ }^{2}$ Estudante do curso de Psicologia da Universidade Estadual de Londrina e Bolsista de Iniciaçáo Científica (PROIC/UEL).
} 
econômico do Brasil, principalmente a partir do que foi chamado de onda neoliberal, as políticas públicas e sociais vêm sofrendo ataques, incluindo o desmantelamento da proteção e direitos sociais previstos e assegurados constitucionalmente.

\section{VISÁO NEOLIBERAL}

A história do neoliberalismo sugere que, seu surgimento teve início entre os anos 1960 e 1970, com implementação a partir das décadas de 1970 e 1980, na Inglaterra com Margareth Tatcher e nos Estados Unidos com o então presidente Ronald Reagan (Setti, 2002). Enquanto isso, na América Latina dos anos 1980, o Chile experienciou o neoliberalismo durante a ditadura de Pinochet, levando-o a ser o primeiro país que “(...) se constituiu no primeiro ciclo neoliberal da história contemporânea" (Pereira, 2004, p.19). Enquanto base de seu fundamento (que remonta, por exemplo, às ideias dos economistas Friedrich August von Hayek e Milton Friedman), a teoria neoliberal aponta "os critérios para uma sociedade baseada na livre concorrência e praticamente na ausência do Estado como agente regulador da sociedade" (Setti, 2002, parágrafo 27), além de defender a mínima interferência do Estado para com a sociedade e, principalmente, seu afastamento da economia.

Assim, o neoliberalismo caracteriza-se enquanto uma doutrina econômica materializada em forma de um projeto político influenciado diretamente pela dinâmica do sistema capitalista, apresentando-se como uma alternativa às crises cíclicas econômicas provenientes de tal modelo. Alguns fatos históricos deram um impulso para que o neoliberalismo se difundisse. Dentre esses destaca-se, desde a queda do muro de Berlim e o fim da Guerra Fria, a um grande desenvolvimento tecnológico (em especial no campo da eletrônica e comunicação) que chegam à reorganização do capitalismo na forma de neoliberalismo (Setti, 2002). Segundo Cerqueira (2008):

O conjunto de medidas dessa ordem quando implementadas visam, de um lado, a diminuição da participação do Estado como agente produtivo e regulamentador da economia na promoção do Estado de bem-estar e, por outro lado, a transferência de recursos financeiros para o Estado a serem carreados para atividade produtiva e/ou investimentos que beneficiem e ampliem a participação das empresas na economia (Cerqueira, 2008, p.174).
Em decorrência das mudanças acima indicadas, destaca-se outro ponto importante para a disseminação dos ideais neoliberais (e suas consequências na política e nas dinâmicas socioculturais, visto que o neoliberalismo também é uma doutrina econômica): a globalização, um cenário no qual os comércios e bancos internacionais podem se comunicar, ultrapassando as barreiras nacionais, e transmitindo mercadorias e informaçóes de forma mundial. A partir disso, Nunes (2003) indica que “(...) o neoliberalismo é o núcleo da matriz ideológica da política de globalização que vem marcando a actual fase do capitalismo à escala mundial" (Nunes, 2003, p.423).

De acordo com Ianni (1998), “a globalização pode assim ser definida como a intensificaçáo das relaçóes sociais em escala mundial, que ligam localidades distantes de tal maneira que acontecimentos locais são modelados por eventos ocorrendo a muitas milhas de distância e vice-versa" (Ianni, 1998, p.151), sugerindo a formação de uma sociedade quase única devido a ultrapassagem dessas barreiras. Nesse sentido, trata-se então, de um fenômeno o qual “(...) acaba produzindo a "flexibilização" de diversos direitos sociais, enfraquecendo a soberania dos Estados-Nação e indicando severas mudanças em suas características" (Mello $\&$ Veronese, 2013, p.245).

Entretanto, com o desenvolvimento dos ideais neoliberais provindos desses acontecimentos, a implementação do neoliberalismo, com intuito de resolver a crise financeira, acarretou em outras questóes. De acordo com Harvey “(...) uma desigualdade social crescente tem sido de fato uma característica tão persistente do neoliberalismo que pode ser considerado estrutural em relaçáo ao projeto como um todo" (Harvey, 2008, p.27), delimitando, então, em conjunto com o aumento das desigualdades, o restabelecimento de poder das classes sociais mais altas.

Nesse sentido, o projeto político que visa a mínima intervenção do Estado no sentido do âmbito da administração pública para com as questóes no campo das políticas sociais (em contraposição ao investimento público presente no modelo de Bem Estar Social), atrela-se a proposição e defesa das propriedades privadas e liberdade de empreendimento (nos quais incluem-se o ramo dos negócios e as empresas) tomadas aqui como principais fonte de investimento e motor econômico. Segundo Mariani (2007):

O mercado e o setor privado são sinônimos de eficiência, de qualidade e de equidade. A solução torna-se, então, o Estado mínimo e a 
necessidade de questionar todas as conquistas sociais, como a estabilidade de emprego, o direito à saúde, à educação e aos transportes públicos. O Estado deve ser reduzido a uma proporçáo mínima, apenas necessária para a reprodução do capital (Mariani, 2007, p.3).

Em contrapartida, o modelo capitalista voltado para a expansão da indústria e valorizaçáo da dimensão do capital privado, o Estado de Bem Estar Social apresentou uma alternativa para amenizar os efeitos do capitalismo, sem, contudo, deixar de ser capitalista, tendo como principal teórico o economista John Maynard Keynes. De acordo com Arienti (2003) “(...) o Estado keynesiano e do bem-estar social contribuiu para a formação de um amplo compromisso social ao garantir pleno emprego e expansão da seguridade social e, por esta razão, considera-se como o Estado ligado ao modo de regulação social da economia" (Arienti, 2003, p.110). Entretanto, conforme pontua Soares (2009) “(...) o Estado, na sua relação com a sociedade, é uma condensação de forças econômicas e extra-econômicas que operam dentro e fora do aparelho estatal tendo em vista a satisfação de interesses de classe contrários entre si” (Soares, 2009, p.163).

Observa-se que nesse modelo, o Estado pode ser tomado a partir de um caráter intervencionista, ou seja, gerador de bens públicos e mediador da economia, além de provedor de políticas protecionistas. A partir de tais características tem-se também a possibilidade de maior desenvolvimento e ampliação dos direitos civis, promovendo uma maior participaçáo social, visto que nesse momento tem-se a preocupação com a proteção social.

Com a intervenção estatal na economia, a expansão dos setores públicos e a redistribuição de renda foram pontos importantes deste modelo. Para além disso, também era preciso gerar lucro e fazer girar a economia, favorecendo as políticas de consumo, algo que passou a ser importante em vista da ampliaçáo do plano industrial. Entretanto, com essa intervençáo, aumentou-se os gastos gerando, com o passar dos anos, um déficit orçamentário. Por isso, de acordo com Forigo (2012):

(...) o Estado do Bem-Estar Social, entrou em crise desde os anos 70, sendo questionado porque, enquanto modelo econômico, fez aumentar o déficit público, propiciou o crescimento de empresas improdutivas, desestimulou o trabalho e a competitividade, reduziu a capacidade de poupança e o excedente de capital para ser reinvestido na produçáo, além de gerar uma enorme inflação (Forigo, 2012, p.56)

Como consequências disso, tem-se a incidência de discursos que apontavam para uma espécie de falência do Estado, gerando a necessidade de mudanças que atingissem tanto no sistema econômico quanto no papel do Estado nesse processo. Desde então, o modelo de Estado neoliberal foi proposto como alternativa ao modelo de Bem-Estar Social (que no Brasil, pode-se observar traços na Constituição de 1988, porém, sem a sua efetiva materialização nos governos subsequentes), sustentando valores como livre mercado e livre-iniciativa, radicalizando a separaçáo entre economia e política, com o Estado intervindo cada vez menos na economia, ocupando a sua funçáo "guarda noturno" (ou seja, proteger a propriedade privada e reprimir qualquer manifestação de descontentamento com o sistema), trazendo o discurso de que "Uma dessas narrativas - talvez uma das mais bem-sucedidas, no sentido de operar como instrumento de coesão social e imposição das idéias dominantes - é aquela que explica os problemas derivados das políticas sociais ou do Estado de Bem-Estar Social” (Moraes, 2002, pp.14-15), pois o investimento nos programas e políticas sociais trariam um prejuízo no sentido do alto investimento nestas para sua consolidação, contribuindo para a ascensão do neoliberalismo.

\section{NEOLIBERALISMO E O CONTEXTO BRASILEIRO}

Com base no exposto sobre o neoliberalismo, entende-se que quanto menos intervenção estatal referente às políticas sociais, melhor as relaçóes de lucro e de acúmulo de riqueza para o Estado, uma vez que o mercado é "(...) o mais eficiente organizador da sociedade" (Gennari, 2002, p.42). Ao adotar um caráter minimamente interventor, o Estado abre espaço para a iniciativa privada estimular a economia a partir da concepçáo de liberdade de mercado.

Assim, o setor privado passaria a ter maior autonomia para atuar no mercado. Como desdobramento desse processo, a ampliação da capacidade de ação do capital privado e o aumento do investimento por parte das empresas, acarretaria, por exemplo, em tese, pela movimentaçáo da economia, maior geração de empregos e aumento do poder de compra devido principalmente pela ampliação do capital circulante. 
É nesse sentido, então, que o investimento em privatizaçóes como política de Estado passa a ser defendida. Ao mesmo tempo em que diminui o papel do Estado no que tange aos serviços por ele executados, amplia a participação de capital privado e agiliza o modo com que essas empresas possam atuar no mercado. Ainda que em um primeiro momento esteja sujeita a diminuição de empregos, com a ampliaçáo do lucro derivados da sua otimizaçáo, essas empresas acabariam por levar a um aumento de oferta de empregos (náo apenas de ordem direta) e, consequentemente, faria a economia se movimentar, promovendo o desenvolvimento do país. De acordo com Mendonça (2003) “(...) o desenvolvimento sustentável [do Estado e da economia] passa a depender do setor privado, já que somente a elevação da taxa de investimento, impulsionada pelas empresas privadas, poderá sustentar uma nova etapa de crescimento" (Mendonça, 2003, p.5).

Entretanto, autores como Magalhães (2016) afirmam que o neoliberalismo não tem como característica o afastamento e esvaziamento do Estado, mas sim “(...) um fortalecimento do Estado a partir de uma forma reestruturada de sua atuação" (Magalhães, 2016, p.36). Nesse sentido, pode-se pensar então que a reestruturação do Estado, acima descrita, seria a sua intervenção enquanto regulador no que diz respeito à manutenção da ordem, ao livre mercado e a propriedade.

Pela influência dessas ideias, no Brasil, é considerado que o neoliberalismo iniciou-se a partir dos anos 1990 com os governos de Fernando Collor de Mello e, posteriormente, de Fernando Henrique Cardoso (conhecido como governo FHC). De acordo com Souza (2003):

Diante da incapacidade de auto-financiamento do Estado, da reduçáo nas taxas de poupança agregada doméstica, das ingentes necessidades de financiamento externo, das profundas mudanças políticas e econômicas no socialismo real, especialmente no leste europeu e China, das forças persuasivas da globalização neoliberal, o Brasil aderiu plenamente ao modelo, elegendo inequivocamente Fernando Collor de Mello, para a Presidência da República, nos 2 turnos, em 1989 (Souza, 2003, p.4).

No governo Collor, as medidas tomadas foram influenciadas pelas políticas marcadas por seu cunho neoliberal, implementando, assim, segundo Maciel (2011):
(...) uma orientação marcadamente ortodoxa, baseada na alta dos juros, restrição ao crédito, no corte de gastos públicos, na liberalização da área financeira e na renegociação da dívida externa, estas últimas medidas visando favorecer a entrada de capitais e a melhora das relaçóes com o sistema financeiro internacional (Maciel, 2011, p.103).

Dentre as realizaçóes do governo, o que se destaca é o Plano Collor, em 1990 que predispóe das seguintes medidas:

(...) a mudança do signo da moeda, a desindexação geral, principalmente entre preços e salários, reformulação dos mercados cambiais, com a criação do dólar livre para as operaçóes de exportação, importação e transações financeiras, programa de privatização, de desregulamentação, supressão de subsídios, reforma administrativa (...) (Gennari, 2002, p.36).

Já no governo Fernando Henrique Cardoso, os processos de liberalização, privatizaçáo e desregulamentação foram intensificados, na qual o investimento nas relações com o setor externo era o plano central do governo. Entre os anos de 1995 e 2002, pôde-se ver o avanço de ideais neoliberais a partir de açóes como o avanço da terceirização no interior do governo, a liberalização comercial e financeira, bem com as reformas trabalhista e previdenciária, inserindo no Brasil uma outra relaçáo entre mercado, economia e Estado. Como indica Sallum Jr (2000):

Foram suspensas as barreiras não-tarifárias às compras do exterior e implementou-se um programa de redução progressiva das tarifas de importação ao longo de quatro anos. Ao mesmo tempo, implantou-se um programa de desregulamentação das atividades econômicas e de privatização de empresas estatais (não protegida pela Constituição) para recuperar as finanças públicas e reduzir aos poucos o seu papel na impulsão da indústria doméstica (Sallum Jr, 2000, p.27).

Entretanto, mesmo com as propostas do governo Fernando Henrique Cardoso (FHC) rumo ao avanço do neoliberalismo no Brasil, é nesse período que se destacam leis, anteriormente criadas, que visavam garantir 
direitos previstos na Constituição Federal Brasileira promulgada em 1988. Nela, a seguridade social tornou-se direito de todo cidadáo brasileiro, inaugurando um novo cenário para as políticas sociais como a Previdência Social, a Saúde - implementação do Sistema Único de Saúde (SUS) - e a Assistência Social (que envolveu, por exemplo, a consolidação da Lei Orgânica de Assistência Social - LOAS, promulgada em 1993).

De acordo com o avanço dos ideais neoliberais, então, implementam-se as chamadas políticas focalizadas, tendo como objetivo a descentralização das políticas sociais com a seguridade social. Segundo Pereira, Silva e Patriota (2006):

(...) a atual configuração do capital determina novas modalidades de reprodução da força de trabalho, ancoradas principalmente nos processos de privatização, focalização e descentralização das políticas sociais. (...) É esta perspectiva que vem determinando as tendências das políticas sociais no Brasil, que em oposição à universalização e a integração com as outras esferas da seguridade social, passando a ser centralizadas em programas sociais emergenciais e seletivos, enquanto estratégias de combate à pobreza (Pereira, Silva \& Patriota, 2006, parágrafo 55).

Observa-se também que os mandatos seguintes representado pelas duas gestôes de Luiz Inácio Lula da Silva e, posteriormente, o governo de Dilma Rousseff (2011-2016), apresentaram aspectos relacionados à manutenção das características neoliberais, inclusive no que diz respeito aos programas sociais. O governo Lula - que vigorou de 2003 a 2010 - caracterizou-se quanto a tentativa de ampliação da distribuição de renda e programas para a erradicação da fome no país, como o Programa Bolsa Família e Fome Zero, conhecidos como programas sociais os quais fazem parte das políticas de focalizaçáo. Entretanto, como ressaltam Yamamoto e Oliveira (2010), algumas características neoliberais se mantiveram, como, por exemplo, o padrão tributário do Brasil que permaneceu o mesmo tal como nos governos anteriores “(...) O governo Lula, em suas duas gestôes, não altera o padrão tributário vigente no período $\mathrm{FHC}$, com a carga na ordem de $37 \%$ do PIB (contra 29\% em 1994) e regressiva (com impostos e contribuiçóes, remetidos ao consumo)" (Yamamoto \& Oliveira, 2010, p.12).

Atualmente, considerando as questôes e o momento político que permeiam o Brasil, pode-se pensar que o governo atual representado por Michel Temer, também segue os passos da linha neoliberal, tornando possível o entendimento de que, após a abertura democrática no Brasil, os governos seguiram pressupostos neoliberais, em maior ou menor grau. De acordo com Santos (2016), o governo Temer tem como princípios norteadores:

a) o econômico (reequilíbrio fiscal, melhoria do ambiente de negócios, reforma previdenciária e reforma trabalhista);

b) o de infraestrutura (programas de concessões, privatizaçóes e atração de investimentos);

c) o social e cidadania (pacto social pelo emprego, programa fazer mais com menos na Saúde, salto de qualidade e gestão na educação, melhora das políticas de transferência de renda);

d) a reconexão do Brasil com o mundo (gestão de crise, emergência e grandes eventos);

e) a gestão pública (programa de modernização do Estado e programa nacional anticorrupção) (Santos, 2016, p.803).

Observa-se que alguns pontos dizem respeito aos pressupostos do neoliberalismo, tais quais: as reformas previdenciárias e trabalhistas, programas de incentivo a privatizaçóes e investimentos, investir menos recursos em órgãos públicos (como saúde), como a manutenção da política de abertura para o capital internacional.

Atualmente, em decorrência das configuraçóes de governo neoliberal presentes desde 1990, considera-se importante ressaltar que, em detrimento dos percursos históricos dos modelos de Estado e suas transiçôes, um importante ponto a colocar é como se constituirá as relaçóes sociais.

Posto isso, é nesses novos modos de se relacionar que esse estudo trabalhará ao inserir o conceito de subjetividade e, consequentemente, subjetividade neoliberal. Portanto, tendo em vista essas mudanças e a implementação de um Estado neoliberal, podemos pensar como esse novo modo político e econômico produziu - e produz- novos modos de subjetivação.

Assim, sintetizando as ideias acima, de acordo com Otranto (1999), o neoliberalismo produziu novas formas de subjetividade a partir da construção de “(...) um novo modelo de relaçóes de classes, a uma nova forma de ideologia democrática e a um determinado modelo de Estado, facilitando a sua penetração para além dos limites econômicos, transformando-o no senso comum do nosso tempo" (Otranto, 1999, p.5), caracterizando a queda da intervenção estatal, pressupondo também o empobrecimento das relaçóes sociais, tornando a sociedade cada vez mais individualista. 


\section{CONSIDERAÇÓES SOBRE A SUBJETIVIDADE NO CONTEXTO NEOLIBERAL}

Considerando o histórico do neoliberalismo e como se dá o contexto do Estado neoliberal, podemos pensar que, em conjunto com as mudanças política e econômica, há outra questão em jogo: a subjetividade. Em tal contexto, a subjetividade defendida e difundida pelo ideário neoliberal pode ser apresentada para pensar as consequências do Estado neoliberal em relação às políticas sociais.

No contexto das políticas sociais, observa-se uma preocupação de aproximar o conceito de subjetividade com o mundo social. Por exemplo, no âmbito do Sistema Único de Assistência Social (SUAS), ao discutir o trabalho a ser realizado no serviço de atendimento às famílias, encontra-se a definição de que:

(...) a subjetividade nesse serviço, [é] compreendida como o espaço íntimo constituído pelas marcas singulares adquiridas no processo de formação individual, bem como pelas crenças e valores compartilhados na dimensão cultural, que acabam por constituir a experiência histórica e coletiva dos grupos e populaçóes em um dado território (Brasil, 2012, p.17).

A subjetividade, então, diz respeito a modos de existência em determinados tempos e espaços e, por isso, é influenciada também por fatores sociais, os quais incluem: a cultura, as relaçôes sociais, e as situaçôes políticas e econômicas daquele contexto. Tal conceito é, portanto, pertinente para pensarmos os modos de existência decorrentes do neoliberalismo. Nesse sentido, ao discorrer sobre a noção de subjetividade, Mansano (2009) coloca que a subjetividade:

(...) não implica uma posse, mas uma produçáo incessante que acontece a partir dos encontros que vivemos com o outro. Nesse caso, o outro pode ser compreendido como o outro social, mas também como a natureza, os acontecimentos, as invençóes, enfim, aquilo que produz efeitos nos corpos e nas maneiras de viver. Tais efeitos difundem-se por meio de múltiplos componentes de subjetividade que estão em circulação no campo social (Mansano, 2009, p.111).
Sendo assim, como a subjetividade não adquire caráter imutável e pode sofrer influências de tais fatores, é possível que haja produçóes de subjetividades que se fazem presentes de acordo com essas influências. Por isso, Mansano (2009) destaca que "um outro ponto importante a ser considerado é que qualquer mudança social passa necessariamente por essa produção viva $\mathrm{e}$ mutante de subjetividades (...) A matéria prima que compóe as subjetividades são variáveis e historicamente localizadas" (Mansano, 2009, p.112, grifo nosso).

A partir do argumento da relação entre subjetividade e fatores sociais, Mancebo (2002), realiza um estudo sobre a subjetividade através de uma perspectiva histórica, enfatizando como essa questão se desdobrou com o avanço do sistema capitalista e como se deram essas passagens nos diferentes momentos do mesmo. Dentre diferentes períodos analisados pela autora, o que mais se destaca é o desenvolvimento e desdobramento do capitalismo - da revolução industrial até o desencadear o neoliberalismo - já que é nesse contexto que surgem questôes importante à Psicologia, como o desenvolvimento da noção de individualidade.

Por isso, ao decorrer do desenvolvimento do capitalismo, aumentou a burocratização e a vigilância para com os indivíduos para que o Estado pudesse ter controle sobre o investimento feito. De acordo com Mancebo (2002):

(...) por um lado, assiste-se ao alargamento dos direitos sociais - no domínio das relaçóes de trabalho, da seguridade, da saúde, da educação e da habitação - que torna possível vivências de autonomia, de liberdade e abre novos horizontes ao desenvolvimento dos indivíduos; mas, por outro lado, (...) as instituiçôes estatais desenvolvidas para fazer jus a esse desenvolvimento societal aumentaram o peso burocrático e a vigilância controladora sobre os indivíduos; sujeitaram-nos intensamente ao ciclo da produçáo e do consumo; aprofundaram o espaço urbano desagregador e atomizado, destruíram muitas redes sociais de interconhecimento, de ajuda mútua e de solidariedade; promoveram uma indústria de tempos livres e uma cultura, que restringiram o lazer a um gozo programado, heterônomo, passivo e individual (Mancebo, 2002, parágrafo 31).

Tendo o Estado a característica de interventor e ampliador dos direitos sociais, o próximo momento 
analisado pela autora é o neoliberalismo. Deste modo, com o avanço da implementação de um Estado neoliberal, novas formas de relações sociais, políticas e econômicas são colocadas, visto que "(...) o fortalecimento das práticas classistas e coletivas, obtido ao longo do período do Bem-Estar, enfraquecem de novo, diante do estímulo neoliberal à competição, ao sucesso a qualquer preço, minando os espaços de ação intersubjetiva e sócio-política" (Mancebo, 2002, parágrafo 45).

Portanto, o movimento histórico do capitalismo e, consequentemente, dos modelos de Estado, promoveram “(...) um processo de subjetivação, que a um só tempo alargou os horizontes possíveis da autonomia liberal, mas que subordinou a individuação às exigências de uma razão tecnológica disciplinar" (Mancebo, 2002, parágrafo 34), promovendo

(...) uma subjetividade engendrada em um continente da cultura do sucesso e da competitividade tendo como referência primária as leis de mercado, amarrando os ideais egóicos à sobrevivência da própria organização e/ou instituição, a obtençáo do lucro e a manutenção dos valores hegemônicos do capital (Oliveira, 2011, p.122).

Indo contra elementos debatidos pelas políticas sociais que apontam para o âmbito do desenvolvimento de potencialidades, construçóes culturais, políticas, a partir de uma visáo de subjetividade e identidade atravessada e caracterizada em sua relação com a participação social e ação coletiva (Brasil, 2016).

Entretanto, o neoliberalismo enquanto teoria e ideologia, é permeado pelas relaçôes de mercado com o objetivo de distanciar o Estado desse aspecto e, por isso, acaba por ressaltar a lógica da competitividade, sobretudo no que diz respeito ao ramo empresarial. É nesse sentido que é introjetada nos indivíduos as relaçóes de mercado, sendo estas um meio de significação e atuaçáo nessa nova realidade. Como destacam Ferreira Neto e Araújo (2014), no contexto neoliberal, a subjetividade “(...) remete a uma subjetividade atomizada, consumista e individualista” (Ferreira Neto \& Araújo, 2014, p.682).

A partir disso e, considerando como a noção de subjetividade é fundamental para o projeto de ser humano do capitalismo, torna-se importante introduzir a discussão sobre o conceito de subjetividade capitalística, levantada pela discussão de Mancebo (2002), mas que encontra desenvolvida por Guatarri e Rolnik (1996). Sobre a questão, os autores Guatarri e Rolnik (1996) afirmam que:
O indivíduo, a meu ver, está na encruzilhada de múltiplos componentes de subjetividade. Entre esses componentes alguns são inconscientes. Outros são mais do domínio do corpo, território no qual nos sentimos bem. Outros são mais do domínio daquilo que os sociólogos americanos chamam de "grupos primários" (cIâ, bando, a turma, etc.). Outros, ainda, são do domínio da produção de poder: situam-se em relação à lei, à polícia, etc. Minha hipótese é que existe também uma subjetividade ainda mais ampla: é o que chamo de subjetividade capitalística (Guatarri \& Rolnik, 1996, p.36).

Nesse sentido, tendo a subjetividade capitalística enquanto conceito norteador, Reishoffer e Bicalho (2009) afirmam que trata-se de uma produção “(...) em larga escala de modos de pensar, sentir e atuar no mundo em escala mundial. São formas de expressão dominantes que produzem sujeitos serializados, normatizados, modelizados de acordo com os padrôes dominantes" (Reishoffer \& Bicalho, 2009, p.437).

Considerando a discussão acima, Grisci (1999) aponta que tal produção "(...) interferirá tanto nos esquemas de conduta, como nos de pensamento, de sentido, de sentimento ou de afeto, entre tantos outros" (Grisci, 1999, p.100). A subjetividade, permeada por todos esses aspectos que a atravessam, constitui assim o que chamamos de sujeito, o qual ocupa um lugar em seu contexto, carregando consigo sua própria história de vida. Assim, pode-se destacar o movimento da constituição do neoliberalismo, como a globalização e todos os acontecimentos decorrentes desta, como fatores importantes que afetam a produção de subjetividade.

Observa-se que um dos elementos centrais da subjetividade neoliberal é a ideia de liberdade individual que tem íntima relação com a defesa de uma liberdade de mercado. Foi nesse sentido que Hayek realizou sua teorização, tendo isso em vista, a contraposição entre indivíduo e Estado. Como aponta Domingues (1997) "(...) enquanto indivíduos, através do mercado, realizam um "planejamento descentralizado", o Estado, 'autoridade única', necessariamente fracassaria ao tentar planejar, de cima para baixo, o funcionamento da economia" (Domingues, 1997, p.81).

Tendo o Estado neoliberal o papel de regulador, seus pressupostos indicam que teria o Estado o papel de coordenação (mínima) do social, no plano da ideologia, uma vez que o neoliberalismo "(...) reinterpreta as necessidades e potencialidades dos indivíduos 
e das coletividades" (Domingues, 1997, p.79) de forma abstrata, ou seja, por meio de uma teoria que implementa as ideias de liberdade individual e de mercado. Desta forma,

“(...) a sociedade atingiu um estágio no qual não há alternativa possível ao domínio completo do mercado no âmbito das relaçóes humanas. Esta concepção implica, na verdade, uma interpretação muito definida da subjetividade humana, individual e coletiva, e dos mecanismos possíveis para coordená-las" (Domingues, 1997, p.79).

É por isso que, do outro lado da mínima intervenção estatal, tem-se a defesa da liberdade individual que, atrelada ao livre mercado, julga o indivíduo enquanto responsável por suas açóes e consequências decorrentes destas, incluindo as falhas pessoais e profissionais. Esses tipos de liberdade (individual e de mercado) são consideradas como imprescindíveis para a fundamentaçáo do Estado neoliberal, porque entende-se que há uma relaçáo inversamente proporcional entre a interferência estatal e a liberdade individual. Como salientam Scheeffer e Cignachi (2013), “(...) quanto maior a área de não interferência, mais ampla a nossa liberdade" (Scheeffer \& Cignachi, 2013, p.80).

Além disso, a ideia de liberdade individual sugere que o indivíduo pode alcançar aquilo que almeja (trabalho, ascensão social, sucesso e realização profissional e pessoal) sem depender de outrem (incluindo aqui o Estado). Tal premissa é defendida, por exemplo, por autores como Mariani (2007) ao apresentar que a liberdade individual pode ser benéfica. Um de seus efeitos está relacionado com a geração da "(...) motivação para que os trabalhadores percebessem que, se trabalhassem bastante, poderiam conseguir melhores salários" (Mariani, 2007, p.4).

Como desdobramento da propagação da liberdade individual chegamos a ideia de empreendedorismo, amplamente difundida pelo neoliberalismo. Desta forma, por ser uma questão valiosa no âmbito do mercado, Lima Júnior (2011), aponta que:

É possível perceber nas propostas da educação empreendedora os sinais da cilada do individualismo, presentes na cartilha do capitalismo neoliberal, capaz de angariar os atores necessários à formação dos lucros, bem como as justificaçóes às práticas educativas mais gerais produzidas nos diversos espaços de formação, reforçando a prática do Você S.A., do você por você mesmo (Lima Júnior, 2011, p.11).

Em tal panorama, o Brasil, por exemplo, é localizado entre os países que mais empreendem, colocando-o entre "(...) os sete que mais empreendem em criação de novas empresas" (Lima Júnior, 2011, p.22), o que não significa necessariamente que tais empreendimentos se manterão ao longo do tempo. Nesse sentido, vê a importância de construir uma formação que englobe o ensino do empreendedorismo com o objetivo de estimular os indivíduos a serem proponentes e donos de suas próprias empresas. Assim, o empreendedorismo se constitui como uma das formas com a qual o neoliberalismo se apoia para disseminar essa nova concepção de indivíduo pautada na ideia de investimento em si mesmo.

Em tal contexto, Vasconcelos (2015) apresenta o conceito de Homo Oeconomicus, no qual a lógica do empreendedorismo seria, também, uma forma de governo, como um exemplo de investimento no poder de governar a si mesmo adentrando, novamente, na liberdade individual característica dos ideais neoliberais. O Homo Oeconomicus é movido a interesses individuais e nesse sentido:

Empreende sobre si, sobre sua subjetividade, guiado por uma lógica custo e benefícios e concorrência de mercado. Esse indivíduo é essencialmente responsável por tudo o que lhe acontece, ele acredita que depende apenas do seu mérito e de suas escolhas individuais para prosperar (Vasconcelos, 2015, p.24).

A ideia de empreender ou empreender em si caracteriza entáo o movimento de flexibilizaçáo dos indivíduos frentes às variabilidades do mundo social, principalmente no que diz respeito a garantia ou melhoria das condiçóes de trabalho e, consequentemente, de vida, o que nos leva a entender que elementos como o sucesso e a ascensão social passam a serem vistos como atribuição da capacidade empreendedora dos indivíduos. Nas palavras de Harvey (2008):

(...) o sucesso e o fracasso individuais são interpretados em termos de virtudes empreendedoras ou de falhas pessoais (como não investir o suficiente em seu próprio capital humano por meio da educação), em vez de 
atribuídos a alguma propriedade sistêmica (como as exclusóes de classe que se costumam atribuir ao capitalismo) (Harvey, 2008, p.76).

Da mesma forma, o afastamento do Estado também contribui para a propagação dessa ideia, associando o empobrecimento da populaçáo a fracassos pessoais, pois:

À medida que reduz os recursos dedicados ao bem-estar social e reduz o seu papel em áreas como a assistência à saúde, o ensino público e a assistência social, que um dia foram fundamentais para o liberalismo embutido, o Estado vai deixando segmentos sempre crescentes da população expostos ao empobrecimento. A rede de seguridade social é reduzida ao mínimo indispensável em favor de um sistema que acentua a responsabilidade individual (Harvey, 2008, p.86).

Posto isso, a premissa de que a subjetividade é localizada em momentos históricos e, portanto, mutáveis, o neoliberalismo, a partir de sua propagaçáo principalmente política, abrange também a produção de subjetividades por meio do discurso presente em suas propostas. Assim, torna-se possível as ideias de liberdade individual e do empreendedorismo, acarretando na disputa pela concorrência no mercado de trabalho, no alto consumo de mercadorias e na individualização cada vez mais presente na sociedade.

\section{CONSIDERAÇÓES FINAIS}

Ainda que as novas formas de se fazer e praticar a Psicologia busquem alternativas para além do modelo tradicional (entende-se aqui clínico), trata-se de um processo histórico recente que está sendo desenvolvido. Por isso, preza-se pela inserção da Psicologia nas políticas sociais, como forma de construir e pensar, em conjunto com diversos profissionais também atuantes, sobre possibilidades de atuação que possam favorecer a construçáo de um posicionamento frente à situação, visto que o contexto no qual se dá as políticas sociais é de ainda mais desigualdade social e precarização dos setores públicos.

Por isso, é necessário ampliar o olhar para além da ação da Psicologia junto às populaçóes e analisar a ciência psicológica como construtora de política pública.
Entende-se que assim, é possível tomá-la como corresponsável pela implementação e consolidação das políticas de modo a ampliar sua ação junto a quem delas possuem direito. Desse modo, a importância de inserir a Psicologia também nessas discussóes, pois enquanto ciência e profissão, apresenta suas contribuiçôes para a construção de possibilidades de resistência frente ao crescente contexto neoliberal emergente, construindo discursos de enfrentamento aos mesmos.

Cabe ressaltar ainda a importância de se problematizar e criticar as práticas profissionais que, ao invés de exercer um movimento de tensionamento em relação a uma lógica individualizante fomentando a coletividade, a cooperação e a solidariedade, produzem exatamente seu oposto, servindo de fundamento epistemológico ao neoliberalismo. Em contraposição a isso, é necessária uma aproximação da Psicologia quanto a suas possibilidades analíticas e operativas no que tange às políticas sociais para que tal lógica não seja reproduzida e os direitos conquistados sejam garantidos.

Considerando as questôes discutidas acima, cabe ressaltar a importância do trabalho da Psicologia em conjunto com as açôes contempladas pelas (ainda) ofertadas políticas sociais. Entende-se que os contextos políticos e sociais possuem suma importância para a constituição e desenvolvimento de elementos subjetivos, e que a ação do profissional psi atuante junto às políticas públicas (em especial àquelas voltadas ao campo da seguridade social) pode contribuir para a análise das condiçóes das políticas de vida ao qual a população está submetida e que tem levado a crescente individualização dos sujeitos no mundo atual, deixando-os à deriva dos efeitos das forças do mercado.

Por fim, é importante pontuar que, mesmo presente em debates de diferentes campos do conhecimento (como a Sociologia, Filosofia, Ciência Política), as discussões sobre neoliberalismo ainda não se esgotam. No que tange a questão da subjetividade, identificamos falta de referenciais teóricos que tangenciem o impacto nas políticas sociais no que diz respeito a produção de subjetividade e problematize as possibilidades e direcionamentos das práticas psi nesse campo. Desta forma, a busca, atenção e desenvolvimento de estudos que possam permear tais elementos tornam-se de grande importância aos pesquisadores da ciência psicológica, em especial nas investigaçôes que remetem às políticas sociais. 


\section{REFERÊNCIAS}

Alves, C.C., Vilela, T.A.S., \& Rodrigues, E.P. (2013). A responsabilidade do Estado enquanto provedor de políticas públicos e o Serviço Social: aspectos polêmicos. III Simpósio de Assistentes Sociais: expressóes socioculturais da crise do capital e as implicaçóes para a garantia do direitos sociais e para o Serviço Social, Belo Horizonte, Minas Gerais, 2013.

Arienti, W.L. (2003). Do Estado keynesiano ao Estado Schumpeteriano. Revista de Economia Politica, 23(4/92), 97-113. Recuperado de http://www.rep. org.br/pdf/92-6.pdf.

Brasil. (2012). Ministério do desenvolvimento social e combate à fome. Orientaçóes técnicas sobre o PAIF. v.1. Brasília, 2012.

Brasil. (2016). Lei no 8.742 de 7 de dezembro de 1993. Lei Orgânica de Assistência Social.

Cerqueira, J.B.A. de. (2008). Uma visão do neoliberalismo: surgimento, atuação e perspectivas. Sitientibus, 39, 169-189.

Domingues, J.M. (1997). Neoliberalismo, racionalidade e subjetividade coletiva. Antropolitica, 2, 79-95.

Ferreira Neto, J.L., \& Araújo, J.N.G. de. (2014). Gestão e subjetividade no SUS: o enfrentamento de impasses em tempos neoliberais. Psicologia \& Sociedade; 26(3), 675-684.

Forigo, M.V. (2012). Crise do Estado de Bem Estar Social e neoliberalismo. Relaçóes internacionais no mundo atual. 3, 52-62.

Gennari, A.M. (2002). Globalização, neoliberalismo e abertura econômica no Brasil no anos 90. Pesquisa \& Debate, 13(1/21), 30-45.

Grisci, C.L.I. (1999). Trabalho, tempo e subjetividade e a constituição do sujeito contemporâneo. Revista de Ciências Humanas, Florianópolis, Edição Especial Temática, 87-106.

Gros, D.B. (2002). Institutos liberais e neoliberalismo no Brasil da nova república (Tese de Doutorado). Instituto de Filosofia e Ciências Humanas, Universidade Estadual de Campinas, Campinas, SP, Brasil.

Guatarri, F., \& Rolnik, S. (1996). Micropolitica: cartografias do desejo. Petrópolis: Vozes.

Harvey, D. (2008). Liberdade é apenas mais uma palavra... In $O$ neoliberalismo: história e implicações. São Paulo: Loyola, 2008, p.15-47.

Harvey, D. (2008). O estado neoliberal. In $O$ neoliberalismo: história e implicações. São Paulo: Loyola, 2008, p.75-96.
Ianni, O. (1998). Globalização e neoliberalismo. São Paulo em perspectiva, 12(2), 1998, 27-44.

Lima Júnior, O.P.A. de. (2011). O espírito do capitalismo e a cultura do empreendedorismo: educação e ideologia. 141 fls. Dissertação (Mestrado em Psicologia) - Pontifícia Universidade Católica de Minas Gerais, Belo Horizonte, 2011. Maciel, D. (2011). O governo Collor e o neoliberalismo no Brasil (1990-1992). Revista UFG, 13(11), 98-108.

Magalhães, F.N.C. (2016). O espaço do estado no neoliberalismo: elementos para uma redefinição crítica. GEOgraphia, 37, 35-59.

Mariani, É.J. (2007). A trajetória de implementação do neoliberalismo. Revista Urutágua, Maringá, 13, 1-7.

Mancebo, D. (2002). Modernidade e produção de subjetividades: breve percurso histórico. Psicol. cienc. prof., 22(1).

Mansano, S.R.V. (2009) Sujeito, subjetividade e modos de subjetivação na contemporaneidade. Revista de Psicologia da UNESP, 8(2), 110-117.

Mello, N. d., \& Veronese, O. (2013). Apontamentos sobre globalização, neoliberalismo e a(s) crises(s) dos Estados-nação: a (im)possibilidade da flexibilização da soberania. Direito em debate, 22(40), 241-261.

Mendonça, S.E.A. (2003). Perspectivas para o mercado de trabalho para os próximos anos. Mercado de trabalho, 22, 3-6.

Moraes, R.C. (2002). Reformas neoliberais e políticas públicas: hegemonia ideológica e redefinição das relações Estado-sociedade. Educ. Soc., Campinas, 23(80), 13-24.

Nunes, A.J.A. (2003). Neoliberalismo e direitos humanos. Revista Da Faculdade De Direito, Universidade De São Paulo, 98, 423-462.

Oliveira, S.N. de. (2011). Liderança e produção de subjetividade na era da performance. Revista de Psicologia, 2 (2), 120-126.

Otranto, C.R. (1999, set.). O neoliberalismo como proposta hegemônica. Série Textos CPDA, $\mathrm{N}^{\mathrm{o}} 10$, p. 2-7.

Pastor, M., \& Brevilheri, E.C.L. (2009 jul/dez..) Estado e política social. Serv. Soc. Rev., Londrina, v. 12, n.1, p. 135-156.

Pereira, W.E.N. (2004 jan/jun.). Do Estado liberal ao neoliberal. Interface, Natal/RN, v.1, n.1.

Pereira, J.D, Silva, S.S. de S., \& Patriota, L.M. (2006). Políticas sociais no contexto neoliberal: focalização e desmonte dos direitos.Qualit@s 
- Revista Eletrônica - ISSN 1677- 4280 Edição Especial.

Reishoffer, J. C., \& Bicalho, P. P. G. de. (2009). Insegurança e produção de subjetividade no Brasil contemporâneo. Fractal: Revista de Psicologia, 21(2), 425-444.

Santos, R. (2016). A retomada do programa neoliberal no governo Temer e seus possíveis impactos sobre a auditoria fiscal do trabalho brasileira. Cadernos do CEAS, Salvador, n. 239, p. 795-812, 2016.

Sallum Jr., B. (2000). O Brasil sob Cardoso: neoliberalismo e desenvolvimentismo. Tempo Social; Rev. Sociol. USP, 11(2): 23-47.

Setti, G.A.M. (2002). A hegemonia neoliberal e o capitalismo contemporâneo. Revista Urutágua, 5.

Scheeffer, F., \& Cignachi, H. (2013), Liberdade (neo) liberal: que liberdade é essa?. Pensamento Plural, $12,75-89$.

Soares, R.P. (2009 jul/dez.). Política social e Welfare State: uma perspectiva histórico-dialética. Argumentum, Vitória, v. 1, n. 1, p. 160-164.

Souza, J. de. (2003). Críticas à construção de um Estado neoliberal no Brasil (1987-2002: 15 anos de profundas mudanças). In VIII Congreso Internacional del CLAD sobre la Reforma del Estado y de la Administración Pública, Panamá, 28-31 Oct. 2003.

Vasconcelos, V.D. (2015). O empreendedorismo de si e o novo homo oeconomicus: discussões sobre trabalho, subjetividade e clínica. 2015. 38 fls. Trabalho de Conclusão de Curso (Graduação em Psicologia) - Universidade Federal do Rio Grande do Sul, Porto Alegre . 2015.

Yamamoto, O. H., \& Oliveira, I. F. de. (2010). Política social e psicologia: uma trajetória de 25 anos. Psic.: Teor. e Pesq., 26 (n. especial), 9-24.

\section{Endereço para correspondência:}

Universidade Estadual de Londrina

Rodovia Celso Garcia Cid - Pr 445 Km 380

Cx. Postal 10.011 - Campus Universitário,

PR, 86057-970, Brasil

Rafael Bianchi Silva

tibx211@yahoo.com.br

Recebido : 30/07/2018

Aceito: 15/09/2018 


\title{
Fatores de risco psicossocial relacionados ao estresse em trabalhadores terceirizados: uma revisáo
}

Psychosocial risk factors related to stress in outsourced workers: a review

\author{
Marina Bernardo Mandarini ${ }^{1}$ \\ Marina Greghi Sticca ${ }^{2}$
}

Universidade de São Paulo

\section{Resumo}

O objetivo desta revisão foi avaliar e sistematizar os dados publicados em periódicos científicos acerca dos fatores de risco psicossocial que podem contribuir para o estresse e afetar a saúde de trabalhadores terceirizados. Foram selecionados 5 estudos brasileiros e 20 internacionais, considerando o período de 2002 a 2017. Os principais fatores de risco psicossocial identificados foram relacionados à organizaçáo do trabalho e conteúdo das tarefas, às exigências no trabalho e às relaçóes sociais e liderança. Verificou-se que o estresse em trabalhadores terceirizados é afetado por características específicas do contexto de trabalho terceirizado. Os resultados enfatizam a importância de se repensar a organização e os aspectos que compóem a terceirização enquanto prática administrativa.

Palavras--chave: Estresse; Fatores de Risco; Saúde do Trabalhador; Serviços Terceirizados.

\begin{abstract}
The objective of this review was to evaluate and systematize data published in scientific journals about psychosocial risk factors that may contribute to stress and may affect the health of outsourced workers. Five Brazilian and 20 international studies were selected, considering the period of 2002 to 2017. The main psychosocial risk factors identified were related to the work organization and content of the tasks, the work demands and the social relations and leadership. It was verified that the stress in outsourced workers is affected by specific outsourced work context characteristics. The results emphasize the importance of rethinking the organization and aspects of outsourcing as an administrative practice.
\end{abstract}

Keywords: Stress; Risk Factors; Occupational Health; Outsourced Services.

A terceirização é uma prática de gestão flexível amplamente utilizada, que consiste na transferência da responsabilidade de um serviço ou parte da produção de uma organização para outra (Oltramari \& Piccinini, 2006). Inserida no contexto de produção flexível, suas principais características referem-se à reduçáo dos gastos, ao aumento da produtividade e à adaptação às exigências impostas pelo mercado (Garza, Valencia \& Fernández, 2012; Vasapollo, 2005). Tais alteraçóes resultam em modificaçóes na natureza das tarefas, na distribuição da atividades, na organização dos relacionamentos entre as empresas e na interação entre os funcionários de ambas as partes (Davis-Blake $\&$ Broschak, 2009), além de causar impactos negativos aos trabalhadores (Lima, 2010).

Estudos têm apontado que a prática de terceirizar serviços geralmente originam alteraçóes negativas nas condições de trabalho, como diminuição do salário e benefícios (Lima, 2010), insegurança, perda do controle sobre as tarefas e ritmo (Zanelli, Calzaretta, García, Lipp \& Chambel, 2010), intensificação do trabalho e redução no número de funcionários (Lima,
2010). A terceirização também gera impactos negativos para a saúde dos trabalhadores, e a revisão de literatura realizada por Mandarini, Alves e Sticca (2016) elencou o estresse como o impacto mais recorrente na saúde dos terceirizados.

As teorias contemporâneas consideram o estresse ocupacional como um estado cognitivo-emocional resultado da interaçáo entre fatores ambientais, contextos psicossociais e organizacionais e fatores individuais (Leka \& Houdmont, 2010). Segundo tais teorias, o estresse é um fenômeno que ocorre a partir da avaliação do trabalhador sobre seu contexto de trabalho, principalmente no que se refere às demandas, reconhecimento, controle sobre o trabalho e suporte social (Cox, Griffiths \& Rial-González, 2000). Pode causar alteraçôes e contribuir para a manifestação de problemas psicológicos e sociais e no empobrecimento da saúde física, interferindo na qualidade de vida e no bem-estar individual (Zanelli et al., 2010). $O$ estresse também afeta negativamente as organizaçóes devido ao aumento do absenteísmo, atrasos,

\footnotetext{
${ }^{1}$ Universidade de São Paulo

${ }^{2}$ Departamento de Psicologia, Psicologia Organizacional e do Trabalho. https://orcid.org/0000-0002-0838-0189
} 
índices de rotatividade, número de acidentes de trabalho e diminuição do desempenho dos trabalhadores (Krumm, 2013).

No contexto organizacional, os fatores que podem causar efeitos adversos físicos ou psicológicos na saúde dos trabalhadores por meio da experiência de estresse são chamados de fatores de risco psicossocial, e compreendem aspectos relacionados à organização, gestão, ambiente de trabalho e características da própria atividade (Cox et al., 2000). Os fatores de risco psicossocial e o estresse ocupacional são reconhecidos como os principais problemas de saúde e segurança no trabalho, gerando altos gastos para a saúde pública (Cox et al., 2000).

Os principais fatores de risco psicossocial identificados pela literatura são agrupados em categorias como conteúdo das tarefas, carga e ritmo de trabalho, ambiente e equipamentos, controle sobre as atividades, desenvolvimento profissional, relacionamentos interpessoais e interface entre trabalho e família, entre outros (Leka \& Houdmont, 2010; Schabracq, Winnubst \& Cooper, 2003). As alteraçóes decorrentes da reorganização da produçáo e dos novos arranjos organizacionais que caracterizam a terceirização podem contribuir para a emergência de novos fatores de risco psicossocial no trabalho, levando ao adoecimento dos trabalhadores (Leka \& Houdmont, 2010; Zanelli et al., 2010).

A literatura aponta que os estudos relacionados à terceirizaçáo estão majoritariamente inseridos no contexto financeiro e administrativo, e aqueles que abordam de forma direta o estresse nos trabalhadores geralmente enfocam suas consequências e não suas causas ou fatores de risco envolvidos (Brooks, 2006). Ademais, deve-se destacar que no atual contexto brasileiro, após a aprovação do projeto de Lei PL 4330/2004, a terceirizaçáo deixa de ser legalizada apenas para as atividades periféricas das organizaçóes e passa a ser liberada para todas as atividades das empresas, inclusive as atividades-fim, possivelmente aumentando o número de terceirizados.

Tendo em vista todos esses aspectos apresentados, torna-se relevante identificar os fatores de risco psicossocial a que estáo submetidos os trabalhadores terceirizados. Sendo assim, a presente revisão sistemática da literatura buscou identificar e sistematizar os fatores de risco psicossocial que podem levar ao estresse de trabalhadores terceirizados.

\section{MÉTODO}

\section{Delineamento do estudo}

Foi realizada uma revisão sistemática da literatura segundo diretrizes para realização de revisão sistemática proposta por Petticrew e Roberts (2006).

\section{Bases de dados, palavras-chave e critérios de inclusão}

Este estudo foi realizado a partir da análise de artigos científicos nacionais e internacionais disponíveis nas bases eletrônicas de dados SciELO, LILACS, Web of Science, PubMed, Scopus e PsycINFO. Tais bases foram escolhidas por serem referência nas áreas de psicologia, saúde e administração, disciplinas que abordam o tema. Foram utilizadas as palavras-chave outsourc*, stress, organizational stress, work stress, occupational stress, psychological well-being, occupational health, psychosocial environment e psychosocial risk.

Tais palavras-chave foram selecionadas após pesquisa de descritores no Vocabulário de Termos em Psicologia, cadastrados na Biblioteca Virtual em Saúde - Psicologia (BVS-Psi) e após verificação das palavras-chave que mais apareciam nos artigos relacionados ao tema. A palavra-chave outsourc ${ }^{*}$ foi utilizada em todas as buscas e foi combinada com cada palavra-chave, individualmente (exemplo: outsourc ${ }^{*}$ AND stress).

O período de busca ocorreu entre Dezembro de 2016 e Março de 2017, considerando os trabalhos publicados entre 2002 e 2017. Para a organizaçáo e sistematização dos estudos encontrados, foi utilizado o software State of Art through Systematic Review (StArt), versão 1.6.3, desenvolvido na Universidade Federal de São Carlos (UFSCar). Essa ferramenta auxilia o planejamento, a execução e a análise final dos estudos encontrados, tornando a revisão sistemática mais ágil, precisa e replicável (Hernandes, Zamboni, Fabbri \& Thommazo, 2012).

A busca e avaliação dos artigos foram realizadas por duas pesquisadoras da área, de acordo com os seguintes critérios de inclusão: (a) trabalhos publicados na língua inglesa, portuguesa ou espanhola, (b) relatos de pesquisa, revisôes de literatura e artigos de comunicação breve, (c) estudos que abordaram o estresse e fatores de risco psicossocial em trabalhadores terceirizados. Os critérios de exclusão foram: (a) livros, capítulos de livros, dissertaçóes e teses, (b) trabalhos que, apesar de abordarem a terceirizaçáo e o estresse, focavam em outros trabalhadores que não os terceirizados, (c) estudos com acesso restrito. 


\section{Coleta de dados}

A princípio, os estudos foram analisados de acordo com os critérios de inclusão, e posteriormente os títulos e resumos foram avaliados, sendo excluídos aqueles que não abordavam o tema e também os artigos duplicados. A partir dessa seleçáo inicial, os artigos considerados relevantes foram lidos e analisados pelas duas pesquisadoras, sendo selecionados apenas os estudos que identificaram, diretamente ou indiretamente, fatores de risco psicossocial relacionados ao estresse de trabalhadores terceirizados (Tabela 1).

\section{Análise de dados}

Após a leitura e avaliação das produções científicas, os dados foram analisados a partir do referencial da análise temática (Smith, 2015), de modo que as pesquisadoras identificaram, examinaram e relataram os padrôes de temas referentes aos fatores de risco psicossocial presentes nas pesquisas, resultando na criação de categorias que se referem à identificação de tais fatores.

\section{RESULTADOS}

A seleção inicial resultou em 5800 artigos, conforme indicado na Tabela 1. Destes, 3167 eram duplicados e 143 foram considerados relevantes. Os estudos considerados relevantes foram lidos na íntegra e 25 deles atenderam a todos os critérios de inclusão previamente estabelecidos. Dos 25 artigos aceitos, 5 foram publicados na língua portuguesa e 20 na língua inglesa.

\section{Tabela 1}

Número de artigos em cada base de dados

\begin{tabular}{ccccc}
\hline Bases de dados & Artigos encontrados & Artigos repetidos & Artigos rejeitados & Artigos aceitos \\
\hline SciELO & 41 & 29 & 9 & 3 \\
LILACS & 26 & 21 & 4 & 1 \\
Web of Science & 180 & 137 & 42 & 1 \\
PubMed & 84 & 69 & 13 & 2 \\
Scopus & 5379 & 2859 & 2504 & 16 \\
PsycINFO & 90 & 52 & 36 & 2 \\
Total & 5800 & 3167 & 2608 & 25 \\
\hline
\end{tabular}

Dos artigos selecionados, foram poucos os que adotaram como objetivo central a identificação ou mensuração de fatores de risco psicossocial, sendo que a maioria tratou tal temática de forma indireta ou aprofundou as relaçóes entre um fator de risco psicossocial específico e o estresse. Em relação ao estresse, a maioria dos autores tratou este tema de forma indireta e não identificou a teoria subjacente utilizada. Além disso, os procedimentos utilizados na coleta de dados dados foram variados, dificultando a comparação dos resultados. Tais resultados indicam a escassez de estudos robustos com a temática do estressse e fatores de risco psicossocial no contexto de trabalho terceirizado.

$\mathrm{Na}$ Tabela 2, foram sistematizadas as categorias de agrupamentos dos fatores de risco psicossocial identificados nos estudos, assim como a frequência e as relaçóes que cada fator de risco psicossocial estabelece com o estresse. Foram identificadas as categorias Organização do trabalho e conteúdo das tarefas, Exigências no trabalho e Relaçóes sociais e liderança.

A categoria Organização do trabalho e conteúdo das tarefas compreendeu os seguintes fatores de risco psicossocial: Conteúdo das tarefas, possibilidade de desenvolvimento e condições físicas $(n=19 ; 76 \%)$, Influência no trabalho e monitoramento constante $(n$ $=10 ; 40 \%)$, e Insegurança $(n=7 ; 28 \%)$. A categoria Exigências no trabalho abrangeu os fatores de risco psicossocial Exigências, ritmo de trabalho e número de trabalhadores $(n=16$; 64\%) e Horários de trabalho e conflito trabalho-família $(n=15 ; 60 \%)$. Por fim, a categoria Relaçóes sociais e liderança compreendeu os fatores de risco psicossocial Relacionamento interpessoal e liderança $(n=12 ; 48 \%)$ e Reconhecimento, salário e benefícios $(n=10 ; 40 \%)$. 


\section{Tabela 2}

Fatores de risco psicossocial, número de artigos e relação com o estresse

\begin{tabular}{|c|c|c|c|}
\hline Categorias & $\begin{array}{c}\text { Fatores de risco psicosso- } \\
\text { cial identificados }\end{array}$ & No de artigos & Relação com o estresse \\
\hline \multirow{3}{*}{$\begin{array}{l}\text { Organização do trabalho } \\
\text { e conteúdo das tarefas }\end{array}$} & $\begin{array}{l}\text { Conteúdo das tarefas, } \\
\text { possibilidade de desen- } \\
\text { volvimento e condi- } \\
\text { çôes físicas }\end{array}$ & 19 & $\begin{array}{l}\text { Maiores índices de acidentes de } \\
\text { trabalho e doenças ocupacionais } \\
\text { Tédio e dificuldade de manter a } \\
\text { atençáo no trabalho } \\
\text { Diminuição do sentido, prazer e } \\
\text { bem-estar no trabalho } \\
\text { Diminuição do controle sobre } \\
\text { o trabalho }\end{array}$ \\
\hline & $\begin{array}{l}\text { Influência no trabalho e } \\
\text { monitoramento constante }\end{array}$ & 10 & $\begin{array}{l}\text { Diminuição do sentido, prazer e } \\
\text { bem-estar no trabalho } \\
\text { Diminuição da autonomia } \\
\text { e controle }\end{array}$ \\
\hline & Insegurança & 7 & $\begin{array}{l}\text { Aumento das exigências } \\
\text { Diminuição do controle sobre } \\
\text { o trabalho }\end{array}$ \\
\hline \multirow[b]{2}{*}{ Exigências no trabalho } & $\begin{array}{l}\text { Exigências, ritmo de } \\
\text { trabalho e número } \\
\text { de trabalhadores }\end{array}$ & 16 & $\begin{array}{l}\text { Aumento das exigências } \\
\text { Realização de práticas inseguras } \\
\text { no trabalho }\end{array}$ \\
\hline & $\begin{array}{l}\text { Horários de trabalho e } \\
\text { conflito trabalho-família }\end{array}$ & 15 & $\begin{array}{l}\text { Alterações físicas e problemas } \\
\text { de saúde } \\
\text { Diminuição do bem-estar e da } \\
\text { qualidade dos relacionamentos } \\
\text { pessoais e familiares }\end{array}$ \\
\hline \multirow{2}{*}{$\begin{array}{l}\text { Relaçôes sociais } \\
\text { e liderança }\end{array}$} & $\begin{array}{l}\text { Relacionamento interpes- } \\
\text { soal e liderança }\end{array}$ & 12 & $\begin{array}{l}\text { Diminuição do prazer e bem-estar } \\
\text { no trabalho } \\
\text { Dificuldade de manter a atenção } \\
\text { no trabalho } \\
\text { Intensificação da insegurança } \\
\text { Não atendimento das demandas }\end{array}$ \\
\hline & $\begin{array}{c}\text { Reconhecimento, salário } \\
\text { e benefícios }\end{array}$ & 10 & $\begin{array}{l}\text { Diminuição do reconhecimento } \\
\text { e recompensa } \\
\text { Necessidade de trabalhar em } \\
\text { outros locais } \\
\text { Diminuição do prazer e bem-estar } \\
\text { no trabalho }\end{array}$ \\
\hline
\end{tabular}

Organizaçáo do trabalho e conteúdo das tarefas

Conteúdo das tarefas, possibilidade de desenvolvimento e condiçóes físicas

Nas pesquisas selecionadas, muitos trabalhadores ocupavam funçóes que demandavam a realizaçáo de tarefas monótonas, pouco variadas e que exigiam a realização de movimentos repetitivos, principalmente nas ocupaçóes referentes ao setor de serviços, um dos mais terceirizados atualmente (Chillida \& Cocco, 2004; Kesavachandran, Rastogi, Das \& Khan, 2006; Nadeem, 2009; Raja \& Bhasin, 2014; Ratnesh, Sultana \& Sinha, 2016; Taylor, D’Cruz, Noronha \& Scholarios, 2013). O 
trabalho monótono foi identificado como um fator que contribuiu para o estresse no trabalho (Seklecka, Marek \& Lacala, 2013), visto que dificulta o envolvimento dos trabalhadores com suas tarefas e torna o trabalho mais custoso, tedioso e sem sentido (Cox et al., 2000; Schabracq et al., 2003).

Tais ocupaçôes ofereceram chances limitadas de desenvolvimento profissional aos trabalhadores, o que foi considerado uma fonte de insatisfação (Budhwar, Varma, Malhotra \& Mukherjee, 2009; Deery, Nath \& Walsh, 2013; Hechanova, 2013; Papadopoulos, Georgiadou, Papazoglou \& Michaliou, 2010; Thite, 2010). Além disso, foi considerado comum que os trabalhadores terceirizados tivessem menos acesso a treinamentos profissionais quando comparados com os trabalhadores contratados (Alvarez, Suarez, Pereira, Figueiredo \& Athayde, 2007; Jain, Giga \& Cooper, 2013; Santos, Lima, Murta \& Motta, 2009), e quando participavam de treinamentos, estes geralmente apresentavam baixa qualidade ou eram inadequados (Druck, 2016; Quinlan \& Bohle, 2008), elevando o risco de acidentes de trabalho (Papadopoulos et al., 2010; Santos et al., 2009) e contribuindo para a diminuição do controle no trabalho (Zanelli et al., 2010).

Além do trabalho monótono com baixas chances de desenvolvimento profissional, alguns estudos identificaram a inadequação do ambiente e dos materiais de trabalho como um fator de risco psicossocial, que, somado aos protocolos de segurança inadequados, contribuiu diretamente para o aumento nos índices de acidentes de trabalho e doenças ocupacionais (Gemma, Fuentes-Rojas \& Soares, 2017; Jain et al., 2013; Zuberi, 2011). Por fim, foram apontadas a realização de atividades em ambientes de trabalho mal planejados (Quinlan \& Bohle, 2008), com exposição a ruídos e adoção de posiçóes corporais desconfortáveis (Papadopoulos et al., 2010) e ausência de informação sobre riscos e medidas de segurança no trabalho.

\section{Influência no trabalho e monitoramento constante}

O elevado grau de monitoramento e avaliação do desempenho e a ausência de possibilidade de influenciar o modo como o trabalho é organizado e realizado foi identificado como um fator de risco psicossocial por 10 estudos (Budhwar et al., 2009; Deery et al., 2013; Jain et al., 2013; Kesavachandran et al., 2006; Nadeem, 2009; Papadopoulos et al., 2010; Raja \& Bhasin, 2014; Ratnesh et al., 2016; Taylor et al., 2013; Zuberi, 2011).

Com a finalidade de controlar a qualidade do trabalho realizado, eram estabelecidos padróes de tarefas a serem executados, sendo que tais padrôes eram constantemente monitorados pelos superiores e acarretavam na redução da autonomia e do controle dos trabalhadores sobre seu próprio trabalho (Papadopoulos et al., 2010). Na pesquisa realizada por Zuberi (2011), a avaliaçáo do desempenho das agentes de limpeza era feita regularmente por meio de inspeçóes e auditorias realizadas pela empresa contratante. Nos casos em que os resultados dessas avaliaçôes eram considerados insatisfatórios, a empresa terceirizada recebia advertências e seu contrato tinha grandes chances de ser finalizado.

Assim como o trabalho monótono, a realização de tarefas excessivamente controladas torna o trabalho fatigante e sem sentido (Schabracq et al., 2003), pois reduz a utilização das habilidades do trabalhador e intensifica a realização de movimentos prescritos, gerando tensão, sentimentos de inutilidade e diminuição do bem-estar (Leka \& Houdmont, 2010).

\section{Insegurança}

Aspectos relacionados à insegurança no trabalho também foram apontados como fatores de risco psicossocial nas pesquisas (Gemma et al., 2017; Jain et al., 2013; Papadopoulos et al., 2010; Taylor et al., 2013). Os trabalhadores que participaram da pesquisa realizada por Snell, Schmitt, Glavas e Bamberry (2015), contratados pela indústria de geração de energia, relataram tensão emocional por não saberem quando e se perderiam seus empregos, já que as negociaçôes entre as empresas eram realizadas de forma sigilosa. Como consequência, eles apresentavam um alto grau de incerteza financeira, relacionada principalmente ao receio de perder o emprego e à incerteza referente ao próximo pagamento, o que levava estes trabalhadores a almejar por um emprego permanente.

A avaliação da empresa terceirizada pela empresa contratante também desempenhou um papel relevante no que diz respeito à insegurança no trabalho. Como o contrato estabelecido entre as empresas determinava as questóes referentes às tarefas e ao quadro de funcionários, alteraçôes neste contrato, muitas vezes derivadas das avaliaçóes realizadas, geravam mudanças significativas para os terceirizados, como sua demissão ou aumento no número de atividades (Druck, 2016; Zuberi, 2011).

Sendo assim, esses trabalhadores experimentavam um estado de tensão constante relacionado ao baixo controle sobre o trabalho, aos altos índices de insegurança e ao esforço frequente para garantir uma avaliação 
de desempenho elevada como tentativa de assegurar o emprego atual (Zanelli et al., 2010).

\section{Exigências no trabalho}

\section{Exigências, ritmo de trabalho e número de trabalhadores}

A sobrecarga de trabalho, geralmente acompanhada pela imposição de metas inatingíveis, foi identificada como um fator de risco psicossocial relacionado ao trabalho terceirizado (Druck, 2016; Hsiao \& Mor Barak, 2014; Quinlan \& Bohle, 2008). De acordo com a pesquisa realizada por Zuberi (2011), após a terceirização dos serviços de apoio em um hospital, os funcionários relataram um aumento na quantidade de trabalho devido ao número inadequado de profissionais. Além disso, a negligência da variabilidade e a complexidade das tarefas foi apontado como um fator que contribuiu para a intensificação do trabalho (Gemma et al., 2017), o que pode acarretar na realização de práticas inseguras que favorecem o desenvolvimento de doenças físicas e o risco de acidentes no trabalho (Papadopoulos et al., 2010).

Como consequência, o ritmo de trabalho tornou-se acelerado e foi percebida pressão constante para a realização das atividades de forma satisfatória no tempo estipulado (Hechanova, 2013; Jain et al., 2013; Kesavachandran et al., 2006; Nadeem, 2009; Raja \& Bhasin, 2014), sendo que alguns trabalhadores relataram não terem tempo suficiente para realizar suas refeiçóes (Ram, Kurpad \& Swaminathan, 2014), fazer intervalos (D'Cruz \& Noronha, 2008) ou interagir com os colegas de trabalho (Taylor et al., 2013).

Outras exigências foram identificadas nos estudos realizados em empresas de call center e TI que atendiam outros países (offshoring): a necessidade de utilizar a língua de origem dos clientes durante o trabalho e adequar seu sotaque e o cuidado em esconder sua identidade para evitar reaçóes agressivas e preconceituosas por parte dos clientes. Tais exigências geraram um aumento no número de demandas e constituíram novas fontes de estresse (Deery et al., 2013; Ratnesh et al., 2016).

\section{Horários de trabalho e conflito trabalho-família}

Questôes relacionadas ao horário de trabalho foram identificadas como prejudiciais aos trabalhadores, sendo o número extenso de horas de trabalho e o trabalho noturno os principais fatores de risco psicossocial apontados nos estudos (Budhwar et al., 2009; D'Cruz \& Noronha, 2008; Hechanova, 2013; Nadeem, 2009;
Ram et al., 2014; Taylor et al., 2013). A realização do trabalho no período noturno foi identificada como uma prática regular para os trabalhadores nos setores de call center e tecnologia da informação (TI) que prestavam serviços a clientes de outros países, prática conhecida como offshoring (Davis-Blake \& Broschak, 2009).

Segundo Raja e Bhasin (2014) e Papadopoulos et al. (2010), trabalhar em horários noturnos pode alterar o ritmo circadiano do indivíduo, resultando em alteraçóes físicas e problemas de saúde relacionados ao sono, irritabilidade, fadiga crônica e estresse. Ao trocar o dia pela noite ou cumprir longas horas de trabalho, os trabalhadores dispunham de menos tempo para conviver com a família e amigos, para se engajar em atividades sociais e de lazer e para cumprir as responsabilidades familiares esperadas (Chillida \& Cocco, 2004; Hsiao \& Mor Barak, 2014; Jain et al., 2013; Ratnesh et al., 2016; Seklecka et al., 2013; Zuberi, 2011), resultando no aumento do estresse e na diminuiçáo do bem-estar e da qualidade dos relacionamentos pessoais e familiares (Papadopoulos et al., 2010).

\section{Relaçóes sociais e liderança}

\section{Relacionamento interpessoal e liderança}

Os seguintes aspectos referentes às características da liderança e do relacionamento entre os trabalhadores e superiores foram identificados como fatores de risco psicossocial: ausência de critérios para promoção de funcionários (Budhwar et al., 2009; Deery et al., 2013; Seklecka et al., 2013), baixos níveis de suporte dos superiores ou colegas de trabalho (Jain et al., 2013; Kesavachandran et al., 2006) e baixa qualidade dos relacionamentos no ambiente de trabalho, caracterizada principalmente pela comunicação escassa (Nandialath, Das \& Mohan, 2012; Quinlan \& Bohle, 2008). Segundo Schabracq et al. (2003), aspectos negativos referentes ao relacionamento no trabalho dificultam o estabelecimento de vínculos significativos, sentimentos de pertencimento ao grupo e manutenção da atenção no trabalho, e contribuem para a diminuição do prazer e bem-estar.

No que diz respeito à liderança, foi apontada a utilização da gestáo baseada no medo, assédio moral e abuso de poder (Druck, 2016), o que ficou evidente no estudo realizado por Santos et al. (2009), em que foi verificada a utilização de expressôes depreceativas para se referir aos trabalhadores, realização de ameaças constantes de demissáo e rotatividade como forma de punição, intensificando a insegurança no trabalho. 
Por fim, o fato do trabalho terceirizado ser constituído por dupla hierarquia (superiores da empresa contratante e superiores da empresa terceira) tornou mais difusa tanto a autonomia dos superiores quanto sua responsabilidade sobre os trabalhadores, sendo que estes relataram dificuldade em ter suas demandas atendidas pelos superiores (Gemma et al., 2017; Hsiao \& Mor Barak, 2014; Taylor et al., 2013).

\section{Reconhecimento, salário e beneficios}

Verificou-se nos estudos que aspectos relacionados ao reconhecimento, salário e benefícios constituíram fatores de risco psicossocial. Entre tais fatores, destaca-se a ausência de reconhecimento, tanto pela chefia da empresa terceirizada quanto da empresa contratante (Gemma et al., 2017), o estigma negativo relacionado ao trabalho (Hechanova, 2013; Santos et al., 2009; Thite, 2010) e o salário baixo ou insuficiente (Alvarez et al., 2007; Deery et al., 2013; Revathi, 2016). As recompensas financeiras, segundo Jain et al. (2013), contribuem para o estilo de vida do trabalhador e influenciam a percepção sobre seu próprio valor para a organização, já que representam um meio de reconhecimento pelo trabalho executado.

No estudo realizado por Zuberi (2011), os participantes relataram enfrentar dificuldades para arcar com seus gastos devido à reduçáo do salário quando passaram de funcionários contratados para funcionários terceirizados. Essa diferença nos salários também foi ressaltada por Druck (2016), sendo que isso levou os trabalhadores a fazer hora extra e a trabalhar em mais de um local ou mais de um turno, o que interferiu negativamente no tempo disponível para realizar atividades sociais ou de lazer.

Além do baixo salário, destacou-se a impossibilidade de usufruir de alguns benefícios exclusivos aos trabalhadores contratados diretamente pela organização, como o uso do restaurante universitário (Gemma et al., 2017) e do sistema de saúde da empresa, além da participação em comitês de saúde e segurança no trabalho (Zuberi, 2011), participação nos lucros e transporte (Druck, 2016).

\section{DISCUSSÃO}

Os fatores de risco psicossocial identificados em profissionais terceirizados nesta revisão foram agrupados nas seguintes categorias: organização do trabalho e conteúdo das tarefas, exigências no trabalho e relaçôes sociais e lideranças. Tais fatores também foram identificados por outros pesquisadores nos mais diversos contextos de trabalho, indicando a possibilidade da existência de um consenso na literatura acerca dos fatores de risco psicossocial (Leka \& Houdmont, 2010; Schabracq et al., 2003).

Entretanto, a partir dos resultados encontrados neste estudo, deve-se ressaltar que determinadas características específicas do contexto de trabalho terceirizado parecem contribuir para o surgimento de algumas particularidades no que diz respeito à origem e exposição dos fatores de risco psicossocial. O contexto de trabalho flexível em que se insere a terceirização é caracterizado essencialmente pelo número enxuto de trabalhadores permanentes, que geralmente ocupam funçóes de alta responsabilidade e importância para a empresa, e pela contratação de trabalhadores temporários, que normalmente executam funçóes de apoio pouco valorizadas e que exigem baixa qualificação (Lima, 2010). Tal divisão do trabalho contribui para o elevado número de terceirizados que exercem atividades repetitivas com poucas chances de desenvolvimento profissional e pessoal, o que favorece o baixo reconhecimento, a fácil substituição destes trabalhadores (Oltramari \& Piccinini, 2006) e intensifica a instabilidade e insegurança no trabalho (Lima, 2010).

A flexibilidade característica da terceirização consiste essencialmente na adaptação da organizaçáo às exigências do mercado e na redução dos gastos relacionados à força de trabalho (Lima, 2010). Sendo assim, as condiçôes de trabalho tornam-se flexíveis, principalmente no que diz respeito aos horários e carga de trabalho, que tendem a gerar uma intensificação do trabalho devido ao esforço em eliminar os tempos ociosos e aumentar a produção (Garza et al., 2012). A redução dos gastos, por sua vez, reflete na contratação de menos funcionários e na diminuição do salário e do investimento em treinamentos e equipamentos adequados (Vasapollo, 2005), que geralmente acarreta conflitos entre o trabalho e a família.

Outra questão que deve ser pontuada é a relevância que a dupla hierarquia apresenta para o contexto de trabalho terceirizado. Neste contexto, a avaliaçáo do desempenho e o controle são realizados tanto pela empresa terceira quanto pela empresa contratante, sendo que tal configuração intensifica a preocupação do trabalhador em garantir uma avaliação de desempenho elevada como tentativa de assegurar o emprego atual (Zanelli et al., 2010). A dupla hierarquia também influencia na ausência de clareza sobre quem detém a responsabilidade sobre a saúde, segurança e treinamento dos trabalhadores (Lair, 2012), o pode gerar 
a deteriorização das condições físicas e a redução de ações que garantem a saúde e a segurança no trabalho (Hasle, 2007).

No contexto de terceirização, também destaca-se a transferência da manutenção do emprego para o trabalhador a partir da intensa avaliação da qualidade dos seus serviços, o que contribui para que a empresa tenha liberdade para despedir parte de seus funcionários sem penalidades, gerando mais insegurança (Vasapollo, 2005).

De modo geral, esta revisão sistemática contribuiu para a identificação dos fatores de risco psicossocial relacionados ao estresse e às características do contexto de trabalho terceirizado. Tendo em vista a aprovaçáo do projeto de Lei que autoriza a terceirização para qualquer tipo de atividade (PL 4330/2004), é essencial que se compreenda quais são os fatores de risco psicossocial a que esses trabalhadores estão submetidos, suas origens e suas possíveis consequências para os trabalhadores terceirizados.

A partir da identificação dos fatores de risco psicossocial e das características da terceirização que os reforçam, é possível e necessário repensar a organizaçáo e os aspectos que compóem a terceirização enquanto prática administrativa, a fim de se reduzir as fontes de estresse no trabalho e prevenir que esses fatores se transformem em um problema significativo para a saúde e segurança dos funcionários e para a empresa. Neste quesito, é fundamental o papel do psicólogo organizacional, que pode atuar tanto na identificaçáo dos fatores de risco psicossocial quanto na sugestão e implementação de estratégias que visam à redução dos aspectos negativos relacionados à prática da terceirização, além da mensuração dos resultados de tais estratégias.

As limitaçóes do estudo referem-se ao período de tempo, às palavras-chave, ao conceito de estresse e à mensuração das variáveis. $\mathrm{O}$ período de tempo utilizado nas buscas poderia ter sido maior, sendo que o estresse no trabalho é um fenômeno que começou a ser estudado há décadas. As palavras-chave utilizadas poderiam ter abrangido os serviços subcontratados, que são semelhantes ao trabalho terceirizado e largamente utilizados. Em relação ao conceito de estresse, este é complexo e abrange diferentes teorias. A maioria dos estudos selecionados para esta revisão não identificou a teoria subjacente relacionada ao estresse utilizada pelos autores, o que apresentou um obstáculo para o estudo do mesmo constructo. Por fim, os artigos utilizaram diferentes procedimentos para coletar dados, o que dificultou a comparaçáo dos resultados, e a maioria não teve como objetivo a identificação dos fatores de risco psicossocial.

A partir dos resultados encontrados e das limitaçóes apontadas, sugere-se a realização de estudo robustos que identifiquem os fatores de risco psicossocial e mensurem o estresse no ambiente de trabalho terceirizado, a fim de se buscar compreender as relaçóes estabelecidas entre eles.

\section{REFERÊNCIAS}

Alvarez, D., Suarez, J. D., Pereira, R., Figueiredo, M., \& Athayde, M. (2007). Reestruturação produtiva, terceirização e relaçóes de trabalho na indústria petrolífera offshore da Bacia de Campos (RJ). Gestão \& Produção, 14(1), 55-68. doi:10.1590/ S0104-530X2007000100006

Brooks, N. (2006). Understanding IT outsourcing and its potential effects on IT workers and their environment. The Journal of Computer Information Systems, 46(4), 46-53. Retrieved from http://www. tandfonline.com/doi/abs/10.1080/08874417.2006 .11645913 ?journalCode $=$ ucis20

Budhwar, P. S., Varma, A., Malhotra, N., \& Mukherjee, A. (2009). Insights into the indian call centre industry: can internal marketing help high employee turnover? Journal of Services Marketing, 23(5), 351362. doi:10.1108/08876040910973459

Chillida, M. S. P., \& Cocco, M. I. M. (2004). Saúde do trabalhador \& terceirização: perfil de trabalhadores de serviço de limpeza hospitalar. Revista LatinoAmericana de Enfermagem, 12(2), 271-276. doi:10.1590/S0104-11692004000200018

Cox, T., Griffiths, A., \& Rial-González, E. (2000). Research on work-related stress. Luxembourg: Office of the Official Publications of the European Communities. Retrieved from https://osha. europa.eu/en/tools-and-publications/publications/ reports $/ 203$

D’Cruz, P., \& Noronha, E. (2008). Doing emotional labour: The experiences of Indian call centre agents. Global Business Review, 9(1), 131-147. doi:10.1177/097215090700900109

Davis-Blake, A., \& Broschak, J. P. (2009). Outsourcing and the changing nature of work. Annual Review Sociology, 35(1), 321-340. doi:10.1146/annurev. soc.34.040507.134641

Deery, S., Nath, V., \& Walsh, J. (2013). Why do offshored Indian call centre workers want to leave their jobs? New Technology, Work and Employment, 28(3), 212-226. doi:10.1111/ntwe.12013 
Druck, G. (2016). Unrestrained outsourcing in Brazil: more precarization and health risks for workers. Cadernos de Saúde Pública, 32(6), e00146315. doi:10.1590/0102-311X00146315

Garza, E. G., Valencia, A. S., \& Fernández, D. C. (2012). Capital, trabajo y nueva organización obrera. México: Maporrúa.

Gemma, S. F. B., Fuentes-Rojas, M., \& Soares, M. J. B. (2017). Agentes de limpeza terceirizados: entre o ressentimento e o reconhecimento. Revista Brasileira de Saúde Ocupacional, 42(4), 1-10. doi:10.1590/2317-6369000006016

Hasle, P. (2007). Outsourcing and employer responsibility: A case study of occupational health and safety in the Danish public transport sector. Relations Industrielles, 62(1), 96-117. doi:10.7202/015799ar

Hechanova, R. M. (2013). The call center as a revolving door: a Philippine perspective. Personnel Review, 42(3), 349-365. doi:10.1108/00483481311320444

Hernandes, E., Zamboni, A., Fabbri, S., \& Thommazo, A. (2012). Using GQM and TAM to evaluate StArt - A tool that supports systematic review. CLEI Electronic Journal, 15(1), 1-13. Retrieved from http://www.scielo.edu.uy/pdf/cleiej/v15n1/ v15n1a03.pdf

Hsiao, H.-Y., \& Mor Barak, M. E. (2014). Job-related stress, social support, and work-family conflict among Mexican workers in a multinational company: A casa study of a Korean-owned, US-branded former "sweatshop" in Mexico. International Journal of Social Welfare, 23(3), 309-320. doi:10.1111/ijsw.12065

Jain, A. K., Giga, S. I., \& Cooper, C. L. (2013). Stress, health and well-being: the mediating role of employee and organizational commitment. International Journal of Environmental Research and Public Health, 10(10), 4907-4924. doi:10.3390/ ijerph10104907

Kesavachandran, C., Rastogi, S. K., Das, M., \& Khan, A. M. (2006). Working conditions and health among employees at information technology - enabled services: a review of current evidence. Indian Journal of Medical Sciences, 60(7), 300-307. doi:10.4103/0019-5359.26606

Krumm, D. (2013). Psicologia do Trabalho: uma introdução à Psicologia Industrial/Organizacional. Rio de Janeiro, RJ: LTC.

Lair, C. D. (2012). Outsourcing and the contracting of responsibility. Sociological Inquiry, 82(4), 557-577. doi:10.1111/j.1475-682X.2012.00419.x

Leka, S. \& Houdmont J. (2010). Occupational Health Psychology. Chichester: Wiley-Blackwell.
Lima, J. C. (2010). A terceirização e os trabalhadores: revisitando algumas questóes. Cadernos de Psicologia Social do Trabaho, 13(1), 17-26. doi:10.11606/ issn.1981-0490.v13i1p17-26

Mandarini, M. B., Alves, A. M., Sticca, M. G. (2016). Terceirizaçáo e impactos para a saúde e trabalho: uma revisão sistemática da literatura. Revista Psicologia: Organizaçôes e Trabalho, 16(2), 143-152. doi:10.17652/rpot/2016.2.661

Nadeem, S. (2009). The uses and abuses of time: globalization and time arbitrage in India's outsourcing industries. Global Networks, 9(1), 20-40. doi:10.1111/j.1471-0374.2009.00240.x

Nandialath, A. M., Das, D., \& Mohan, R. (2012). Modelling heterogeneity in perceptions of stress in Indian call centres: a latent class analysis. International Journal of Business Innovation and Research, 6(5), 481-498. doi:10.1504/IJBIR.2012.048782

Oltramari, A. P., \& Piccinini, V. C. (2006). Reestruturação produtiva e formas de flexibilização do trabalho. Organizaçóes \& Sociedade, 13(36), 85-106. doi:10.1590/S1984-92302006000100005

Papadopoulos, G., Georgiadou, P., Papazoglou, C., \& Michaliou, K. (2010). Occupational and public health and safety in a changing work environment: an integrated approach for risk assessment and prevention. Safety Science, 48(8), 943-949. doi: 10.1016/j.ssci.2009.11.002

Petticrew, M., \& Roberts, H. (2006). Systematic reviews in the Social Sciences: a practical guide. Oxford: Blackwell Publishing.

Quinlan, M., \& Bohle, P. (2008). Under pressure, out of control, or home alone? Reviewing research and policy debates on the occupational health and safety effects of outsourcing and home-based work. International Journal of Health Services, 38(3), 489523. doi:10.2190/HS.38.3.g

Raja, J. D., \& Bhasin, S. K. (2014). Health Issues Amongst Call Center Employees, An Emerging Occupational Group in India. Indian Journal of Community Medicine, 39(3), 175-177. doi:10.4103/0970-0218.137156

Ram, A., Kurpad, A., \& Swaminathan, S. (2014). Understanding the health behaviors of India's information technology and business process outsourcing employee. International Journal of Workplace Health Management, 7(4), 213-228. doi:10.1108/IJWHM-07-2013-0029

Ratnesh, M., Sultana, S., \& Sinha, A. R. (2016). Women employees in indian BPO industries towards balancing their professional and personal 
life: some key issues. International Journal of Applied Business and Economic Research, 14(6), 4647-4658. Retrieved from http://www.serialsjournals.com/ serialjournalmanager/pdf/1469790735.pdf

Revathi, G. (2016). A study on factors causing stress among the BPO employees in health sector Chennai City - with reference to educational qualification and pay package. International Journal of Pharmacy \& Technology, 8(3), 16575-16580. Retrieved from http://www.ijptonline.com/wp-content/ uploads/2016/10/16575-16580.pdf

Santos, M. C. O., Lima, F. P. A., Murta, E. P., \& Motta, G. M. V. (2009). Desregulamentação do trabalho e desregulação da atividade: o caso da terceirização da limpeza urbana e o trabalho dos garis. Produção, 19(1), 202-213. doi:10.1590/ S0103-65132009000100013

Schabracq, M. J., Winnubst, J. A. M., \& Cooper C. L. (Eds.) (2003). The handbook of work of health psychology (2nd Ed.). Chichester: Wiley.

Seklecka, L., Marek, T., \& Lacala, Z. (2013). Work satisfaction, causes, and sources of job stress and specific ways of coping: a case study of white-collar outsourcing service employees. Human Factors and Ergonomics in Manufacturing \& Service Industries, 23(6), 590-600. doi:10.1002/hfm.20554

Smith, J. A. (Ed.) (2015). Qualitative psychology: $A$ practical guide to research methods (3rd Ed.). London: SAGE.

Snell, D., Schmitt, D., Glavas, A., Bamberry, L. (2015). Worker stress and the prospect of job loss in a fragmented organization. Qualitative Research in Organizations and Management: An International Journal, 10(1), 61-81. doi:10.1108/ QROM-03-2014-1210

Taylor, P., D'Cruz, P., Noronha, E., \& Scholarios, D. (2013). The experience of work in India's domestic call centre industry. The International Journal of Human Resource Management, 24(2), 436-452. doi $: 10.1080 / 09585192.2011 .561216$

Thite, M. (2010). All that glitters is not gold: employee retention in offshored Indian information technology enabled services. Journal of Organizational Computing and Electronic Commerce, 20(1), 7-22. doi:10.1080/10919390903482390

Vasapollo, L. (2005). O trabalho atipico e a precariedade. São Paulo: Expressão Popular.

Zanelli, J. C., Calzaretta, A. V., García, A. J., Lipp, M. E. N., \& Chambel, M. J. (2010). Estresse nas organizaçóes de trabalho: compreensão e intervenção baseadas em evidências. Porto Alegre, RS: Artmed.
Zuberi, D. (2011). Contracting out hospital support jobs: the effects of poverty wages, excessive workload, and job insecurity on work and family life. American Behavioral Scientist, 55(7), 920-940. doi:10.1177/0002764211407835

\section{Endereço para correspondência:}

Programa de Pós-Graduação em Psicologia

Universidade São Paulo

Av. Prof. Mello Moraes 1721 - Sala 13

Cidade Universitária

São Paulo, SP

CEP: 05508-030

Marina Greghi Sticca

marinagreghi@hotmail.com

Recebido em 24/04/2018

Aceito em 19/06/2019 


\title{
Estigma social de profesionales de la salud hacia personas que usan drogas
}

\author{
Social stigma from health professionals towards people who use drugs
}

\author{
Andrés Felipe Tirado Otálvaro ${ }^{1}$ \\ Gustavo Adolfo Calderón Vallejo ${ }^{2}$ \\ Sandra Milena Restrepo Escobar ${ }^{3}$ \\ Valentina Vásquez Gallón ${ }^{4}$ \\ Isabel Cristina Orozco Giraldo ${ }^{5}$
}

\section{Resumo}

Se realizó una investigación cualitativa con enfoque hermenéutico en la cual se entrevistaron 15 profesionales sanitarios que trabajan en servicios de Atención Primaria en Salud o en centros especializados de atención a personas que usan alcohol y otras drogas en Medellín y su área metropolitana, con el objetivo de comprender las actitudes estigmatizantes hacia dicha población. Se concluye que los juicios morales y las conductas negativas de los profesionales hacia estos sujetos, derivadas de la escasa formación y entrenamiento en el tema; sumado a las debilidades propias del sistema de salud colombiano para brindar una atención integral, se convierten en importantes barreras para acceder a los servicios de promoción, prevención, tratamiento y rehabilitación.

Palavras--chave: Estigma Social; Trastornos relacionados con sustancias; Alcoholismo; Centros de tratamiento de abuso de sustancias; Atención primaria de salud.

\section{Abstract}

Qualitative research with a hermeneutic approach. We interviewed 15 health professionals who work in Primary Health Care services or specialized centers for the care of people who use alcohol and other drugs in Medellin and its metropolitan area, with the aim of understanding stigmatizing attitudes towards this population. It is concluded that the moral judgments and the negative behaviors of the professionals towards these subjects, derived from the lack formation and training in this area; added to the weaknesses of the Colombian health system to provide comprehensive care, becomes in an important barrier to access the services of promotion, prevention, treatment and rehabilitation.

Keywords: Social Stigma; Substance-related disorders; Alcoholism; Substance abuse treatment centers; Primary health care.

El estigma es el resultado de un proceso que involucra cinco componentes interrelacionados entre sí, los cuales incluyen en primer lugar, el etiquetamiento de las personas debido a sus diferencias; en el segundo, la construcción de estereotipos sociales para los que portan la etiqueta negativa; en el tercero, se presenta una separación entre quienes llevan consigo la marca de indeseables y los que no; en el cuarto, debido al etiquetamiento se produce la pérdida de la condición de sujeto, lo que da lugar a situaciones de devaluación, rechazo, discriminación y exclusión; y por último, en el quinto componente, se presenta un ejercicio desigual del poder de parte de los que estigmatizan hacia los que son estigmatizados (Link \& Phelan, 2006).
Los Trastornos por Uso de Sustancias (TUS) son una de las condiciones más estigmatizadas a nivel mundial, incluso por encima de enfermedades como el SIDA (Van Boekel, Brouwers, Van Weeghel, \& Garretsen, 2013), la depresión, la lepra o la esquizofrenia (Ronzani, Higgins-Biddle \& Furtado, 2009). La estigmatización hacia las Personas que Usan Drogas (PUD) y hacia las Personas que Usan Alcohol (PUA), no es un asunto ajeno al personal de salud; situación que se evidencia en las actitudes negativas hacia los pacientes con dicho diagnóstico por parte de los profesionales sanitarios, sumado al poco interés y satisfacción que manifiestan respecto al trabajo con esta población, ya que consideran que son sujetos desafiantes, estresantes y difíciles de manejar (Ronzani et al., 2009; Van Boekel

\footnotetext{
1 Enfermero, Magíster en Epidemiología, PhD en salud Pública. Grupo de Investigación en Cuidado, Universidad Pontificia Bolivariana. Medellín, Colombia.

${ }^{2}$ Sociólogo, Magíster en Estudios Urbano Regionales. Grupo de Investigación en Farmacodependencia, Docente Universidad Católica Luis Amigó. Medellín, Colombia. Correspondencia: gustavo.calderonva@amigo.edu.co

${ }^{3}$ Psicóloga, Especialista en Farmacodependencia, Magíster en Educación y Desarrollo Humano. Grupo de Investigación en Farmacodependencia,

Docente Universidad Católica Luis Amigó. Medellín, Colombia. Correspondencia: sandra.restrepoes@amigo.edu.co

${ }^{4}$ Estudiante de Enfermería. Universidad Pontificia Bolivariana. Medellín, Colombia. Correspondencia: valentina.vasquezg@upb.edu.co

${ }^{5}$ Administradora en Salud. Universidad Católica Luis Amigó. Medellín, Colombia. Correspondencia: isabel.orozcogi@amigo.edu.co
} 
et al., 2013; Van Boekel, Brouwers, van Weeghel, \& Garretsen, 2014).

Un estudio realizado con prestadores de atención primaria en Brasil, indica que es frecuente que el personal sanitario atribuya categorías morales a la práctica del consumo (Ronzani et al., 2009), hecho que según lo indica la evidencia científica disponible, se encuentra asociado con una fuerte percepción por parte del personal asistencial de que el consumo de drogas obedece a defectos del carácter, motivo por el cual se tiende a responsabilizar a los usuarios de dichas sustancias de su condición (da Silveira, Martins, Soares, Gomide, \& Ronzani, 2011; Ronzani, Noto, \& Silveira, 2015). La literatura sobre el tema muestra que el personal de enfermería y los agentes comunitarios de salud tienen un juicio moral más severo respecto al uso de sustancias, en especial la marihuana y la cocaína (Ronzani et al., 2009); en contraste con lo anterior, los profesionales que trabajan en centros especializados para el tratamiento de adicciones, al igual que aquellos que tienen una mayor experiencia personal, laboral o de contacto con PUA-PUD, informaron actitudes más positivas y mostraron mayor consideración respecto a dicha población, en comparación con los profesionales de los servicios generales y de psiquiatría (Van Boekel et al., 2013, 2014).

En consideración con lo anterior se llevó a cabo esta investigación, la cual tuvo como objetivo comprender las actitudes estigmatizantes de los profesionales de salud que trabajan en Medellín y su área metropolitana, hacia las personas que consumen alcohol y otras drogas, con el fin de tener un insumo descriptivo-hermenéutico inicial para un estudio multicéntrico desarrollado por la Red Latinoamericana de Investigación sobre Estigma y Drogas.

\section{MÉTODO}

\section{Tipo de estudio y enfoque}

Se realizó una investigación cualitativa, con un enfoque hermenéutico y un alcance descriptivo-interpretativo, acerca del estigma social de los profesionales de la salud hacia las personas que consumen alcohol y otras drogas. Lo hermenéutico se entiende como la construcción de un texto social a partir de la palabra de los actores consultados, para ser interpretado por el grupo de investigación y de manera conjunta ser triangulado con la discusión de la literatura científica sobre el tema (Cadenas, 2016).

\section{Participantes, mapeo y muestreo}

Los participantes fueron 15 profesionales del área de la salud entrevistados entre los meses de mayo y junio del año 2018, diferenciando los que laboran en servicios de Atención Primaria en Salud (APS) y los que trabajan en centros especializados de atención a personas que usan alcohol y otras drogas.

Se realizó muestreo intencional (con propósito), en el cual se busca a los participantes de acuerdo con la información que puedan proporcionar, de manera que los escogidos brinden la mayor riqueza interpretativa respecto al objetivo propuesto (Martínez-Salgado, 2012). En tal sentido, se hizo un rastreo de las principales instituciones del Área Metropolitana del Valle de Aburrá donde laboran profesionales de la salud en las áreas mencionadas, y se contactaron a aquellos que quisieran compartir sus percepciones acerca del fenómeno de estudio desde diferentes perspectivas, tratando de incluir diferentes voces en términos de su profesión, edad, género y experiencia profesional. Siguiendo las recomendaciones de Taylor \& Bogdan (1992), se seleccionaron los participantes en función de su potencial para ayudar a refinar o expandir conceptos, diversificando los informantes con el objetivo de descubrir toda la gama de perspectivas acerca del tema de investigación hasta saturar las categorías; en consideración con lo anterior, se incluyeron diez mujeres y cinco hombres, con edad promedio de 42 años; de los cuales siete son psicólogos, dos médicos generales, un psiquiatra, tres trabajadoras sociales y dos enfermeras, una de ellas pedagoga. Todos tenían nivel de formación de especialización o maestría.

\section{Proceso de recolección}

Como técnica se eligió la entrevista semiestructurada y en profundidad, por ofrecer la posibilidad de un acercamiento lo más natural posible, pero con detenimiento y detalle respecto al fenómeno de estudio (Taylor \& Bogdan, 1992). Inicialmente se realizó un contacto con las personas y las instituciones que facilitaron la recolección, con el fin de presentarles el estudio, los responsables, los propósitos y los procedimientos necesarios para la realización del proceso. Se les indicó que la información se recogería con un criterio de anonimato, confidencialidad y voluntariedad. Las entrevistas tuvieron una duración entre 40 y 65 minutos y exploraron preguntas como ¿Qué piensa acerca de las PUA-PUD? ¿En su práctica profesional cómo se brinda atención a las PUA-PUD? ¿Qué sentimientos despierta 
en usted la atención de las PUA-PUD? ¿De qué manera los prejuicios hacia las PUA-PUD afectan la relación entre estos y los profesionales de la salud?, entre otras. La información fue grabada, trascrita e interpretada por los investigadores responsables del proyecto. En este sentido, siguiendo las recomendaciones (Íniguez, 2003), no se transcribieron sólo las palabras sino también los suspiros, pausas e interrupciones, de manera que el texto fuera lo más fiel posible a los relatos de los participantes.

\section{Proceso de sistematización, validación e interpretación de la información}

El proceso descriptivo y de interpretación, se llevó a cabo a partir de las entrevistas trascritas; se hizo el señalamiento por párrafos de frases cortas con sentido, de donde derivaron los códigos que fueron agrupados por categorías. Posteriormente, se hizo una descripción de lo hallado y se llevaron los textos a plenaria de los investigadores, para ser revisados y confrontados en consenso, con el objetivo de dar cumplimiento a los criterios de rigor en el análisis en términos de auditabilidad/credibilidad (Creswell \& Miller, 2000). Luego, se retomó la búsqueda exhaustiva de fuentes documentales por parte del equipo de investigación para analizar los resultados encontrados con el marco referencial. Como estrategia de análisis conjunto, se parte de los resultados escritos y se cotejan con lo hallado en fuentes secundarias y la respectiva interpretación de los investigadores (Navarrete, 2011).

La validación cualitativa se lleva a cabo mediante un proceso de revisión permanente y sistemático de la información recogida. Para ello los procesos de identificación de categorías previas y emergentes, los hallazgos iniciales y los análisis finales son trabajados por cada investigador y luego discutidos entre todos. Esto permite un análisis interno sobre lo hallado, para obtener una visión de conjunto, de tal manera que las unidades de sentido estén presentes en sus relaciones, semejanzas y diferencias (Cadenas, 2016).

Esta investigación fue aprobada por la Vicerrectoría de Investigaciones de la Universidad Católica Luis Amigó. Se cumplió con los requisitos exigidos en la Resolución No 008430 de 1993 expedida por el Ministerio de Salud de Colombia, en relación a los estudios clasificados como "Investigación con riesgo mínimo", protegiendo en todo momento los principios éticos fundamentales de beneficencia, no maleficencia, respeto y justicia.

\section{RESULTADOS}

Los participantes perciben el consumo de drogas dependiendo de su formación y el acercamiento que hayan tenido al tema desde la academia y desde su práctica profesional, y aunque se encontró que tanto los que trabajan en APS como los que lo hacen en centros especializados tienen un juicio estigmatizante acerca de las personas que usan drogas, y ven la abstinencia total como el principal objetivo a conseguir, debido a la falta de criterios clínicos precisos, a la multiplicidad de factores que condicionan la adicción y a la deficiente formación que sobre el tema reciben en sus pregrados universitarios; hay aspectos que diferencian la manera como éstos entienden el uso de sustancias, pues mientras que los primeros suelen relacionarlo de manera más frecuente con asuntos familiares y contextuales generadores de conflictos, los segundos lo asocian a factores genéticos y a una historia familiar de consumo, lo que genera una alta predisposición a la adicción.

Así pues, las múltiples maneras de entender el consumo, el tipo de formación recibida y el ejercicio profesional en la práctica marcan la pauta de cómo se interviene el asunto desde cada una de las orillas arriba descritas. A continuación, se describe cómo los entrevistados abordan su praxis y los sentimientos que se generan a partir de la atención que brindan a las PUAPUD en su ejercicio profesional.

\section{Atención a las personas que usan alcoholy otras drogas desde la práctica profesional}

$\mathrm{Al}$ indagar con los profesionales de atención especializada sobre el asunto, se encontró que estos presentan poca credibilidad y confianza hacia las PUA-PUD, debido a la falta de voluntad de dichos sujetos para suspender o abandonar el consumo; circunstancia que genera complicaciones y sobrecostos al sistema, ya que dichos pacientes recurren con menor frecuencia a los servicios de salud y cuando lo hacen, la gravedad de la atención es mucho más alta. Esta situación se refleja en la práctica en la poca motivación por parte de los profesionales que laboran en dichos servicios para la atención de esta población.

Hay profesionales que los consideran estorbo, que consideran que no tienen voluntad, que generan sobrecostos al sistema de salud, que los rechazan en general, porque digamos que hay mucho médico o mucho profesional que también les da temor, porque como piensan 
que son peligrosos, que son ladrones, que van a hacer daño, más bien asumen una actitud de rechazo que se manifiesta de distintas maneras (Entrevista 1 con profesional de centro especializado pág. 2).

Los profesionales de APS entrevistados desempeñan sus funciones en diferentes frentes, ya sea a través de una consulta institucional en la que se brindan servicios de promoción y prevención general (control prenatal, crecimiento y desarrollo, enfermedades crónicas no transmisibles, entre otras), o por medio de actividades en terreno, las cuales incluyen diversas estrategias de prevención con población escolar o familiar (no necesariamente en temas relacionados con el consumo), así como actividades de mitigación del riesgo a través de los centros de escucha intra o extramurales; es por esto que, a diferencia de lo que ocurre con los profesionales que laboran en centros especializados, en la práctica de APS el estigma opera de manera diferente, en tanto los usuarios no llegan en estado de intoxicación y normalmente acceden a estos servicios por razones que no necesariamente se encuentran asociadas al uso de sustancias.

En este orden de ideas, es común que los profesionales que laboran en APS a nivel institucional, en especial psicólogos o enfermeras, se valgan de la anamnesis y de la historia clínica para indagar acerca del consumo, pues al ser este un tema sensible, prefieren abordarlo de manera indirecta para no herir susceptibilidades, ya que normalmente las personas no van a consulta por problemas relacionados con el uso de sustancias. Llama poderosamente la atención que dichas estrategias no se emplean con todas las personas que asisten a consulta de APS, sino que se utilizan de manera particular y selectiva sólo con aquellos que por su manera de vestir o de hablar le indican al profesional que posiblemente consumen drogas; o por el contrario, con las personas que tienen signos físicos visibles que podrían indicar dependencia a sustancias; situación que es aprovechada por los profesionales, bien sea para brindar orientación acerca de la necesidad de escalar la consulta a un nivel de complejidad mayor, o incluso para generar sentimientos de culpa en los usuarios de dichas sustancias respecto a la necesidad de mantenerse abstemios.

"Siempre nos metemos con el ser que más amamos, no queremos destruirlo, entonces cuando van con la mamá, si vemos que hay ciertas ganas de salir (...) siempre se utiliza, se aprovecha”. (Entrevista 2 con profesional de APS pág. 12).

Por otra parte, los profesionales de APS que laboran en terreno, enfocan su trabajo principalmente en tareas de prevención del consumo a nivel escolar, con jóvenes en parques o a través de visitas casa a casa. Dichas actividades inician generalmente con temas de prevención universal para enganchar a estas personas a los programas y posteriormente brindar educación sobre asuntos como el fortalecimiento del carácter y la autoestima, habilidades para la vida, resolución de problemas, manejo de la frustración, así como temas relacionados con los efectos físicos de las drogas, los riesgos del consumo, y la afectación de la vida académica, familiar y social ocasionada por el uso de alcohol y otras drogas; normalmente estos temas se trabajan con los jóvenes a través de la discusión de situaciones hipotéticas en la cuales se recrean escenarios de adicción que llevan a las personas a la desescolarización, los problemas familiares e incluso a vivir en las calles, para a partir de allí plantear una reflexión acerca del tema.

Los profesionales que trabajan en servicios especializados encuentran menos barreras para abordar temas relacionados con el uso de drogas, en tanto las personas que allí acuden; independientemente de si lo hacen por voluntad propia o por presión de sus familias, asisten puntualmente para buscar ayuda a sus problemas de consumo. A diferencia de estos, los profesionales de APS relatan las dificultades que tienen para tratar estos temas con los jóvenes ya que en múltiples ocasiones se encuentran con personas que manifiestan abiertamente su consumo e incluso lo defienden, por medio de argumentos que van desde la inocuidad de sustancias como el alcohol y la marihuana, hasta la capacidad que ellos tienen para manejar las drogas sin que se vean afectadas sus esferas de relacionamiento social, académico o familiar. Lo anterior les genera impotencia con relación a su praxis, ya que como ellos mismos lo manifiestan, su labor no les permite hacer intervención más allá de la educación y la remisión del caso, (sólo cuando la persona está interesada en ingresar en la ruta de atención definida en la política pública al respecto), por lo que su actuación se limita en los casos en los cuales no hay voluntad de cambio, a brindar información sobre las posibilidades de atención, recomendaciones sobre el uso seguro de las sustancias, a la persuasión y a delegar la responsabilidad del asunto al joven y a su familia.

Yo llego hasta donde puedo llegar, hago mi derivación, mi remisión y la familia ya se 
encarga de ubicar el muchacho (...) Obligar al muchacho, esa parte ya le toca a la familia, (...) Porque no es mi labor, no me puedo extralimitar, yo tengo hasta un punto, yo llego, canalizo y remito, ya no puedo hacer nada más, (...) yo no me puedo meter porque entonces se viene la problemática penal, si este muchacho se vuelve un drogadicto, cae a la calle, le pasa alguna cosa, va a llegar la mamá a decir: pero la doctora se mantenía con él, ¿entonces cuál fue la intervención de la doctora? entonces ya uno se cuida mucho de esa parte legal. (Entrevista 3 con profesional de APS pág. 6).

\section{Sentimientos respecto a la atención de personas que usan alcohol y otras drogas}

Debido al acercamiento académico al tema, al entrenamiento específico recibido, al tipo de pacientes que manejan y a la experiencia profesional; los sentimientos que se generan a partir de la atención de las PUA-PUD en la praxis son diferentes para quienes laboran en servicios especializados, que para aquellos que lo hacen en APS, pues mientras que los primeros manifiestan asuntos relacionados básicamente con el sistema de salud colombiano, los segundos al no tener contacto de manera permanente con este tipo de pacientes, manifiestan asuntos de tipo personal frente a la atención.

De este modo, los profesionales que trabajan en centros especializados, centran su mirada en asuntos clínicos relacionados con los comportamientos asociados al abuso de sustancias o a la atención integral en salud, y aunque destacan que es frecuente encontrar poco compromiso por parte de los pacientes para su intervención, los sentimientos que esto les genera, no necesariamente se relacionan con dicha situación, sino con las barreras del Sistema General de Seguridad Social en Salud colombiano para acceder a servicios de tratamiento y rehabilitación de manera constante y efectiva; situación que se exterioriza en sentimientos de frustración, angustia, tristeza y rabia, ya que las debilidades propias del Sistema, se ven reflejadas en constantes ingresos y recaídas, debido a la intermitencia en el tratamiento.

El que está dentro de la salud presta un mal servicio. Vos vas a consultar porque tenés una relación de dependencia con una sustancia $\mathrm{y}$ encuentras un profesional que hace una devolución inadecuada, entonces comienza uno como a desgastarse del sistema de salud, ¿a qué voy a ir allá si no me prestan atención?, si el psiquiatra dice: "no, yo no te voy a internar, ¿para qué te vamos a internar si vos no respondes a nada? (Entrevista 2 con profesional de centro especializado pág. 5)

A diferencia de estos, los profesionales que trabajan en APS manifestaron múltiples sentimientos respecto a las PUA-PUD, y aunque piensan que hay mucho por hacer desde el punto de vista profesional por estas personas, es común encontrar que existe aversión hacia el trabajo con esta población, evitación y prácticas recriminatorias respecto al uso de sustancias; elementos que según ellos mismos lo manifiestan, guardan relación con el poco entrenamiento y capacitación que tienen, no sólo frente a las drogas, sino también frente al manejo de las personas que las consumen, motivo por el cual argumentan que no se sienten preparados para atender a los usuarios de dichas sustancias y que en tal sentido, prefieren trabajar o con otro tipo de pacientes o delegar su atención al personal especializado en el tema.

Del mismo modo, fue común encontrar en los relatos de los entrevistados de APS sentimientos de lástima, tristeza y pesar hacia las PUD, en especial hacia aquellos que iniciaron su consumo a una edad temprana; sentimientos que posteriormente se transforman en impotencia, cuando al hacer la intervención del caso desde las posibilidades que les brinda su conocimiento y la ley, no encuentran una respuesta positiva por parte de los usuarios, cuando éstos manifiestan su intención de no querer abandonar el consumo; hecho que se refleja en la práctica comunitaria en una distancia social hacia estas personas, debido a la frustración que les genera no poder hacer nada por una persona que no tiene interés en buscar ayuda a su problema.

Eso genera inclusive frustración, porque uno quisiera que con los argumentos que uno da, poder movilizarlos, pero no, es muy difícil, o sea, yo sé que yo me puedo sentar con una persona consumidora de droga y decirle miles y miles de cosas, sentarme 2 , 3 horas, conversar, y al otro día encontrarlo en la calle (...) yo me vengo con mi corazón partido, pero como te digo, no puedo echarme encima todo eso, pero si siento una frustración muy grande (Entrevista 3 con profesional de APS pág. 6). 
Otros sentimientos relatados por los profesionales de APS entrevistados, son el miedo, la prevención y el rechazo frente de las PUA-PUD, ya que temen ser víctimas de robos, insultos o agresiones, pues manifiestan que cuando estas personas se encuentran agitados por el uso de las sustancias, es posible que la situación se salga de control, y sienten que no tienen un entrenamiento adecuado como profesionales para intervenir estos casos.

\section{Estigma hacia las personas que usan alcohol y otras drogas}

Aunque en las entrevistas, tanto los profesionales de APS como aquellos que trabajan en servicios especializados manifestaron no tener actitudes estiqmazantes, es común que empleen etiquetas derivadas de su formación clínica para referirse a sus pacientes; en este orden de ideas, es frecuente que independiente del tipo de consumo (experimental, ocasional, habitual o compulsivo), se refieran a estos sujetos, no como personas que usan alcohol $\mathrm{u}$ otras drogas, sino como alcohólicos, drogadictos, borrachitos, marihuaneros, o simplemente consumidores.

Es común que los profesionales sanitarios trasladen la responsabilidad del estigma en los demás: la familia, la sociedad en pleno e incluso otros profesionales. Así pues, quienes laboran en centros especializados manifiestan que el estigma se da de manera más frecuente en la atención primaria, debido a que los profesionales que allí trabajan, no logran quitar la etiqueta de delincuentes hacia las PUA-PUD, sienten miedo y piensan que los van a robar; situación que según ellos mismos manifiestan, repercute directamente en la atención, pues al romperse el vínculo con el usuario, se genera una barrera adicional de acceso en el sistema de salud.

Por su parte, quienes trabajan en servicios de APS manifiestan que el estigma se presenta de manera más frecuente en los servicios psiquiátricos y de urgencias, ya que es común que a estos lugares ingresen personas en estado de intoxicación, lo que genera incomodidades por parte de los profesionales que allí laboran, debido a que son pacientes de difícil manejo y al poco entrenamiento que tienen para la atención de estos casos; lo anterior, se traduce en acciones de rechazo o malos tratos hacia esta población, e incluso hacia sus familias, en tanto fue común escuchar relatos que indican que dichos profesionales sólo atienden a los usuarios de drogas cuando tienen una condición de urgencia que así lo amerite, y que de lo contrario le indican a las familias que deben llevar al paciente a su casa y traerlos nuevamente al servicio cuando hayan pasado los signos de intoxicación.

Una persona adicta es una persona complicada, es un paciente agitado, es un paciente que no va ser fácil de manejar (...) fuera de eso es costoso, entonces casi siempre le hacen el feo, porque huele mal, porque llegan vomitados, orinados, poposiados, porque llevan días en la calle (...) y la mayoría de los hospitales no están preparados, ni los enfermeros, ni los médicos, y tampoco tienen especialistas en el tema para trabajar este tema de salud mental, entonces se combina todo eso, entonces uy que aburrición con este paciente. (Entrevista 4 con profesional de APS pág. 14).

\section{Barreras para acceder a servicios de prevención, tratamiento y rehabilitación debido al estigma}

Al margen de las marcadas diferencias entre los profesionales entrevistados acerca de la manera como realizan su práctica profesional, hay un punto en el que convergen sus discursos y es el estigma hacia el uso de alcohol y otras drogas como una barrera determinante para acceder a los servicios de tratamiento y rehabilitación.

Los participantes del estudio no desconocen los importantes avances que sobre el tema se han logrado en el país en materia legislativa, sin embargo, manifiestan que aún persiste una marcada discriminación hacia las PUA-PUD debido a los mitos que en la sociedad se han tejido en torno al consumo de sustancias; situación que se hace manifiesta en la práctica en múltiples dificultades para acceder a una atención integral, en tanto las instituciones de salud ponen diferentes barreras burocráticas para la no prestación del servicio, debido al costo que implica tratar una adicción, considerando la poca motivación de los pacientes por su recuperación, las múltiples recaídas y la escasa evidencia de efectividad de los tratamientos en términos de abstinencia total, con lo cual reflejan un desfase entre lo moral y lo ético al momento de la atención de esta población.

Sumado a lo anterior, los entrevistados manifiestan que el estatus de enfermedad de las adicciones no es suficientemente sólido, y al no ser considerado como una enfermedad prioritaria, no es posible garantizar atención y cobertura de manera integral, motivo por el cual los profesionales tienen que solicitar exámenes 
o interconsultas sin especificar la condición de consumo del paciente, lo que en ocasiones implica mentir al Sistema para poder garantizar atención de estas personas, pues se asegura que identificar el verdadero diagnóstico del paciente puede generar demoras para su atención, debido a que no es fácil que se aprueban intervenciones para esta población. Esta situación, indican los participantes del estudio, limita las posibilidades de atención a la capacidad de pago de los usuarios ya que los obliga a tener que buscar tratamientos de manera particular, pues el Sistema no tiene el músculo suficiente para dar respuesta a las necesidades de esta población. Esto a su vez favorece el acceso a diferentes alternativas de tratamiento por fuera de las contempladas en el sistema de salud colombiano, las cuales en múltiples ocasiones obligan a las PUA-PUD a trabajar vendiendo dulces o galletas para poder cubrir con esto el costo de sus tratamientos.

La cobertura integral en salud para las PUAPUD es un asunto complejo en el país, en especial para aquellos que no están afiliados al Sistema General de Seguridad Social en Salud. Pese a esto, la afiliación per-se no es una garantía de atención, ya que es frecuente la negación de citas y la prestación de tratamientos intermitentes; y aunque en este último punto existe una responsabilidad compartida entre las Entidades Promotoras de Salud y el paciente que abandona su tratamiento, también es claro que en múltiples ocasiones hay una negativa directa por parte de estas entidades en brindar un tratamiento integral, debido al costo que supone el mismo, lo que obliga a los usuarios a instaurar maniobras legales como la acción de tutela para poder acceder a la atención. Lo anterior genera frustración e impotencia en los profesionales sanitarios, ya que la falta de continuidad en el tratamiento aumenta las recaídas, favorece la deserción y disminuye las posibilidades de recuperación de los pacientes; lo anterior, sumado al escaso presupuesto destinado en el país para la atención en salud mental, agudiza las barreras de acceso y permanencia para las PUA-PUD.

Por último, los participantes del estudio manifiestan que aunque el Estado tiene la responsabilidad de garantizar el derecho fundamental a la salud para la población sin discriminación, los profesionales sanitarios también tienen un papel protagónico en este asunto, al ser los encargados de identificar, diagnosticar, intervenir o remitir los casos a un nivel de complejidad mayor; en tal sentido, admiten reconocer que el trato despectivo y estigmatizante hacia las PUA-PUD retrasa la búsqueda de tratamiento y dificulta la alianza terapéutica, motivo por el cual abogan por la necesidad de una mayor capacitación y entrenamiento en el manejo de esta población, para lo cual se requiere de una mayor inversión presupuestal por parte del Estado y un compromiso firme desde la academia por los temas de salud mental.

Yo pienso que la formación para trabajar con este tipo de usuarios no debe ser téc nica sino humana, porque vos técnicamente sabes (...) pero desde lo humano no hay una manera en que te preparen para enfrentarte a este personal sin creer que todo está perdido (...) vos sos profesional de la salud $\mathrm{y}$ te dijeron que vos vas a salvar personas (...) pero cuando te dicen que es drogadicto, no hay nada que hacer, entonces ahí no voy yo. (Entrevista 1 con profesional de APS pág. 14).

\section{DISCUSIÓN}

Berger y Luckmann plantean que las personas construyen el significado respecto a un fenómeno, dependiendo del contexto social al que pertenezcan (Berger \& Luckmann, 2005), de ahí que tanto el concepto que se tenga acerca de las drogas, como la manera de abordar las situaciones derivadas de dicha concepción, se encuentran ligadas a las realidades en las cuales se desenvuelven los sujetos (Ralet, 2000; Smith, Earnshaw, Copenhaver, \& Cunningham, 2016); a partir de dicho planteamiento, es posible argumentar los datos encontrados en este estudio, según los cuales, los profesionales del sector salud perciben el consumo de sustancias y a las personas que las usan, dependiendo de su formación y el acercamiento que han tenido al tema desde su praxis, y a partir de allí, lo intervienen de manera diferente. Del mismo modo, Blumer argumenta que los seres humanos como sujetos sociales, actúan frente a los femémonos de acuerdo con el significado que construyen de los mismos (Blumer, 1982), motivo por el cual es posible entender cómo la manera de abordar los asuntos relacionados con el consumo de sustancias es diferente para los profesionales que laboran en centros especializados, que para aquellos que desempeñan su trabajo en APS, no sólo porque las realidades que abordan en su práctica diaria son diferentes, sino porque su experiencia y su acercamiento al tema también lo son. 
Esta investigación reveló que los profesionales de salud entrevistados estigmatizan a las personas que usan alcohol y drogas, independiente del contexto en el que trabajen; situación que guarda relación con la literatura sobre el tema, la cual reporta que los profesionales sanitarios tienen actitudes estigmatizantes respecto a esta población, debido a las connotaciones morales construidas frente a la práctica del consumo, según las cuales, tanto las sustancias como las personas que las usan son consideradas indeseables (Kulesza et al., 2016; Vásquez, 2009).

Específicamente para los profesionales que laboran en APS es más difícil abordar el tema del consumo de drogas que para aquellos que lo hacen en servicios especializados, no sólo porque no trabajan de manera exclusiva con usuarios de dichas sustancias, sino porque al ser un asunto privado y con amplias connotaciones morales, no es común que se manifieste abiertamente por las personas que acuden a estos servicios, pues sienten vergüenza y temor de ser juzgados por parte de quienes allí laboran (Geffner, Zalazar, Mascayano, \& Agrest, 2017; Van Boekel et al., 2014). La estigmatización y el juicio moral acerca del uso de alcohol y otras drogas puede afectar negativamente la prestación de los servicios de salud e incidir en la permanencia de los usuarios en estos programas (Ronzani et al., 2009), por lo que Oliveira et al, concluyen que la estigmatización puede ser más perjudicial que la propia enfermedad (Oliveira \& Ronzani, 2012).

El uso de alcohol y otras drogas al ser considerados como una cuestión de responsabilidad individual, son unos de los fenómenos sociales más estigmatizados, por lo que a menudo refuerzan las posiciones y los sentimientos morales por parte de los profesionales de salud hacia los usuarios de dichas sustancias (Ronzani et al., 2009). Este estudio encontró similitudes con los datos reportados por otras investigaciones, respecto a los sentimientos de los proveedores de servicios de salud hacia a las PUA-PUD según los cuales, es común que los profesionales sanitarios sientan miedo, rechazo y prevención hacia estos sujetos, pues los ven como un grupo difícil de intervenir, en tanto consideran que son manipuladores, desafiantes y potencialmente violentos (Clarke et al., 2015; Paiva, Ferreira, Martins, Farias \& Ronzani, 2014). Estas actitudes contrastan con los sentimientos de lástima hacia estas personas debido a su condición de consumo, al igual que la sensación de frustración e impotencia con relación a su práctica profesional por la poca motivación de los usuarios de dichas sustancias frente a su recuperación y las múltiples recaídas; situación que podría explicarse en el primero de los casos en la creencia de que el inicio y la permanencia en el consumo obedecen a asuntos de debilidad en el carácter (París Pombo et al., 2009) y en el segundo, a la visión de la abstinencia total como principal indicador de rehabilitación (Kelleher \& Cotter, 2009; UNODC, 2011).

Este estudio encontró que los profesionales de APS no sólo tienen juicios severos hacia las PUD, sino que sienten que no tienen ni el entrenamiento, ni las competencias suficientes para atender a las personas con un uso problemático de sustancias, por lo cual prefieren delegar la atención de dichas personas a profesionales que laboran en servicios especializados, situación análoga a lo reportado en la literatura (Van Boekel et al., 2014), en la cual se describe que en términos generales los profesionales de la salud tienen bajos niveles de conocimiento sobre los TUS y piensan que carecen de habilidades específicas para la atención de estos sujetos (Kelleher \& Cotter, 2009; Van Boekel et al., 2013).

La situación que se acaba de presentar deriva en prácticas recriminatorias por parte del personal de salud hacia las PUA-PUD, al igual que el empleo del miedo y la culpa como estrategias de disuasión y control, tal como lo evidenció este estudio. El estigma se construye a partir de las relaciones que se dan entre las personas en un momento y una realidad determinada (da Silveira et al., 2011), en las cuales la distribución desigual del poder juega un papel fundamental (Link \& Phelan, 2001); lo anterior explica por qué es común que el personal de salud busque imponer sus creencias y prejuicios sobre las personas que usan alcohol y otras drogas (Van Boekel et al., 2013), motivo por el cual sigue siendo frecuente usar el miedo como principal estrategia de prevención prohibicionista, camuflada en los argumentos científicos de la ciencia médica dominante (Martínez \& Pallarés , 2013) bajo la mirada pasiva de un Estado que ve a los usuarios de drogas a través de sus políticas, no como ciudadanos responsables de sus actos y con capacidad de elección, sino como niños a los que hay que proteger y cuidar (Lobos, 2012).

Lo anterior se traduce en la práctica clínica y comunitaria en la incapacidad de los profesionales para dar solución a un problema complejo, lo que redunda en sentimientos de rabia y frustración frente a un sistema de salud inoperante respecto a sus expectativas de lograr la abstinencia total, por lo cual es común que los profesionales sanitarios trasladen la responsabilidad de la recuperación en la familia, el sistema de salud o la sociedad en pleno (Ronzani et al., 2015). Sumado a lo anterior, y tal como lo reveló este estudio, el hecho de que la atención integral para los TUS no esté lo 
suficientemente clara en la política nacional en términos de la actuación por parte de los profesionales de la salud y de las responsabilidades de cada una de las instituciones involucradas en el sistema, hace que la prestación del servicio se diluya en la práctica y se tenga que recurrir a mecanismos legales para buscar la garantía del derecho a la atención en salud, pues los exagerados trámites administrativos para acceder a dichos servicios, sumados a la negativa constante por parte de las Empresas Promotoras de Salud para cubrir programas de rehabilitación, hacen que los usuario se desmotiven y decidan asumir los costos por cuenta propia, lo que en diversas oportunidades redunda en que las personas se vean obligadas a acudir a servicios de baja calidad, lo que se traduce en mayores probabilidades de sufrir una afectación a su integridad (Uprimny, Guzmán, Parra, \& Bernal, 2014).

Por último, los participantes del estudio manifiestan que aunque el Estado tiene la responsabilidad de velar por la garantía del derecho fundamental a la salud para la población sin discriminación, los profesionales sanitarios también tienen un papel protagónico en este asunto, al ser los encargados de identificar, diagnosticar, intervenir o remitir los casos a un nivel de complejidad mayor, y en tal sentido, reconocen que el trato despectivo y estigmatizante hacia las PUA-PUD retrasa la búsqueda de tratamiento y dificulta la alianza terapéutica, tal como lo indica la evidencia científica sobre el tema (Van Boekel et al., 2013), motivo por el cual abogan por la necesidad de una mayor capacitación y entrenamiento en el manejo de esta población para lo cual se requiere de una mayor inversión presupuestal y un compromiso firme desde la academia por los temas de salud mental.

\section{CONCLUSIONES}

Los profesionales de la salud atribuyen estereotipos negativos a las personas que usan drogas pues entienden el consumo como una condición negativa, independiente del servicio donde laboren. Ya que los usuarios de dichas sustancias presentan múltiples recaídas y reingresos al sistema, debido al escaso compromiso que tienen frente a su recuperación, los profesionales sanitarios, ven frustradas sus esperanzas de que se alcance el objetivo primordial buscado, la abstinencia total. Esta situación se manifiesta en la práctica en comportamientos represivos, disuasivos o autoritarios hacia a esta población, sin un análisis situacional profundo y consciente acerca de las condiciones que atraviesan el consumo, debido a que frecuentemente se centra la atención en las drogas y no en los sujetos.

Las actitudes negativas de los profesionales de la salud hacia las PUA-PUD, al igual que los enfoques evitativos para la atención de esta población, se convierten en una importante barrera para acceder a los servicios de promoción, prevención, tratamiento y rehabilitación, lo cual, sumado a las debilidades propias del sistema de salud colombiano para brindar una cobertura integral en salud y a la moralización, derivada de la escasa capacitación de los profesionales sanitarios para comprender un fenómeno hipercomplejo, genera mayores dificultades para la atención, lo que podría no sólo agravar la condición de salud de las PUD, sino también, afectar su calidad de vida.

\section{Limitaciones}

Es preciso aclarar que al acercarse al tema desde un enfoque histórico hermenéutico, la interpretación de los datos no es aséptica, pues justamente la hermenéutica en términos de Geertz es la comprensión de la comprensión (Geertz, 1994); y ya que la comprensibilidad se alcanza por medio de la interacción de los sujetos a través del lenguaje en un proceso en el cual el investigador involucra de manera directa su experiencia con los datos provenientes de las narraciones de los informantes, (Taylor \& Bogdan, 1987), los hallazgos no alcanzan un nivel de generalización en términos de inferencia estadística, motivo por el cual se invita a leer los hallazgos en el contexto y temporalidad histórica en los que se allegaron.

\section{Conflicto de intereses}

Se manifiesta que no hay conflicto de intereses ya que el dinero para la ejecución del estudio provino de fondos de la Universidad Católica Luis Amigó y de la Universidad Pontificia Bolivariana, destinados para el apoyo de la investigación.

\section{Agradecimientos}

A los participantes del estudio y a las directivas de las instituciones donde laboran, por permitirnos el tiempo y el espacio para la realización de las entrevistas. 


\section{REFERENCIAS}

Berger, P. L. \& Luckmann, T. (2005). La construcción social de la realidad. Buenos Aires: Amorrortu.

Blumer, H. (1982). El Interaccionismo simbólico: perspectiva y método. Hora Nova.

Cadenas, D. M. R. (2016). El rigor en la investigación cualitativa: Técnicas de análisis, credibilidad, transferibilidad y confirmabilidad. Sinopsis Educativa, 7(1), 17-26.

Clarke, D. E., Gonzalez, M., Pereira, A., BoyceGaudreau, K., Waldman, C. \& Demczuk, L. (2015). The impact of knowledge on attitudes of emergency department staff towards patients with substance related presentations: a quantitative systematic review protocol. JBI database of systematic reviews and implementation reports, 13(10), 133-145.

Creswell, J. W. \& Miller, D. L. (2000). Determining validity in qualitative inquiry. Theory into practice, 39(3), 124-130.

da Silveira, P. S., Martins, L. F., \& Ronzani, T. M. (2009). Moralização sobre o uso de álcool entre agentes comunitários de saúde. Psicologia: Teoria e Prática, 11(1), 62-75.

da Silveira, P. S., Martins, L. F., Soares, R. G., Gomide, H. P. \& Ronzani, T. M. (2011). Revisão sistemática da literatura sobre estigma social e alcoolismo. Estudos de Psicologia, 16(2), 131-138.

Geertz, C. (1994). Conocimiento local: Ensayos sobre la interpretación de las culturas. Editorial Paidós.

Geffner, N., Zalazar, V., Mascayano, F. \& Agrest, M. (2017). Revisión de programas anti-estigma y a favor de la recuperación. Acta Psiquiátr Psicol Am Lat, 63(3), 189-202.

Íñiguez, L. (2003). El análisis del discurso en las ciencias sociales: variedades, tradiciones y práctica. En Análisis del discurso. Manual para las ciencias sociales (pp. 83-124). Barcelona: Universitat Oberta Catalunya.

Kelleher, S. \& Cotter, P. (2009). A descriptive study on emergency department doctors' and nurses' knowledge and attitudes concerning substance use and substance users. International Emergency Nursing, 17(1), 3-14.

Kulesza, M., Matsuda, M., Ramirez, J. J., Werntz, A. J., Teachman, B. A. \& Lindgren, K. P. (2016). Towards greater understanding of addiction stigma: Intersectionality with race/ethnicity and gender. Drug and alcohol dependence, 169, 85-91.
Link, B. G. \& Phelan, J. C. (2001). Conceptualizing stigma. Annual Review of Sociology, 27, 363-385.

Link, B. G. \& Phelan, J. C. (2006). Stigma and its public health implications. Lancet, 367(9509), 528-529.

Lobos, M. (2012). Políticas públicas para el tratamiento y rehabilitación de personas con consumo problemático de drogas. Santiago de Chile: Facultad de Ciencias Sociales de la Universidad de Chile.

Martínez P \& Pallarés J. (2013). Riesgos, daños y placeres. En De riesgos y placeres: Manual para entender las drogas (pp. 23-36). Lleida, España: Editorial Milenio.

Martínez-Salgado, C. (2012). El muestreo en investigación cualitativa: principios básicos y algunas controversias. Ciência \& Saúde Coletiva, 17, 613-619.

Navarrete, J. V. M. (2011). Problemas centrales del análisis de datos cualitativos. Revista latinoamericana de metodología de la investigación social, (1), 47-60.

Oliveira, M. C. de \& Ronzani, T. M. (2012). Estigmatização e prática de profissionais da APS referentes ao consumo de álcool. Psicol Ciênc Prof, 32(3), 648-661.

Paiva, F. S., Ferreira, M. L., Martins, M. Z. F., Farias, S. L. C. \& Ronzani, T. M. (2014). A percepção profissional e comunitária sobre a reinserção social dos usuários de drogas. Psicologia \& Sociedade, 26(3), 696-706.

París Pombo, M. D., Pérez Floriano, L. R. \& Medrano Villalobos, G. (2009). Estigma y discriminación hacia las y los usuarios de drogas y sus familiares. México: Consejo Nacional para Prevenir la Discriminación. Recuperado de http:// videoconferencia.dpe.gob.ec/handle/39000/959

Ralet, O. (2000). Condicionantes políticos y económicos. Análisis de la influencia de estos factores en la construcción social del "problema de la droga". En Contextos, sujetos y drogas: un manual sobre drogodependencias (pp. 39-47). Barcelona: Fundación de Ayuda contra la Drogadicción.

Ronzani, T. M., Higgins-Biddle, J. \& Furtado, E. F. (2009). Stigmatization of alcohol and other drug users by primary care providers in Southeast Brazil. Social science \& medicine, 69(7), 1080-1084.

Ronzani, T. M., Noto, A. R. \& Silveira, P. S. da. (2015). Reduzindo o estigma entre usuários de drogas. Juiz de Fora, Brasil: Editora 
UFJF. Recuperado de https://xa.yimg.com/ $\mathrm{kq} / \mathrm{groups} / 22825293 / 1389638837 / \mathrm{name} /$ reduzindo_o_estigma_entre_usuarios_de_drogas. pdf

Smith, L. R., Earnshaw, V. A., Copenhaver, M. M. \& Cunningham, C. O. (2016). Substance use stigma: Reliability and validity of a theory-based scale for substance-using populations. Drug and alcohol dependence, 162, 34-43.

Taylor, S. J. \& Bogdan, R. (1987). Introducción a los métodos cualitativos de investigación: la búsqueda de significados. España: Editorial Paidós.

Taylor, S. J. \& Bogdan, R. (1992). La entrevista en profundidad. En Introducción a los métodos cualitativos de investigación: la búsqueda de significados (pp. 100-132). España: Editorial Paidós.

UNODC. (2011). De la coerción a la cohesión: Tratamiento de la drogodependencia mediante atención sanitaria en lugar de sanciones. New York: UNODC.

Uprimny, R., Guzmán, D., Parra, J. \& Bernal, C. (2014). Políticas frente al consumo de drogas de uso ilícito en Colombia. En En busca de los derechos: Usuarios de drogas y las respuestas estatales en América Latina. Madrid: CEDD.

Van Boekel, L. C., Brouwers, E. P., Van Weeghel, J. \& Garretsen, H. F. (2013). Stigma among health professionals towards patients with substance use disorders and its consequences for healthcare delivery: systematic review. Drug and alcohol dependence, 131(1-2), 23-35.

Van Boekel, L. C., Brouwers, E. P., van Weeghel, J. \& Garretsen, H. F. (2014). Healthcare professionals' regard towards working with patients with substance use disorders: comparison of primary care, general psychiatry and specialist addiction services. Drug and alcohol dependence, 134, 92-98.

Vásquez, A. (2009). El estigma sobre la drogodependencia y su relación con la accesibilidad a servicios de salud, II Congreso Internacional de Investigación y Práctica Profesional en Psicología XVII Jornadas de Investigación Sexto Encuentro de Investigadores en Psicología del MERCOSUR. Facultad de Psicología - Universidad de Buenos Aires, Buenos Aires. Recuperado de https://www. aacademica.org/000-031/290.pdf .

\section{Endereco para correspondencia:}

Pontifícia Universidad Bolivariana

Colombia

Cq. 1 \#70-01, Medellín, Antioquia, Colômbia

Andrés Felipe Tirado Oltávaro

felipe.tirado@upb.edu.co

Recebido: 12-12-2018

Aceito em: 27-02-2019 


\title{
Relaciones sociales y prácticas cotidianas del habitante de calle en Medellín, Colombia ${ }^{1}$
}

\author{
Trelationships and daily practices of homeless people in Medellín, Colombia
}

\author{
Maricelly Gómez Vargas ${ }^{2}$ \\ Gustavo Adolfo Calderón Vallejo ${ }^{3}$ \\ Lucas Dávila Cañas ${ }^{4}$ \\ María Jimena Osorio Salazar ${ }^{5}$ \\ Emerson José Caro Cencio ${ }^{6}$ \\ Jonhatan Castaño Gómez ${ }^{7}$
}

\begin{abstract}
Resumo
Para este artículo se destacan las relaciones sociales y las prácticas cotidianas de 16 personas habitantes de calle que fueron entrevistadas en Medellín, Colombia, previo a un ejercicio de observación y aplicando la etnografía como modalidad a través de la cual se describieron y analizaron los resultados. Se identifica que la población habitante de calle se ha consolidado como un grupo que ha adoptado unas dinámicas sociales que los caracterizan y diferencian de otros grupos poblacionales en lo relacionado con prácticas de sobrevivencia y el modo de relacionarse con el contexto que les rodea, pese a que algunas de ellas son también extrapolables a un contexto social más amplio. Finalmente, el consumo de sustancias psicoactivas es transversal a las prácticas y relaciones de estos participantes.
\end{abstract}

Palavras--chave: Habitantes de Calle; Relaciones Sociales; Prácticas Cotidianas;

\begin{abstract}
For this article we highlight the social relationships and daily practices of 16 street people who were interviewed in Medellin, Colombia, prior to an observation exercise and applying ethnography as a modality through which the results were described and analyzed. It is identified that the street population has consolidated as a group that has adopted social dynamics that characterize them and differentiate them from other population groups in relation to survival practices and how to relate to the context surrounding them, despite that some of them are also extrapolated to a broader social context. Finally, the consumption of psychoactive substances is transversal to the practices and relationships of these participants.
\end{abstract}

Keywords: Homeless People; Social Relationships; Daily Practices.

A partir del siglo XXI la humanidad se ha enfrentado a grandes cambios en diferentes ámbitos, a nivel social específicamente las comunidades han sido atravesadas por transformaciones multiculturales que permean todo lo relativo a la vida cotidiana, esto responde a los procesos de globalización y mercantilización que generan una reacción de la sociedad estableciendo una innegable alteración de las dinámicas colectivas por lo que el ser humano se ha visto obligado a adaptarse a nuevos estilos de vida. De este modo, sin darse cuenta, un ciudadano inmerso en un contexto empieza a ser parte de un colectivo donde la cultura ya no depende tanto de él mismo, sino de las tendencias globales (Duhau $\&$ Giglia, 2008). En este sentido, las expresiones culturales

\footnotetext{
${ }^{1}$ Este artículo es producto del Proyecto de Investigación "Identidades y diversidades culturales del habitante de calle: Más allá de los imaginarios alrededor del consumo de psicoactivos”, financiado por la Universidad Católica Luis Amigó y por la Secretaría de Inclusión Social, Familia y Derechos Humanos de Medellín. Un especial agradecimiento a los ciudadanos habitantes de calle que compartieron los testimonios sobre las experiencias de su vida a través de las entrevistas, en torno a los temas en cuestión.

${ }^{2}$ Magíster en Psicología, docente Universidad Católica Luis Amigó, miembro del grupo de investigación en farmacodependencia y otras adicciones (GIFA)

${ }^{3}$ Magíster en Estudios Urbanos Regionales, docente Universidad Católica Luis Amigó, líder grupo de investigación en farmacodependencia y otras adicciones (GIFA), correo: gcalderonvallejo@gmail.com

${ }^{4}$ Psicólogo, especialista en intervenciones psicosociales, estudiante de maestría en intervenciones psicosociales de la Universidad Católica Luis Amigó. Joven investigador del grupo de investigación en farmacodependencia y otras adicciones (GIFA). Correo: davilac88@gmail.com.

${ }^{5}$ Licenciada en educación especial. Estudiante de la maestría en intervenciones psicosociales de la Universidad Católica Luis Amigó. Correo: jimeos29@hotmail.com

${ }^{6}$ Maestro en artes plásticas, especialista en intervenciones psicosociales, estudiante de maestría en intervenciones psicosociales de la Universidad Católica Luis Amigó. Correo: yaacaboo@outlook.com

${ }^{7}$ Psicólogo. Miembro del equipo de Análisis y planeación social de la Secretaría de Inclusión Social, Familia y Derechos Humanos de Medellín. Correo: jonhatan.castano@medellin.gov.co
} 
están influenciadas por las interacciones producto de las experiencias de vida de cada uno de los habitantes de un contexto. Es así como la experiencia heterogénea se transmuta y en ésta emergen identidades grupales, expresadas a través de las prácticas y modos en que los sujetos pertenecientes a estos grupos se relacionan entre sí y con otros actores sociales.

En la literatura se encuentra un abordaje de las costumbres de los habitantes de calle y las características propias de relacionarse con el otro y su contexto próximo, se describen las prácticas cotidianas y la manera particular de habitar un espacio público para sobrevivir (Marcadet, 2007). Algunos autores por su parte se han centrado en analizar dichas prácticas desde componentes y patrones comportamentales concluyendo que estos no responden a unos estándares socialmente constituidos (García-López, 2003).

Autores como Pérez (2003), afirman que los habitantes de calle han construido una sus expresiones culturales de grupo a través de la adopción de prácticas y costumbres propias, y además ha sido considerado como un sujeto que en la calle desarrolla sus interacciones y vínculos interpersonales, mediaciones socioculturales y satisfacen sus necesidades de supervivencia (Tirado \& Correa, 2009).

La comprensión sobre el fenómeno de la habitancia en calle exige un abordaje de las maneras en que se establecen los vínculos en el día a día y las prácticas que se gestan tanto a nivel individual como colectivo y que tienen lugar en el desarrollo de la vida cotidiana en la calle como escenario de socialización. De allí que, de acuerdo con la información aportada por los participantes y para efectos de este artículo, las prácticas y las relaciones configuran una vía propicia para el acercamiento a los habitantes de calle, reconocer las actividades que desarrollan para la supervivencia, las que se realizan de manera individual y en conjunto con otros, las prácticas alimentarias y los lugares que visitan con frecuencia.

Los habitantes de calle son una población que ha asumido su vida en espacios públicos de la ciudad, constituyendo sus dinámicas cotidianas en función del contexto que habitan. Para este artículo se presentan las relaciones y las prácticas cotidianas de los participantes del estudio, las cuales van a permitir reconocerlo como un ser con unas particularidades que aportarían a los procesos de intervención y a las políticas públicas para ser ajustadas acorde a las limitaciones y potencialidades de este grupo de personas en Medellín.

\section{MÉTODO}

\section{Enfoque Del Estudio}

Se desarrolló una investigación cualitativa cuyo objetivo fue describir e interpretar las identidades y diversidades culturales a partir de las relaciones sociales y las prácticas cotidianas encontradas en los habitantes de calle de la ciudad de Medellín. Se usó una modalidad etnográfica, entendida como una metodología por medio de la cual se aprehende el modo de vida de una colectividad específica; a través de ella se describe e interpretan las expresiones culturales, los estilos de vida y la estructura social de una comunidad. Metafóricamente es una especie de "retrato" del modo de vida de un núcleo social, llámese grupo étnico, barrio, colectivo social, familia (Rodríguez, Gil \& García, 1996).

\section{Participantes}

Los participantes fueron habitantes de calle cuya espacialidad son diferentes sitios que ellos van eligiendo por posibilidades y condiciones para su sobrevivencia. Con el apoyo de personal de la Secretaria de Inclusión Social, Familia y Derechos Humanos de Medellín que los identificaron, se eligieron 16 habitantes de calle para ser observados en su cotidianidad y entrevistados previas garantías éticas.

Como criterios de inclusión se tuvieron en cuenta: que fueran habitantes cuyo hábitat sea la calle y mayores de edad.

\section{Instrumento}

En cuanto al instrumento, se construyó una guía de observación para la fase exploratoria, la cual fue desestructurada para observar patrones culturales y formas de vida generales, posteriormente y con las categorías previas establecidas en una fase de profundización se aplicaron a los habitantes de calle una entrevista semiestructurada. La aplicación se realizó por parte de los mismos investigadores, previa aprobación de un consentimiento informado.

\section{Validación}

Se trianguló la información recogida en la observación y en las entrevistas. También se triangularon los datos con lo encontrado en fuentes secundarias y las apreciaciones de quienes trabajan diariamente desde la institucionalidad con ellos en sus contextos. 
La revisión permanente y sistemática de la información recogida, permitió la validación de lo hallado y con esto se obtuvo una visión de conjunto entre los investigadores, que facilitó la revisión y análisis de las categorías emergentes, de tal manera que las unidades de significación estuvieron presentes en sus relaciones, semejanzas y diferencias.

\section{Proceso de Recolección}

Inicialmente se hicieron contactos con líderes habitantes de calle, por medio de profesionales que trabajan en el Sistema Habitante de Calle de Medellín, para presentarles el proyecto y hacer un proceso de sensibilización, que posibilitó la planificación y aplicación voluntaria de los instrumentos. La información recogida en las entrevistas semiestructuradas fue grabada y se garantizó a los 16 entrevistados el anonimato para una mayor libertad en sus respuestas. En Medellín, el Sistema Habitante de Calle cuenta con varias sedes a donde llegan las personas en esta condición para obtener alimentación, implementos de aseo, además de atención médica y psicosocial. Las entrevistas se realizaron en esos espacios para mayor seguridad y privacidad en el momento de la interacción entre los investigadores y los participantes. Posteriormente la información se trascribió, para la sistematización, descripción e interpretación.

\section{Proceso de Descripción e Interpretación de la Información}

Se fragmentaron los textos en citas, se hizo la respectiva codificación en una matriz de Excel y para enriquecer la lectura de resultados se tuvieron en cuenta las anotaciones efectuadas al margen en los dos instrumentos aplicados. Se analizaron las tendencias, las similitudes y diferencias, y se discutió con otra información recogida y seleccionada en fuentes secundarias.

\section{Limitaciones}

Se tomaron los testimonios de habitante de calle sobre su percepción en torno a la vivencia de normas y valores en su entorno sociocultural. Desde lo cualitativo se hace una interpretación sobre lo afirmado a través del lenguaje por ellos con el fin de lograr una comprensión de cómo viven su cotidianidad con respecto al tema y entorno a las interacciones que ellos construyen como sujetos. La intención no fue alcanzar un nivel de generalización a partir de deducciones estadísticas. Por eso para leer los resultados se debe considerar que su alcance tiene un mejor sentido para el contexto en que se vive.

\section{Conflicto De Intereses}

Se expresa que no hay conflicto de intereses, porque el dinero para la ejecución de la investigación fue proveído por el fondo que La Universidad Católica Luis Amigó tiene destinado para ello.

\section{RESULTADOS}

\section{Relaciones De Los Habitantes De Calle}

Dentro de la categoría de relaciones, se describen algunas maneras en las que el habitante de calle establece sus vínculos y cómo interactúa con otros en diferentes dimensiones de la vida cotidiana. De allí que en el establecimiento de las relaciones, se encuentran algunas generalidades para el grupo poblacional, sin embargo, de acuerdo con los testimonios de los participantes, se logran identificar características que particularizan los modos de relacionamiento entre los habitantes de calle, a saber, la cultura y lugares de procedencia, las edades o ciclo evolutivo de las personas, el uso de sustancias psicoactivas, las actividades que realizan e incluso el espacio de ciudad en el que se dan estas interacciones, entre otros.

Durante el proceso investigativo se observaron diferentes formas en las que se dan las relaciones en el habitante de calle, entre las cuales resulta pertinente presentar el consumo de sustancias psicoactivas como una práctica que favorece el encuentro con otros y permanecer reunidos alrededor de este propósito y el desarrollo de otras actividades bajo los efectos de las mismas, como por ejemplo bailar, escuchar música o cantar. Ahora bien, encontramos que algunos habitantes de calle, bajo los efectos del consumo de sustancias psicoactivas, prefieren alejarse y buscar espacios solitarios, evitar el encuentro y contacto con otros, sin embargo, ello también está sujeto al tipo de sustancias que las personas consumen y los efectos que esta genera a cada sujeto.

Otro escenario en el cual se logran evidenciar los modos de relacionamiento, está referido a las actividades que se encaminan a la consecución de recursos económicos, y algunos de los participantes prefieren hacerlo en solitario, por ejemplo, el reciclaje, las ventas ambulantes, la mendicidad y otros oficios varios, $y$ sólo hasta la culminación de la labor se disponen para reunirse y compartir lo producido con otros. También 
hay algunos que se reúnen en pequeños grupos para generar acciones como el hurto.

Por su parte, se encuentra que en gran medida esta población establece lazos transitorios de relacionamiento con el otro en temas como las relaciones sentimentales o de pareja, estas se establecen como un mecanismo de ayuda para vivir el día a día y suplir algunas de sus necesidades; no obstante, llegan a establecer fuertes vínculos en lo que a las relaciones de amistad se refiere, aun cuando estas pueden verse afectadas rápidamente por dificultades propias del medio de sobrevivencia en calle, y se identifica que estas relaciones se fundan en la satisfacción de necesidades personales con un nivel de reciprocidad importante, dichos intereses en gran parte de los casos se presentan explícitamente entre las partes, lo cual no niega la existencia de movimientos de solidaridad entre la población, con diferentes objetivos.

Otro hallazgo importante es la percepción que tienen los participantes del otro semejante no habitante de calle y del par habitante de calle, sintiendo discriminación por parte de ambos. Describen que muchas de las formas en que se relacionan se caracterizan por ser hostiles, donde lo que prima es el bien particular, trasgrediendo la integridad del otro. También hay unos casos en los que pueden verse menos discriminados al recibir ayuda de otras personas en la calle, de quienes reciben dinero para comprar sustancias psicoactivas o para alimentarse, y se sienten a gusto cuando reciben ayudas de los programas estatales o de asociaciones sin ánimo de lucro que les provee alimentación con cierta periodicidad.

Esto da cuenta también de que existe una dimensión de las relaciones que se instala a nivel de la interacción con las instituciones y con sus funcionarios. En términos generales, los participantes reportan un estilo de relacionamiento con estos actores, que destacan como de bienestar, reciprocidad y soporte tanto afectivo como material, al menos en lo que a las entidades estatales o privadas de carácter social se refiere. Sin embargo, se observa que en gran medida tienen dificultad a la hora de relacionarse con otras instituciones, tales como la Policía Nacional o personal de espacio público, debido al trato que de estas reciben, causándoles gran malestar la manera como los desplazan de espacios donde habitan y de los cuales se sientes apropiados.

Finalmente, en lo que respecta a las relaciones con el grupo familiar o red de apoyo, se pudo observar que hay una ruptura radical, haciendo mención de esto como la causa por la cual llegan a la situación de calle, destacándose también que algunos de los participantes continúan teniendo contacto con sus familias o redes de apoyo con cierta frecuencia, recibiendo incluso algunos apoyos de carácter económico, alimentario o de vestido.

\section{Prácticas Cotidianas De Los Habitantes De Calle}

Dentro de las prácticas asociadas para la subsistencia en calle se encuentran aquellas actividades a través de las cuales logran acceder o suplir algunas necesidades de carácter económico, alimentario o para consumo de sustancias psicoactivas, como el reciclaje, las ventas ambulantes, el hurto, la prostitución y la mendicidad, esta última dirigida a la consecución de dinero, prendas de vestir o alimentos.

Se destacan otras actividades como la elaboración de pipas para vender, el intercambio de objetos como cigarrillos, maquillaje, ropa, comida y el cuidado de locales comerciales, actividades realizadas generalmente en solitario, pues manifiestan cierta preferencia por permanecer sólos para reflexionar y pensar. Entre las actividades realizadas en compañía, los participantes refieren el consumo de drogas, que también realizan a solas, dialogar, jugar y con frecuencia en estos espacios se presentan discusiones y peleas.

Por otra parte, con relación al dinero no expresan tener hábito de ahorro y lo usan en gran medida para comprar drogas, pues las necesidades asociadas a la alimentación las logran suplir a partir de diversas prácticas, entre ellas la mendicidad. De las prácticas alimentarias, cabe añadir que existe una preferencia por la comida tradicional, y también es habitual el consumo de snacks. Es importante destacar que los alimentos pueden obtenerse acudiendo a los botes de la basura, pidiéndoselos a las personas que lo están consumiendo o comprándolos, no siendo ésta la práctica más habitual. Con relación a la alimentación es importante señalar que no existen hábitos alimenticios, incluso pueden postergar la ingesta de alimentos por varios días en función del consumo de sustancias psicoactivas que a su vez mitiga la sensación de hambre.

Así mismo, se encuentran las prácticas relacionadas con los lugares que frecuentan, muchos de los cuales se caracterizan porque es allí donde pueden acceder al consumo de drogas. Otros lugares se escogen para conseguir dinero, acudiendo a las zonas céntricas de la ciudad, y algunos prefieren permanecer en el mismo lugar y no tener que desplazarse. También reportan deambular por diferentes lugares, retornando la mayoría de veces a los sitios donde pueden acceder al uso de drogas. Otro aspecto importante al momento de referir los lugares de frecuencia, tiene que ver con los espacios en que 
pasan la noche, para lo cual recurren a la elaboración de refugios con material plástico, cartón, entre otros. Y otros prefieren simplemente las aceras y puertas de los locales comerciales, de los cuales son desalojados con regularidad; de esto se desprenden también las prácticas de autocuidado, pues se identifica que pasan largos periodos sin realizarse aseo personal o bañarse, y por eso acuden a los centros de básica ${ }^{1} \mathrm{u}$ hoteles, así mismo, las necesidades fisiológicas se realizan en baños públicos o zonas públicas como la calle o espacios verdes.

\section{DISCUSIÓN}

La calle es un escenario posible para la satisfacción de necesidades básicas y al mismo tiempo un espacio en el cual se pueden realizar actividades y prácticas vinculares. Delgado (2002) sostiene que las sociedades humanas son una manifestación de complejidad, al mismo tiempo que indica que la calle es un espacio público en el que a pesar de la vigilancia y las violencias, se puede respirar mejor que en escenarios como la empresa, la escuela y el hogar. Es tal vez esta una de las razones por las cuales algunos de los participantes de esta investigación deciden habitar la calle como su lugar de socialización y generación de vínculos y relaciones, pues expresan que en la calle se liberan de algunas presiones sociales aun cuando deban someterse a otras, encontrando formas para hacer frente a dichas adversidades, por medio del encuentro con el otro, bien sea a través de relaciones duraderas o efímeras, instrumentales o no y para el uso de sustancias psicoactivas, entre otras.

Moreno, Espinosa \& Zapata (2017) identificaron la importancia del grupo en el escenario de la calle para minimizar la vulnerabilidad frente a los actos de violencia por parte de otras personas o grupos. Si bien en las narrativas de los informantes podemos constatar los argumentos propuestos por Delgado (2002), es importante contextualizar los presupuestos del autor, pues este propone la calle como un escenario público en el cual se dan relaciones de manera transitoria, incluso entre el habitante de calle y el transeúnte, sin embargo, en la calle se dan otros modos de interacción entre los grupos que hacen de este un lugar, no de tránsito, sino de habitabilidad, tal como los resultados indican. El habitante de calle establece vínculos no sólo con otros habitantes de calle, sino con quienes transitan por las calles y el espacio público, adicionalmente habitan y se

1 Centros de atención que ofrece alimentación, un lugar donde dormir $\mathrm{y}$ asearse, tener acceso al documento de identidad, $\mathrm{y}$ al cual pueden asistir de manera voluntaria y no permanente. vinculan con el entorno de tal manera que se apropian del mismo, lo significan y lo modifican en su cotidianidad, aún más, el habitante de calle a pesar de la aparente precariedad de los vínculos en el espacio público, logra poblar la calle con prácticas y sentidos en el día a día (Rosa, 2012).

Así mismo Correa (2007) describe cómo en la calle se logran construir relaciones de gratificación entre los actores sociales que le habitan a pesar de las dificultades que este escenario supone con relación a las prácticas de supervivencia, el encuentro con actores sociales legales e ilegales, entre otras adversidades.

También se construyen representaciones entre los habitantes de calle alrededor de la amistad y las relaciones que entre sí mismos establecen, encontrando dificultades para considerar la existencia de vínculos fraternos y cercanos hasta vínculos en los que hay quienes darían la vida por el otro, es en esta perspectiva que Correa (2007) comprende que en la calle se construyen realidades complejas desarrollando códigos, cultura, moral y prácticas propias de solidaridad, respeto, convivencia y libertad; al mismo tiempo, el espacio público se puede entender como un espacio en el cual se da el cruce de la diferencia en donde se tejen vínculos solidarios o todo lo contrario (Boy, Marcús \& Perelman, 2015).

De acuerdo con los resultados, es posible afirmar entonces que el habitante de calle tal como cualquier actor social en otros contextos, no puede prescindir de la existencia del otro para lograr la satisfacción de necesidades humanas, particularmente necesidades básicas, aun cuando bajo la influencia de algunas prácticas se lleven a cabo actividades en solitario, es decir, que logran prescindir del otro en escenarios específicos, pero del otro como sujeto social, así entonces, el sujeto habitante de calle deberá construir redes para garantizar el acceso a servicios gubernamentales $\mathrm{u}$ ofertas de organizaciones sociales y la satisfacción de necesidades tales como alimentación y autocuidado (Boy, Marcús \& Perelman, 2015).

Resulta importante destacar que en las redes construidas en la calle como escenario de sobrevivencia, no sólo actúan los grupos de habitantes de calle, sino también otros actores que se encuentran en este espacio y que no son habitantes de calle, entre los cuales se identifican los comerciantes, jibaros, vendedores ambulantes, estableciendo interacciones de cooperación que nutren también los modos de relacionamiento con el habitante de calle, este último encontrando allí la posibilidad de sobrevivir a través de múltiples actividades y satisfacer sus propias necesidades (Moreno, Espinosa \& Zapata, 2017). 
Similar al estudio acá presentado, el abordaje del habitante de calle se ha realizado desde la perspectiva descriptiva de algunas de sus costumbres cotidianas y de sus características de relacionamiento con el otro y el contexto que les rodea. En este sentido, se evidencia una marcada tendencia por identificar características de las prácticas cotidianas que se presentan en el contexto de calle, por ejemplo, la especificidad de un sitio frecuentado y las actividades realizadas en él (Marcadet, 2007).

Otros autores abordan las prácticas de los habitantes de calle con el fin de analizar diversos patrones comportamentales y de relacionamiento social del sujeto, por ejemplo, García-López (2003), enfatiza que las prácticas cotidianas de esta población van encaminadas a efectuar movimientos de "anti-disciplina" que no responden a unos estándares socialmente constituidos pero que se establecen como un modo de relacionamiento en el cual las prácticas propias se trasforman en una extensión de la persona a modo de herramienta con la que se vincula con los otros y su contexto próximo en un marco aparentemente instaurado.

Las prácticas de los ciudadanos habitantes de calle, implican en sí mismas, la exploración de actividades, costumbres, rituales y otras interacciones sociales que configuran escenarios para que la identidad y la cultura callejera sean posibles. Entendiendo la cultura callejera según Pérez (2003) como los modos de vida, las costumbres, conocimientos y la elaboración de estrategias para la sobrevivencia, siendo así la calle un lugar para la creación de códigos y una cultura propia, tal como sucede en cualquier modo de cultura.

Si bien Pérez (2003) asume tácitamente la existencia de una cultura callejera, no se tiene claridad respecto de su conformación y el modo en que se construye; sin embargo, es imposible no reconocer el papel activo de los sujetos en el marco de algunas prácticas, tácticas y saberes comunes en espacios callejeros (Saucedo \& Taracena, 2011). Es el caso de las prácticas de consumo de sustancias psicoactivas que son transversales a las actividades, costumbres y rituales de los habitantes de calle, bien sean estas de carácter grupal o individual.

En la cultura callejera se destacan aspectos como la sexualidad, las adicciones y la violencia, entendidos estos últimos como expresión de goce y libertad (Pérez, 2003). Además, autores como Cortés, Gómez, Martínez \& Quintana (2015) afirman que los habitantes de calle adquieren la connotación de ser recolectores de bienes y servicios urbanos (alimentos, monedas, ropa, entre otros), en este sentido, se desarrolla un modo de vivir y asumir la vida, donde la calle se transforma en lenguaje de ciudad tejida a través de tradiciones y soportes simbólicos para personas que han optado por renunciar a lo irrenunciable. Dadas estas condiciones, es posible pensar las maneras de estar en la calle como la reproducción de estructuras pre-callejeras, de prácticas socioculturales, elementos y patrones sociales de origen, aunque en algunos casos aparecen reproducciones creativas (Saucedo \& Taracena, 2011).

Se podría señalar que el habitante de calle al igual que cualquier otro sujeto, configura identidades y prácticas marcadas por el dinamismo de los flujos y las relaciones, como miembros de un grupo humano, que realizan actividades fundamentales en su cotidianidad, es decir, su significación a partir de elementos comunes al grupo, que ayudan a la demarcación y construcción que, en este caso, está dada por elementos tanto físicos como simbólicos: un fogón construido con piedras, los instrumentos de cocina camuflados en el árbol, los cartones y plásticos que constituyen su refugio. Así mismo, los rituales corporales, los gestos de aceptación o rechazo, el lenguaje y muchas otras prácticas que ayudan a construir un cierto nivel de pertenencia e identidad de grupo (Ortiz, 2004), esto quiere decir, que hay unas particularidades que les permite asumir una identidad como grupo social, pero al mismo tiempo se evidencian unas diversidades en sus prácticas cotidianas, una heterogeneidad acorde a sus historias personales, lugares de origen, niveles de formación, entre otros, y por eso la coexistencia de unas identidades y diversidades culturales del habitante de calle.

A partir de lo expuesto por los participantes, es importante resaltar las prácticas más comunes encontradas y que confluyen con los planteamientos de algunos autores como lo es la recolección de bienes y servicios urbanos (alimentos, dinero, ropa, entre otros), el consumo de drogas y la manera de relacionarse con el otro. Cortés, Gómez, Martínez \& Quintana (2015). Mencionan que esta población a través de dichas prácticas desarrolla otro modo de vivir y asumir la vida, así mismo Lindon (2005) nombra las prácticas como modo de sobrevivencia donde la calle se transforma en lenguaje de ciudad que se teje a través de tradiciones y soportes simbólicos; sin embargo, el abordaje de los autores no va encaminado a considerar dichas prácticas como parte de una construcción propia de identidad cultural.

Se podría señalar que el habitante de calle configura prácticas marcadas por el dinamismo de su contexto próximo y las relaciones, como miembros de un grupo que realizan actividades fundamentales en su cotidianidad, es decir, su significación a partir de elementos comunes al grupo, que ayudan a la demarcación 
y construcción que, en este caso, está dada por elementos tanto físicos como simbólicos: pedir dinero y alimentos, recolectar los cartones y plásticos para la construcción de un refugio, acumular objetos, realizar rituales corporales, y desarrollar prácticas gestuales de aceptación o rechazo y otras prácticas que ayudan también a construir un cierto nivel de pertenencia de grupo, que según Ortiz (2004) son los elementos que constituyen y dan lugar a un sujeto dentro de un colectivo. Es así como la adopción de prácticas comunes que de manera generalizada son reconocidas tanto por el grupo como por el contexto que les rodea, establece procesos de identidad (Navarro \& Gaviria, 2010).

Finalmente, la relación de esta población con el consumo de psicoactivos o con conductas adictivas se ha identificado en diversos estudios a nivel local, nacional e internacional (Montecino, 2008; Valderrama, Sánchez, Cárcamo \& Mazo, 2016; Restrepo, 2016), unas enfatizándolo como un factor mantenedor de la elección por la vida en la calle, y otras considerándola como una de las razones por las cuales llegaron a esa situación, es decir, como un factor explicativo y causal. En este estudio, fue identificada como una práctica que transversaliza la forma de relación con otros y como una prioridad entre sus necesidades básicas que tiene incidencia en el manejo del dinero, o en los lugares donde permanecen, siendo así un eje en las identidades y diversidades culturales del habitante de calle que evidencia en pequeña escala lo que en la sociedad en general se ha conocido como la lucha contra las drogas y el narcotráfico, en otras palabras, así como el consumo de drogas es una constante en este grupo poblacional, también lo es en otros niveles socioeconómicos, en niños, jóvenes y adultos con o sin educación, y por tanto no es una condición que lo particulariza y le otorga identidad propia.

\section{CONCLUSIONES}

Las personas habitantes de calle han constituido unas prácticas cotidianas que dan respuesta a su forma de vida y la interacción con el contexto que les rodea. Estas prácticas se han consolidado extendiéndose al colectivo como tal creando identidad de grupo el cual las establece y reconoce como propias. Es así como la dinámica cotidiana se funda en unos roles específicos que asume cada individuo componiendo una imagen que se traslada a la colectividad.

En consonancia con lo anterior, se puede afirmar que los habitantes de calle han adoptado unas prácticas propias que responden a su forma de vida, las cuales se clasifican en prácticas de subsistencia que hacen alusión a las actividades que logran suplir necesidades básicas, las prácticas individuales y grupales que distinguen las actividades realizadas cuando están sólos, tales como pensar y reflexionar, y las actividades grupales como los juegos; también las prácticas alimentarias en las que se evidencia una preferencia por la comida tradicional y una ausencia de hábitos alimenticios y, finalmente, las prácticas relacionadas con los lugares que frecuentan en los cuales realizan actividades específicas como conseguir dinero, consumir drogas y pasar la noche.

De acuerdo con lo expuesto, es importante mencionar que, salvo algunas prácticas asociadas a la supervivencia en un contexto especifico como la calle, se configuran una prácticas que podrían denominarse culturales o identitarias muy particulares y específicas, que pudieran diferenciarse de algunas prácticas o modos de relacionarse de otros contextos o grupos poblacionales en otras condiciones y escenarios de vida; sin embargo, existen modos de relacionamiento y prácticas que podrían extenderse a un contexto más amplio y que son homologables a la cultura pensada en una dimensión macro, es decir, que existen conductas, modos de hacer vínculo y prácticas sociales que transversalizan los subgrupos poblacionales, a saber, actividades que en ocasiones algunas personas prefieren realizarlas en solitario o en conjunto, relaciones de pareja o sentimentales de corta duración, relaciones de la vida cotidiana que podrían denominarse instrumentales o en beneficio de la satisfacción de necesidades, relaciones de amistad duraderas, la estigmatización y en ocasiones relaciones hostiles, son manifestaciones culturales que podrían encontrarse en cualquier expresión o interacción humana más allá de la condición de calle.

Por último, es importante señalar que el consumo de drogas atraviesa la mayoría de las prácticas que realizan los habitantes de calle y muchas ellas se dan en función de dicha actividad, como conseguir dinero, frecuentar lugares específicos y relacionarse con otros con el único objetivo de consumir drogas.

\section{RECOMENDACIONES}

Aunque se reconoce que existen procesos de acompañamiento, formación y desarrollo, además de una política para contribuir a la solución de las problemáticas que viven los habitantes de calle, se recomienda que se profundice en una línea sobre características culturales de los grupos de habitante de calle, para que se les reconozca en su cotidianidad y en sus contextos como ciudadanos y como sujetos de derechos y no sólo 
se les señale y se les hostigue desde el todo social, como personas generadoras de problemas. Brindándoles oportunidades y partiendo de sus diferencias y sus potencialidades podremos encontrar aportes desde ellos para una reconstrucción del tejido social. Esto se logrará en una mejor forma si los conocemos desde la investigación y los reconocemos como ciudadanos.

\section{AGRADECIMIENTOS}

Agradecemos a los ciudadanos habitantes de calle que compartieron los testimonios sobre las experiencias de su vida. También a la Secretaria de Inclusión Social, Familia y Derechos Humanos de Medellín por su participación e intercambio de ideas y experiencias y a la Vicerrectoría de Investigaciones de la Universidad Católica Luis Amigó y al Programa Jóvenes Investigadores.

\section{REFERENCIAS BIBLIOGRÁFICAS}

Boy, M.; Marcús, J. \& Perelman, M. (2015). La ciudad y el encuentro de la diferencia. Adultos que viven en la calle y mujeres que habitan en hoteles-pensión. Ciudad de Buenos Aires, $2007-$ 2011. Estudios Demográficos y Urbanos, 30 (2), 369-404. Recuperado de: http://www.redalyc.org/ pdf/312/31242739004.pdf

Correa, M. (2007). La otra ciudad - Otros sujetos: los habitantes de la calle. Trabajo Social, 0(9), 37-56. Recuperado de https://revistas.unal.edu.co/index. $\mathrm{php} /$ tsocial/article/view/8511

Cortés, G. V.; Gómez, P. N.; Martínez R. M. \& Quintana, C. K. (2015). Habitar en la calle: una forma de vida. Cuadernos De Investigación Estudiantil En Psicología, 2 (2), 48-53. Recuperado de http:// www.unisanitas.edu.co/publicaciones/index.php/ cipsico/article/view/66

Delgado, M (2002). Anonimato y ciudadanía. Universitat de Barcelona / Institut Catalá d'Antropologia. Mugak (1). Recuperado de http://mugak.eu/revista-mugak/no-20/ anonimato-y-ciudadania

Duhau, E. \& Giglia, A. (2008). Las reglas del desorden: habitar la metropoli. México: Universidad Autónoma Metropolitana, Unidad Azcapotzalco, Siglo XXI Editores

García-López, N. (2003). De Certeau, Michel. La invención de lo cotidiano. Athenea Digital. Revista De Pensamiento E Investigación Social, 1(4).
Recuperado de http://atheneadigital.net/article/ view/n4-garcia-2/103-html-es

Não tem numero de pagina

Lindon, A. (2005). Imaginarios Urbanos de la dominación y la resistencia: de la utopía de la periferia a las geografías personales, Revista de Ciencias Sociales y Humanidades, (64-65), 7-14. Recuperado de https://dialnet.unirioja.es/servlet/ articulo?codigo $=5838900$

Marcadet, Y. (2007). Habitar en el centro de la Ciudad de México Prácticas espaciales en la Santa María La Ribera. Alteridades, 17 (34), 39-55. Recuperado de http://www.redalyc.org/pdf/747/74711468004.pdf Montecino Soto, L. (2008). Personas en situación de calle en Santiago de Chile: identidad y futuro. Discurso y Sociedad, 2 (2), 330-356.

Moreno, C., Espinosa, G. \& Zapata, L, (2017). Entre el hogar y el asfalto: relatos y experiencia de vida de habitantes en condición de calle. Revista Lasallista de Investigación, 14, 65-72. Recuperado de: http:// www.scielo.org.co/pdf/rlsi/v14n2/1794-4449rlsi-14-02-00065.pdf

Navarro, O. \& Gaviria, M. (2010) Representaciones sociales del habitante de calle. Universitas Psyhcologica, 2 (9), 345-355. Recuperado de http://www.scielo. org.co/pdf/rups/v9n2/v9n2a04.pdf

Ortiz, A. (2004). La sensibilización hacia el habitante de calle, brigadas y comunidad desde la lúdica como estrategia de un proceso de inclusión social. Trabajo presentado en $8^{\circ}$ Congreso Nacional de Recreación, Organizado por Funlibre, Bogotá, Colombia. Recuperado de http://www.redcreacion.org/ documentos/congreso8/comfenalco.html

Pérez García, J. (2003). La infancia callejera: apuntes para reflexionar el fenómeno. Revista Española de Educación Comparada, 0(9), 153-186. Recuperado de http://revistas.uned.es/index.php/REEC/article/ view/7375/7043

Restrepo, A. (2016). El ser humano al límite: una mirada reflexiva al habitante de calle. Drugs and Addictive Behavior, 1(1), 89-100.

Rodríguez G.; Gil, J. \& García, E. (1996). Metodología de la investigación cualitativa. Ediciones Aljibe, Archidona, Málaga. 
Rosa, P. (2012). Usos estigmatizados del espacio púbico. Habitar las calles de la Ciudad Autónoma de Buenos Aires. Ponencia presentada al Seminario Internacional "Desafíos de las políticas del Espacio Público. Prácticas Culturales e Innovación Social, Movimientos, Dinámicas y Mecanismos". Organizado por el Centro de Estudios Urbanos y Regionales (CEUR-CONICET) el 9 de abril de 2012. Buenos Aires, Argentina.

Saucedo, I. A. \& Taracena, B. E. (2011). Habitar la calle: pasos hacia una ciudadanía a partir de este espacio. Revista Latinoamericana de Ciencias Sociales, Niñez y Juventud, 1 (9), 269-285. Recuperado de http:// www.redalyc.org/articulo.oa?id=77320072014

Tirado, F \& Correa, M. (2009). Accesibilidad de la población habitante de calle a los programas de Promoción y Prevención establecidos por la Resolución 412 de 2000. Investigaciones Andinas, 18 (11), 23-35. Recuperado de http://www.scielo. org.co/pdf/inan/v11n18/v11n18a03.pdf

Valderrama Restrepo, A., Sánchez Gómez, L. M., Cárcamo Marenco, M. L. \& Mazo Beltrán, A. X. (2016). Cultura e identidad sobre el consumo de drogas en los habitantes de la calle del municipio de Medellín. Drugs and Addictive Behavior, 1(2), 191-199.

\section{Endereco para corespondencia:}

Universidad Luis Amigó

Colômbia

Tv. 51a \#\#\#67B 90, Medellín, Antioquia, Colômbia

Maricelly Gómez Vargas

maricellygomez@gmail.com

Recebido: 05-02-2019

Aceito em: 27-02-2019 


\title{
Mulheres e loucura: a (des)institucionalizaçáo e as (re)invençóes do feminino na saúde mental
}

Women and madness: the (des) institutionalization and the (re)inventions of the feminine in mental health

\author{
Thaiga Danielle Momberg Silva ${ }^{1}$ \\ Marcos Roberto Vieira Garcia ${ }^{2}$ \\ Universidade Federal de São Carlos - UFSCar
}

\begin{abstract}
Resumo
A partir de uma pesquisa qualitativa desenvolvida por meio de observação participante, entrevista aberta e análise de prontuários, o artigo almejou investigar as especificidades das mulheres no processo de desinstitucionalização na cidade de Sorocaba/SP, considerando como as questôes de gênero se articulam com a loucura. Buscou compreender, também, como as mulheres que atualmente residem nos Serviços Residências Terapêuticos (SRTs) vivenciam sua independência diante das marcas da institucionalização, levando em consideração todo o silenciamento histórico vivenciado, o que se soma ao estigma da loucura atribuído a elas. Os resultados demonstraram dispositivos de controle da sexualidade e da feminilidade no manicômio e, também, fora dele, que levam à infantilização e à tutela das moradoras. Ressalta-se, a partir disso, a necessidade de interseccionar a discussão da saúde mental com as questóes de gênero, classe e raça.
\end{abstract}

Palavras--chave: Saúde mental; Serviços Residenciais Terapêuticos; Desinstitucionalização; Mulheres.

\begin{abstract}
TBased on a qualitative research developed through participant observation, open interview and analysis of patients' records, the article aimed to investigate the specificities of women in the process of deinstitutionalization in the city of Sorocaba / SP, considering how gender issues are articulated with madness. It also sought to understand how the women who currently reside in the Therapeutic Residences Services (SRTs) experience their independence in the face of the marks of institutionalization, taking into account all the historical silencing experienced, which adds to the stigma of the madness attributed to them. The results demonstrated mechanisms of control of sexuality and femininity in the asylum and, also, outside it, which lead to the infantilization and guardianship of the dwellers. From this, we emphasize the need to intersect the discussion of mental health with issues of gender, class and race.
\end{abstract}

Keywords: Mental health. Therapeutic Residential Services. Deinstitutionalization. Women.

O presente artigo apresenta uma pesquisa cujo tema é o processo de (des)institucionalização na área da saúde mental em Sorocaba, com o intuito de investigar as especificidades das mulheres egressas de manicômios, considerando como as questóes de gênero se articulam com sua tutela e/ou independência.

Buscou compreender, também, como as mulheres que atualmente residem nos Serviços Residências Terapêuticos (SRTs) vivenciam sua independência diante das marcas da institucionalizaçáo, levando em consideração todo o silenciamento histórico vivenciado por estas, o que se soma ao estigma da loucura atribuído a elas, interseccionando a discussão também pelas categorias de raça e classe.

O trabalho da pesquisa se consolidou por meio de observação participante de SRTs femininas, análise de prontuários de suas moradoras nos serviços de saúde mental e entrevista aberta com uma delas. A pesquisa $^{3}$ seguiu os parâmetros éticos recomendados, o que incluiu sua explicação minuciosa, a garantia de anonimato para as participantes e a apresentaçáo do Termo de Consentimento Livre e Esclarecido (TCLE). O projeto de pesquisa foi submetido e aprovado pelo Comitê de Ética em Pesquisa da Universidade (referência omitida),

\footnotetext{
${ }^{1}$ Possui Mestrado em Educação pela Universidade Federal de São Carlos. Possui graduaçáo em Psicologia pela Universidade Paulista. Atualmente é psicóloga na Prefeitura da Estância Turística de Salto.

${ }^{2}$ Possui graduação em Psicologia pela Universidade de São Paulo (1992), mestrado em Psicologia Social pela Universidade de São Paulo (2000) e doutorado em Psicologia Social pela Universidade de São Paulo (2007). É professor do Departamento de Ciências Humanas e Educaçáo da Universidade Federal de São Carlos (UFSCAR) - Campus Sorocaba, professor permanente do Programa de Mestrado em Educação da UFSCar campus Sorocaba; coordenador do Grupo de Pesquisa "Saúde Mental e Sociedade" (UFSCAR) e integrante do Núcleo de Estudos para a Prevenção da Aids (NEPAIDS/USP) e do Grupo de Pesquisa Educação, Comunidade e Movimentos Sociais (GECOMS/UFSCar); coordenador do Centro de Referência em Educação na Atenção ao Usuário de Drogas da região de Sorocaba (CRR-UFSCar-Sorocaba).

${ }^{3}$ A pesquisa foi apresentada na dissertação de mestrado junto ao Programa de Pós-Graduaçáo e Educação da UFSCar - campus Sorocaba (Momberg, 2018).
} 
número do parecer 2.075.850. Também foi submetido e aceito pela área de Divisão de Estágio, Aperfeiçoamento, Especializaçáo e Residência em Saúde da Secretaria de Saúde local.

A relevância do presente estudo está atrelada à mudança da lógica manicomial presente na cidade e a implementação de uma rede substitutiva, entendendo que deve possibilitar novas abordagens, princípios e valores às pessoas em situação de sofrimento psíquico, sendo capaz de impulsionar formas mais adequadas de cuidado no seu âmbito familiar, social e cultural (Valverde, 2010).

Segundo Rotelli e colaboradores (2009), a base dos projetos de desinstitucionalizaçáo reside na ruptura da causalidade linear da doença-cura, problema-solução, e na reconstrução do "objeto" enquanto sujeito histórico. Ainda, ressaltam que as novas instituiçôes devem estar à altura da complexidade da tarefa de intervir na sua existência-sofrimento, remetendo ao processo da constante reconstruçáo do sujeito. Cabe salientar que as dificuldades de superação do modelo manicomial vão além do mero fechamento de hospitais e da abertura de novos serviços, pois há uma lógica historicamente institucionalizada a ser rompida.

De acordo com o Ministério da Saúde (2004), o Serviço Residencial Terapêutico (SRT) - ou residência terapêutica ou simplesmente "moradia" - "são casas localizadas no espaço urbano, constituídas para responder às necessidades de moradia de pessoas portadoras de transtornos mentais graves, institucionalizadas ou não". (Brasil, 2004, p. 6). A proposta de criação dos SRTs foi desenvolvida com o intuito de possibilitar a reduçáo de leitos dos manicômios, auxiliando as/os moradoras/es na superação da condição cronificante e estigmatizante de "moradores de hospital".

A região na qual Sorocaba se encontra foi até recentemente, o maior da América Latina em termos de concentração de instituiçóes do tipo, passando a ser considerado o maior polo manicomial do país. Sorocaba teve um histórico da presença de manicômios desde a abertura de uma colônia agrícola provisória no final do século XIX, passando pela abertura de um pequeno manicômio em 1928 e pela grande expansão destes nas décadas de 60 e 70, durante o regime militar, com a contrataçáo de leitos privados pelo sistema público de saúde, o que gerou uma "indústria manicomial" na região (Garcia, 2012). Cabe ressaltar que alguns registros apontam que as condiçóes das/os internas/os nesse manicômio eram de extremo sofrimento e violação de direitos humanos.
Diante desse cenário, o Fórum da Luta Antimanicomial de Sorocaba (FLAMAS) denunciou essas violaçóes que ocorriam no interior dos sete manicômios de Sorocaba e regiáo, o que repercutiu na assinatura de um Termo de Ajustamento de Conduta (TAC), no final de 2012, obrigando os entes federativos (União, Estado e municípios envolvidos) a desativar os manicômios da região em um prazo de 4 anos, o que se configurou como o maior processo de desinstitucionalização no Brasil recente. O manicômio Vera Cruz tornou-se conhecido nacionalmente como "palco das atrocidades" a partir das graves violaçóes de direitos humanos denunciados no Programa televisivo Conexão Repórter, que registrou pacientes comendo fezes, sem roupas, sem colchão para dormir, além de violência física e verbal por parte dos funcionários e trabalhos forçados, em imagens que chocaram a sociedade, que quase nunca tem acesso ao que ocorre do outro lado dos muros desses espaços.

Buscou-se no decorrer da pesquisa problematizar a saúde mental e a questão de gênero, defendendo a perspectiva que a saúde mental masculina é tratada de forma distinta da feminina, desde a maneira de se compreender a doença e suas causas, como na forma de tratá-la. De acordo com Scott (1995, p. 11), entende-se gênero, aqui, como "um elemento constitutivo de relaçôes sociais baseado nas diferenças percebidas entre os sexos", e "(...) uma forma primeira de significar as relaçôes de poder".

Para Beauvoir (1980), a mulher foi sempre tratada como o outro, como o segundo sexo, e essas diferenças são produzidas e mantidas no âmbito social e cultural. Ao abordar a questão de gênero enquanto saber e considerar as relaçóes de poder presentes na diferença entre o que é ser homem e o que é ser mulher, pode-se afirmar que o silêncio e a invisibilidade caracterizam a história das mulheres. O lugar das mulheres no espaço público sempre foi problemático, pelo menos no mundo ocidental. O homem público, sujeito eminente da cidade, encarnava a honra e a virtude. A mulher pública constitui a vergonha, a parte escondida, território de passagem, sem individualidade própria (Perrot, 2007). Para Perrot (2007), a invisibilidade e o silenciamento fazem parte da história das mulheres, pois elas atuam em família, confinadas em casa, sem liberdade, e esta "invisibilidade" é a garantia de uma cidade tranquila, sendo sua aparição, inclusive, motivo de medo.

Cabe ressaltar, ainda, a necessidade de racializar o debate político, levando em consideração que o Brasil foi marcado por mais de 354 anos de escravidáo negra e tornou-se o último país do mundo a aboli-la, 
relembrando a desumanização das pessoas escravizadas, suas dores e tortura e múltiplas violências. De acordo com Davis (2016), a categoria "mulher" pode ser considerada uma armadilha se despojada do seu contexto racial e de classe. Considera que os mitos fundadores $\mathrm{da}$ feminilidade - que são caracterizados pela delicadeza, fragilidade, instinto materno natural, dedicação aos cuidados e submissão - são, na verdade, construções sociais e políticas, frutos do capitalismo, que necessita da produção e reprodução no lar de seres humanos para o trabalho, mediante a criação da figura típica da "dona de casa", ao mesmo tempo em que cristaliza o trabalho doméstico como aquele não-produtivo e sem remuneração. A estudiosa também ressalta que as mulheres negras, durante e após a escravidão, trabalharam fortemente fora de casa, sendo oprimidas e violentadas.

Segundo Brah (2006), não podemos analisar isoladamente os problemas que afetam as mulheres, muito menos universalizá-los: "Dentro dessas estruturas de relaçôes sociais não existimos simplesmente como mulheres, mas como categorias diferenciadas" (Brah, 2006, p. 341), isto é, os discursos de feminilidades assumem significados específicos a partir das diferenças trajetórias que atravessam não apenas as questôes de gênero, mas de raça, classe, sexualidade, geraçáo, entre outros.

Lugar de ambiguidades e espaço por excelência da loucura, o corpo e a sexualidade femininos inspiraram grande temor aos médicos e aos alienistas, constituindo-se em alvo prioritário das intervençóes normatizadoras da medicina e da psiquiatria. Muitas crenças pertencentes a antigas tradiçôes e no âmbito dos mais variados saberes - muitas das quais remontam à antiguidade clássica - seriam retomadas e redefinidas pelo alienismo do século XIX. Entre os alienados considerados "rebeldes a qualquer tratamento, por razóes mais morais do que propriamente médicas", Pinel incluía as mulheres que se tornavam irrecuperáveis por "um exercício não conforme da sexualidade, devassidão, onanismo ou homossexualidade" O temperamento nervoso, intimamente relacionado à predisposição às nevroses e nevralgias, era frequentemente considerado como típico das mulheres, "cujas funçôes especiais ao sexo, em muito contribuem para o seu desenvolvimento". (Eengel, 2006, p. 333).

Marcinik e Mattos (2016) nos convocam a pensar a partir do conceito da interseccionalidade, ou seja, a desconstruçáo de uma perspectiva universalizante da(s) mulher(es) e das características que são produzidas por concepçóes dominantes. Deve-se ampliar e compreender a racialização do gênero por meio da interseccionalidade das diferenças e compreender o impacto das diversas violências e exclusóes sociais que as questóes étnico-raciais produzem. No contexto da saúde mental, deve-se ampliar o debate das questóes de gênero, raça e classe, que são pouco problematizadas e reproduzem formas de opressões, que reforçam a invisibilidade que essas mulheres vivenciam pelo estigma que carregam enquanto "loucas".

As mulheres da presente pesquisa são negras e pobres. Entende-se que tais componentes facilitam a marginalização e a institucionalização precoce, resultando na manicomialização. A mulher pobre e negra carrega o sofrimento e a estigmatizaçáo desde o passado colonial até os dias atuais. As inúmeras discriminaçôes de gênero, raça e classe se refletem diretamente nas representaçôes em relação ao "ser mulher negra", seja em relação ao seu corpo enquanto objeto sexual, ou ao trabalho doméstico como seu destino natural, o que favorece a institucionalização precoce desde a infância, o que inclui a manicomializaçáo. Para Santos (2009), ser mulher e negra no Brasil significa estar inserida em um ciclo de marginalização e de discriminação social.

De acordo com Engel (2006), a loucura das mulheres se refere o tempo todo a uma suposta "essência” feminina e sua sexualidade, enquanto a loucura masculina se manifestaria na capacidade que os homens teriam ou não em desempenhar seus papeis na sociedade. Assim, a mulher é historicamente diminuída, aprisionada à uma ideia esperada de corpo e sexualidade, enquanto ao homem é atribuída a razão.

Para Garcia (1994), desde o início do século XIX, as mulheres caíram sob o controle psiquiátrico, levando ao confinamento em manicômios. A partir da metade do século XIX, cresceu o número de mulheres internadas em manicômios em relação aos homens, o que está associado ao modo como a doença mental feminina foi encarada como associada à condição das mulheres, a partir da expectativa de que as mulheres estariam sempre na iminência de um ataque "dos nervos".

Pode-se afirmar, também, que o manicômio reproduz os estereótipos de gênero, afinal, enquanto se relegava aos homens as atividades ao ar livre, o que contribuiria para a cura, no caso das mulheres isso se daria por meio do trabalho doméstico, corroborando a ideia que a condição feminina se relacionava aos espaços fechados (Cunha, 1986).

Chesler (1972) considera que os manicômios servem como depósito para as mulheres, que recebem tratamento psiquiátrico desde muito cedo, funcionando como uma família burocratizada, na qual a degradação e a fragmentação do ser passam a ser experienciadas pela paciente mulher e infantilizada. Pode-se afirmar que a 
proteção de pais e mães é supostamente transferida para as/os profissionais dessas instituiçóes.

\section{MÉTODO}

A pesquisa se concentrou em dois Serviços Residenciais Terapêutico (SRTs) femininos, compostos - cada um - por 10 egressas de um manicômio feminino na cidade de Sorocaba-SP. Caracteriza-se como uma pesquisa de abordagem qualitativa a partir da produção de narrativas e tendo como fonte de dados os prontuários, observação participante (apoiada em diário de campo) e entrevista aberta com uma moradora de SRT Também foi utilizado material escrito (cartas) de uma moradora, de acordo com seu pedido, que optou por não gravar entrevista, mas desejou contribuir para a investigação.

A análise de prontuários corresponde a uma modalidade de análise documental. Para Souza, Kantorski e Luiz (2011), que investigam a análise de prontuários no campo da saúde mental, é importante que as informaçóes sejam trabalhadas para torná-las mais compreensíveis, correlacionando-as aos dados oriundos de outras fontes, como é o caso dos diários de campo da observação participante e da entrevista no caso da presente pesquisa.

Os diários de campo, prontuários e entrevista foram analisados a partir da proposta de análise categorial de conteúdo proposta por Bardin (1979). Esta técnica caracteriza-se pela classificação dos elementos a serem analisados por uma diferenciação temática e um reagrupamento subsequente pela analogia estabelecida entre eles. A categorização permite, desta forma, condensar os dados brutos em representações mais simples, o que permite estabelecer inferências e interpretar os dados. Está ligada à ideia, portanto, de busca de uma maior visibilidade dos dados, facilitando o trabalho de relacioná-los o referencial teórico.

Cabe ressaltar que, durante o trabalho de campo, algumas moradoras tiveram dificuldade em se comunicar verbalmente, uma das consequências da institucionalização. Por esse motivo, apenas quatro mulheres serão apresentadas na sequência, ressaltando a utilização de nome fictício visando garantir seu anonimato.

Antônia afirmou ter 43 anos, ser pobre e negra, e se recordar da infância com várias dificuldades financeiras.

"Eu tive depressão né? Não consegui cuidar da minha filha, eu tinha 13 anos, eu descobri tarde e não adiantou tomar o chá, não desceu, eu me sentia triste, eu era danada, nós era pobre, faltava as coisas, tive irmãos e minha tia não quis cuidar de mim, fui morar com minha vó”. (Antônia)

Segundo informações encontradas no seu prontuário:

Na infância Antônia morava com seus pais e sua irmã mais nova, com diversas dificuldades principalmente financeiras. Seu pai veio a falecer quando ela estava com 3 anos de idade. A mãe apresentava problemas de alcoolismo, necessitando sempre de auxílio de membro da família para cuidar das filhas. Por volta dos 6 anos de idade foi morar com os avós paternos. Neste local começou a frequentar a escola, onde apresentava dificuldades de aprendizagem e possuía poucos amigos. Após aproximadamente 3 anos, voltou a morar com a máe em uma casa simples com condiçôes precárias e com dificuldades financeiras. Na adolescência apresentava auto-estima rebaixada, insegurança para trabalhar e para relacionamentos amorosos. Trabalhou em diversas casas de família como empregada doméstica (Prontuário médico da paciente Antônia, s. d.).

Antônia é diagnosticada pelo CID 10: F31.0 (Transtorno Afetivo Bipolar) e é descrita em seu prontuário como tendo discurso coerente e pensamento organizado, sendo afetiva e tendo boa interação com todos. É referida como independente e autônoma nas atividades de vida diária, possui seus aspectos cognitivos preservados, assim como atenção, memória e concentraçáo. O prontuário conta, também, que ela apresenta vínculo precário e fragilizado com os irmãos, é curatelada e, desde dezembro de 2014, não tem acesso aos seus benefícios previdenciários.

Já a moradora Maria contou que tem 47 anos e teve uma infância conturbada. Viveu parte de sua infância na rua e foi internada ainda muito jovem na Fundação Estadual para o Bem-Estar do Menor (FEBEM, atual Fundação Casa). Seus sintomas eram caracterizados por agressividade, de acordo com seu prontuário. Após a internação na FEBEM, foi encaminhada ao manicômio, onde residiu mais da metade de sua vida. Também teve uma infância privada de condiçôes financeiras e é negra. Segundo a moradora, "eu fui 
pra FEBEM, vivi lá, não lembro quando, mas eu era pequena, minha mãe bebia, depois fui pro hospital". Segundo seu prontuário:

Menor internada em 30.11.1982, apresenta boas condiçôes de saúde física, executa satisfatoriamente as tarefas que lhe são atribuídas, porém com certa lentidão. Apresenta certa timidez, tornando assim muitas vezes um relacionamento difícil tanto com os funcionários como com as demais internas. A menor nunca recebeu visitas, continuará recebendo treinamento nas atividades domésticas, assim como nos trabalhos manuais, para que futuramente possamos colocá-la em casa de família como empregada doméstica. (Prontuário da paciente Maria, 16 de maio de 1986).

Consta em seu histórico, de acordo com seu prontuário, que Maria foi internada em 1971, por meio do Juizado de Menores, após ter sido encontrada em estado de abandono em casa e por sua genitora realizar uso abusivo de álcool, o que acarretou em sua prisão. $\mathrm{Na}$ sequência, Maria se manteve sob os cuidados da antiga FEBEM, passando por vários abrigos. Em 1986, ela foi transferida para um manicômio em Sorocaba, com diagnóstico de retardo mental leve e episódios esporádicos de agressividade, onde permaneceu por 13 anos. Em 1999, foi transferida para outro manicômio, onde ficou por mais 15 anos. Não há registro de nenhuma visita à paciente e nem procura por ela durante todo o tempo da internação. Segundo seu prontuário:

Diagnóstico: CID F70.0 (Retardo Mental Leve). É considerada independente nas atividades de vida diária (AVDs) como higiene pessoal e alimentação, boa comunicação, aspectos cognitivos preservados, como orientação temporal e espacial, bem como resoluçóes de problemas, boa convivência com as demais usuárias (Prontuário da paciente Maria, s. d.).

A terceira moradora, Mercedes, não sabe sua idade, aparentando ter 35 anos. Negra e pobre, apresenta dificuldades na linguagem verbal. Não recorda o motivo pelo qual foi internada, mas sabe que o foi ainda na infância. De acordo com seu prontuário, tem 38 anos. Foi encaminhada para a FEBEM com um ano de idade, devido ao abandono familiar. Aos dois anos de idade, foi transferida para um abrigo, onde permaneceu por 12 anos. Em 1991, foi transferida para o manicômio, com diagnóstico de retardo mental leve e por conta do fato do abrigo encerrar suas atividades. Durante todo o processo de internação, não há nenhum registro de visitas e/ou vínculos familiares. Consta em seu prontuário:

Diagnóstico: F70.0 (Retardo Mental Leve). É independente nas Atividades de Vida Diária (AVDs), como higiene pessoal e alimentação. Apresenta certa dificuldade na fala, porém com boa comunicação verbal, aspectos cognitivos preservados, como orientação temporal e espacial, bem como resoluçôes de problemas, boa convivência com as demais usuárias. Apresenta quadro cínico e psiquiátrico estáveis. A paciente é curatelada, porém atualmente seu benefício encontra-se bloqueado pela justiça [...]. (Prontuário da paciente Mercedes, s. d.).

Por fim, Fátima, 25 anos, negra e pobre, passou a viver em um abrigo após a mãe perder sua guarda aos 11 anos. Afirma que nunca conseguiu ler nem escrever e foi encaminhada à Associação dos Pais e Amigos dos Excepcionais (APAE) por causa dessa dificuldade. Frequentou essa instituição até ser internada no manicômio. Não se recorda quantos anos tinha quando foi mandada para o hospital, mas se lembra que ainda era criança, tendo ficado, aproximadamente, 15 anos internada.

Eu não sabia ler, e nem escrever, mandaram eu pra lá, eu queria aprendê, a professora me acusou, dizia que eu era louca, que eu tinha passado fezes na parede, eu não tinha feito nada, fui pro hospital e o juiz falou que eu ia ser moradora. (Fátima).

De acordo com seu prontuário, Fátima tem 25 anos, foi encaminhada para a instituição de acolhimento - "abrigo" - desde os 11 anos de idade, pois os pais realizavam uso abusivo de bebida alcoólica, além de haver uma suspeita de tentativa de abuso sexual por parte de seu pai. Em 2005, foi transferida para o manicômio devido às crises de agressividade. De acordo com seu prontuário: Recebeu alta, mas foi impedida de retornar ao abrigo devido o mesmo acolher crianças até os 12 anos, Fátima tinha passado desta idade. Assim permaneceu internada, como moradora do Hospital Mental 
até 23.07.2014. Com o advento do TAC - Termo de Ajustamento de Conduta, esta foi transferida para o Pólo de Desinstitucionalização, onde conheceu seu atual companheiro Tem em seu prontuário a hipótese diagnóstica de "Retardo mental leve".

Fátima carrega desde a infância um histórico de institucionalização. Cabe ressaltar que o motivo que a levou a permanecer enquanto "moradora" do manicômio foi o fato de a instituição de acolhimento não receber mais crianças na sua faixa etária.

\section{RESULTADOS E DISCUSSÃO}

O trecho abaixo, retirado do prontuário de Maria, mulher negra e de classe baixa, desde muito cedo institucionalizada, nos faz refletir sobre a intersecção entre gênero e raça:

A menor nunca recebeu visitas, continuará recebendo treinamento nas atividades domésticas, assim como nos trabalhos manuais, para que futuramente possamos colocá-la em casa de família como empregada doméstica. (Prontuário médico da paciente Maria, 16 de maio de 1986).

Segundo Davis (2016), é possível observar uma relação direta entre escravismo e trabalho doméstico. No Brasil ainda se mantém fortemente como uma atividade feita, em sua maioria, por mulheres negras, relembrando também que a escravidáo foi usada como modelo para a precarização do trabalho para a população negra. Devido ao sistema de contratação de pessoas encarceradas, a população negra foi forçada a representar o mesmo papel que a escravidáo anteriormente lhe reservava.

Segundo informaçóes do prontuário, Maria, desde pequena, foi ensinada a desempenhar funçóes domésticas, tida como sua única opção de inserção social fora da instituição. Desde muito cedo, quando foi internada ainda na infância, foi estimulada a aprender o trabalho doméstico, visto como única possibilidade de trabalho formal. Foi, desta forma, privada da educação formal e das inúmeras chances que poderiam surgir, devido à sua institucionalização em espaços para "menores” e manicômios por, praticamente, a vida inteira.

Atualmente, é possível perceber que a rotina de Maria na RT em que reside consiste em realizar tarefas domésticas, auxiliando na limpeza de cozinha, organizaçáo de roupas e no cuidado com outras moradoras que possuem pouca ou nenhuma autonomia. Raramente sai da casa. Afirma que não gosta de passear e que "tem que limpar". As cuidadoras da RT dizem que ela é organizada, "prendada" e que frequentemente ajuda, ficando chateada se não realiza as atividades. Percebe-se grande organização, limpeza e cuidados nas atividades que realiza. Não é comum encontrar Maria fazendo alguma atividade de lazer, nem sequer sentada no sofá para assistir à televisão, como as demais mulheres. Geralmente, está na cozinha, nos cuidados com roupas de cama, ou auxiliando as cuidadoras e técnica de referência com a medicação.

De acordo com Chesler (1972), as internaçóes em manicômios costumam aproximar mais a mulher do que o homem da experiência familiar, fato que pode ser justificado por elas se sentirem "em casa". A mesma autora ressalta que pacientes mulheres, assim como meninas, são supervisionadas de perto por outras mulheres, enfermeiras atendentes, que são relativamente sem força em termos de hierarquia hospitalar.

Desta forma, pode-se afirmar que a lógica manicomial permanece presente nas RTs em questáo, onde se percebe a "supervisão" das profissionais, bem como o incentivo às mulheres permanecerem nos domínios do privado, realizando atividades diárias, negando-se sua autonomia, a vivência da sexualidade e sua socializaçáo no mundo público, dentre outros aspectos.

Mercedes, também mulher negra e de classe baixa, apresenta características muito parecidas com as de Maria, no que diz respeito à realização das atividades da casa. Frequentemente, auxilia na organizaçáo e limpeza do local e náo faz atividades fora da RT. Segundo a técnica de enfermagem, ela não sai, pois não sabe pegar ônibus e se perde muitas vezes. Ambas costumam sair com a técnica de enfermagem para levar alguma moradora na UBS em consultas, ou em lojas quando precisam comprar algo, prática que era comum quando viviam no manicômio. Outra semelhança em relação a essas mulheres é a "ausência" de uma vida fora da RT, pois quando questionadas sobre suas vidas enquanto mulheres, sexualidade, relacionamentos interpessoais, as duas afirmam que não possuem.

Seu comportamento difere do de Antônia, que tem mais autonomia e costuma realizar passeios com maior independência, além de namorar. É perceptível, no dia a dia, o incômodo de Mercedes e Maria com o comportamento de Antônia, pois a mesma realiza tarefas de limpeza na casa, mas numa frequência menor, e constantemente está realizando outras atividades. Ela gosta de escrever textos e sair com o namorado. Isso gera desconforto também em relação às cuidadoras, que questionam sobre o "apetite sexual" de Antônia, 
quando afirmam que a mesma "apronta demais" quando sai, fazendo refletir sobre a questão de tutela ainda presente nas RTs, onde as mulheres pouco são estimuladas a vivenciar uma vida "comum" como qualquer pessoa adulta, vivenciando sua sexualidade.

De acordo com Chesler (1972), considerando que as mulheres têm tido desde sempre sua sexualidade reprimida, a tentativa de escapar de tal repressão é vista como perigosa pelas/os profissionais do manicômio. Diante disso, compreende-se que a sexualidade dessas mulheres é entendida como tabu. Seguindo-se a lógica imposta a muitas delas, a manifestação da sexualidade é vista como atrelada à loucura. O desejo sexual pode existir, desde que seja extremamente controlado, de acordo com um padrão pré-estabelecido de apetite sexual, o que reforça paradigmas sobre o feminino, reprime a sexualidade e demais aspectos que não são encarados como comportamentos adequados a uma mulher.

Antônia afirmou que, desde muito nova, gostava de leitura e escrita, entretanto era pouco incentivada por causa das atividades que ela precisava realizar, provavelmente, em uma referência aos afazeres domésticos, situação bastante comum. Conforme Hooks (1995) existe um teor de recriminação em relação às meninas negras que se dedicam a atividades individuais, sendo altamente reprovável a abdicação das obrigações domésticas por atividades de leitura e escrita.

Fátima, assim como Maria e Mercedes, não sabe ler e nem escrever, o que reafirma a privação presente já na infância no que diz respeito à escolarização. Cabe ressaltar, ainda, que Fátima era criticada pelas outras moradoras da RT devido ao não-cumprimento de certas "regras". A técnica de enfermagem relatou que ela não "obedecia", queria sair e voltar "do seu modo e quando quisesse", além de não ajudar nos afazeres da casa. Isso mostra que condutas fora das expectativas de gênero e raça, mesmo mostrando maior autonomia por parte de Fátima, eram objeto de críticas na RT.

Eu acho errado internar a pessoa a força, só interna a pessoa a força se ela quiser. Acho errado. $\mathrm{Na}$ época a gente era chamado de louco, naquela época, eu lembro disso até hoje. Me colocaram na ambulância, tem a gradinha sabe, já ouviu falar da ambulância, me colocavam lá e me chamavam de louca. Desse jeito, aqui agora, nessa residência aqui é um amor, é muito bom. Eu me sinto em casa, mãe D. deixa eu dormir na casa do W. D. é um amor, não tenho o que falar dela. Eu tô bem feliz. (Fátima)
De acordo com o prontuário de Fátima, foi possível observar a transferência de uma RT para a outra, bem como aspectos que demonstram sua autonomia e que incomodavam a gestão da SRT:

Em junho de 2015 Fátima recebeu alta do Pólo de Desinstitucionalização e foi morar em uma RT, onde continuou com seus comportamentos pueris, com birras e agressividade, se recusando em muitos momentos a comer e tomar suas medicaçóes. Ainda, demonstrava-se frustrada por não receber seu dinheiro do BPC, o qual continua bloqueado devido as questóes judiciais relacionadas com o processo de tutela e curatela. [...] Foi para casa da família em junho de 2016, acompanhada pela referencia técnica da RT, onde morava, para rever a irmã. Deste modo, ficou combinado que iria morar com a mesma dali 30 dias. Entretanto, Fátima depois de alguns dias, relatou que estava bem na RT, considerando estar perto de seu namorado rejeitando a proposta de morar com a irmá. (Prontuário da paciente Fátima, s. d.).

Percebe-se, por meio desse relato, a necessidade de se considerar a capacidade de escolha das pessoas que saem dos manicômios após períodos longos de internação; no caso citado, Fatima passou grande parte de sua infância em instituiçôes asilares, atualmente criando laços afetivos em Sorocaba, embora seus vínculos familiares estejam em outra cidade. Diante disso, teve como preferência a escolha de permanecer em Sorocaba, o que foi respeitado pela equipe técnica. Consta ainda em seu prontuário:

Em julho de 2016 Fátima saiu abruptamente da RT na companhia de seu namorado para morarem sozinhos, sem orientaçáo final da equipe. Desde então, residem em uma casa precária onde dividem as despesas com aluguel e alimentaçáo, sendo acompanhada pela equipe do CAPS. Fátima demonstra interesse pelos cuidados da casa, como o preparo das alimentaçóes, enquanto o companheiro preocupa-se com a continuidade do tratamento e administração das medicaçôes. Vale ressaltar que o relacionamento é sempre conflituoso com muitas discussóes e brigas, quando recorrem aos técnicos da equipe. (Prontuário da paciente Fátima, s. d.). 
Por meio do relato acima, pode-se problematizar a questão do papel social da mulher interna, que, geralmente, está associada às tarefas concretas do dia a dia, enquanto da figura masculina é esperada maior responsabilidade no sentido racional, embora a questáo da irracionalidade esteja presente em ambos, devido ao estigma de associado ao manicômio. Fátima demonstra autonomia, como aponta seu prontuário:

Em fevereiro de 2017 Fátima foi sozinha de ônibus buscar auxílio da irmã, onde resolveu morar. Então sua irmã a acolheu e foi realizado contato com o CRAS para articular a continuidade do tratamento. Em março retornou para sua casa. (Prontuário da paciente Fátima, s. d.).

Fátima, durante entrevista realizada em agosto de 2017, afirmou que decidiu voltar para a RT, pois ela e o namorado brigavam bastante:

"Eu e W. briga demais, não deu certo, mas a gente continua junto, aqui é bom [se referindo à RT atual], posso ver ele, sair, nois briguemos muito. Ele tem os problema dele também né?" (Fátima, agosto de 2017).

De acordo com seu prontuário, após decisão de Fátima voltar a residir em RT, foi pensando em nova inserção em outra residência, o que se deu em abril de 2017, onde Fátima está até os dias de hoje, sem quaisquer dificuldades de adaptação. No seu prontuário, consta que

Fátima questionou sobre seu direito já conquistado [de ir e vir] e me pediu para visitar W. [seu namorado] e ir ao cinema no sábado com seu namorado. Foi orientada que sim, desde que não atrapalhe seu PTS (Prontuário da paciente Fátima, s. d.).

Entende-se que o campo psiquiátrico desempenha uma função de normalização, padronizando comportamentos considerados aceitáveis para as mulheres egressas de manicômios. Pode-se perceber que a não-adequação a padróes impostos é um fator que contribui para sua internação e institucionalização.

As marcas da institucionalização carregam diferentes formas de opressão, seja por classe, raça, e/ou gênero. Para as mulheres, os limites eram muito mais rígidos, e elas tinham que se encaixar no que era ser mulher, mãe e esposa.
Nem todas as mulheres que viveram na primeira metade do século XX escolheram viver a vida nas formas prescritas. Na população feminina do Sanatório Pinel, podemos encontrar inúmeras histórias de 50 mulheres que buscaram certa autonomia frente às pressóes que a sociedade lhes impunha, mas também mulheres que, mesmo desempenhando uma função a elas delegada, sofreram crises relacionadas a esses papéis. Essas manifestaçôes, aos olhos das "instituições reguladoras", foram vistas como sinais de demência e desequilíbrio mental. (Vacaro, 2011, p. 10-11).

A análise dos prontuários das moradoras aqui pesquisadas mostra em muitos momentos a não-correspondência a um comportamento tido como "normal". Entende-se que as mulheres foram historicamente restritas apenas ao papel de "filhas-esposas-máes", e qualquer tentativa de "fugir" deste seu único destino passa a ser julgada, tendo como uma das consequências possíveis a atribuição de "loucura" e sua segregação em manicômios.

Para Cunha (1986), as mulheres, em qualquer situação social, incluindo em situação de internamento, serão inferiorizadas quando comparadas aos homens, evidenciando as diferenças no modo de se compreender a "loucura".

Parâmetros diferentes orientam a construção da "loucura" - e, portanto, da "normalidade" - para cada um dos sexos, remetidos a um desenho idealizado dos papéis sexuais e dos diferentes atributos de gênero. Assim cabia ao homem "normal" a tarefa de provedor da família, de trabalhador dedicado e quanto o "exemplo" de uma vida morigerada e livre dos vícios e dos "excessos". À mulher restavam as tarefas estratégicas da reprodução e da conservação da família e do lar, de "ser - para - com - os - outros" conforme exigiriam sua própria determinação biológica e as inclinaçôes naturais do seu espírito. (Cunha, 1986, p. 126).

A história de Antônia, mulher, negra e sobrevivente do manicômio, talvez seja a que melhor exemplifique esse processo. Conforme seu prontuário,

Antônia teve alguns relacionamentos amorosos com homens casados, se envolvendo com várias pessoas na mesma época. Por esse motivo, ao engravidar, não sabia quem era o pai da criança. Durante a gravidez Antônia residia com sua avó materna, sentia-se deprimida, chorava bastante, sentia arrependimento de algumas situaçóes 38 que passou. Após o parto de sua filha, os sintomas de Antônia se intensificaram, apresentando alucinaçóes auditivas e visuais e delírios inclusive 
de cunho persecutório. Permaneceu com sua filha, residindo na casa de sua avó materna, até a menina completar 2 meses de vida. Após isso, foi adotada por um casal que Antônia conhecia. Antônia então fora internada no manicômio pela primeira vez. Após sua alta, Antônia passou a visitar a filha, porém foi proibida por essa família de ver a filha pois teria tentado agredi-la algumas vezes. (Prontuário da paciente Antônia, s. d.).

Possuía uma vida promíscua, aos olhos da sociedade, por manter relaçôes sexuais com vários parceiros. Afirmou que, muitas vezes, optava por ter essas relaçóes em troca de roupas e presentes com pouco valor financeiro, visto que vivia em condição de miséria. Sentia-se culpada e deprimida por náo conseguir seguir os dogmas impostos pela igreja que foi "obrigada" a frequentar pela tia materna, com quem passou a conviver após o abandono da genitora. É possível perceber que sua condição de "ser louca" se relaciona ao julgamento do modo como a mulher vivencia a sua sexualidade.

De acordo com Hooks (1995), para justificar a exploração masculina branca e o estupro das negras durante a escravidáo, a cultura branca teve de produzir uma iconografia de corpos de negras que insistia em representá-las como altamente dotadas de sexo a perfeita encarnaçáo de um erotismo primitivo e desenfreado.

Pode-se afirmar que a escravidão foi um dos episódios mais violentos da história do povo brasileiro, que a violência esteve presente de todas as formas possíveis e que a mulher negra foi objetificada, reforçando a ideia do corpo enquanto objeto de servidáo para os homens brancos. Isso nos deixou marcas profundas no sentido de naturalizar a violência contra as mulheres, assim como reificar a associação entre mulheres e o trabalho doméstico, e institucionalizar muitas das mulheres consideradas "loucas", em sua maioria negras e de classe baixa, no manicômio, destituindo-as de sua liberdade e de tudo que as caracterizava como humanas.

Segundo Engel (2006), na construção dos diagnósticos da doença mental em mulheres, a psiquiatria deu grande destaque à menstruação e à maternidade, considerando que o início e o fim do período menstrual seriam, frequentemente, momentos propícios à manifestação de distúrbios mentais, bem como a maternidade poderia curar ou intensificar a loucura feminina. É importante ressaltar, nesse discurso, a expectativa de que uma mulher seja capaz de desempenhar a maternidade de modo natural, pois este é seu papel social, atrelado ao seu corpo, restringindo-se, novamente, a figura da mulher a ele. Antônia compartilhou que realizou abortos por conta de algumas gravidezes indesejadas. Contou que tomava chás que a impediam de dar continuidade às gestaçóes. Entretanto, na última vez que engravidou, ela disse que não conseguiu abortar, pois descobriu tardiamente que estava grávida e não sabia quem era o pai, devido a ter vários parceiros sexuais.

Eu já tinha tomado o chá, minha tia não deixava tomar pílula, na última vez não deu certo, acho que o tempo, sei lá, eu tomei, era uma bruxa que dava o chá, eu era danada, gostava de sair, minha filha nasceu, eu chorava muito, pela doença, cheguei no hospital balançando minha filha, assim, sem estar com ela. (Antônia).

Após o parto, Antônia não conseguiu desempenhar as funções de maternagem, afirmando não conseguir realizar os cuidados necessários à criança. Passados três meses do nascimento de sua filha, os sintomas depressivos foram se intensificando, teve surtos frequentes de choro e impulsividade, e foi internada no manicômio, após entregar a bebê para adoção. É possível observar que Antônia não conseguiu desempenhar o papel de boa filha, boa esposa e boa mãe que the era naturalmente esperado pelo fato de ser mulher. A gestação foi indesejada, e após o nascimento, aparentemente, não conseguiu lidar com a condição de ser mãe. Devido aos seus comportamentos "inadequados", não poderia mais conviver em sociedade e, por isso, as relaçóes, os laços sociais e familiares foram rompidos em busca da normatização de comportamentos esperados. Seu destino foi o manicômio. Além do mais, vale problematizar a questáo do aborto presente na vida de muitas mulheres, entendendo que, na estrutura da sociedade capitalista, patriarcal e racista, o corpo das mulheres está a serviço da lógica de produção, ou seja, servir ao trabalho doméstico, à manutençáo do lar e da vida humana, sendo necessário o cumprimento dos papeis que lhes são fortemente impostos: o de mãe e esposa.

O corpo da mulher é visto como o corpo para a reprodução e maternidade. Especialmente para as mulheres negras, trata-se de um corpo que está ali para satisfazer os desejos sexuais, muitas vezes, sendo violado pelo estupro, violência esta fortemente naturalizada pela sociedade.

Outra questão relevante aqui se refere à esterilização das mulheres pobres, que acompanha uma concepção de higienização e limpeza social. No caso das mulheres que possuem transtornos mentais, presume-se que não devam gerar filhas/os. Desde a entrada nos manicômios, é comum a aplicação de injeções de anticoncepcionais. E 
quando questionadas sobre essa prática, ainda presente na rotina da RT, as cuidadoras afirmam que é para a proteção das mulheres, no sentido de náo engravidarem, pois não teriam condições de desempenhar a função da maternagem, o que mostra a reprodução da negação histórica da autonomia e escolha no caso de mulheres consideradas "loucas". Antônia transgride em sua sexualidade, ao afirmar:

Eu sempre fui danada, gosto de namorar, no manicômio não podia namorar, lá só tinha mulher tamém, e eu acho errado, pela força divina eu conheci J. no V., ele é um urso, me trata bem. (Antônia, maio de 2017).

Percebe-se, a partir das análises feitas, que a loucura feminina transformou-se a transgressão social ou moral em doença mental, por meio de discursos daqueles que detêm o poder, seja ele político, religioso, médico, jurídico ou até mesmo familiar. Além disso, cabe refletir que é vigente um senso de moralidade, construído historicamente por bases cristâs e que dialoga com a ideologia burguesa, que costuma classificar os indivíduos como "bons" ou "maus", em especial as mulheres, de acordo com suas atitudes, favorecendo a construçáo de um pensamento maniqueísta que gera a invisibilidade das contradiçôes sociais e individualiza os problemas, no qual a minoria é oprimida.

\section{CONSIDERAÇÓES FINAIS}

Os resultados da pesquisa demonstraram a presença e ramificação dos dispositivos de controle da sexualidade e da feminilidade no manicômio e, também, fora dele, o que foi evidenciado pelos diversos mecanismos que levam à infantilização e à tutela das moradoras. Ressalta-se, também, que esses processos devem ser entendidos a partir de uma abordagem interseccional, que leve em conta a discussão da saúde mental em suas interfaces com as questôes de gênero, classe e raça.

Pode-se afirmar que a relação entre mulheres e loucura deve ser destacada também como uma questáo social, pois aponta para as relações de gênero, culturais e morais, levando em consideração nosso país, extremamente machista e misógino, que também carrega uma herança escravocrata, na qual o corpo da mulher ainda é visto como mercadoria, visão reforçada pela grande mídia e que incita a desvalorização da mulher, reduzindo-a meramente à sua sexualidade e atribuindo distúrbios de saúde mental - por exemplo, a histeria - em qualquer situação que contrarie os argumentos machistas, sexistas e racistas.

Portanto, entende-se que o movimento antimanicomial, que visa garantir a liberdade como forma de tratamento para questóes subjetivas e psíquicas, deveria estar fortemente relacionado ao movimento feminista, já que a lógica manicomial também é usada para reprimir e normatizar as diferenças de gênero. $\mathrm{O}$ movimento da luta antimanicomial busca não apenas a desativação do manicômio como instância física, mas acabar com o poder manicomial e suas estratégias de controle. Portanto, pensar a luta antimanicomial sem considerar as questôes de gênero, classe e raça pode ser arriscado, no sentido de reproduzir violências e de ser subserviente aos interesses racistas e patriarcais. De acordo com Martins et al. (2017), o lema "Por uma sociedade sem manicômios" se vincula à luta pela transformação da sociedade capitalista, mas deve incluir, também, a luta contra o machismo e o racismo. Deve-se atentar, ademais, ao fato que o racismo pode ser (re)produzido, se for abandonada a discussáo da branquitude enquanto privilégio racial, invisibilizando as interseçôes de gênero e raça. No Brasil, negras/os e as/ os indígenas sofrem racismo, extermínio e invisibilização. Ao se ampliar a discussão para as questôes de saúde mental, considerando o histórico das pessoas que foram estigmatizadas como "loucas", é muito provável que se identifique que grande parte das pessoas internadas era negra e de camadas populares, reflexo significativo de nossa herança escravocrata.

É urgente, enfim, refletir sobre nossas lutas no campo da saúde mental, incluindo a discussão do lugar racializado da mulher. Falar e problematizar o racismo exige a reflexão acerca dos lugares que ocupamos, das nossas práticas, e o reconhecimento do lugar privilegiado que as mulheres brancas ocupam. Ser antimanicomial é almejar romper com todos os paradigmas presentes numa sociedade marcantemente manicomial, mas também racista e misógina. De acordo com Roeder (2016), faz-se necessário construir políticas que articulem gênero e saúde mental, possibilitem a comunicação com as diversas áreas de conhecimento e levem em consideração os princípios da equidade e da integralidade nas açóes.

Finalmente, ressalta-se a importância de se refletir e proporcionar outros diálogos no campo da saúde mental que possam contemplar as questôes de gênero, raça, classe e demais categorias, para que seja possível se pensar sobre a desinstitucionalização de forma plena, de forma a se acabar com lógicas segregacionistas, desumanas e opressoras. Almeja-se, também, que profissionais da saúde, pesquisadoras/es e militantes estejam cientes do compromisso social, sendo necessária e urgente a busca 
por estratégias e potencialidades para que a luta em busca de uma sociedade mais justa e igualitária continue, na qual a liberdade seja um elemento central no cuidado em relação às pessoas consideradas loucas.

\section{REFERÊNCIAS}

BARDIN, Laurence. Análise de Conteúdo. Lisboa: Ediçôes 70, 1979.

BEAUVOIR, Simone de. O segundo sexo: fatos e mitos. São Paulo: Difusão Européia do Livro, 1980. V. 1.

BRAH, Avtar. Diferença, diversidade, diferenciação. Cad. Pagu, Campinas, n. 26, p. 329- 376, jun. 2006.

BRASIL. Secretaria de Atenção à Saúde. Departamento de Açóes Programáticas Estratégicas. Residências terapêuticas: o que são, para que servem. Brasília: Ministério da Saúde, 2004.

CHESLER, Phyllis. Women and Madness. New York: Doubleday, 1972.

CUNHA, Maria Clementina Pereira O espelho do mundo: Juquery, a história de um asilo. São Paulo: Paz e Terra, 1986.

DAVIS, Angela. Mulheres, raça e classe. São Paulo: Boitempo, 2016

ENGEL, Magali. Psiquiatria e Feminilidade. In: DEL PRIORE, Mary (Org). História das Mulheres no Brasil. São Paulo: Contexto, 2006. p. 322-361.

GARCIA, Carla Cristina. Ovelhas na névoa: um estudo sobre as mulheres e a loucura. Rio de Janeiro: Rosa dos Tempos, 1994.

GARCIA, Marcos Roberto Vieira. A mortalidade nos manicômios da região de Sorocaba e a possibilidade da investigaçáo de violaçóes de direitos humanos no campo da saúde mental por meio do acesso aos bancos de dados públicos. Rev. psicol. polít., São Paulo, v. 12, n. 23, p. 105-120, jan. 2012

HOOKS, Bell. Intelectuais Negras. Revista Estudos Feministas, Florianópolis, v. 3, n. 2, p. 464, jan. 1995.

MARCINIK, Georgia Grube; MATTOS, Amana Rocha. Branquitude e racialização do feminismo: um debate sobre privilégios. In: OLIVEIRA, João Manuel de; AMÂNCIO, Lígia (Orgs.). Géneros e sexualidades: Interseçóes e Tangentes. Lisboa: Centro de Investigação e de Intervenção Social (CIS-IUL), 2017. p. 159-173.

MARTINS, Beatriz Adura et al. (Ainda) Por uma sociedade sem manicômios: experiências do Núcleo Estadual da Luta Antimanicomial do Rio de Janeiro. O Social em Questão, Rio de Janeiro, ano XX, n. 37, p. 221-238, jan./abr. 2017.
MOMBERG, Thaiga. Entre lírios e delírios: a (des) institucionalização e as (re) invençóes do feminino na saúde mental de Sorocaba. 2018. 84 f. Dissertação (Mestrado em Educação) - Centro de Ciências Humanas e Biológicas, Universidade Federal de São Carlos, Sorocaba.

PERROT, Michele. Minha história das mulheres. São Paulo: Contexto, 2007.

ROEDER, Maika Arno. Gênero e Saúde Mental nos Serviços Residenciais Terapêuticos: fragmentos de vidas contidas. São Paulo: Phorte, 2016.

ROTELLI, Franco; AMARANTE, Paulo Duarte de Carvalho. Reformas psiquiátricas na Itália e no Brasil: aspectos históricos e metodológicos. In: BEZERRA JR., Benilton; AMARANTE, Paulo Duarte de Carvalho (Orgs.). Psiquiatria sem hospício: Contribuições

SANTOS, Walkyria Chagas da Silva. A mulher negra brasileira. Revista África e Africanidades, Rio de Janeiro, ano 2, n. 5, p. 1-5, maio 2009.

SCOTT, Joan Wallach. Gênero: uma categoria útil de análise histórica. Educação \& Realidade, Porto Alegre, v. 20, n. 2, p. 71-99, jul./dez. 1995

SOUZA, Jaqueline, KANTORSKI, Luciane Prado, VILLAR, Margarita Antônia. Análise documental e observação participante na pesquisa em saúde mental. Revista Baiana de Enfermagem, v.25, n.2, p. 2218, 2011

VACARO , Juliana Suckow. A Construção do Moderno e da Loucura: Mulheres no. Sanatório Pinel de Pirituba (1929 - 1944). 2011. 63 f. Dissertação (Mestrado em História Social) - Faculdade de Filosofia, Letras e Ciências Humanas, Universidade de São Paulo, São Paulo.

VALVERDE, Dayana Lima Dantas. Reforma Psiquiátrica: Panorama Sócio-histórico, Político e Assistencial. Rede PSI, 21 nov. 2010.

\section{Endereço para correspondência:}

UFSCar - Universidade Federal de São Carlos

Rod. Washington Luiz, s/n,

São Carlos - SP,

CEP: 13565-905,

Thaiga Danielle Momberg Silva

thaigamomberg@hotmail.com

Recebido em 24/08/2018

Aceito em 17/10/2018 


\title{
Transtornos Mentais Comuns entre Trabalhadores do Sistema Prisional
}

\author{
Common Mental Disorders among Prison Officers
}

\author{
Ana Izabel Oliveira Lima ${ }^{1}$ \\ Universidade Potiguar - UNP \\ Magda Dimenstein ${ }^{2}$ \\ Universidade Federal do Rio Grande do Norte
}

\section{Resumo}

Investigou-se a incidência de Transtorno Mental Comum entre agentes penitenciários vinculados às instituiçóes prisionais do estado de Rio Grande do Norte. Dos 903 agentes, 403 (44,6\%) responderam ao SRQ-20 (Self-ReportingQuestionnaire), representando 19 das 34 unidades prisionais existentes. Os resultados indicam incidência de $23,57 \%$ de casos indicativos de TCM entre os trabalhadores. Como determinantes sobressaem o tipo de unidade prisional, estar em relacionamento estável, possuir outra ocupação na área de segurança, ter mais de 10 anos de profissão e dobrar de turno mais de uma vez no último mês. Destaca-se a relação entre vulnerabilidade, saúde mental e trabalho. Tal articulação deve ser compreendida para além do discurso biomédico, incorporando outros saberes ligados aos sujeitos que são afetados pelo sofrimento.

Palavras--chave: Sistema Prisional; Saúde Mental; Vulnerabilidade..

\begin{abstract}
The work investigates the incidence of common mental illnesses among correctional officers in the state of Rio Grande do Norte. 403 (44,.6\%) prison officers, of 903 in Rio Grande do Norte, answered the SRQ-20 (Self-Reporting Questionnaire), representing 19 prison units out of a total of 34 . The results point to a $23.57 \%$ incidence of suspected cases. Determinants factors of this situation are: the type of prison unit, a stable relationship, another working as a security, working for more than 10 years, and doubling of the number of shifts more than once in one month. The relationship between vulnerability, mental health and word can be understood beyond the traditional technical-scientific discourse, incorporating other knowledge related to the subjects that are affected by the suffering.
\end{abstract}

Keywords: Prison System; Mental Health; Vulnerability.

Os transtornos mentais e comportamentais estão entre as principais causas de absenteísmo, causando perdas anuais médias de 200 dias de trabalho. Tais quadros são frequentes e comumente incapacitantes. Os trabalhadores com sofrimento mental demoram mais tempo para se reinserir no mercado de trabalho do que trabalhadores com outras patologias. $\mathrm{O}$ impacto socioeconômico desses transtornos é relevante e ações de prevenção de tais agravos ainda representam desafios aos programas de promoção à saúde (Nieuwenhuijsen, Verbeek, Boer, Blonk, \& Van Dijk, 2006; Brasil, 2014).

Dentre as variáveis associadas ao afastamento do trabalho por adoecimento, independentemente de sua duração ou diagnóstico, destacam-se: aspectos sociodemográficos (sexo feminino, idade avançada, ser solteiro, baixa escolaridade, baixo padrão socioeconômico); fatores adversos externos ao trabalho (dificuldades financeiras) e condiçôes de trabalho (turnos vespertino-noturno e noturno, tipo de emprego e tempo na função, mais de um vínculo de trabalho e ter vínculo de trabalho como servidor público, trabalho com cargas físicas extenuantes, ritmo acelerado de trabalho, condições ambientais desfavoráveis) (Seligmann-Silva, 2011; Lhuilier, 2014).

Alguns sintomas não preenchem critérios para sua caracterização como transtornos mentais específicos, mas provocam sofrimento psíquico de caráter incapacitante, como é o caso dos Transtornos Mentais Comuns (TMC). Essa expressão criada por Goldberg e Huxley (1992) designa sintomas de insônia, fadiga, irritabilidade, esquecimento, dificuldade de concentração e queixas somáticas, que podem gerar incapacitação funcional (Assunção \& Silva, 2013).

Diferentes quadros de TMC têm sido qualificados como motivadores de Licenças para Tratamento de Saúde (LTS) e de benefícios de saúde e previdenciários. Os transtornos do humor, incluindo os quadros depressivos, são os mais frequentes Transtornos Mentais Comuns relacionados ao trabalho em estudos epidemiológicos no

\footnotetext{
${ }^{1}$ Doutora em Psicologia pela UFRN. Professora do curso de Psicologia da UNP.

2 Profa. Titular do Depto. de Psicologia da UFRN
} 
Brasil entre 2008 e 2011 (Silva Júnior \& Ficher, 2014). Isso indica a necessidade de maior atenção às condições laborais na medida em que os agravos à saúde relacionados à ocupação restringem a autonomia e capacidade produtiva dos trabalhadores.

Todavia, alguns setores se destacam no que se refere ao impacto na saúde dos trabalhadores. O sistema prisional tem se configurado como um problema de grande magnitude na atualidade. Segundo o Sistema Integrado de Informaçóes Penitenciárias (INPOFEN) do Ministério da Justiça (Brasil, 2015), o Brasil ocupa a terceira posição no ranking mundial relacionada à população carcerária (775.668 pessoas presas). Inúmeros são os problemas que atravessam esse sistema: questôes relacionadas à saúde dos detentos, altos índices de reingresso, dificuldade de reinserçáo sociolaboral de ex detentos.

Nesse sentido, o agente de segurança penitenciária - que tem a função de efetuar a segurança da Unidade Penal em que atua, vigiar, fiscalizar, inspecionar, revistar e acompanhar os presos, zelando pela ordem e segurança deles - está submetido a um alto risco de sofrimento mental, tendo em vista as condições infraestruturais de trabalho, as dificuldades para a realização das atividades, jornada excessiva, perda de liberdade e predominância dos sentimentos e sensaçóes típicos de tensionamento devido à insegurança, ansiedade e sensaçáo de estar sendo vigiado (Lourenço, 2010).

Por atuarem diretamente com os detentos, e por serem vistos por estes como os responsáveis pelo confinamento, os agentes penitenciários estáo constantemente expostos às situaçôes de estresse desencadeadas por agressôes, ameaças e possibilidades de rebeliôes, momento em que sua própria integridade física está em jogo (Fernandes, et al. 2002). Dessa forma, os agentes têm seus cotidianos marcados pelo contato direto com situações de violência, tortura, agressão, vigilância e outros mecanismos utilizados para punir o desvio, adequar e manter a ordem social, estando ligados assim, desde sempre, ao encarceramento, à exclusão e à violência (Lourenço, 2010). Ademais, o trabalho nas prisóes é, em geral, precário e insalubre. Predominam condiçóes propícias à proliferação de epidemias e desenvolvimento de patologias. Há uma prevalência considerável de casos de DST/AIDS, tuberculose, pneumonias, dermatoses, hepatites, etc. (Brasil, 2015). Dessa forma, a classe de agente penitenciário é considerada uma ocupação arriscada e estressante.

Nos últimos anos, foram feitas algumas pesquisas sobre a saúde física e psicológica dessa categoria (Lourenço, 2010; Vasconcelos, 2000). Entretanto, a despeito das evidências relacionadas às condiçôes inadequadas no processo de trabalho, ainda há poucos estudos que informam sobre o adoecimento destes trabalhadores marcados pela vulnerabilidade do/no cárcere (Lourenço, 2010).

Para compreender a interface entre o trabalho e a vida dos agentes penitenciários, é necessário ter uma compreensáo ampliada dos problemas que perpassam sua realidade de trabalho. Para isso, deve-se considerar sua complexidade a partir incorporação de conceitos como o de vulnerabilidade, o qual expressa "o potencial de adoecimento relacionados a todo e cada indivíduo que vive em um certo conjunto de condiçóes" (Ayres et al., 2003, p. 40).

Buscando ampliar o conceito de vulnerabilidade, os autores indicam três planos interdependentes de determinação e, consequentemente, de apreensão da vulnerabilidade de indivíduos, grupos sociais e coletividades. Essas três dimensôes são: individual, social e programática. A individual abrange o campo das relaçôes profissionais, situação psicoemocional, suporte social e valores vigentes no meio. Já a dimensão social trata principalmente de salários e níveis de renda, relaçóes de gênero e normas sociais. A programática aborda a vulnerabilidade no tocante à definição de políticas específicas para a saúde e sua organização e respeito, proteção e promoção dos direitos humanos (Razzouk, Lima \& Cordeiro, 2016).

Dessa forma, o aprofundamento e utilização do conceito de vulnerabilidade para pensar a realidade local é fundamental, pois permite enxergar possibilidades de produções singulares na relação entre saúde e trabalho dos agentes. Diante dos desafios de mudança a curto prazo da lógica precária de trabalho desses profissionais, assim como da implantação de projetos terapêuticos articulados às situaçóes de trabalho, essa pesquisa foi realizada com objetivo de mapear a incidência de transtornos mentais comuns (TMC) em agentes penitenciários trabalhadores do sistema prisional de um Estado do Nordeste brasileiro e ampliar a visibilidade da área para essa problemática.

\section{MÉTODO}

Esta pesquisa caracteriza-se como um estudo quantitativo, baseado na utilização de protocolos estabelecidos e técnicas específicas, que fornece uma descrição quantitativa ou numérica de tendências, atitudes ou comportamentos de uma população ao estudar uma amostra dela (Creswell, 2007). 


\section{Local e participantes}

Após autorização pela gestão do sistema prisional estadual do Rio Grande do Norte, bem como pelo comitê de ética local (parecer número 760.701), foram selecionadas as unidades prisionais e os participantes da pesquisa. O Estado conta com 34 unidades prisionais (09 penitenciárias estaduais, 01 penitenciária federal, 01 unidade psiquiátrica de custódia e tratamento, 03 cadeias públicas e 20 Centros de Detenção Provisória/ CDP), aproximadamente 7.200 presos, custodiados por 902 agentes penitenciários. O CDP tem por função custodiar presos temporariamente. É uma unidade de ingresso e classificaçáo para o sistema prisional estadual, diferenciando-se das penitenciárias que se destinam aos presos já condenados para o cumprimento de pena de reclusão em regime fechado ou semiaberto.

\section{Critérios de inclusão}

(1) unidades prisionais destinadas a presos já sentenciados e (2) CDPs com maiores índices de fugas, motins e intervençôes da vigilância sanitária diante das condiçôes estruturais e de insalubridade. Tomamos como base os dados fornecidos pela Secretaria de Estado da Justiça e da Cidadania/SEJUC. Das 34 instituiçóes, participaram do estudo 19 unidades prisionais, sendo 12 penitenciárias: 06 localizadas na capital, 04 da região oeste do estado, 01 na regiáo agreste do estado e 01 na regiáo central do estado; 01 Unidade Psiquiátrica de Custódia e Tratamento (localizada em Natal), 01 Penitenciária Federal (localizada em Mossoró) e 05 Centros de Detenção Provisória de Natal.

\section{Participantes}

O total de agentes penitenciários no estado é de 902 servidores distribuídos nessas unidades. Destes, 403 aceitaram participar da pesquisa através da assinatura de Termo de Consentimento Livre e Esclarecido (TCLE). Constituíram-se em critérios de exclusão: a recusa em participar da pesquisa e existência de condição médica ou psicológica que impossibilitasse a participação.

\section{Instrumentos}

Utilizamos o Self-Reporting Questionnaire (SRQ20) desenvolvido pela Organização Mundial de Saúde (1994) para rastreamento de TMC. O instrumento consiste em vinte questôes relacionadas à condição de saúde mental nos últimos trinta dias, com resposta simples (sim/não). Cada resposta SIM equivale a um ponto, podendo variar, portanto, de zero (nenhuma probabilidade de TMC) a vinte (extrema probabilidade de TMC). Consideramos nessa pesquisa o ponto de corte $\geq 7$ para considerar indicativo de Transtorno Mental Comum (Gonçalves, Stein \& Kapczinsk, 2008). Além disso, junto ao SRQ-20, foi utilizado um questionário sociodemográfico com intuito de obter dados para compor o perfil geral dos agentes penitenciários: sexo, renda, estado civil, escolaridade e obter informaçóes sobre o trabalho e cuidado com a própria saúde mental.

\section{Procedimentos}

O grupo de pesquisadores - formado por uma psicóloga e cinco graduandos em psicologia - passaram por treinamento antes de iniciar a coleta de dados, bem como foi realizada etapa piloto com a participação de 15 agentes penitenciários da Unidade Psiquiátrica de Custódia e Tratamento. A coleta de dados ocorreu nos locais de trabalho dos agentes penitenciários entre os meses de outubro de 2014 e janeiro de 2015.

\section{Análise de dados}

Os dados coletados foram analisados através do programa SPSS (StatisticalPackage for the Social Sciences - pacote estatístico para as ciências sociais, versão 20) em termos de frequência absoluta e percentual, utilizando o teste Qui-quadrado $\left(x^{2}\right)$ para investigar se existe relação de dependência entre as variáveis contrastadas. Esse teste investiga a associação entre as variáveis contrastadas comparando os valores observados (valores reais) com os valores que deveriam ser esperados considerando que as variáveis são independentes. Foi ainda utilizado o teste Kruskal Wallis para avaliar a hipótese de que várias amostras têm a mesma distribuição. Ou seja, no caso desta pesquisa, este teste indicou a distribuição das respostas positivas do teste SRQ-20 em relaçáo às demais variáveis, evidenciando se existem variáveis que estão relacionadas ao aumento de respostas positivas e, consequentemente, a maior probabilidade do desenvolvimento de transtornos mentais comuns. Nos testes aplicados, o índice de significância adotado foi de 5\%.

\section{RESULTADOS}

\section{Perfil dos Participantes}

Do total de 903 agentes do Estado, 403 agentes penitenciários participaram desta pesquisa, dos quais 66 
estão lotados nos 05 Centros de Detenção Provisória e

337 em 14 penitenciárias. $\mathrm{O}$ perfil de tais agentes pode ser observado na Tabela 1 .

\section{Tabela 1}

Perfil dos participantes

\begin{tabular}{|c|c|c|}
\hline Variáveis & Especificações & Frequência (\%) \\
\hline \multirow[t]{2}{*}{ Unidade Prisional } & Centro de Detenção Provisória & $66(16,4)$ \\
\hline & Penitenciária & $337(83,6)$ \\
\hline \multirow[t]{2}{*}{ Sexo } & Masculino & $365(90,6)$ \\
\hline & Feminino & $38(9,4)$ \\
\hline \multirow[t]{3}{*}{ Tempo de trabalho } & 0 a 5 anos & $215(53,3)$ \\
\hline & 5 a 10 anos & $30(7,4)$ \\
\hline & 10 a 15 anos & $158(39,2)$ \\
\hline \multirow[t]{7}{*}{ Idade } & 20 a 25 anos & $7(1,7)$ \\
\hline & 25 a 30 anos & $79(19,6)$ \\
\hline & 30 a 35 anos & $106(26,6)$ \\
\hline & 35 a 40 anos & $87(21,6)$ \\
\hline & 40 a 45 anos & $69(17,1)$ \\
\hline & 45 a 50 anos & $43(10,7)$ \\
\hline & 50 a 55 anos & $12(3)$ \\
\hline \multirow[t]{3}{*}{ Estado Civil } & Solteiro & $115(28,5)$ \\
\hline & Casado ou em união estável & $257(63,7)$ \\
\hline & Separado & $31(7,7)$ \\
\hline \multirow[t]{4}{*}{ Número de filhos } & Não tem & $122(30,3)$ \\
\hline & 1 & $117(29)$ \\
\hline & 2 & $112(27,8)$ \\
\hline & 3 ou mais & $52(12,9)$ \\
\hline \multirow[t]{6}{*}{ Religião } & Católico & $238(59,1)$ \\
\hline & Protestante & $77(19,1)$ \\
\hline & Espírita & $11(2,7)$ \\
\hline & Umbanda/candomblé & $2(0,5)$ \\
\hline & Sem religião & $17(4,2)$ \\
\hline & Outra & $58(14,4)$ \\
\hline \multirow[t]{5}{*}{ Renda Familiar } & 2 a 3 salários mínimos & $22(5,5)$ \\
\hline & 4 a 5 salários mínimos & $214(53,1)$ \\
\hline & 6 a 7 salários mínimos & $62(15,4)$ \\
\hline & 8 a 9 salários mínimos & $38(9,4)$ \\
\hline & Acima de 10 salários mínimos & $67(16,6)$ \\
\hline \multirow[t]{4}{*}{ Escolaridade } & Ensino médio completo & $85(21,1)$ \\
\hline & Ensino Superior incompleto & $91(22,6)$ \\
\hline & Ensino superior completo & $205(50,6)$ \\
\hline & Pós-Graduação & $22(5,5)$ \\
\hline
\end{tabular}




\begin{tabular}{ccc}
\hline Possui outra ocupação? & Sim & $88(21,8)$ \\
& Não & $315(78,2)$ \\
\hline Qual é essa outra ocupação? & Na área de segurança & $15(17,0)$ \\
& Outra área & $73(83,0)$ \\
\hline Dobra de turno no último mês & Nenhuma vez & $260(64,5)$ \\
& 1 vez & $41(10,2)$ \\
& 2 vezes & $30(7,4)$ \\
Recursos de cuidado em saúde & 3 vezes & $47(11,7)$ \\
mental já procurados & 4 ou mais vezes & $25(6,2)$ \\
& Nunca procurou & $310(76,9)$ \\
& Atenção básica & $4(1,0)$ \\
& CAPS & $2(0,5)$ \\
& Psiquiatra, Psicólogo & $70(17,4)$ \\
& Grupo da igreja & $174,2)$ \\
\hline
\end{tabular}

Incidência de Transtorno Mental Comum entre agentes penitenciários

A incidência de Transtornos Mentais Comuns na amostra geral foi de $23,57 \%$ (ver Tabela 2), percentual dentro da média encontrada em alguns estudos realizados no Brasil (entre 28,7\% a 50\%) (Razzouk, Lima \& Cordeiro, 2016;Rodrigues, Rodrigues, Oliveira, Laudano \& Sobrinho, 2014).

\section{Tabela 2}

Incidência de Transtornos Mentais Comuns por tipos de Unidade prisional

\begin{tabular}{|c|c|c|c|c|}
\hline & & & $\mathrm{N}$ & $\%$ \\
\hline \multirow[t]{3}{*}{ Penitenciária } & Ponto de corte & abaixo do ponto de corte & 256 & $75 \%$ \\
\hline & & acima do ponto de corte & 81 & $24 \%$ \\
\hline & & Total & 337 & $100 \%$ \\
\hline \multirow[t]{3}{*}{$\mathrm{CDP}$} & Ponto de corte & abaixo do ponto de corte & 52 & $78 \%$ \\
\hline & & acima do ponto de corte & 14 & $21 \%$ \\
\hline & & Total & 66 & $100 \%$ \\
\hline \multirow[t]{3}{*}{ Total } & Ponto de corte & abaixo do ponto de corte & 308 & $76 \%$ \\
\hline & & acima do ponto de corte & 95 & $23 \%$ \\
\hline & & Total & 403 & $100 \%$ \\
\hline
\end{tabular}

Como pode-se observar na Tabela 2, não há diferença significativa entre os percentuais de agentes que ultrapassaram o ponto de corte nas penitenciárias (24,04\%) em comparação com os agentes dos Centros de Detenção Provisória $(21,21 \%)$. Os trabalhadores que apresentam indicativo de TMC trabalham, em sua maioria, na Unidade Psiquiátrica de Custódia e Tratamento $(43,75 \%)$, na Penitenciária Estadual da região central do estado $(46,51 \%)$ e na Penitenciária Federal (36\%). O Centro de Detenção Provisória que apresentou maior índice de TMC é o da zona sul da capital (26,67\%).

Dos agentes que estão acima do ponto de corte, ou seja, que têm indicativo de ter Transtorno Mental Comum, 48,42\% trabalham no sistema entre 10 a 15 anos, $71,5 \%$ têm entre 30 e 45 anos, $62,1 \%$ estão casados, $62,1 \%$ tem de 1 a 2 filhos, $50 \%$ são católicos, $45,2 \%$ tem ensino superior completo, $30,5 \%$ possuem outra ocupação, $31,0 \%$ possuem outra ocupação na área de segurança, 33,6\% dobraram de turno no último mês, $62,1 \%$ nunca procuraram cuidado em saúde mental. 
Em relação às dimensões do SRQ-20, foi possível perceber que quase metade dos agentes afirmou dormir mal $(40 \%)$, que o trabalho causa sofrimento diário $(40 \%)$ e que se sente constantemente nervoso, tenso e preocupado (43\%), atingindo maiores pontuaçôes em questôes relacionadas ao humor depressivo-ansioso $(59,55 \%$ - dor de cabeça, dorme mal, desconforto estomacal, má digestão, falta de apetite, tremores) e sintomas somáticos $(53,35 \%$ - nervoso, assustam-se com facilidade, tristeza, choram com mais frequência).
Com relação ao tempo de trabalho e dobra de turno (Tabela 3), embora o teste do qui quadrado revele $p$ maior que 0,05 , foi detectada incidência de TMC em sujeitos com tempo de trabalho entre 10 e 15 anos de profissão e que dobraram de turno, corroborando com os achados de Alves (2009), Fernandes et al. (2002), Lourenço, (2010) e Souza e Rumin (2013),que evidenciaram maior incidência de TMC entre os agentes penitenciários que permanecem mais tempo no trabalho.

\section{Tabela 3}

Fatores associados à TMC

\begin{tabular}{cc}
\hline Variável & valor- $\boldsymbol{p}^{*}$ \\
\hline Ter outra ocupação & 0,019 \\
Trabalhar na área de segurança & 0,014 \\
10 a 15 anos de trabalho & 0,09 \\
Dobra de turno & 0,34 \\
Relacionamento estável & 0,02 \\
Já ter buscado cuidado em saúde mental & 0,018 \\
\hline
\end{tabular}

*Adotando o Intervalo de confiança de $95 \%$, a probabilidade de significância, valor-p, deve ser menor ou igual a 0,05

A partir do teste estatístico Kurskal Wallis foi encontrada diferença entre a média do número de respostas positivas no SRQ-20 entre os agentes de uma das Penitenciárias Estaduais que ficam localizadas na capital do Estado quando comparado com os agentes da Unidade de Custódia e Tratamento Psiquiátrico e a Penitenciária Estadual que fica na região central do Estado $\left(X^{2}(13)=45,45 ; p=0,00\right)$.

Foi possível observar que a unidade prisional localizada na capital do Estado apresenta menos respostas positivas por participante do que a Unidade Psiquiátrica de Custódia e Tratamento e a Penitenciária Estadual da região central do estado. Ela é destinada a presos de maior periculosidade, tem um número menor de presos em comparaçáo com as demais unidades prisionais, pouco convívio dos agentes com os apenados, além de terem critérios mais claros em relação às revistas das celas e dos visitantes e à busca de equipes extras para transporte de presos, pois, segundo eles, ajudam a diminuir a sensação de insegurança.

Constatou-se ainda diferença entre o número de respostas positivas no SRQ-20 em relação ao tempo de trabalho $(\mathrm{p}=0,016)$, ter outra ocupação $(\mathrm{p}=0,003)$ e a ocupação em questáo ser na área de segurança $(\mathrm{p}=0,017)$, apontando que quanto maior o tempo de trabalho, mais respostas positivas.

\section{DISCUSSÃO}

\section{O trabalho do agente como produtor de sofrimento}

De acordo com os resultados deste estudo, os agentes penitenciários que apresentaram indícios de TMC tem outra ocupação, dobram mais frequentemente de turno, assim como estão há mais tempo na função de agente penitenciário. Dados corroborados por outros estudos que investigaram a relação entre trabalho e saúde mental no mesmo público (Souza $\&$ Rumin, 2013; Lourenço, 2010). De acordo com tais estudos, é evidente a relação entre os agravos em saúde e as condições e organização do trabalho no sistema prisional.

De acordo com Lourenço (2010), alguns fatores estão associados à incidência de TMC, como eventos de vida, saúde e trabalho estressantes, dificuldades financeiras, assim como imersão em contexto de violência. 
Fatores esses que ratificam nossos resultados quanto à associação entre condições precárias e processos opressivos de trabalho e sofrimento mental, com destaque para sintomas depressivos-ansiosos (nervosismo, tensão, agitação, tristeza), sintomas somáticos (dor de cabeça, insônia, desconforto estomacal, má digestão, falta de apetite, entre outros) e pensamentos depressivos (sentimento de inutilidade, ideação suicida, perda de interesse na vida).

Em todas as unidades prisionais (com exceção da Penitenciária Federal, já que é de segurança máxima e obrigatoriamente possui estrutura adequada para seu funcionamento), há um cenário de desorganização, abandono, violaçáo e sofrimento dos trabalhadores do sistema prisional, já descrito em outros estudos (Souza \& Rumin, 2013; Vasconcelos, 2000). Durante as visitas, era recorrente o discurso de desamparo no que se refere às condiçôes para realização do trabalho, visto que os próprios agentes compram munição, fardamento, câmeras, medicamentos para os presos. A estrutura física das prisôes também é precária, sempre em péssimo estado de conservação, com moveis quebrados, instalações com fiações visíveis, esgoto à céu aberto e materiais inadequados para revistas. Reclamações em relação à comida - muitas vezes motivo de intoxicação alimentar - são constantes. Foi ainda possível constatar que as salas destinadas ao descanso dos agentes são menores que as celas dos detentos, não possuem ventilaçáo e apresentam forte evidência de mofo e sujeira. De acordo com a fala dos agentes: "é muito difícil alguém ter essa função e não adoecer”.

O trabalho do agente penitenciário é desgastante e humilhante, pois eles se sentem esquecidos pelo Estado e desvalorizados pela sociedade, o que afeta diretamente o desempenho e a saúde dessa classe de trabalhadores. Além disso, mudanças nos hábitos e comportamentos em decorrência do exercício da profissão marcaram os discursos dos agentes penitenciários: mudanças quanto à forma de falar, de se comportar, dificuldades em desenvolver novas relaçóes de amizade e de se relacionar com o cônjuge. Nota-se que o agente penitenciário é submetido cotidianamente a efeitos dessocializadores, pois sáo obrigados a uma adotar um outro modo de vida devido às características do trabalho, que podem gerar sentimentos de inferioridade, empobrecimento psíquico e despersonalização (Lourenço, 2010).

Desse modo, ao aprender o ofício, esses trabalhadores acabam por aprender um determinado modo de habitar o espaço da prisão. A formação de agentes penitenciários é marcada por um processo de militarizaçáo e produçáo de sujeitos violentos, violadores e violados. Mais do que uma decisão individual, a violência é sentida como característica do próprio processo de subjetivação pelo qual esses trabalhadores passam ao ingressar em outro universo de trabalho e vida.

Dessa forma, intimidações sofridas pelos trabalhadores durante o exercício de suas funçôes são relacionadas ao aumento de fadiga e estresse, depressão, tendências suicidas, ansiedade, queixas psicossomáticas, agressividade e outros sintomas, incluindo os transtornos do estresse pós-traumático (Assunção \& Silva, 2013). Gaulejac (2001) aponta que pessoas submetidas a diversas violências humilhantes tais como processos de estigmatização, coisificaçáo, dependência e perda de dignidade, podem apresentar sentimento de vergonha e de humilhação pela negação da sua condição de sujeito. Nesse sentido, algumas unidades prisionais se destacaram no que se refere à incidência de transtornos mentais comuns. Apresenta-se a seguir as reflexóes que podem ser feitas a partir de cada unidade.

$\mathrm{Na}$ Unidade Psiquiátrica de Custódia e Tratamento que se destina a inimputáveis e semi-inimputáveis, ou seja, incapazes de entender a ilicitude do fato,para cumprimento de medida de segurança - o relato dos agentes penitenciários evidencia a falta de treinamento para lidar com transtornos mentais. Cenário que obriga os agentes a utilizarem "muito mais a intuição e a experiência acumulada do que o treinamento que tiveram quando entraram" para conseguir desempenhar suas atividades.

Estudos como os de Fernandes et al. (2002) e Lourenço (2010) indicam problemas relacionados à formação profissional dessa categoria, pois embora exista uma capacitação formal, é comum um tipo de orientação informal que ocorre no dia a dia do trabalho, através do contato com profissionais mais antigos, sem conhecimento técnico específico e qualificado para a função. Isso gera insegurança, maior tensão nas tarefas, compromete os processos de trabalho no cárcere e gera sofrimento.

Se no Hospital de Custódia e Tratamento Psiquiátrico existe alta demanda aliada ao baixo controle sobre os processos de trabalho, na Penitenciária Federal tanto a demanda quanto o controle em relação ao trabalho são baixos, devido à rigidez dos procedimentos estabelecidos pelo Governo Federal na organização das condiçôes do trabalho.

Já em relação à Unidade Prisional da região central do Estado, é clara a sobrecarga de trabalho. Além de ser uma penitenciária destinada a presos já condenados, ainda faz a função de centro de detenção provisória para a qual são encaminhadas todas as pessoas detidas na região. Dessa forma, o trabalho é constantemente 
caracterizado pelos próprios agentes como adoecedor. Diante do medo de rebelióes e fugas, tendo em vista a dimensão da unidade, para os agentes é praticamente impossível conseguirem conter algum movimento de forma eficiente, gerando constante tensão.

A desvalorização profissional sobressai a partir das observaçôes de alguns agentes. É comum serem comparados a "cães de guarda", como se a única tarefa do agente fosse contenção física e disciplinar dos apenados. O próprio discurso privatizante e tecnológico do Sistema Penitenciário alega que os "novos" dispositivos de segurança e controle podem reduzir, senão eliminar, a necessidade dos agentes penitenciários (Alves, 2009).

Nesse sentido, tais julgamentos de valor sobre o trabalho contaminam o agente. Considerado como um "trabalho sujo", ou seja, tarefas física ou simbolicamente humilhantes, degradantes, tarefas que são sinônimo de transgressão dos valores morais e possuem baixa desejabilidade social ou representação social depreciativa - seja por razóes de riscos à saúde inerentes à atividade em questáo (como no caso dos coveiros, mantenedores de sistemas de esgotamento e armazenamento de dejetos sanitários, lixeiros e catadores de lixo), seja no caso de indesejabilidade social intrínseca ao tipo de atividade, apesar da aceitação social da ideia de sua necessidade e inevitabilidade, como é o caso da atividade dos agentes, tudo isso impacta na vida do trabalhador. Trata-se de profissóes ou tarefas que têm por objeto o negativo psicossocial (Lhuilier, 2014), ou seja, aquilo que é rejeitado e fica nos bastidores.

Das unidades prisionais que se destacaram, a última é o Centro de Detenção Provisória da zona sul da capital do estado. O CDP, que deveria ser uma unidade de ingresso e classificação para o Sistema Prisional Estadual, é, na verdade, carceragem instalada em antigas delegacias, inclusive abrigando presos já condenados (Brasil, 2015). De acordo com o relato dos agentes, há noites em que apenas um agente penitenciário está de plantão e dois policiais militares auxiliam na guarda. Em 2015, a Vara de Execuçóes Penais da capital decidiu pela interdição dessa unidade após constatar superlotação e problemas sanitários.

O trabalho nos CDPs é marcado pelo intenso convívio com os presos e tarefas de escolta seja para outra unidade prisional, seja para serviços de saúde. É um trabalho realizado entre corredores apertados, geralmente úmidos, quentes, malcheirosos, sujos e só parcialmente iluminados. Observamos então uma dupla penalização do agente penitenciário: a privação da liberdade e o precário estado de saúde que ele vive durante sua permanência no trabalho.

\section{Vulnerabilidade, saúde e trabalho do agente penitenciário}

O conceito de vulnerabilidade (Ayres et al., 2003) apresenta-se como extremamente potente para o fortalecimento de discussóes e reflexóes sobre o trabalho do agente penitenciário, considerando os três eixos: individual, social e programático, para evidenciar sofrimentos que vão além de questôes meramente individuais.

Ayres et al. (2003), ao expor as dimensôes de vulnerabilidade para o estabelecimento de análises de coletivos, destacam a dimensão individual relacionada à qualidade de informaçáo que os indivíduos dispóem sobre o problema, à capacidade de elaborar estas informaçóes e transformá-las em práticas de prevençáo e proteção da saúde. Nesse sentido, pode-se pensar que o processo de construção da identidade de agente penitenciário produz alteraçóes nos modos de vida e na subjetividade de cada trabalhador do sistema prisional, que desencadeiam sofrimentos, o engessamento na função/ vida de agente e incapacidade de elaboração de mecanismos de promoção/proteção à saúde, tal como foi possível constatar na pesquisa e nos relatos dos agentes.

Outro fato que demostra essa transformação é a diferença de comportamentos entre agentes com diferentes tempos de trabalho, aspecto que se sobressaiu nas conversas informais. Agentes com maior tempo se mostraram mais agitados, reclamam mais do dia a dia, relatam histórias de adoecimento, de quadros de transtornos mentais (surtos psicóticos, por exemplo), têm problemas com a família (se divorciaram algumas vezes), quase não têm lazer e, quando tem, preferem em ambientes fechados (beber com os colegas, jogar vídeo game, ping pong, jogar bola). Já os agentes com menor tempo de trabalho relatam que é um trabalho com muitas vantagens, como trabalhar $24 \mathrm{~h}$ e folgar $72 \mathrm{~h}$, o que proporciona maior tempo para sair com os amigos, frequentar a faculdade, sair com a esposa, dentre outras atividades. Fica evidente que quanto mais o tempo passa, o agente se encontra preso não somente ao presídio, mas também à uma vida atravessada pelo sofrimento.

Como citado anteriormente, a dimensão social relaciona-se às possibilidades de obter e elaborar informações, acesso aos meios de comunicação, escolarização, recursos materiais, influência nas decisôes políticas, enfrentamento de barreiras sociais, etc. Nesse quesito são claras as dificuldades vivenciadas pelos agentes de segurança penitenciária. $\mathrm{O}$ contexto de desvalorização profissional é evidente, o estigma e discriminação em relação à profissão. $\mathrm{O}$ discurso dos gestores das unidades deixa transparecer que um dos grandes responsáveis 
pelas fugas e desorganização das unidades prisionais é a figura do agente penitenciário, que devido à corrupçáo "permite que os presos façam o que quiserem dentro do presídio".

Outra questão importante diz da impossibilidade de transformar a própria realidade. Muitos agentes afirmaram querer voltar a estudar para buscar outro emprego, mas como necessitam de "bicos" para complementar a renda, náo conseguem estudar por falta de tempo. A dificuldade em ter acesso aos serviços de saúde também se faz presente nos discursos, devido à falta dinheiro para buscar um serviço na rede privada de saúde ou pelo medo de buscar cuidado nos serviços públicos e falar da profissáo, o que segundo os entrevistados, pode colocar em risco sua vida.

Dessa forma, a vulnerabilidade está na falta de acesso a certos bens materiais e de serviço. O componente programático refere-se aos recursos sociais e políticas públicas ligadas ao problema. Como fatores que poderiam ajudar para prevenir o adoecimento do agente penitenciário, tanto agentes quanto familiares e gestores indicam a necessidade de maior investimento por parte do governo na segurança das unidades, contratação de mais agentes penitenciários, operacionalização do plano de cargos e salários dos agentes, assim como a criação de um serviço de suporte em saúde mental especialmente para os trabalhadores da segurança pública.

Torna-se então necessário investir em um maior aprofundamento em discussóes acerca da operacionalização das políticas de saúde do trabalhador no Brasil, especialmente no que diz respeito à saúde mental, assim como em propostas de cuidado que podem ser desenvolvidas em articulação com os locais de trabalho e serviços da Atenção Primária, Psicossocial, da Assistência Social e demais dispositivos das redes de atençáo.

\section{CONCLUSÃO}

Essa investigação, que teve por objetivo investigar a incidência de transtornos mentais comuns entre agentes penitenciários, reafirmou a tese de que as consequências promovidas pelo trabalho no cárcere são degradantes. Assistimos à deterioração das condiçóes e processos de trabalho que se traduzem em um aumento vertiginoso de sofrimento, nas doenças profissionais e na insegurança. Instaura-se a lógica de desgaste, na qual o esgotamento profissional e o estresse são moedas correntes, já que a angústia de jamais fazer o suficiente, de não estar à altura das expectativas, de não preencher os objetivos, de não ver sentido e valorização no trabalho, de viver em um cárcere até mesmo fora do presídio é uma constante.

A discussóes aqui construídas foram orientadas por uma concepção de saúde mental que possibilite uma certa liberdade ao sujeito de modo que ele possa dialogar com as diversas instâncias sociais, como saúde, justiça e trabalho, sem se render a um discurso normativo, possibilitando um espaço para sua singularidade e modos de vida. "É importante destacarmos este aspecto de eterna criação e recriação das condiçóes de manutenção da saúde mental do sujeito" (Gama, Campos \& Ferrer, 2014).Dessa forma, a aproximação entre vulnerabilidade social e saúde mental deve ser trabalhada com elementos que extrapolem o discurso técnico-científico tradicional incorporando outros saberes ligados aos sujeitos que são afetados pelo sofrimento. Gama, Campos e Ferrer (2014) apontam que o papel do profissional técnico de saúde precisa ser repensado, saindo do lugar tradicional que é de imposição de uma certa lógica para se transformar em uma espécie de mediador entre comunidade e recursos da sociedade no processo de construção da saúde (Ayres, 2003).

É importante reconhecer as dificuldades que acompanham a prática da pesquisa, principalmente em se tratando de uma pesquisa dentro do sistema prisional. Desde a demora no fornecimento da autorização para entrar nas unidades, olhares de desconfiança emanados pelos gestores e agentes prisionais - sempre questionando o motivo de tal pesquisa, se isso traria algum benefício para os trabalhadores - até o cenário de abandono encontrado pelos pesquisadores, os quais muitas vezes tiveram que realizar as aplicaçóes dos instrumentos de pesquisa em meio a restos de comida, ratos e baratas como companheiros de pesquisa.

A questão da relação saúde mental/trabalho do agente penitenciário é de ampla complexidade e de difícil abordagem em função de todos os condicionantes antes indicados. Após o percurso final da pesquisa, ficou claro o que já se anunciou nos primeiros contatos com profissionais desta área: eles exercem um trabalho que é fonte de sofrimento e adoecimento, em um ambiente desumano, que muitas vezes nos leva a desumanizar os que ali estão.

Desejamos mudanças na direçáo do cuidado extrapolando práticas centradas na doença e na intervenção medicamentosa para intervençôes que valorizem a criação de sentidos para o sofrimento mental e que produzam ampliação das relaçóes sociais e potencialidades de vida (Gama, Campos \& Ferrer, 2014). 


\section{REFERÊNCIAS}

Alves, V. (2009). Condições de trabalho de funcionários penitenciários de Avaré-SP e ocorrência de transtornos mentais comuns (Dissertação de Mestrado, Faculdade de Medicina de Botucatu, Universidade Estadual Paulista, Botucatu, São Paulo).

Assunção, A. Á., \& Silva, L. S. (2013). Condiçôes de trabalho nos ônibus e os transtornos mentais comuns em motoristas e cobradores: Regiáo Metropolitana de Belo Horizonte, Minas Gerais, Brasil, 2012. Cadernos de Saúde Pública,29(12), 2473-2486.https://dx.doi. org/10.1590/0102-311X00181412

Ayres, J. R. C. M., França Junior, I., Calazans, G. J., \& Saletti Filho, H. C. (2003).O conceito de Vulnerabilidade e as práticas de saúde: novas perspectivas e desafios. In D. Czeresnia, C. M. Freitas (Orgs.), Promoçâo da Saúde: conceitos, reflexóes, tendências (pp. 39-53). Rio de Janeiro: Ed Fiocruz.

Brasil. (2015). Levantamento Nacional de Informaçóes Penitenciárias - INFOPEN. Departamento Penitenciário Federal. Brasília: Ministério da Justiça. Recuperado em http://www.justica.gov.br/noticias/ mj-divulgara-novo-relatorio-do-infopen-nesta-tercafeira/relatorio-depen-versao-web.pdf. Acesso em: 01 de dezembro de 2015.

Brasil. (2014). I Boletim Quadrimestral sobre beneficios por Incapacidade. Brasília: Secretaria de Políticas da Previdência Social. Recuperado em 02 de agosto de 2015, de http://www.previdencia.gov.br/wp-content/ uploads/2014/04/I-Boletim-Quadrimestral-deBenef\%C3\%ADcios-por-Incapacidade1.pdf

Creswell, J. W. (2007). Projeto de Pesquisa: método qualitativo, quantitativo e misto. (2 ${ }^{\mathrm{a}}$. ed.). Porto Alegre: Artmed/Bookman.

Fernandes, R. C. P., Neto, A. M. S., Sena, G. M., Leal, A. S., Carneiro, C. A. P., \& Costa, F. P. M. (2002). Trabalho e cárcere: um estudo com agentes penitenciários da Região Metropolitana de Salvador, Brasil. Cad. Saúde Pública, Rio de Janeiro, 18 (3), 807-816.http://dx.doi.org/10.1590/ S0102-311X2002000300029

Gama, C. A. P., Campos, R. T. O., \& Ferrer, A. L. (2014). Saúde mental e vulnerabilidade social: a direção do tratamento. Revista Latinoamericana de Psicopatologia Fundamental, 17(1), 69-84.https:// dx.doi.org/10.1590/S1415-47142014000100006

Gaulejac, V. (2001). Psicossociologia e sociologia clínica. In J. N. G. Araújo \& T. C. Carreteiro (Orgs.), Cenários sociais e abordagem clínica. São Paulo: Escuta.
Goldberg, D. \& Huxley, P. (1992). Common mental disorders: a bio-social model. London; New York: Tavistock; Routledge.

Gonçalves, D. M.; Stein A. T., \& Kapczinski F. (2008). Performance of the Self-Reporting Questionnaire as a psychiatric screening questionnaire: a comparative study with Structured Clinical Interview for DSMIV-TR. Cad Saúde Pública; 24(2), 380-90.

Lhuilier, D. (2014). Introdução à psicossociologia do trabalho. Cadernos de Psicologia Social do Trabalho, 17(spe), 5-20.https://dx.doi. org/10.11606/issn.1981-0490.v17ispe1p5-19

Lourenço, A. S. (2010). O espaço de vida do Agente de Segurança Penitenciária no cárcere: entre gaiolas, ratoeiras e aquários. (Tese de doutorado, Instituto de Psicologia, Universidade de São Paulo, São Paulo, São Paulo).

Nieuwenhuijsen K., Verbeek, J. H., de Boer, A. G., Blonk, R. W., \& Van Dijk FJ. (2006). Predicting the duration of sickness absence for patients with common mental disorders in occupational health care. Scand J Work Environ Health. 32(1), 67-74.

Organização Mundial da Saúde/OMS. (1994). SelfReporting Questionnaire (SRQ-20): development, reliability and feasibility. Addiction. 2283-94. Razzouk, D., Lima, M. G. A., \& Cordeiro, Q. (2016). Saúde Mental e Trabalho. São Paulo: Conselho Regional de Medicina do Estado de São Paulo.

Rodrigues, E. P., Rodrigues, U. S., Oliveira, L. M. M., Laudano, R. C. S., \& Sobrinho, C. L. Na. (2014). Prevalência de transtornos mentais comuns em trabalhadores de enfermagem em um hospital da Bahia. Revista Brasileira de Enfermagem, 67(2), 296-301.doi: https://dx.doi. org/10.5935/0034-7167.20140040

Seligmann-Silva, E. (2011). Trabalho e desgaste mental: o direito de ser dono de si mesmo. São Paulo: Cortez.

Silva Junior, J. S., \& Fischer, F. M. (2014). Adoecimento mental incapacitante: benefícios previdenciários no Brasil entre 2008-2011. Revista de Saúde Pública, 48(1), 186-190. https://dx.doi. org/10.1590/S0034-8910.2014048004802

Souza, J. C.,\& Rumin,C. R. (2013).O serviço de atenção à saúde mental aos trabalhadores do sistema prisional. Revista Transformaçôes. Disponível em: http:// www.ip.usp.br/portal/index.php?option=com_con tent \&view=article\&id=1923:v3n 1a05-o-servicode-atencao-a-saude-menta-aos-trabalhadores-dosistema-prisional $\&$ catid $=340 \&$ Itemid $=91$ Acesso em $12 / 04 / 2016$ 
Vasconcelos, A. S. F. (2000). A saúde sob custódia:um estudo sobre Agentes de Segurança Penitenciária no Rio de Janeiro (Dissertação de mestrado, Fundação Oswaldo Cruz, Escola Nacional de Saúde Pública, Rio de Janeiro, Rio de Janeiro).

\section{Endereço para correspondência:}

UnP - Universidade Potiguar

R. Asp. Santos, 307 - Santos Reis,

Parnamirim - RN, 59140-295, Brasil

Ana Izabel Lima

anaizabel.psi@gmail.com

Recebido :24/05/2018

Aceito: 19/06/2018 


\title{
Práticas sexuais de homens que fazem sexo com homens: adaptaçáo de questionário
}

Sexual practices of men who have sex with men: questionnaire adaptation

\author{
Raquel de Andrade Souza Ew ${ }^{1}$ \\ José Manuel Martínez ${ }^{2}$ \\ Fernanda Torres de Carvalho ${ }^{3}$ \\ Kátia Bones Rocha ${ }^{4}$
}

\begin{abstract}
Resumo
Este artigo trata da adaptação transcultural para o português do Cuestionario de Investigación sobre Prácticas Sexuales de Hombres que Practican Sexo con Hombres - CIPRASEX HSH. O instrumento parte da Teoria do Comportamento Planejado, apresentando como dimensões: fator atitudinal, norma subjetiva e controle comportamental, associados ao não uso de preservativos de HSH. A adaptação envolveu quatro fases: tradução e tradução reversa do questionário; avaliação por juízes e público-alvo; estudo piloto com 20 participantes; elaboração da versão brasileira. Constatou-se boa equivalência conceitual e semântica entre a versão final em português e o original, bem como caráter inovador do instrumento no contexto brasileiro. O CIPRASEX HSH poderá auxiliar no desenvolvimento de intervençôes específicas no âmbito da saúde e prevenção do HIV.
\end{abstract}

Palavras--chave: Comportamento sexual; HIV; HSH; Preservativo; Prevenção \& controle.

\section{Abstract}

This article deals with the cross-cultural adaptation to Portuguese of the Cuestionario de Investigación sobre Prácticas Sexuales de Hombres que Practican Sexo con Hombres - CIPRASEX MSM. Instrument based on the Theory of Planned Behavior, introduces as dimensions: attitudinal factor, subjective norm and behavior control, associated with the no use of condoms of MSM. The adaptation involved four phases: survey translation and reverse translation; judegs and target public evaluation; pilot study with 20 participants; elaboration of the Brazilian version. There is good semantics and conceptual equivalence between the Portuguese version and the original one, and the innovative profile of the instrument in the Brazilian context. CIPRASEX MSM may assist in the development of specific interventions in health and HIV prevention.

Keywords: Sexual behavior; HIV; MSM; Condoms; Prevention \& control.

A epidemia causada pelo Vírus da Imunodeficiência Humana/Síndrome da Imunodeficiência Adquirida (HIV/ AIDS) entre Homens que fazem Sexo com Homens (HSH) vem crescendo em diferentes países (Beyrer et al., 2012; Kirby, 2015). No relatório global da UNAIDS (2016) homens gays e outros HSH representam 30\% das novas infecçôes pelo HIV na América Latina, 49\% das novas infecçôes na Europa Ocidental e Central e na América do Norte e 18\% das novas infecçôes na Ásia e no Pacífico. De acordo com Boletim Epidemiológico HIV/Aids (2016), 50,4\% dos casos de infecção por HIV entre os homens em 2015 foram entre $\mathrm{HSH}$, enquanto $36,8 \%$ foram por exposição heterossexual e 9,0\% bissexual. Há também uma tendência de aumento na proporção de casos de AIDS em HSH nos últimos dez anos, a qual passou de 35,3\% em 2006 para 45,4\% dos casos notificados em 2015. Esses dados mostram a necessidade urgente de compreensão dos fatores associados à exposiçẫo ao risco de infecção por HIV nesta população-chave e a garantia de que ela seja incluída nas respostas à AIDS com pleno acesso a serviços de saúde.

Sabe-se que um importante fator de risco para Infecções Sexualmente Transmissíveis (IST) e que aparece associado ao aumento de casos de HIV em HSH na América Latina é o sexo anal, insertivo ou receptivo, sem o uso do preservativo (Julio et al., 2015; Pinheiro, Calazans, \& Ayres, 2013; Wade, Harper, \& Bauermeister, 2017). Estudos desenvolvidos no Brasil destacam que mais de $30 \%$ dos HSH entrevistados referiram um uso inconsistente de preservativo nos últimos 6 meses (Rocha, Gomes, Camelo, Ceccato,

\footnotetext{
${ }^{1}$ Doutora em Psicologia pela Pontifícia Universidade Católica do Rio Grande do Sul

${ }^{2}$ Docente no Programa de Pós-graduaçáo em Psicologia da Universidad Autónoma de Madrid

${ }^{3}$ Doutora e Psicóloga na Secretaria Estadual da Saúde do Rio Grande do Sul

${ }^{4}$ Docente no Programa de Pós-graduação em Psicologia da Pontifícia Universidade Católica do Rio Grande do Sul
} 
\& Guimarães, 2013) e 12 meses (Brignol \& Dourado, 2011).

A situação de não fazer sexo seguro pode estar vinculada a diferentes fatores, entre eles: a ampliação do acesso à terapia antirretroviral (Maksud, Fernandes, $\&$ Filgueiras, 2015); o engajamento no sexo desprotegido como ato político (Silva \& Iriart, 2010); confiança no parceiro (Antunes \& Paiva, 2013); problemas de saúde mental - depressão, distúrbios do sono e ideação suicida - em decorrência de fatores socioculturais tais como estigma, discriminação e violência homofóbica (Alvy et al., 2011; Guimarães et al., 2013; Rocha et al., 2013); consumo de álcool e drogas ilícitas (Alvy e et al., 2011; Rocha et al., 2013; Carrico, Woolf-King, Neilands, Dilworth, \& Johnson, 2014); aspectos do controle emocional, como a aceitação e autoestima relacionadas à própria sexualidade (Traen et al., 2014).

Cabe destacar que o uso de aplicativos móveis tem modificado o dia-a-dia das interaçóes, interferindo inclusive na busca por relaçóes afetivas e sexuais entre homens. O desejo de relaçôes homoeróticas, associado à segurança de buscar parceiros sem o risco de retaliação física ou moral, torna as mídias digitais um espaço de visibilidade e de negociação para encontros sexuais entre homens (Miskolci, 2017). Assim, torna-se importante a investigação para compreensão da dinâmica interferente nas relaçôes sexuais sem preservativos, para a criação de intervenções específicas para HSH no âmbito da saúde, buscando a prevenção do HIV e outras IST (Antunes \& Paiva, 2013).

Nesta perspectiva, a Universidad Autónoma de Madrid (UAM) estabeleceu um estudo junto ao Centro de Saúde Sandoval (Ayuntamiento de Madrid), cujos serviços também incluíam o aconselhamento e testagem rápida para HIV, para validar modelos psicossociais que permitissem explicar o uso ou náo uso de preservativo em HSH (Rojas, 2004). O resultado foi o desenvolvimento do instrumento Cuestionario de Investigación sobre Prácticas Sexuales de Hombres que Practican Sexo con Hombres - (CIPRASEX HSH), que permite verificar a intençáo de realizaçáo de sexo não seguro e dos fatores associados ao não uso de preservativos, como tipos de parceiros (fixos e eventuais), frequência que realizou sexo sem preservativo, condição sorológica do parceiro, uso de substâncias, entre outros fatores.

O CIPRASEX HSH é um questionário anônimo, auto preenchido e estruturado, focado nas práticas sexuais, que parte da Teoria do Comportamento Planejado (TCP), cujo modelo teórico considera que um dos aspectos determinantes da conduta é a intenção, entendida como sendo a predisposiçáo cognitiva e emocional de realizar determinadas ações (Ajzen \& Fishbein, 1980; Ajzen, 1991). Para Rojas (2004) a intenção seria determinada por três fatores: identidade pessoal, identidade social e controle percebido sobre o comportamento. A identidade pessoal se refere à atitude dos sujeitos que se embasa nas crenças que estão associadas a determinadas condutas (expectativas, resultados e valoração). A identidade social está relacionada à norma subjetiva, que se operacionaliza com a percepçáo que o sujeito apresenta sobre a opinião das pessoas e de grupos que são para ele importantes e o quanto o sujeito se dispóe a acatar essas opinióes. O controle percebido sobre o comportamento se caracteriza como auto eficácia, ou seja, reflete a facilidade ou dificuldade percebida pelo sujeito em realizar a conduta (Ajzen, 2002; Rojas, 2004).

Em parceria com a UAM, o projeto está sendo replicado no Brasil, sendo previstas fases de adaptação e validaçáo do instrumento, validação do modelo teórico, além de construção e avaliação de uma intervenção preventiva específica para a população de HSH. No Brasil, faltam instrumentos que avaliem quais variáveis se associam à utilização de preservativo entre HSH. Diante disso, o presente artigo tem como objetivo apresentar o processo de adaptação do CIPRASEX HSH para o português.

\section{MÉTODO}

\section{Participantes}

Participaram 20 usuários HSH recrutados em um Centro de Testagem e Aconselhamento (CTA), localizado na cidade de Porto Alegre/RS, no período de novembro de 2016 a janeiro de 2017 . Todos os participantes eram maiores de 18 anos, com média de idade de 29 anos.

\section{Instrumento}

O CIPRASEX HSH é um questionário de fatores sociais e individuais que compóem a autogestáo de práticas sexuais de exposição ao risco de Infecções Sexualmente Transmissíveis (IST) entre HSH, entendendo-se como práticas de exposição ao risco o não uso de preservativo nas relaçóes sexuais anais. A versão original do questionário foi criada a partir do modelo da Teoria do Comportamento Planejado (Ajzen \& Fishbein, 1980; Ajzen, 1991) que serviu de base para construção de um instrumento que investiga as atitudes sociais inter-relacionadas com as expectativas de conduta valorizadas e as crenças que o sujeito apresenta 
sobre suas capacidades de realização para determinadas condutas relacionadas ao uso de preservativo (Martín, Martínez, \& Rojas, 2011).

O estudo original de elaboração do CIPRASEX $\mathrm{HSH}$, apresentou medida de adequação amostral, com correlaçôes elevadas na dimensão de atitude geral para os diferentes itens (acima de 0,50); muito elevadas para os itens que correspondem a intenção condutual (acima de 0,80 ) e com $65,46 \%$ de variância explicada para os itens referentes a dimensão do controle percebido sobre o comportamento (Rojas, 2004).

O CIPRASEX HSH destaca-se por ser um questionário totalmente estruturado para população $\mathrm{HSH}$. Seus itens foram elaborados a partir da apresentaçáo de situaçóes sociais, mesclando expectativas e probabilidades de conduta dos participantes, bem como a avaliação das consequências e opiniôes normativas que apresentam e o quanto estas interferem na intenção e na conduta de risco. O questionário completo na versão original é composto pelas variáveis:

$1^{\circ}$ - Variáveis principais (170 itens): compóem propriamente o instrumento e se referem aos construtos da TCP (atitude até a conduta, norma subjetiva, controle percebido sobre o comportamento) associadas às crenças que darão o grau de intenção para realização da conduta de uso ou náo do preservativo. São divididas em 3 dimensóes (atitude geral, norma subjetiva, controle percebido sobre o comportamento) e a intenção respondidas por meio de respostas tipo likert com intervalo de sete pontos. Essas dimensôes apresentam diferentes opções de respostas relacionadas à Teoria do Comportamento Planejado, associadas às crenças (crença normativa pessoal, motivaçáo para acatar opiniáo das pessoas que são relevantes, probabilidade de consequências e valoração de consequências). Posteriormente, apresentaremos a partir das análises realizadas que na versão em português o instrumento ficou com 88 itens.

$2^{\circ}$ - Variáveis associadas (30 itens): 1) Sociodemográficas (nome, idade, endereço do correio eletrônico e/ou fone contato); 2) Relacionadas com a história sexual do sujeito (orientação sexual, número de parceiros, número de relações sexuais sem preservativos, parceiros com quem mantém sexo inseguro, sorologia dos parceiros, tipos de relaçóes anais, existência prévia de IST, aspectos referentes ao início das relaçôes sexuais, número de testes de HIV) e 3) Consumo de substâncias (consumo de álcool e outras drogas);

$3^{\circ}$ - Variáveis de comprovação de conduta (15 itens): Estas perguntas são respondidas um mês após o preenchimento das questôes anteriormente referidas.
Os itens de comprovação de conduta são relativos à reflexão sobre a conduta de risco, conduta de risco no último mês (número de relaçóes, número de parceiros, porcentagem de relaçóes sexuais nas quais não foi utilizado o preservativo), estabilidade atitudinal, intenção de realizar conduta de risco (próximo mês, ano), probabilidade da intenção e do desejo de realizar conduta de risco (próximo mês, ano). Estes itens não compuseram o estudo Piloto.

No estudo original, as variáveis principais e variáveis associadas são questionadas no primeiro contato com os participantes e um mês após este contato é aplicado o questionário com as variáveis de comprovaçáo de conduta. Cabe destacar, que os autores do CIPRASEX HSH enfatizaram a importância de no processo de adaptação, respeitando a estrutura teórica do instrumento, que alguns itens pudessem ser excluídos já que o instrumento completo era muito extenso o que dificultava o seu preenchimento.

\section{Procedimentos}

Os participantes inicialmente foram convidados a participar de uma entrevista semiestruturada com o objetivo de verificar em que medida as respostas dadas eram congruentes com os itens avaliados nas dimensóes (atitude, norma subjetiva e controle percebido sobre o comportamento) do CIPRASEX HSH. Na sequência, responderam ao questionário durante o tempo de espera pelos resultados dos exames de HIV e outras IST. A aplicação do piloto ocorreu em espaço físico destinado à pesquisa junto ao CTA, com duração estimada entre 30 a 40 minutos, coincidindo com o período de execução do teste rápido. As entrevistas foram realizadas pela pesquisadora, sendo gravadas e transcritas posteriormente. A pesquisa considerou os aspectos éticos exigidos da Resolução 466/2012. Todos participantes assinaram ao Termo de Consentimento Livre e Esclarecido, tendo sido o projeto previamente aprovado pelo Comitê de Ética em Pesquisa da Pontifícia Universidade Católica do Rio Grande do Sul ( $N^{\circ}$ do parecer: 1.892.233).

\section{Análise de dados}

O processo de adaptação do CIPRASEX HSH (Figura1) foi composto por 4 fases. Fase 1: Tradução e tradução reversa do questionário; Fase 2: Avaliação por experts e pelo público-alvo; Fase 3: Estudo piloto; Fase 4: Versáo brasileira do CIPRASEX HSH, a partir da análise qualitativa do estudo piloto. 


\section{Figura 1.}

Fases para a adaptação transcultural do CIPRASEX HSH

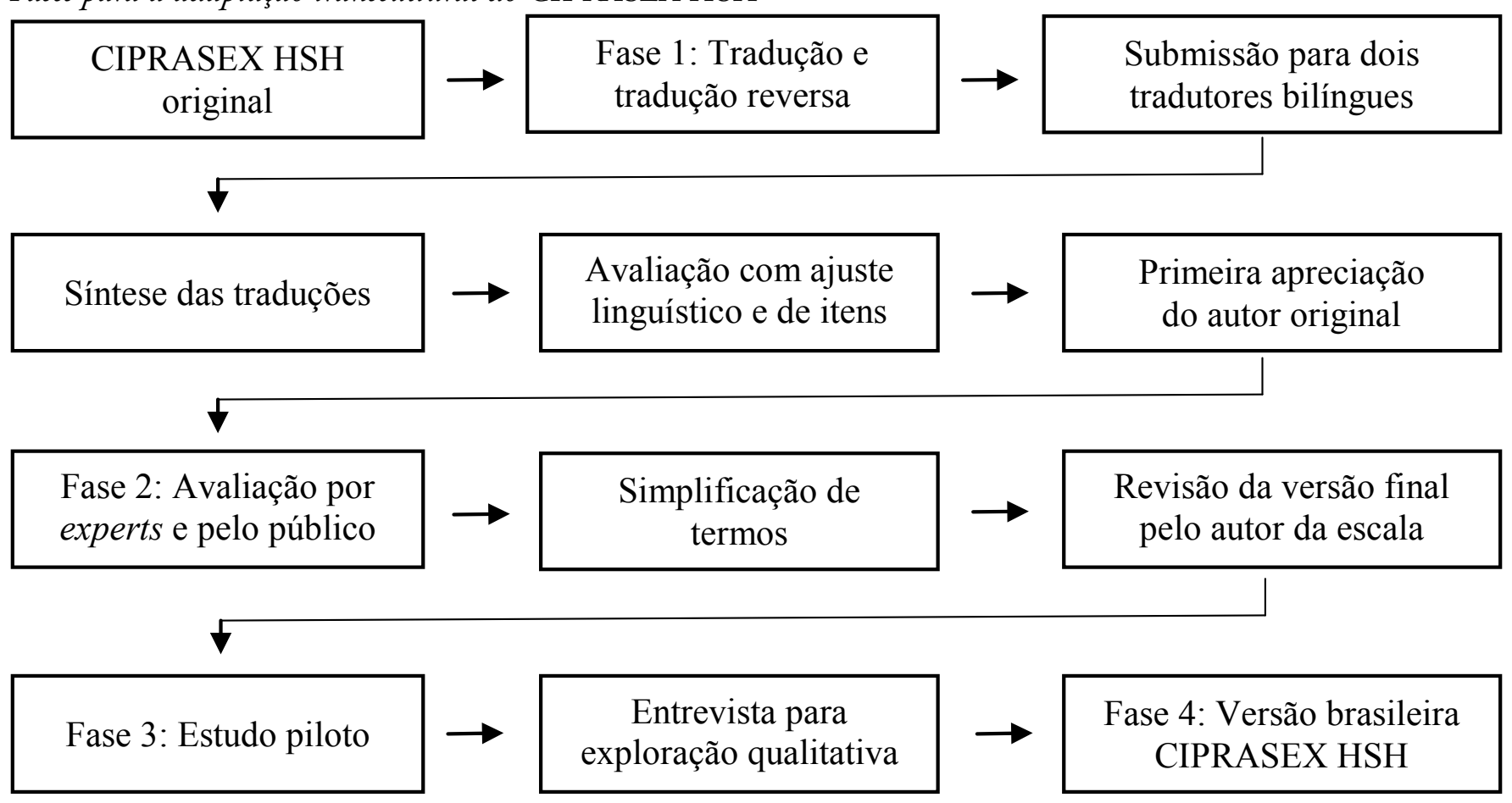

\section{RESULTADOS}

\section{Fase 1 - Traduçáo e traduçáo reversa do questionário}

Em um primeiro momento, o instrumento completo foi traduzido do espanhol para o português por dois tradutores bilíngues fluentes no idioma de origem e nativos no idioma alvo, sendo que um dos tradutores estava familiarizado com o construto avaliado. Depois, o artigo sofreu a tradução reversa, ou seja, foram traduzidos os itens do português novamente para o espanhol. Conforme Tanzer (2005), para que haja uma traduçáo adequada, é necessário que não apenas sejam observados os aspectos linguísticos, mas que também haja um tratamento equilibrado entre os aspectos culturais, contextuais e científicos do instrumento.

A partir das traduçóes realizadas, os pesquisadores verificaram as versóes traduzidas e identificaram 40 itens que necessitavam ajuste linguístico com substituição de termos utilizados (por ex.: "vem rapidamente à mente" por "vem rapidamente à minha cabeça"), visando uma linguagem mais clara. Neste momento, houve discussão entre os pesquisadores responsáveis pela adaptaçáo do instrumento para avaliação e definição das diferentes traduçóes para cada item em particular. Foi realizada a síntese das versóes com o objetivo de chegar a uma única versão que atendesse aos seguintes aspectos: avaliação do nível de complexidade da tradução e da manutenção da equivalência com o instrumento original nos aspectos semânticos (mesmo significado), idiomático (adaptação por expressão equivalente), experiencial (se é aplicável no contexto cultural de destino) e conceitual (se avalia o mesmo aspecto) (Borsa, Damásio, \& Bandeira, 2012). Após, a versão traduzida e ajustada foi submetida primeiro à apreciação de um dos autores do instrumento original, que aprovada resultou na versáo apresentada para os experts e público-alvo.

\section{Fase 2 - Avaliaçáo da síntese por experts e pelo público-alvo}

$\mathrm{Na}$ continuação da etapa de adaptação cultural foi enviado o questionário para análise de experts (pesquisadores $(n=3)$, profissionais aconselhadores do Centro de Testagem e Aconselhamento (CTA) - psicólogos e enfermeiros $(n=5)$, informantes-chave HSH $(n=4)$ a fim de que apontassem suas questóes e sugestóes para melhor adequaçáo do instrumento. Todos indicaram que existiam alguns itens com enunciados iguais e que, apesar de apresentarem diferentes opçóes de resposta (por ex.: "Fazer sexo anal com homens sem preservativo para mim é algo que me faria sentir maior compromisso na minha relação: muito improvável/ muito provável; falso/verdadeiro; mau/bom”), geravam a sensação de que estes itens eram repetidos. Nesse sentido, 
questionaram a possibilidade de exclusão de alguns destes itens juntos aos autores da escala. Os aconselhadores também sugeriram adequação de linguagem com simplificação de termos, principalmente nos itens que apresentavam sentenças de formulaçáo negativa (por ex.: "Quando faço sexo anal SEM preservativo, penso que nada de ruim vai acontecer". Alterada por: "Quando faço sexo anal SEM preservativo, penso que algo de ruim vai acontecer"), tendo em conta que esta estrutura de frase poderia provocar confusão na compreensão e na resposta, além de aumentar a dificuldade para usuários do serviço, já que alguns apresentam baixa escolaridade. Foram alterados 17 itens com formulação negativa.

Como resultado da aplicação dos questionários, os informantes-chave $\mathrm{HSH}$ ainda indicaram que o instrumento era muito longo e que apresentava blocos inteiros nos quais os respondentes tinham a sensação de já terem respondido alguns itens anteriormente, assim como referido anteriormente. Importante esclarecer que as repetiçóes no CIPRASEX HSH original eram propositais e se configuravam na repetição de itens com mudanças nas opçóes de respostas (identificando probabilidade, veracidade e valoração). Alguns ainda eram repetidos para confirmarem se o participante estava lendo o instrumento.

Assim, uma vez agrupadas todas as observaçóes levantadas tanto pela equipe de profissionais como pelo público-alvo, reuniu-se um comitê para avaliação de todos os aspectos a serem ajustados tais como estrutura, clareza do rapport dos itens, disposição das informaçóes no instrumento, aspectos linguísticos e repetições. Os pesquisadores a partir das observaçôes indicadas iniciaram o processo de reorganização do instrumento. Importante ressaltar que o instrumento original não teve sua publicação psicométrica publicada em forma de artigo científico, estes dados estão descritos na tese de Rojas (2004), e o instrumento recebeu o prêmio Virgilio Palacio em 2004 da Secretaria de Saúde de Asturias e da Organização não Governamental Médicos del Mundo. Dessa forma, o estudo em português atenderá a observaçáo da dificuldade identificada pelos autores de aplicação do instrumento devido à sua extensão, considerando a necessidade de simplificação dos itens. Com o auxílio e revisão de um dos autores do instrumento, foram retirados os itens que empiricamente verificou-se a percepção de repetiçáo pelos grupos e que não comprometiam o conteúdo e o que o construto teórico pretende medir. Esta adaptação foi realizada nos grupos de pesquisa envolvidos com participação dos professores pesquisadores da Espanha e do Brasil, profissionais do CTA e informantes-chave HSH.

Realizou-se a análise qualitativa do questionário através de oito rodadas de análise para ajustamento e verificação da configuração do questionário. Assim, dos 200 itens da versão original (variáveis principais com 170 itens e variáveis associadas com 30 itens) ficaram 114 itens na versão reduzida adaptada (variáveis principais com 88 itens e variáveis associadas com 26 itens). $\mathrm{Na}$ figura 2 pode-se verificar como se apresentam as dimensóes do instrumento no questionário original e os 86 itens retirados.

\section{Figura 2.}

Dimensöes do CIPRASEX HSH em espanhol e itens excluídos na versäo brasileira

DIMENSÓES

DESCRIÇÃO TEÓRICA

$\left(\mathrm{n}^{\mathrm{o}}\right.$ itens no total )
a) Frequência da conduta de risco no passado (2)
b) Recência da conduta (1)

c) Probabilidade de realizar a conduta (1)

Atitude até a conduta d) Conduta - mediçáo de escala (1)

e) Valorização da conduta- atitude geral e modelo do processamento espontâneo (10)

f) Estabilidade atitudinal (1)

g) Modelo do processamento espontâneo (2)

h) Hábitos relacionados a con-

duta sexual de risco (3)
DESCRIÇÃO TEÓRICA

( $n^{\circ}$ itens excluídos)

c) Probabilidade de realizar a conduta (1)

e) Valorização da conduta- atitude geral (1) 


\begin{tabular}{|c|c|c|}
\hline DIMENSÓES & $\begin{array}{c}\text { DESCRIÇÃO TEÓRICA } \\
\left(\mathrm{n}^{\mathrm{o}} \text { itens no total }\right)\end{array}$ & $\begin{array}{c}\text { DESCRIÇÃO TEÓRICA } \\
\text { (no itens excluídos) }\end{array}$ \\
\hline Normas subjetivas & $\begin{array}{l}\text { a) Norma subjetiva geral - opinião (1) } \\
\text { b) Rechaço à conduta (1) } \\
\text { c) Norma subjetiva geral - moti- } \\
\text { vação para acatar (1) } \\
\text { d) Crenças de conduta - expectativas (19) } \\
\text { e) Crenças de conduta - proba- } \\
\text { bilidade de expectativas (19) } \\
\text { f) Crenças de conduta - valori- } \\
\text { zação das expectativas (19) } \\
\text { g) Crenças normativas - opi- } \\
\text { nião dos outros (8) } \\
\text { h) Crenças normativas - motivação } \\
\text { para acatar a opinião dos outros (8) } \\
\text { i) Crenças normativas pesso- } \\
\text { ais - variável externa (1) } \\
\text { j) Crenças de controle - situaçóes que difi- } \\
\text { cultam e facilitam o uso de preservativo (17) } \\
\text { l) Importância pessoal da conduta (2) } \\
\text { m) Crenças normativas - o quanto } \\
\text { prejudica / beneficia outros (9) } \\
\text { n) Importância da opinião dos referentes (9) }\end{array}$ & $\begin{array}{l}\text { a) Norma subjetiva } \\
\text { geral - opinião (1) } \\
\text { c) Norma subjetiva geral - moti- } \\
\text { vaçáo para acatar (1) } \\
\text { d) Crenças de conduta } \\
\text { - expectativas (19) } \\
\text { f) Crenças de conduta - valo- } \\
\text { rizaçáo das expectativas (19) } \\
\text { g) Crenças normativas - opi- } \\
\text { nião dos outros (1) } \\
\text { h) Crenças normativas - opi- } \\
\text { nião dos outros (8) } \\
\text { i) Crenças normativas pesso- } \\
\text { ais - variável externa (1) } \\
\text { j) Crenças de controle - situ- } \\
\text { açóes que dificultam e facili- } \\
\text { tam o uso de preservativo (1) } \\
\text { k) Importância pes- } \\
\text { soal da conduta (1) } \\
\text { l) Crenças normativas - o quanto } \\
\text { prejudica / beneficia outros (9) }\end{array}$ \\
\hline $\begin{array}{l}\text { Controle percebido } \\
\text { sobre } \\
\text { o comportamento }\end{array}$ & $\begin{array}{l}\text { a) Controle percebido - medição geral (1) } \\
\text { b) Controle percebido - auto capa- } \\
\text { cidade percebida (1) } \\
\text { c) Controle percebido - auto eficácia geral (1) }\end{array}$ & $\begin{array}{l}\text { c) Controle percebido - } \\
\text { auto eficácia geral (1) }\end{array}$ \\
\hline Intenção & $\begin{array}{l}\text { a) Intenção - primeira medi- } \\
\text { ção probabilidade (2) } \\
\text { b) Esforço (1) } \\
\text { c) Intenção- probabilidade } \\
\text { d) Desejo (1) } \\
\text { e) Intençáo - segunda medição (2) } \\
\text { f) Intenção - probabili- } \\
\text { dade segunda medição (2) } \\
\text { g) Desejo - probabilidade (1) }\end{array}$ & $\begin{array}{l}\text { a) Intenção - primeira medi- } \\
\text { ção probabilidade (2) } \\
\text { b) Esforço (1) } \\
\text { d) Desejo (1) } \\
\text { e) Intenção - segunda medição (2) } \\
\text { g) Desejo - probabilidade (1) }\end{array}$ \\
\hline Crenças & $\begin{array}{c}\text { a) Modelo de crenças de saúde } \\
\text { - gravidade percebida (7) } \\
\text { b) Otimismo ilusório (2) } \\
\text { c) Modelo de crenças de } \\
\text { saúde - benefícios (2) } \\
\text { d) Modelo de crenças de saúde - custos (4) } \\
\text { e) Modelo de crenças de } \\
\text { saúde - autoeficácia (2) } \\
\text { f) Modelo de crenças de saúde } \\
\text { - benefícios e custos (2) } \\
\text { g) Modelo de crenças de saúde } \\
\text { - autocapacidade (1) }\end{array}$ & $\begin{array}{l}\text { a) Modelo de crenças de saúde } \\
\text { - gravidade percebida (4) } \\
\text { b) Otimismo ilusório (2) }\end{array}$ \\
\hline
\end{tabular}




\begin{tabular}{|c|c|c|}
\hline DIMENSÓEES & $\begin{array}{c}\text { DESCRIÇÃO TEÓRICA } \\
\left(n^{\circ} \text { itens no total }\right)\end{array}$ & $\begin{array}{c}\text { DESCRIÇÃO TEÓRICA } \\
\left(\mathrm{n}^{\mathbf{0}} \text { itens excluídos }\right)\end{array}$ \\
\hline $\begin{array}{l}\text { Fatores socio- } \\
\text { demográficos }\end{array}$ & $\begin{array}{c}\text { a) Orientação sexual (1) } \\
\text { b) História sexual - começo } \\
\text { das relaçóes sexuais (3) } \\
\text { c) Parceiros e tipos de relaçóes de risco (2) } \\
\text { d) História sexual- número de par- } \\
\text { ceiros sexuais (1) } \\
\text { e) História sexual - porcentagem de risco (1) } \\
\text { f) História sexual - sorologia par- } \\
\text { ceiros esporádicos (1) } \\
\text { g) Hábitos tóxicos (3) } \\
\text { h) Identidade pessoal (2) } \\
\text { i) História Sexual - histórico de IST (2) } \\
\text { j) História sexual - sorolo- } \\
\text { gia das parcerias estáveis (1) } \\
\text { 1) Modelo de crenças de saúde - situaçóes conhe- } \\
\text { cidas a respeito de pessoas com HIV/Aids (4) } \\
\text { m) Identificação (3) } \\
\text { n) Modelo de crenças de saúde- } \\
\text { chaves para ação (2) } \\
\text { o) História sexual - abusos (2) } \\
\text { p) História sexual - testes de HIV e sorologia (2) }\end{array}$ & \\
\hline
\end{tabular}

A síntese foi realizada a partir da comparação de quais itens não estavam ajustados, de acordo com coincidência entre as observaçóes dos pesquisadores e dos colaboradores, sendo realizados os ajustes e exclusão dos itens. Na sequência, o autor da escala juntamente com um convidado bilíngue, externo à pesquisa, revisou a versão final em português e espanhol e verificou que os itens excluídos não comprometiam os construtos e dimensōes do instrumento.

\section{Fase 3 - Estudo Piloto}

O desenvolvimento do estudo piloto se desdobrou em dois momentos:

a) Entrevista para exploração conceitual qualitativa das dimensóes avaliadas (atitude, norma subjetiva e controle percebido sobre o comportamento)
Inicialmente, os participantes responderam a 5 perguntas abertas: 1) o que você acha que facilita o uso do preservativo? (controle percebido); 2) o que você acha que dificulta o uso de preservativo? (controle percebido); 3) quais pessoas você acha que podem te influenciar no uso do preservativo? (norma subjetiva); 4) quais pessoas você acha que podem lhe influenciar para não usar o preservativo? (norma subjetiva); 5) quais são as consequências de fazer sexo sem preservativo? (fator atitudinal). Tais respostas foram gravadas e posteriormente transcritas. As respostas dadas à entrevista semiestruturada foram submetidas à análise de conteúdo de Bardin (2010). A partir desta análise, procurou-se identificar as respostas mais frequentes referidas nas entrevistas e analisar se estas estavam ou não contempladas no questionário original. A seguir apresentamos a Tabela $1 \mathrm{com}$ os dados da exploração conceitual.

\section{Tabela 1.}

Respostas da exploração conceitual qualitativa das dimensóes avaliadas

\begin{tabular}{|c|c|c|c|}
\hline Dimensôes & Perguntas & Respostas referentes & Fatores (Percentual de referências) \\
\hline Fator Atitudinal & $\begin{array}{l}\text { Consequência de fazer } \\
\text { sexo sem preservativo }\end{array}$ & 22 & $\begin{array}{c}\text { - Doenças /IST }(77,3 \%) \\
\text { - Sofrimento psicológico }(13,6 \%) \\
\text { - Mais prazer }(9 \%)\end{array}$ \\
\hline
\end{tabular}




\begin{tabular}{|c|c|c|c|}
\hline Dimensões & Perguntas & Respostas referentes & Fatores (Percentual de referências) \\
\hline \multirow[b]{2}{*}{$\begin{array}{c}\text { Fator } \\
\text { Normativo }\end{array}$} & $\begin{array}{l}\text { Pessoas poderiam } \\
\text { influenciar no uso } \\
\text { de preservativos }\end{array}$ & 32 & $\begin{array}{l}\text { - Própria pessoa, parceiros e pes- } \\
\text { soas infectadas }(50 \%) \\
\text { - Pais, profissionais da saúde } \\
\text { e médicos }(28,1 \%) \\
\text { - Amigos, pessoas esclareci- } \\
\text { das/informadas, família, } \\
\text { pessoas náo confiáveis ou } \\
\text { com aparência de doença } \\
(21,9 \%)\end{array}$ \\
\hline & $\begin{array}{l}\text { Influenciadores } \\
\text { para o náo uso } \\
\text { do preservativo }\end{array}$ & 35 & $\begin{array}{l}\text { - Parceiros }(40 \%) \\
\text { - Pessoas confiáveis }(14,2 \%) \\
\text { - Pessoas alcoolizadas, pes- } \\
\text { soas sem educaçáo /formação } \\
\text { e pessoas que querem transmitir }(17,2 \%) \\
\text { - Amigos, pessoas que se con- } \\
\text { sideram sadias, pessoas } \\
\text { náo conhecidas, pessoas que } \\
\text { insistem, homem da noite } \\
\text { e homem heterossexual }(17,2 \%) \\
\text { - Ninguém }(11,4 \%)\end{array}$ \\
\hline \multirow{2}{*}{$\begin{array}{c}\text { Fator controle } \\
\text { percebido sobre } \\
\text { o comportamento }\end{array}$} & $\begin{array}{c}\text { Fatores que podem } \\
\text { facilitar o uso } \\
\text { do preservativo }\end{array}$ & 41 & $\begin{array}{l}\text { - Conscientização através das } \\
\text { campanhas/mídia e ter } \\
\text { preservativos consigo }(43,9 \%) \\
\text { - Gratuidade/distribuição de pre- } \\
\text { servativos }(12,2 \%) \\
\text { - Não conhecer a pessoa }(7,3 \%)\end{array}$ \\
\hline & $\begin{array}{l}\text { Fatores que dificultam } \\
\text { o uso do preservativo }\end{array}$ & 60 & $\begin{array}{l}\text { - Muito tesão e o desconforto } \\
\text { que o preservativo produz } \\
(26,7 \%) \\
\text { - Perda da sensibilidade }(11,7 \%) \\
\text { - Uso de álcool e drogas }(10 \%)\end{array}$ \\
\hline
\end{tabular}

Em relação ao fator atitudinal, o maior número de respostas sobre as consequências de fazer sexo sem preservativo se referiu às doenças. Quanto ao fator normativo, os influenciadores mais citados tanto para o uso como para o náo uso de preservativos foram os próprios parceiros. Em relaçáo ao controle percebido sobre o comportamento, a conscientização através de campanhas e mídia foram mais referidas como fatores que podem facilitar o uso do preservativo e o tesáo como interferindo na dificuldade para o uso.

\section{b) Aplicação do CIPRASEX HSH}

Em seguida, os participantes do piloto responderam ao questionário CIPRASEX HSH - versão traduzida/reduzida na presença da entrevistadora. Ao responderem ao questionário, os participantes podiam esclarecer suas dúvidas sobre a compreensão dos itens. Todos os itens não compreendidos durante o preenchimento das respostas foram registrados com as respectivas dúvidas e sugestóes para melhor compreensão.

Ainda, para plena certificação da verificação do entendimento sobre os itens, após a conclusão de resposta do questionário, foi realizado um sorteio de uma pergunta de cada dimensão (fator atitudinal, norma subjetiva e controle percebido) para que o participante explicasse sua compreensão sobre o item. Os respondentes foram estimulados a comentar os itens de difícil compreensão e também avaliar globalmente o instrumento.

Os participantes apresentaram suas dificuldades de compreensão, o que levou à alteração dos seguintes itens do instrumento: 1) identificação de quais pessoas/ contextos eram referentes para o participante em relação ao uso do preservativo; 2) a opiniáo do participante se 
direciona (mais contra/mais a favor) em fazer sexo anal sem preservativo; 3 ) dificuldade do uso do preservativo quando a outra pessoa insiste muito em fazer sexo anal sem preservativo; 4) dificuldade do uso do preservativo se a outra pessoa está disposta em fazer sexo anal (ativo ou passivo) sem preservativo; 5) dificuldade do uso do preservativo ao sentir-se deprimido/triste; 6) se a disponibilidade das medicaçóes torna infectar-se com HIV algo nada/muito perigoso. A partir das observações dos participantes se reconfigurou a diagramação do instrumento, adequando estes itens com a finalidade de torná-los ainda mais claros.

\section{Fase 4: Versão brasileira do CIPRASEX HSH}

Como mencionado até aqui, utilizaram-se diversas fontes de análise aos itens do questionário, o que, além de resultar na redução do instrumento, levou à inclusão de itens a partir de fatores mencionados nas entrevistas como relevantes para o uso de preservativos. Desta forma, os itens sociodemográficos incluídos foram: religião; escolaridade; participação em movimento LGBT; informaçóes na escola sobre o uso de preservativos; uso da Profilaxia Pós-Exposição (PEP) e da Profilaxia Pré-Exposição (PREP); orientação sexual e sobre o uso de aplicativos para encontros sexuais.

Novos itens específicos da TCP e crenças foram incluídos a partir dos resultados da pesquisa e se referem aos seguintes pontos: conduta de ter preservativos ("quando faço sexo anal tenho preservativos disponíveis por perto"); importância da opinião de outros profissionais da saúde em relação ao uso de preservativo; influência dos referentes sociais/institucionais no uso do preservativo (como mídia/campanhas em relação ao uso de preservativo, participação em movimentos LGBT, informaçóes recebidas na escola sobre práticas sexuais seguras, crença(s) religiosa(s) e encontrar preservativos gratuitos nas unidades de saúde) e crenças de controle (saber usar o preservativo).

A inclusão de itens referentes a aplicativos móveis se fez necessária à medida que os próprios participantes comentaram sobre a alteraçáo do comportamento de busca de parceiros com a chegada dos aplicativos para relacionamento. Assim, na subcategoria história sexual foram incluídos os itens: "você usa aplicativos de celular para procura de parceiros sexuais?"; "nos últimos 12 meses quantos parceiros sexuais conheceu através de aplicativos de celular?" $\mathrm{Na}$ subcategoria crenças de controle, incluiu-se: "conhecer o parceiro sexual por aplicativo de celular me dificulta o uso/me facilita o uso de preservativo". Além disso, o campo descritivo teórico de uso de drogas (no original denominado hábitos tóxicos) foi desdobrado em nove itens correspondendo a nomeação de cada substância tóxica.

Sendo assim, a versão após aplicação piloto ficou com 142 itens (43 sociodemográficos e 99 itens específicos da TCP e crenças). Configurando-se um acréscimo de 17 novos itens sociodemográficos e 11 novos itens específicos da TCP e crenças.

\section{DISCUSSÃO}

Considera-se um importante avanço o processo de adaptação do questionário CIPRASEX HSH para a realidade brasileira. Trata-se de um instrumento com itens diretos e claros sobre as práticas sexuais e sua relação com o uso de preservativos, voltado especificamente a HSH. Por meio das entrevistas semiestruturadas realizadas durante o estudo piloto, foi possível observar que as informações referidas pelos participantes em relação ao uso do preservativo condizem com as dimensóes previstas no questionário original. Além disso, identifica-se relação entre tais dimensôes e a literatura, salientando-se eixos como consequências em fazer sexo sem preservativos - doenças, sofrimento psicológico e mais prazer (Martín et al., 2011; Silva \& Iriart, 2010; Pinheiro et al.,2013); aspectos que dificultam o uso de preservativos - tesão, desconforto, perda de sensibilidade e o uso de álcool e outras drogas (Martín et al., 2011; Alvy et al., 2011; Rocha et al., 2013; Carrico et al., 2014).

Em relação às pessoas importantes que influenciam no uso dos preservativos na relaçáo sexual, é possível identificar a força de interferência dos parceiros, da representação de confiança atribuída ao outro (Antunes \& Paiva, 2013) e da própria opinião sobre o processo decisório no uso de preservativos. Observa-se no estudo que a influência familiar é limitada, como também foi verificado no estudo realizado na Espanha (Martín et al., 2011). Nas entrevistas foram mencionados conflitos familiares a respeito da homoafetividade e mesmo a ocultação da homossexualidade no contexto familiar e social.

Em concordância com o autor do instrumento, os processos de tradução e retradução foram feitos também com o objetivo de ter uma versão menos extensa do CIPRASEX HSH. Nesta direção, a participação de pesquisadores, trabalhadores de serviços de saúde e informantes chaves foram fundamentais para pensar uma versão do instrumento que fosse realmente adequada ao contexto brasileiro. Entretanto, nesta adaptação se mostrou também necessária a inclusão de itens.

Nas entrevistas identificaram-se aspectos que 
também se apoiam em questôes culturais já mencionadas na literatura, como fatores de interferência no comportamento das pessoas em relação à sexualidade de forma geral e, de forma decorrente, ao uso dos preservativos. Exemplos disso é a importância dos movimentos sociais na constituição das políticas públicas de enfrentamento ao HIV/AIDS no Brasil (Grangeiro, Silva, \& Teixeira, 2009), da escola como espaço de constituição de cidadania, respeito e inclusão das diversidades (Figueiró, 2006) e o papel da comunicação dentro da formação cultural brasileira. Assim, incluíram-se itens no questionário que investigam a influência de outros profissionais da saúde e instituiçóes sociais (escola, mídia, ativismo em grupos LGBT) sobre a intenção de uso de preservativos, bem como o papel da comunicação virtual nesse processo.

O uso das tecnologias e dos aplicativos foi mencionado especialmente quando os participantes respondiam ao item sobre a prática de sexo anônimo, presente no questionário e que se referia aos espaços públicos (parques, banheiros, etc.). Ao responder este item, os participantes associavam e questionavam se a prática de sexo anônimo também se referia ao uso dos aplicativos de celular, ou se o aumento no número de parceiros e exposiçáo ao risco estaria ligado a esses aplicativos, tendo em vista sua popularizaçáo no contexto gay (Miskolci, 2014; Miskolci 2017; Pelúcio, 2016).

O propósito desse questionário é preencher uma importante lacuna em relação à identificação de fatores associados ao náo uso de preservativos entre $\mathrm{HSH}$. Assim como indicam Borsa et al. (2012), a tradução demandou um trabalho de equipe não só para verificação da compreensão semântica, idiomática e conceitual, mas especialmente no aspecto experiencial, no quanto os itens faziam sentido e eram aplicáveis ao subgrupo populacional a que se destina, o que é reforçado pela literatura.

Importante salientar que esta pesquisa descreve o processo de adaptação do questionário CIPRASEX $\mathrm{HSH}$, sendo que estudos psicométricos do instrumento se fazem necessários para verificação de sua capacidade preditiva. Recomendam-se estudos futuros em que sejam realizadas as análises fatoriais exploratórias para confirmar a adequação dos itens às dimensóes. Espera-se que esse instrumento possa ser futuramente utilizado por serviços de saúde, como forma de auxiliar na identificação de aspectos relevantes e singulares dos usuários em relação à intenção, suas crenças e estratégias de prevenção.

\section{REFERÊNCIAS}

Ajzen, I. (2002). Perceived behavioral control, selfefficacy, locus of control, and the Theory of Planned Behavior. Journal of Applied Social Psychology, 32(4), 665-683. doi: 10.1111/j.1559-1816.2002. tb00236.x

Ajzen, I. (1991). The theory of planned behavior. OrganizationalBehavior and Human Decision Processes, 50, 179-211. doi:10.1016/0749-5978(91)90020-T

Ajzen, I., \& Fishbein, M. (1980). Understanding attitudes and predicting social behavior. New Jersey: Prentice Hall.

Alvy, L. M., McKirnan, D. J., Mansergh, G., Koblin, B., Colfax, G. N., Flores, S. A., Hudson,S. (2011). Depression is associated with sexual risk among men who have sex with men, but is mediated by cognitive escape and self-efficacy. AIDS and Behavior, 15(6), 1171-1179. doi:10.1007/s10461-010-9678-z

Antunes, M. C., \& Paiva, V. S. F. (2013). Territórios do desejo e vulnerabilidade ao HIV entre homens que fazem sexo com homens: desafios para a prevenção. Temas em Psicologia, 21(3), 1125-1143. doi:10.9788/TP2013.3-EE17PT

Boletim Epidemiológico HIVIAids 2016. (2016). Ministério da Saúde. Secretaria de Vigilância em Saúde. Departamento de DST, Aids e Hepatites Virais. Recuperado de http://www.aids.gov.br/pt-br/ pub/2016/boletim-epidemiologico-de-aids-2016

Bardin, L. (2010). Análise de conteúdo. São Paulo: Ediçôes 70.

Beyrer, C., Baral, S. D., Van Griensven, F., Goodreau, S. M., Chariyalertsak, S., Wirtz, A. L., \& Brookmeyer, R. (2012). Global epidemiology of HIV infection in men who have sex with men. The Lancet, 380, 367-377. doi:10.1016/S0140-6736(12)60821-6

Borsa, J. C., Damásio, B. F., \& Bandeira, D. R. (2012). Adaptação e validação de instrumentos psicológicos entre culturas: algumas considerações. Paidéia, 22(53), 423-432. doi:10.1590/S0103-863X2012000300014

Brignol, S., \& Dourado, I. (2011). Inquérito sociocomportamental sobre as práticas sexuais desprotegidas entre homens que fazem sexo com homens usuários da Internet. Revista Brasileira de Epidemiologia, 14, 423-434. http://dx.doi. org/10.1590/S1415-790X2011000300007.

Carrico, A. W., Woolf-King, S. E., Neilands, T. B., Dilworth, S. E., \& Johnson, M. O. (2014). Stimulant use and HIV disease management among men in same-sex relationships. Drug and 
alcohol dependence, 139, 174-177. doi:10.1016/j. drugalcdep.2014.03.025.

Figueiró, M. N. D. (2006). Educação sexual: como ensinar no espaço da escola. Revista Linhas, 7 (1). Recuperado de http://www.periodicos.udesc.br/ index.php/linhas/article/view/1323.

Grangeiro, A., Silva, L. L. D., \& Teixeira, P. R. (2009). Resposta à aids no Brasil: contribuiçóes dos movimentos sociais e da reforma sanitária. Revista Panamericana de Salud Pública, 26(1), 87-94. Recuperado de: https://scielosp.org/pdf/rpsp/ v26n1/13.pdf

Guimarães, M. D. C., Ceccato, M. D. G. B., Gomes, R. R. F. M., Rocha, G. M., Camelo, L. D. V., Carmo, R. A., \& Acurcio, F. D. A. (2013). Vulnerabilidade e fatores associados com HIV e sífilis em homens que fazem sexo com homens, Belo Horizonte, MG. Revista Médica de Minas Gerais, 23(4), 412426. doi: 10.5935/2238-3182.20130067

Julio, R. S., Friedman, R. K., Cunha, C. B., De Boni, R. B., Cardoso, S. W., Torres, T., ... \& Grinsztejn, B. (2015). Unprotected Sexual Practices Among Men Who Have Sex with Women and Men Who Have Sex with Men Living with HIV/AIDS in Rio de Janeiro. Archives of sexual behavior, 44(2), 357365.doi:10.1007/s10508-014-0357-4

Kirby, T. (2015). New HIV diagnoses in MSM in high-income countries. The Lancet Infectious Diseases, 15(1), 23-24. https://doi.org/10.1016/ S1473-3099(14)71068-0

Martín, M.J., Martínez, J.M. \& Rojas D. (2011). Teoría del comportamiento planificado y conducta sexual de riesgo en hombres homosexuales. Revista Panamericana de Salud Publica, 29(6), 433-443. Retrieved from: http://iris.paho.org/xmlui/ handle/123456789/9497

Maksud, I., Fernandes, N. M., \& Filgueiras, S. L. (2015). Technologies for HIV prevention and care: challenges for health services. Revista Brasileira de Epidemiologia, 18, 104-119. doi:10.1590/1809-4503201500050008

Miskolci, R. (2017). Desejos Digitais: uma análise sociológica por parceiros on-line. Belo Horizonte: Autêntica Editora.

Miskolci, R. (2014). Negociando visibilidades: segredo e desejo em relaçôes homoeróticas masculinas criadas por mídias digitais. Bagoas - Estudos gays, gêneros e sexualidades, 8(11), 51-78. Recuperado de: https:// periodicos.ufrn.br/bagoas/article/view/6543

Pelúcio, L. (2016). Afetos, mercado e masculinidades contemporâneas: notas inicias de uma pesquisa em aplicativos móveis para relacionamentos afetivos/sexuais. Contemporânea - Revista de Sociologia da UFSCar, 6(2), 309-333. doi: 10.4322/2316-1329.016

Pinheiro, T. F., Calazans, G.J., \& Ayres, J. R. C. M. (2013). Uso de Camisinha no Brasil: um olhar sobre a produção acadêmica acerca da prevenção de HIV/ Aids (2007-2011). Temas em Psicologia, 21 (3), 815836. doi: 10.9788/TP2013.3-EE07PT

Rocha, G. M., Gomes, R. R. D. F. M., Camelo, L. D. V., Ceccato, M. D. G. B., \& Guimarães, M. D. C. (2013). Sexo anal receptivo desprotegido entre homens que fazem sexo com homens, Belo Horizonte, MG. Revista Médica Minas Gerais, 23 (4), 437-445. doi: 10.5935/2238-3182.20130069

Rojas, D. (2004). Conducta sexual de riesgo para las infecciones de transmisión sexual en hombres que practican el sexo con hombres (HSH): desarrollo de un modelo predictivo. Tesis doctoral, Universidad Autónoma de Madrid, Madrid.

Silva, L.A.V., \& Iriart, J.A.B. (2010). Práticas e sentidos do barebacking entre homens que vivem com HIV e fazem sexo com homens. Interface - Comunicação, Saúde, Educação, 14 (35), 739-752. doi: 10.1590/ S1414-32832010005000021

Tanzer, N. K. (2005). Developing tests for use in multiple languages and cultures: A plea for simultaneous development. In R. K. Hambleton, P. F. Merenda, \& C. D. Spielberger (Eds.), Adapting educational and psychological tests for cross-cultural assessment (pp. 235-264). Mahwah, NJ: Lawrence Erlbaum.

Traen, B., Hald, G.M., Noor, S.W., Iantaff, A., Grey, J. \& Rosser, B.R.S. (2014). The relationship between use of sexually explicit media and sexual risk behavior in men who have sex with men: exploring the mediating effects of sexual self-esteem and condom use self-efficacy. International Journal of Sexual Health, 26, 13-24. doi: 10.1080/19317611.2013.823900. UNAIDS (2016). Get on the fast-track: the lifecycle approach to HIV. Retrieved from: http:// www.unaids.org/sites/default/files/media_asset/ Get-on-the-Fast-Track_en.pdf

Wade, R., Harper, G. W., \& Bauermeister, J. A. (2017). Psychosocial Functioning and Decisional Balance to Use Condoms in a Racially/Ethnically Diverse Sample of Young Gay/Bisexual Men Who Have Sex with Men. Archives of Sexual Behavior, 47(1), $195-$ 204. doi:10.1007/s10508-016-0912-2 
Endereço para correspondência:

Programa de Pós-graduação em Psicologia

Pontifícia Universidade Católica do Rio Grande do Sul

Av. Ipiranga, 6681 - Prédio $81-6^{\circ}$ andar -

sala 603 - Partenon

Porto Alegre/RS

CEP 90619-900

Raquel de Andrade Souza Ew

email: raquelew@hotmail.com

Recebido em 09/09/2018

Aceito em 08/10/2018 


\title{
Evidências de estrutura interna da Escala Baptista de Depressão - Versão Idoso (EBADEP-ID)
}

\author{
Evidence of the internal structure of the Baptista Depression Scale - Elderly Version (EBADEP-ID)
}

\author{
Makilim Nunes Baptista ${ }^{1}$ \\ Felipe Augusto Cunha ${ }^{2}$ \\ Maria Andreia da Nóbrega Marques ${ }^{3}$ \\ Universidade São Francisco
}

\section{Resumo}

O objetivo do presente estudo foi investigar propriedades psicométricas da Escala Baptista de Depressão-Versão Idoso (EBADEP-ID). Participaram da pesquisa 244 idosos do estado do Piauí, sem diagnóstico de depressão, com faixa etária variando de 60 a 96 anos $(\mathrm{M}=68,85 ; \mathrm{DP}=9,19)$, sendo $67,9 \%$ do sexo feminino. Os principais resultados indicaram que dos 30 itens iniciais a escala foi reduzida para uma versão mais breve de 15 itens. A escala apresentou uma melhor adequação com uma solução de dois fatores, ambos apresentando valores adequados de alfa de Cronbach (F1: 0,90 e F2: 0,88). Por fim, conclui-se que a EBADEP-ID demonstrou evidências de validade de estrutura interna aceitáveis.

Palavras--chave: Sintomatologia Depressiva; Análise Fatorial Exploratória; Teoria de Resposta ao Item.

\begin{abstract}
The objective of the present study was to investigate the psychometric properties of the Depression-Elderly Baptista Scale (EBADEP-ID). A total of 244 elderly people from the state of Piauí, with no diagnosis of depression, ranging in age from 60 to 96 years $(\mathrm{M}=68.85, \mathrm{SD}=9.19), 67.9 \%$ of them female. The main results indicated that of the 30 initial items the scale was reduced to a shorter version of 15 items. The scale was better suited to a two-factor solution, both presenting adequate values of Cronbach's alpha (F1: 0.90 and F2: 0.88). Finally, it is concluded that EBADEP-ID has demonstrated evidence of acceptable internal structure validity.
\end{abstract}

Keywords: Depressive Symptomatology; Exploratory Factor Analysis; Item Response Theory.

A população idosa no Brasil vem aumentando nos últimos anos. Estimativas apontam que até 2030 aproximadamente 41,5 milhóes de idosos farão parte da população do país, com possibilidades de postergar a expectativa de vida para 85 anos (Instituto Brasileiro de Geografia e Estatística, 2010). Considerando o aumento significativo desse público, é importante entender o impacto que o envelhecimento acarreta para essas pessoas, por exemplo, mudanças vinculadas ao âmbito físico (corpo) e psicológico (Silva et al., 2017). O idoso não desenvolve somente doenças de base fisiológica, tais como hipertensão arterial, astenia e dor crônica, mas também chances de desencadear possíveis transtornos psiquiátricos, como a depressão, consequentemente trazendo mais limitaçóes para a vida desse sujeito (Ortiz \& Wanderley, 2013).

A depressão é um transtorno psiquiátrico que não afeta somente os idosos, mas todas as faixas etárias, interferindo negativamente na funcionalidade do indivíduo. Os sintomas da depressão são variados, afetando no estado psicológico, comportamental e físico, podendo apresentar oscilaçôes de frequência, intensidade e duração, dependendo do momento que o sujeito se encontra (Fried, 2017). Por isso, a depressão é vista como um grave

\footnotetext{
${ }^{1}$ Possui graduação em Psicologia pela Universidade Sao Judas Tadeu (1995), mestrado em Psicologia pela Pontifícia Universidade Católica de Campinas (1997) e doutorado pelo departamento de Psiquiatria e Psicologia Médica da Universidade Federal de São Paulo (2001). Atualmente é docente do Programa de Pós-Graduação Stricto-Sensu em Psicologia da Universidade São Francisco - Itatiba; bolsista produtividade pelo CNPq; Coordenador do Laboratório de Avaliação Psicológica em Saúde Mental (LAPSAM-III) do Programa de Pós- Graduação Stricto-Sensu em Psicologia da Universidade São Francisco; Membro do Grupo de Trabalho de Família da União Latino-Americana de Entidades de Psicologia (ULAPSI); Membro del Red Mundial Suicidólogos. Tem experiência na área de Psicologia, com ênfase em Avaliação Psicológica, Tratamento e Prevenção Psicológica, atuando principalmente nos seguintes temas: depressão, suporte familiar, suicídio, adolescentes e estresse.

${ }^{2}$ Psicólogo pela Universidade São Francisco, Itatiba. Mestre e Doutorando em Psicologia pelo Programa de Pós Graduação stricto sensu da Universidade São Francisco, com ênfase em Avaliação Psicológica em Saúde Mental como bolsista CAPES.

${ }^{3}$ Possui graduação em Psicologia pela Universidade Estadual do Piaui- UESPI/Faculdade de Ciências Médicas (2003), Mestrado em Educação pela Universidade Federal do Piauí (2009) e Doutorado em Psicologia pela Universidade Sáo Francisco (2016). Pós-doutorado em Psicologia pela Universidade São Francisco (2017). Atualmente é psicóloga do Centro Integrado de Reabilitação, gerente de reabilitação intelectual do Centro Integrado de Reabilitação, professora do Centro Universitário Santo Agostinho e professora adjunta da UESPI.
} 
problema de saúde mental, constituída por uma variedade de sintomas, sendo estes importantes no momento de rastrear a frequência, intensidade e duraçáo da tipologia da depressão (World Health Organization, 2017).

Existem alguns sintomas importantes no transtorno depressivo, tais como o humor deprimido, anedonia, fadiga, alterações no apetite e sono, que são comuns tanto na faixa etária adulta quanto na velhice (American Psychological Association - APA, 2014). Porém, existem outros sintomas e comportamentos mais específicos nos idosos, sendo esses, o declínio e perdas de habilidades físicas decorrentes da própria idade, dores constantes provindas de doenças crônicas, viuvez, sentimento de desamparo, afastamento do âmbito profissional (aposentadoria), diminuição da rede social e morte de amigos e familiares; podendo ser considerados fatores agravantes para o quadro depressivo dessa faixa etária (Xavier et al., 2014).

No que diz respeito ao rastreamento da sintomatologia depressiva no idoso, existem algumas limitaçóes no momento de identificar com expertise se o indivíduo apresenta um possível episódio depressivo. Frequentemente os sintomas da depressão estão interligados com outras doenças clínicas e consequentemente diminuindo as funçóes cognitivas do indivíduo, tornando uma linha tênue entre o que é considerado patológico e normal nos idosos (Chiesi, 2017).

Dentre os principais sintomas depressivos, entende-se que o declínio das funçóes cognitivas (memória e atenção) no idoso são consequências do envelhecimento. Essas funções normalmente são prejudicadas com mais intensidade quando se tem o diagnóstico de depressão, fazendo com que esses sujeitos sofram com mais prejuízos cognitivos (Braga, Santana, $\&$ Ferreira, 2015). Assim, por conter vários sinais similares entre a depressão e os demais transtornos psiquiátricos, no momento de realizar um diagnóstico diferencial surgem algumas dificuldades, tais como analisar com precisão os sintomas a partir de cada fase do desenvolvimento humano que o sujeito se encontra (Batistoni, Neri, \& Cupertino, 2010).

Uma das maneiras de rastrear com precisão e acurácia um determinado episódio depressivo é a partir de técnicas e instrumentos de avaliação. Os testes de autorrelato ou mesmo as entrevistas clínicas, são meios instrumentais importantes para auxiliar no manejo clínico do profissional, por exemplo, analisar as várias formas que a depressão pode afetar o estado emocional e físico do sujeito (Chiesi, 2017; Van Loo et al., 2012). Para facilitar esse momento de avaliação, algumas escalas foram elaboradas para rastrear sintomatologia depressiva nos idosos, sendo essas a Geriatric Depressive Scale - GDS (Yesavage et al., 1983).

A GDS é um instrumento de rastreio autoaplicável ou realizado por um entrevistador, com itens dicotômicos para discriminar possíveis sintomas depressivos dos sinais do envelhecimento. A escala apresenta duas versôes, uma de 30 itens e outra com 15 itens, sendo sua versão reduzida. Vários estudos sobre a GDS foram realizados no Brasil, no intuito de assegurar a qualidade psicométrica da escala no âmbito nacional. Na pesquisa de Sousa et al. (2007) que teve como objetivo avaliar as evidências de validade e fidedignidade da GDS nas versôes de 30 e 15 itens em idosos hospitalizados, apresentando respectivamente o alfa de Cronbach de $0,94 \mathrm{e}$ 0,91 para cada versão. Em um outro estudo de Paradela, Lourenço e Veras (2005) que o objetivo também foi buscar evidências de precisão para a GDS na versão reduzida, os autores encontraram o alfa de Cronbach adequado de 0,90 e pontos de corte para idosos hospitalizados e grupo não clínico.

Outros instrumentos amplamente usados na população idosas são o Beck Depression Inventory-II (BDI-II; Gorenstein, Pang, Argimon, \& Werlang, 2011) e a Escala de Avaliação de Depressão de Hamilton (HRSD; Hamilton, 1967). Ambas escalas foram traduzidas e validadas para a população brasileira, porém não são especificas somente para o público idoso, porque os instrumentos focam com mais intensidade nos sintomas somáticos e vegetativos da depressão, não destacando os aspectos cognitivos, afetivos e sociais, que seriam mais relevantes para esse perfil de idade (Hiesi, et al., 2017).

Pensando no uso de instrumentos não específicos para os idosos e as dificuldades de separar os possíveis sintomas depressivos dos sintomas orgânicos decorrentes de outras doenças neurológicas, Baptista (2013) construiu a Escala Baptista de Depressão para Idosos (EBADEP-ID). A EBADEP-ID, destaca-se por ser uma escala nacional que utiliza critérios de classificação para Transtorno Depressivo Maior, pensando nas possíveis consequências que o envelhecimento acarreta no sujeito, responsáveis por dificultar na avaliação psicológica, dando mais ênfase para os sintomas cognitivos, de humor e sociais vinculados a depressão.

A EBADEP-ID foi baseada nos mesmos descritores que deram origem à Escala Baptista de Depressão para Adultos EBADEP-A (Baptista, 2012) e à versão InfantoJuvenil (Baptista, 2017), porém, essas escalas na versão adulta e infanto-juvenil são unifatoriais, diferenciando da EBADEP-ID que foi encontrada uma solução melhor de dois fatores. Portanto, todas versôes são baseadas nos mesmos descritores, que são os indicadores de classificação do 
DSM-IV-TR e DSM-5 (American Psychiatric Association, 2013), CID-10 (Organização Mundial da Saúde, 1993), Terapia Cognitiva da Depressão (Beck et al., 1979) e princípios da Terapia Comportamental (Ferster, Culbertson, \& Boren, 1977). Inicialmente foram criados 70 itens no formato dicotômico para a EBADEP-ID porém, após a realização de análises de conteúdo e de semântica, 40 itens foram excluídos, por não condizerem com a pertinência teórica da depressão em idosos, e também por serem itens de difícil entendimento e com descritores mais vegetativos, como por exemplo, "tenho dificuldade em dormir" e "Meu apetite não continua mais como antes" totalizando uma versão mais atual do instrumento com 30 itens (Baptista, 2016).

Em um estudo que utilizou a EBADEP-ID também como instrumento para rastrear sintomatologia depressiva, Coutinho, Hamdan e Baptista (2016) tiveram como objetivo buscar evidências de validade baseada na relação com outras variáveis para a escala. A amostra da pesquisa foi constituída por 202 idosos de centro de convivência, asilares e internados em hospital; composto na maioria por homens $(\mathrm{n}=106)$, com a idade da amostra total variando entre 60 e 90 anos $(\mathrm{M}=68 ; \mathrm{DP}=7,22)$. Os instrumentos utilizados, além da EBADEP-ID, foram o Mini-Mental State Exam (MMSE) e a Geriatric Depression Scale (GDS-15), que serviram como escalas complementares para caracterizar a amostra. Os resultados demonstraram que a EBADEP-ID possuiu uma boa capacidade de discriminar os vários grupos de idosos avaliados, $\mathrm{e}$ correlacionou positivamente com a GDS-15 $(r=0,76)$, constatando algumas similaridades entre as escalas, ambas com o intuito de fornecer rastreio da sintomatologia depressiva nos idosos.

A necessidade de ter um instrumento de rastreio da depressão para os idosos é importante, por isso a necessidade de realizar um estudo exploratório com foco psicométrico para EBADEP-ID. A procura de evidências de validade é de suma importância para a sustentação de um instrumento psicológico. Assim, a presente pesquisa teve como objetivo analisar as evidências de estrutura interna da Escala Baptista de DepressãoVersão Idoso (EBADEP-ID).

\section{MÉTODO}

\section{Participantes}

A amostra foi composta por 244 idosos da capital e do interior do estado do Piauí, sem diagnóstico clínico de transtorno mental, relatado pelo próprio indivíduo. A idade desses participantes variou entre 60 e 96 anos $(M=68,85 ; D P=9,19)$, sendo que $62,3 \%$ $(n=152)$ eram do sexo feminino. Quanto ao estado civil, a maior parte dos participantes foi composta por $52,4 \%(n=127)$ casados e $22,5 \%(n=55)$ de viúvos. Os demais sujeitos ficaram entre solteiros $13,2 \%(n=32) \mathrm{e}$ separados $11,9 \%(n=29)$.

\section{Instrumentos}

Escala Baptista de Depressão - Versão Idosos EBADEP-ID (Baptista, 2013): A EBADEP-ID é um instrumento para rastrear sintomas depressivos em idosos, autoaplicável ou aplicado por um entrevistador. A escala possui 30 itens, como por exemplo, "Estou me sentindo mais triste"; "Prefiro a solidão"; "Consigo me concentrar nas atividades" e "Gosto de mim" todos com formato de respostas dicotômicas (sim ou não) pontuadas de 0 a 1 ponto. Dentre esses itens, os principais sintomas da depressão são abordados, tais como, baixa autoestima, dificuldades em resolver problemas, sentimento de incapacidade, percepçáo de apoio social, choro, anedonia, entre outros. O diferencial da EBADEP-ID é que o instrumento não aborda somente os sintomas vegetativos por serem comuns no quadro do envelhecimento natural, e focam sintomas em dimensáo cognitiva e social, baseados nos manuais psiquiátricos e nas duas principais teorias que foram precursoras na compreensão da depressão (cognitivo e comportamental).

\section{Procedimentos}

Após a autorização da instituição para a pesquisa e a aprovação do comitê de ética e pesquisa (CAAE: 60623516.7.0000.5514). os sujeitos respondentes do estudo receberam o Termo de Consentimento Livre e Esclarecido (TCLE) impresso em duas vias, que constavam as informaçóes pertinentes da pesquisa. $\mathrm{O}$ instrumento foi aplicado de forma individual em centros de recreação para idosos, e a coleta teve duração aproximada de 20 minutos.

\section{Análise de Dados}

Os dados foram analisados a partir do programa Factor (versão 10.3.01, Lorenzo-Seva \& Ferrando, 2006) para realizar análise paralela e depois Análise Fatorial Exploratória (AFE), sendo utilizado o método de estimação Unweighted Least Squares (ULS), a partir de uma matriz de correlaçóes policóricas, com método de retenção Minimum Average Partial (MAP, Velicer, 
1976). Foi escolhido a rotação direct oblimim. O índice Kaiser Meyer Olkin - KMO, que verificou a homogeneidade dos itens e foi considerando como muito bom se tiver valores entre 0,80 e 0,90 e ruim se for encontrado valores abaixo de 0,30 . Após a AFE, foram encontrada uma solução melhor com dois fatores, que também foi analisada a partir da Teoria de Resposta ao Item (TRI), por meio do modelo de Rasch, para itens dicotômicos, a partir do programa Winsteps 3.74. A análise para verificar o ajuste dos itens foi avaliado segundo os índices de infit e outfit, sendo que o valor deveria estar entre 0,60 e 1,40 (Linacre, 2011). E por último foi feita uma Análise Fatorial Confirmatória (AFC) através do programa Mplus para confirmar a hipótese da solução de dois fatores encontrada na AFE. Foram utilizados os seguintes índices de ajustes para a AFC, Qui quadrado e os graus de liberdade (X2/g.l), Root Mean Square Error of Approximation (RMSEA), Comparative Fit Index (CFI) e Tucker-Lewis index (TLI) (Marôco, 2014).

\section{RESULTADOS}

Inicialmente foi feita uma análise paralela, que demonstrou uma solução de até três fatores. A partir desse resultado preliminar, foi necessário verificar a adequação da amostra para possível análise fatorial exploratória $(\mathrm{KMO}=0,79, \chi 2$ de Bartlett $=10147,1$, $p<0,001)$. Além da análise paralela foram utilizados, também, dois outros métodos de retenção, sendo esses Minimum Average Partial (MAP) e HULL. O HULL considerou mais adequada uma solução unifatorial, e já o MAP uma soluçáo de dois fatores. (Lorenzo-Seva \& Van Ginkel, 2016; Lorenzo-Seva, 2003). Considerando os índices de ajustes e a pertinência do modelo cognitivo da depressão, a solução mais adequada foi com dois fatores, totalizando 15 itens, e os demais itens foram excluídos porque os valores das cargas fatoriais apresentados foram menores que 0,40. Assim, o índice de ajuste Global Fit Index (GFI) e o Comparative Fit Index (CFI) foram respectivamente de 0,97 e 0,98, com uma variância explicada de $41,17 \%$ total dos itens, explícitos na Tabela 1.

\section{Tabela 1}

Cargas Fatoriais da EBADEP-ID

\begin{tabular}{cccc}
\hline \multicolumn{3}{c}{ Fatores } & \\
\hline Itens & 1 & 2 & $\mathrm{~h}^{2}$ \\
\hline 1 & $-0,53$ & 0,55 & 0,30 \\
3 & 0,12 & 0,49 & 0,24 \\
5 & $-0,01$ & 0,65 & 0,42 \\
11 & 0,52 & $-0,03$ & 0,22 \\
12 & $-0,05$ & 0,47 & 0,36 \\
14 & $-0,01$ & 0,60 & 0,27 \\
15 & $-0,02$ & 0,52 & 0,40 \\
17 & 0,63 & 0,03 & 0,16 \\
18 & 0,41 & 0,10 & 0,30 \\
20 & 0,55 & 0,01 & 0,33 \\
22 & $-0,05$ & 0,56 & 0,25 \\
26 & 0,42 & $-0,20$ & 0,24 \\
27 & $-0,03$ & 0,49 & 0,56 \\
28 & 0,75 & 0,02 & 0,57 \\
30 & 0,75 & 0,03 & \\
\hline Eingenvaluesues & 3,59 & 2,58 & \\
\hline Var. Explicada & $23,98 \%$ & $17,19 \%$ & \\
\hline
\end{tabular}

Foram excluídos 13 itens na primeira etapa de rotação da análise fatorial, por não terem carregados em nenhum fator, sobrando 17 itens. Posteriormente, foram excluídos mais dois itens que não carregaram nos 
fatores específicos. Por fim restaram 15 itens, subtraídos dos 30 totais presentes na EBADEP-ID, reorganizados em dois fatores, com eigenvalues de 3,59 no Fator 1 (Humor deprimido e Autoestima) e 2,58 no Fator 2 (Anedonia e Desesperança) (Tabela 1).

A melhor solução encontrada foi a de dois fatores, sendo o F1 composto por sete itens com semântica positiva referentes a humor e autoestima, e o F2 contendo oito itens com semântica negativa sobre anedonia e desesperança. A correlação entre o F1 e F2 foi de $r=$ $-0,20(p<0,001)$, demonstrando um valor baixo entre os fatores; e o alfa de Cronbach dos fatores foram de 0,90 (F1) e 0,88 (F2) apresentando um nível adequado para a consistência interna da escala. $\mathrm{Na}$ sequência foi usado um procedimento estatístico complementar para analisar os resultados provenientes do estudo, no caso, o modelo da Teoria de Resposta ao Item (TRI). Na Tabela 2 são apresentados os dados do F1 e F2 dos 244 sujeitos da amostra.

\section{Tabela 2}

Análise dos itens da EBADEP-ID pelo modelo de Rasch para os fatores 1 e 2

\begin{tabular}{|c|c|c|c|c|c|}
\hline Itens do fator 1 & Escore Bruto & Dificuldade (b) & Infit & Outfit & $\begin{array}{l}\text { Correlação } \\
\text { Item-total }\end{array}$ \\
\hline 11 & 229 & 0,67 & 1,04 & 1,24 & 0,62 \\
\hline 17 & 238 & $-0,88$ & 0,85 & 1,07 & 0,56 \\
\hline 18 & 240 & $-1,50$ & 1,45 & 1,94 & 0,32 \\
\hline 20 & 225 & 1,13 & 0,97 & 0,92 & 0,70 \\
\hline 26 & 232 & 0,27 & 1,22 & 1,27 & 0,54 \\
\hline 28 & 235 & $-0,22$ & 0,77 & 0,65 & 0,67 \\
\hline 30 & 230 & 0,54 & 0,73 & 0,65 & 0,74 \\
\hline Média & 232,7 & 0,00 & 1,00 & 1,11 & \\
\hline DP & 4,9 & 0,86 & 0,24 & 0,41 & \\
\hline Itens do fator 2 & Escore Bruto & Dificuldade (b) & Infit & Outfit & $\begin{array}{l}\text { Correlação } \\
\text { Item-total }\end{array}$ \\
\hline 1 & 60 & 0,10 & 1,00 & 1,00 & 0,60 \\
\hline 3 & 93 & $-0,96$ & 1,12 & 1,16 & 0,60 \\
\hline 5 & 68 & $-0,17$ & 0,86 & 0,77 & 0,67 \\
\hline 12 & 69 & $-0,20$ & 1,08 & 1,15 & 0,58 \\
\hline 14 & 64 & $-0,04$ & 0,93 & 0,90 & 0,64 \\
\hline 15 & 34 & 1,20 & 0,94 & 0,72 & 0,57 \\
\hline 22 & 48 & 0,56 & 0,96 & 0,87 & 0,60 \\
\hline 27 & 78 & $-0,50$ & 1,11 & 1,16 & 0,58 \\
\hline Média & 64,3 & 0,00 & 1,00 & 0,97 & \\
\hline $\mathrm{DP}$ & 16,8 & 0,61 & 0,09 & 0,17 & \\
\hline
\end{tabular}

$\mathrm{Na}$ tabela 2 pode ser notado que a maioria dos itens apresentaram bons índices de ajustes (Infit $e$ Outfit). Apenas o item 18 "Gosto de mim" pertencente ao F1 demonstrou desajuste no Outfit, com base na adequação de valores proposto por Linacre (2011), considerando valores aceitáveis entre 0,60 e 1,40, porém não foi descartado, porque representa um aspecto importante no momento de avaliar sintomatologia depressiva. Outra característica avaliada dos itens, foi o nível de dificuldade entre os fatores, mostrando que no F1 foram expressas variaçóes entre -1,50 e 1,13 e F2: -0,96 e 1,20 . Esses valores de $b$ explicaram a intensidade da 
característica avaliada pelo item, como por exemplo no item 20 "Sinto-me com disposição", sentir-se disposto seria um aspecto mais difícil ou com chances de ser menos endossado na escala, sendo que o item 03 "Tenho sentido vontade de chorar" foi um item mais fácil de responder, demonstrando que os sujeitos respondentes da escala, necessitaram de um nível intermediário para entender e concordar com os itens do instrumento. Por fim, a partir da correlação item-total, quase todas foram adequadas, apresentando valores moderados $(0,54$ a 0,74; Dancey \& Reidy, 2006).

Assim, outra característica avaliada no instrumento foi a distribuição e o agrupamento em relação aos itens e às pessoas, demonstrado na Figura 1. Observa-se que a visualização dos Mapas de itens apresenta a letra $M$ na figura, situada na régua que divide o mapa entre itens e pessoas, demonstrando a posição média dos itens enquanto das pessoas.

\section{Figura 1.}

Mapa de pessoas e itens para o Fator 1 e 2.

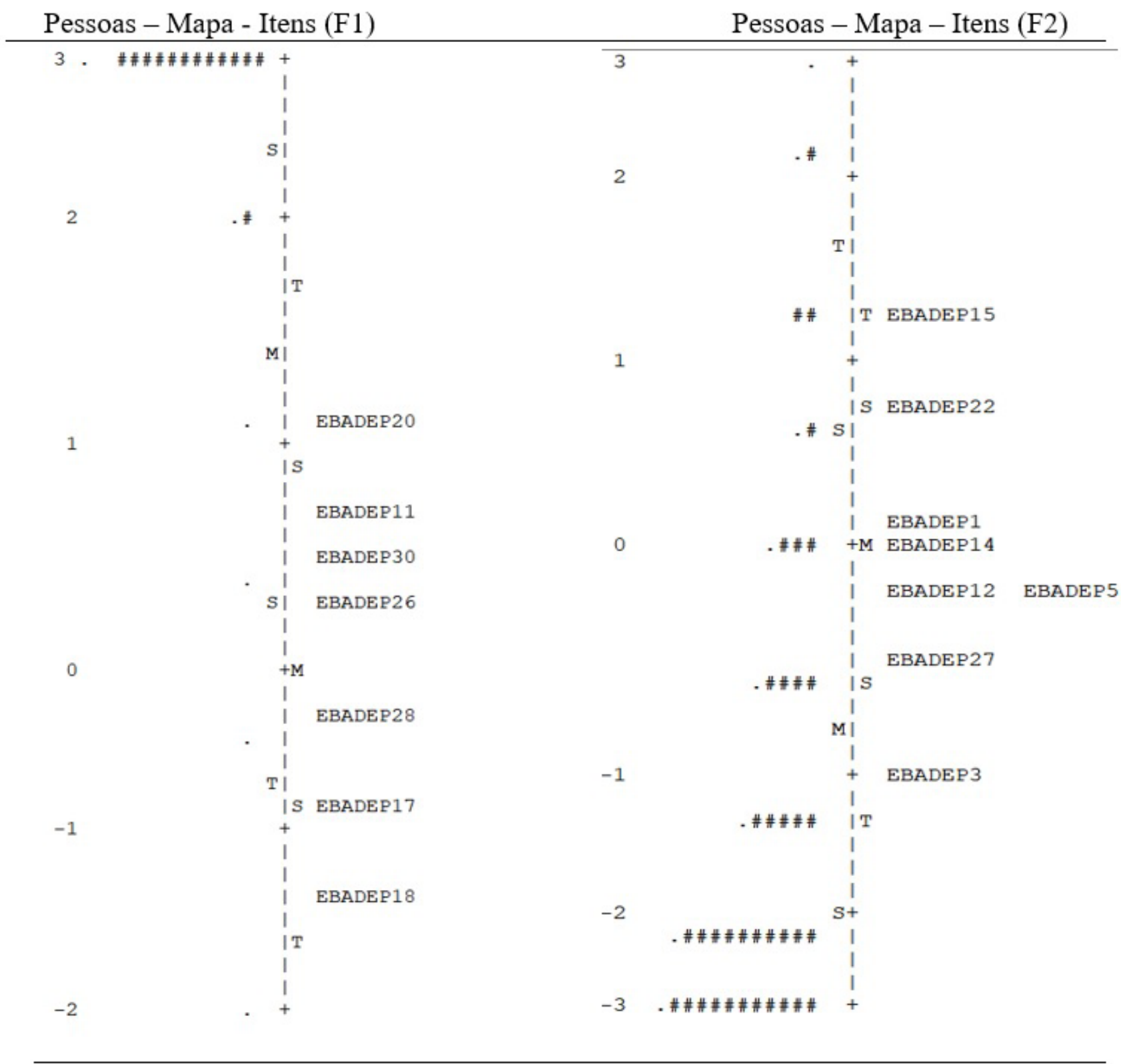

Legenda: Cada “\#” equivale a 11 pessoas. Cada “.” Equivale de 1 a 10 pessoas

Por meio da TRI é possível identificar a preci- 1 demonstra que os respondentes se agruparam são real dos itens, assim, no mapa de itens do Fator entre -2 e 3, porém, a maioria se agrupou no nível 3, 
subsequentemente os itens entre - 1,5 e 1 , demonstrando que os itens foram endossados facilmente pela população, não apresentando dificuldade de interpretação. Os itens, segundo o mapa que foram considerados mais difíceis foram o 20 (Sinto-me com disposição) e o 11 (Consigo me concentrar nas atividades) e os mais fáceis, 18 (Gosto de mim) e 17 (Gosto da minha vida).

No fator 2, as pessoas se agruparam entre $-3 \mathrm{e}$ 3 , tendo um maior acumulo de respondentes no nível -3 e -2 , e os itens entre -1 e 1 , demonstrando que os sujeitos apresentaram mais dificuldade de endossar os itens do F2. Os itens mais endossados foram o 3 "Tenho sentido vontade de chorar" e o 27 "Viver está cada vez mais difícil", e os menos endossados, 22 "Meus dias têm sido vazios" e 15 "Minha vida está cada vez pior". No caso da EBADEP-ID não ser uma escala de habilidade, que náo existe respostas erradas ou certas, a dificuldade de cada item é avaliado a partir da frequência da resposta; então frequentemente os itens mais "difíceis" são aqueles que tiverem pontuação mais baixa. Por fim, considerando os escores brutos de respostas, o F1 obteve maiores pontuaçôes, quase não discriminado os itens, consequentemente porque por ser formulado por itens com semântica positiva, teve uma maior pontuaçáo do grupo, por serem sujeitos saudáveis e sem diagnóstico de depressão.

Por último, foi realizada uma AFC para confirmar se a solução com dois fatores foi a melhor encontrada. Então os resultados foram satisfatórios, observando que o X2/g.l $=118.785 / 89$ e os índices de ajustes, RMSEA= $0.037, \mathrm{CFI}=0.95$ e TLI= 0,94. Assim, confirmando a hipótese que a EBADEP-ID ficou mais adequada com o modelo de dois fatores, sendo esses o Fator 1 (Humor deprimido e Autoestima) e Fator 2 (Anedonia e Desesperança).

\section{DISCUSSÁO}

A presente pesquisa teve como objetivo principal realizar análises psicométricas da Escala Baptista de Depressão para idosos (EBADEP-ID). A Análise Fatorial Exploratória (AFE) e a Análise Fatorial Confirmatória (AFC), junto do uso da Teoria de Resposta ao Item (TRI), especificamente o modelo de um parâmetro de Rasch, foram usadas para buscar evidências de validade de estrutura interna, sendo esses métodos bastante utilizados por profissionais da psicologia no âmbito da avaliação psicológica (Primi, Muniz, \& Nunes 2009; Segabinazi et al., 2012)

A partir dos primeiros resultados encontrados segundo a AFE, foi observado que a versão breve da escala ficou com 15 itens, apresentando cargas fatoriais adequadas nos dois fatores. Esses fatores foram nomeados como humor e autoestima (F1) e Anedonia e Desesperança (F2). Segundo a classificação do Transtorno Depressivo Maior pelo DSM-5, entende que esses fatores foram separados a partir dos principais sintomas da depressão (APA, 2014) e outros sintomas presentes no modelo cognitivo da depressão, que no caso a desesperança (Beck \& Haigh, 2014).

No estudo de Shafer (2006), em que o principal objetivo foi verificar as dimensóes fatoriais dos principais instrumentos que avalia depressão, no caso, Beck Depression Inventory (BDI), Center for Epidemiological Studies Depression Scale (CES-D), Hamilton Rating Scales for Depression (HRSD) e Zung Self-Rating Depression Scale (SDS). Esses instrumentos apresentaram diversas dimensôes teóricas para a divisáo dos fatores, sendo que as categorias comuns entre todas escalas foram os sintomas gerais de depressão, sintomas somáticos, sintomas positivos, atitudes negativas voltadas para si e afetos depressivos gerais. Percebe-se que a maioria dos testes de depressão partilham fatores e descritores teóricos parecidos entre si, apenas o BDI que contem mais itens focados na teoria cognitiva da depressão, tais como a EBADEP-ID, que teve como base teórica a teoria cognitiva da depressão, dando mais ênfase para os sintomas cognitivos e menos para os vegetativos/somáticos.

Comparando a EBADEP-ID com as outras versões do instrumento, sendo essas a de adulto e infanto-juvenil (Baptista, 2012; Baptista, 2017), a versão para idosos não obteve uma estrutura fatorial unidimensional como as demais, mas sim, uma solução com dois fatores. Considerando os sintomas da depressão a partir dos resultados obtidos a partir das análises fatoriais, entende-se que os principais sintomas carregados nos fatores foram os de humor e os cognitivos. Nota-se que esses resultados vão ao encontro dos achados científicos, porque espera-se que os idosos tenham uma diferenciação desses sintomas, porque normalmente pelo seu quadro de saúde e características naturais da idade mais avançada, os sintomas somáticos e vegetativos são mais comuns, não sendo considerados sinais decisivos no momento de considerar um possível transtorno depressivo (Apóstolo et al., 2014; Chiesi et al., 2017).

Na solução encontrada de dois fatores, também foram apresentados índices favoráveis de fidedignidade, sendo esses 0,88 (F1) e 0,90 (F2). Esses índices podem ser comparados com outros instrumentos amplamente usados no contexto da avaliaçáo da depressao geriátrica, como por exemplo a escala no formato reduzido da GDS- 15, apresentando fidedignidade de 0,91, 
demonstrando que os valores foram altos (Paradela, Lourenço \& Veras, 2005). No que diz respeito aos outros resultados da AFE, a variância explicada foi satisfatória (41,17\%), que segundo Abelson (1985), considera esse indicador como um critério importante para avaliar se as distribuiçôes dos itens foram adequadas.

A partir do modelo da TRI, foi analisado também o índice de dificuldade (b) dos itens da EBADEP-ID. A grande maioria dos respondentes apresentou respostas esperadas. No que diz respeito ao ajuste de itens (infit e outfit), apenas um item ficou fora do intervalo do valor de 0,60 e 1,40, no caso o 18 "Gosto de mim", podendo ser um item a ser reavaliado em um futuro estudo. Portanto, escala apresentou índices adequados, seguindo os valores esperados (Linacre, 2011). Por fim, para verificar a unidimensionalidade do instrumento, foi realizada uma análise de resíduos por componentes principais, pressupondo o critério de inferioridade, sendo que os resíduos considerados maiores de 2,0 eigenvalue são considerados como não unidimensional (Linacre, 2009). Observou-se um primeiro resíduo com eigenvalue igual a $2,7(6,3 \% ; 17,8 \%$ da variância explicada), acima do que era esperado.

Em relação aos itens do F2, esses foram menos endossados, comparados ao F1. Um dos motivos seria que nesse fator os itens são apresentados com uma semântica negativa, dificultando um pouco a interpretação dos respondentes, pensando que a amostra da pesquisa foi constituída com sujeitos saudáveis. Os idosos por não apresentar sintomatologia depressiva, não pontuaram com frequência o $\mathrm{F} 2$, por isso esse fator apresentou diferença quando comparado com o F1. Assim, a EBADEP-ID foi construída pensando em avaliar todo o continuum da sintomatologia depressiva, por isso a necessidade de ter itens negativos e positivos, que segundo Moreno e Carneiro (2016) salientam que é importante ter a dimensão de todos os aspectos da depressão, por tratar-se de um construto multidimensional e complexo.

Outra hipótese para explicar essa pontuação mais alta no F1 e também essa solução de dois fatores, sendo um composto por itens positivo e outro por negativos, seria um possível Efeito de Método. Lindwall et al. (2012) comentam que isso pode acontecer quando a escala possui dimensões semânticas opostas, podendo causar um possível viés. Portanto, foi realizada uma AFC para mostrar que os dois fatores encontrados foram pertinentes com a dimensão teórica proposta pelos autores.

Algumas análises de dimensionalidade de instrumentos que sáo construídos no formato de itens positivos e negativos, demonstram estruturas fatoriais distintas, sendo mais associada pela junção dos itens, do que pelo formato semântico e do fator em si. Assim, futuramente seria necessário um estudo para realizar análises de vieses de semântica, que segundo Wetzel, Lüdtke, Zettler e Böhnke (2015) existem dois tipos, o Estilo de Resposta Extrema (ERS) e o Estilo de Resposta de Aquiescência (ARS), que respectivamente significa a tendência do sujeito preferir responder categorias de resposta extrema, como por exemplo "discordo totalmente e concordo fortemente" e tendência de preferir categorias declarando concordância , como por exemplo "concordar ou concordar totalmente".

A partir dos resultados obtidos, foi notado que a EBADEP-ID apresentou uma estrutura fatorial de dois fatores, diferente das outras versóes do instrumento (adulto e infanto-juvenil). Portanto, foi utilizado os mesmos descritores teóricos para a construção da escala na versão idosos, por isso, futuramente serão realizados novas estudos para confirmar essa estrutura encontrada. Assim, alguns itens foram excluídos com a intenção de transformar a escala mais coerente com a literatura e condizente com sua proposta de rastreamento para os idosos, totalizando 15 itens. Algumas limitaçóes fizeram parte deste estudo tais como a amostra reduzida de idosos, sendo todos de uma única região do Brasil e nenhum participante com diagnóstico clínico. Importante considerar que para estudos futuros incluir amostras de outras regiôes do país e idosos com diagnóstico de depressão.

\section{REFERÊNCIAS}

Abelson, R. P. (1985). A variance explanation paradox: When a little is a lot. Psychological Bulletin, 97(1), 129-133. doi: 10.1037/0033-2909.97.1.129

Alencar, M. A., Bruck, N. N. S., Pereira, B. C., Câmara, T. M. M., \& Almeida, R. D. S. (2012). Perfil dos idosos residentes em uma instituição de longa permanência. Revista Brasileira de Geriatria e Gerontologia, 15(4), 785-796. doi:10.1590/ S1809-98232012000400017

American Psychiatric Association - APA. (2014). Manual Diagnóstico e Estatístico dos Transtornos Mentais - DSM- $V$. Porto Alegre: Artmed.

Baptista, M. N. (2012). Escala Baptista de Depressáo: versão adulto (EBADEP-A). São Paulo: Vetor.

Baptista, M. N. (2016). Escala Baptista de Depressáo para Idosos (EBADEP-ID). Relatório náo publicado. Universidade São Francisco. 
Baptista, M. N. (2017). Escala Bapstista de Depressão (Versão Infanto-Juvenil). Relatório não publicado. Universidade São Francisco.

Batistoni, S. S. T., Neri, A. L., \& Cupertino, A. P. F. B. (2010). Medidas prospectivas de sintomas depressivos entre idosos residentes na comunidade. Revista Saúde Pública, 44(6), 1137-1143. Recuperado de http://www.producao.usp.br/ bitstream/handle/BDPI/2664/art_BATISTONI_ Medidas_prospectivas_de_sintomas_depressivos_ entre_idosos_2010.pdf?sequence $=1$

Beaudreau, S. A. \& O'Hara, R. (2009). The association of anxiety and depressive symptoms with cognitive performance in community-dwelling older adults. Psychology and Aging, 24(2), 507-512. doi: 10.1037/ a0016035

Beck, A. T., \& Haigh, E. A. (2014). Advances in cognitive theory and therapy: The generic cognitive model. Annual Review of Clinical Psychology, 10, 1-24. doi: 10.1146/annurev-clinpsy-032813-153734

Beck, A. T., Kovacs, M., \& Weissman, A. (1979). Assessment of Suicidal Intention: The Scale for Suicide Ideation. Journal of Consulting and Clinical Psychology, 47(2), 343-352. doi: http://dx.doi. org/10.1037/0022-006X.47.2.343

Chiesi, F., Primi, C., Pigliautile, M., Ercolani, S., Staffa, M. C. della, Longo, A., . . Mecocci, P. (2017). The local reliability of the 15 -item version of the Geriatric Depression Scale: An item response theory (IRT) study. Journal of Psychosomatic Research, 96, 84-88. doi: 10.1016/j.jpsychores.2017.03.013

Coutinho, F. L., Hamdan, A. C., \& Baptista, M. N. (2016). Escala Baptista de Depressão para Idosos EBADEP-ID: Evidências de validade. Perspectivas en Psicología, 13(2), 1-9. Recuperado de http:// www.seadpsi.com.ar/revistas/index.php/pep/article/ view/1./pdf

Ferster, C. B., Culbertson, S., \& Boren, M. C. (1977). Depressão clínica. In C. B. Ferster, S. Culbertson, \& M. C. Boren (Eds.), Princípios do comportamento (pp. 699-725). São Paulo: Hucitec.

Fried, E. I. (2017). The 52 symptoms of major depression: Lack of content overlap among seven common depression scales. Journal of Affective Disorders, 208(15), 191-197. doi: 10.1016/j. jad.2016.10.019

Braga, I. B., Santana, R. C., \& Ferreira., D. G. (2015). A Depressão no Idoso. Id on Line Revista de Psicologia, 26(9), 142-151. doi:https://doi.org/10.14295/ idonline.v9i26.332
Hutz, C. S., Bandeira, D. R., \& Trentini, C. M. (2015). Psicometria (pp.55-82). Porto Alegre: Artmed.

Instituto Brasileiro de Geografia e Estatística (IBGE) (2010). Sinopse do Senso Demográfico de 2010. Recuperado de http://www. ibge.gov.br/home/ estatistica/populacao/censo2010/default_sinopse. shtm.

Linacre, J. M. (2009). Winsteps Rasch measurement computer program. Chicago, Ilinois: Winsteps.

Linacre, J. M. (2011). A user's guide to Winsteps, Program Manual 3.74.0. Chicago: Winsteps.com.

Lindwall, M., Barkoukis, V., Grano, C., Lucidi, F., Raudsepp, L., Liukkonen, J., \& ThøgersenNtoumani, C. (2012). Method effects: The problem with negatively versus

positively keyed items. Journal of Personality Assessment, 94(2), 196-204. doi: 10.1080/00223891.2011.645936

Marôco, J. (2014). Análise de equações estruturais: Fundamentos teóricos, software $\&$ aplicações. $2^{\mathrm{a}}$ Edição. Report Number, Lda.

Moreno, R. A., \& Carneiro, A. M. (2016). Instrumentos de Avaliação de Depressão. Em C. Gorenstein, Y-P. Wang, \& I. Hungerbühler, Instrumentos de Avaliação em Saúde Mental (pp. 211-222). Porto Alegre: Artmed.

Organizaçáo Mundial da Saúde. (1993). Classificaçâao de transtornos mentais e de comportamento da CID10: Descriçóes clínicas e diretrizes diagnósticas. Porto Alegre: Artmed.

Ortiz, B.R. \& Wanderley, K. D. A. S. (2013). Reflexôes Sobre o Uso da Escala de Depressão Geriátrica (GDS-15) em Idosos Hospitalizados. Revista Kairós Gerontologia, 16 (3), 307-316. doi:10.1590/ S0047-20852007000200005

Paradela, E. M. P., Lourenço, R. A., \& Veras, R. P. (2005). Validação da escala de depressão geriátrica em um ambulatório geral. Revista de Saúde Pública, 39(6), 918-923. doi: 10.1590/ S0034-89102005000600008

Primi, R., Muniz, M., \& Nunes, C. H. S. S. (2009). Definiçóes contemporâneas de validade de testes psicológicos. Em C. S. Hutz. (Ed.), Avanços e polêmicas em avaliação psicológica (Vol. 1, pp. 243265). São Paulo: Casa do Psicólogo.

Segabinazi, J. D, Zortea, M., Zanon, C., Bandeira, D. R., Giacomoni, C. H., \& Hutz, C. S. (2012). Escala de afetos positivos e negativos para adolescentes: adaptação, normatização e evidências de validade. Avaliaçâo Psicológica, 11(1), 1-12. Recuperado de 
http://pepsic.bvsalud.org/pdf/avp/v11n1/v11n1a02. pdf

Shafer, A. B. (2006). Meta-analysis of the factor structures of four depression questionnaire: Beck, CES-D, Hamilton, and Zung. Journal Clinical Psychology, 62(1), 123-146. doi: 10.1002/jclp.20213

Silva, V. de L., Medeiros, C. A. C. X., Guerra, G. C. B., Ferreira P. H. A., Araújo Jr., J. R., Barbosa, S. J. de A., \& Araújo, A. (2017). Quality of life, integrative community therapy, family support, and satisfaction with health services among elderly adults with and without symptoms of depression. Psychiatric Quarterly, 88(2), 359-369. doi: 10.1007/ s11126-016-9453-z

Silva, A. R., Sgnaolin, V., Nogueira, L. E., Loureiro, F., Engroff., P., \& Gomes, I. (2017). Doenças crônicas não transmissíveis e fatores sociodemográficos associados a sintomas de depressão em idosos. Jornal Brasileiro de Psiquiatria, 66(1), 45-51. Recuperado de https://www.researchgate.net/profile/ Eduardo_Nogueira/publication/316738701_ Noncommunicable_chronic_diseases_and_ sociodemographic_factors_associated_with_ symptoms_of_depression_in_elderly

Velicer, W. (1976). Determining the number of components from the matrix of partial correlations. Psychometrika, 41(3), 321-327. doi:10.1007/ BF02293557

Vignola, R. C. B. \& Tucci, A. M. (2014). Adaptation and validation of the depression, anxiety and stress scale (DASS) to Brazilian Portuguese. Journal of Affective Disorders, 155, 104-109. doi:10.1016/j. jad.2013.10.031

Wetzel, Lüdtke, Zettler, \& Böhnke (2015). The Stability of extrema response style and acquiescence over 8 years. Assessment, 12(4), 1-13. doi: $10.1177 / 1073191115583714$

World health organization - WHO (2017). Mental health: New underst anding, new hope. Genova, WHO, 2017. Recuperado de http://www.who.int/ whr/2017/en/.

\section{Endereço para correspondência:}

Programa de Pós-Graduação Stricto Sensu em Psicologia USF - Universidade São Francisco

R. Waldemar César da Silveira, 105 Jardim Cura D’ars

Campinas - SP

CEP $13045-510$

Makilim Nunes Baptista

makilim01@gmail.com

Recebido em 05/09/2018

Aceito em 11/10/2018 


\title{
Traços frios e insensíveis no DSM-V: Implicaçóes teóricas e clínicas para o estudo da psicopatia
}

\author{
Callous and unemotional traits in the DSM-V: Theoretical and
} clinical implications for the study of psychopathy

\author{
Guilherme Welter Wendt ${ }^{1}$
}

Silvia Koller ${ }^{2}$

Universidade Federal do Rio Grande do Sul

\section{Resumo}

O construto da psicopatia, inicialmente atribuído somente a adultos, tem sido estendido para a infância e adolescência. Níveis significativos de traços psicopáticos são altamente prevalentes em crianças, adolescentes e adultos quando comparados com outras desordens, como a esquizofrenia, o que enfatiza a necessidade de estudos mais aprofundados a respeito. O presente manuscrito debate acerca da relevância da identificação clínica de traços frios e insensíveis (callous-unemotional traits) e implicaçôes para a pesquisa e prática em Psicologia em crianças e adolescentes. Estudos empíricos sobre o perfil de crianças e adolescentes com índices elevados de traços psicopáticos, incluindo funcionamento neuropsicológico e dificuldades associadas são comparados e avaliados criticamente. De modo similar, o texto enfatiza meios de diagnóstico, prevenção e intervenção psicológica.

Palavras--chave: Distúrbios do Comportamento; Saúde da Criança; Saúde do Adolescente; Diagnóstico; Psicopatia.

\section{Abstract}

The construct of psychopathy, initially limited to adulthood, has been extended to childhood and adolescence. Significant levels of psychopathic personality traits are highly prevalent in children, adolescents and adults when compared to other disorders, such as schizophrenia, which emphasizes the necessity for a better understanding. This manuscript discusses the relevance of clinical identification of callous-unemotional traits in children and adolescents and the implications for researchers and practitioners. Empirical studies about the profile of children and adolescents with high levels of psychopathic personality traits - including neuropsychological functioning and associated difficulties - are compared and critically examined. Similarly, the text discusses forms of diagnosis, prevention, and psychological intervention.

Keywords: Behavior Disorders; Child Health; Adolescent Health; Diagnosis; Psychopathy.

Na última edição do Diagnostic and Statistical Manual of Mental Disorders (Manual Diagnóstico e Estatístico dos Transtornos Mentais; DSM-V) o diagnóstico de Transtorno de Conduta (TC) passou a incluir novos especificadores, abarcando a presença de Emoçóes Pró-Sociais Limitadas (EPSL) (American Psychiatric Association [Associação Americana de Psiquiatria], 2013). Modificação semelhante foi recentemente incluída na $11^{\mathrm{a}}$ edição da Classificação Internacional de Doenças, razão pela qual os profissionais de saúde devem, na medida do possível, buscar obter maiores informações a respeito das EPSL (Fanti, Kyranides, Lordos, Colins, \& Andershed, 2018).

As EPSL são uma extensão do conceito de psicopatia, utilizado em adultos, sendo referidas na literatura internacional como traços frios e insensíveis (callous-unemotional traits; Jones \& Wendt, 2015). Embora, no Brasil, haja certo interesse no estudo de problemas comportamentais do tipo psicopático entre adultos (Gomes \& Almeida, 2010; Hauck-Filho, Teixeira, \& Dias, 2009), nota-se que investigaçôes sobre o tema focando em crianças e adolescentes são raras (Rigatti, DeSouza, Salum, Alves, Bottan, \& Heldt, 2018). Os quadros de psicopatia possuem três dimensóes fenotípicas que, embora distintas, são correlacionadas entre si (Blair, Budhani, Colledge, \& Scott, 2005). A primeira refere-se à dimensão afetiva, que abarca as EPSL. A segunda relaciona-se com comportamentos antissociais e impulsivos. A terceira dimensão, de cunho interpessoal, inclui traços de grandiosidade, narcisismo e manipulação (Frick \& Marsee, 2018). Embora associaçóes distintas entre as três dimensôes psicopáticas com os problemas de conduta tenham sido identificadas, especial foco tem sido dado as EPSL (Fanti et al., 2018). Isso porque características das EPSL fornecem informaçóes relevantes para entender responsividade ao tratamento

\footnotetext{
${ }^{1}$ Psicólogo (PUCRS), Mestre em Psicologia Clínica (UNISINOS) e Doutor em Psicologia (Goldsmiths, Universidade de Londres). Atualmente, é Pós-Doutorando junto ao Programa de Pós-Graduação em Psicologia (UFRGS, com bolsa do CNPq).

${ }^{2}$ Professora Doutora Titular da Universidade Federal do Rio Grande do Sul. Bolsista de Produtividade em Pesquisa do CNPq (Nível 1A).
} 
e, ademais, apresentam poder elevado na prediçáo de risco para o envolvimento com comportamentos antissociais severos ao longo do desenvolvimento (Frick, Ray, Thornton, \& Kahn, 2014).

As seguintes questôes permeiam o presente manuscrito: Qual a relevância teórica e clínica dos traços frios e insensíveis (que denotam limitada capacidade de expressão de emoções positivas)? Quais as formas de identificação dos traços frios e insensíveis/EPSL? E quais são as implicaçóes para a pesquisa e prática em Psicologia? Serão expostas evidências sobre o perfil de crianças e adolescentes com EPSL - incluindo funcionamento neuropsicológico e dificuldades associadas -, bem como seráo revisitados estudos que possam ser úteis no processo de prevençáo, diagnóstico e intervenção psicológica. Em síntese, espera-se contribuir para a atualização teórica de profissionais das áreas da clínica e da pesquisa.

\section{Relevância clínica do Transtorno de Conduta e dificuldades emocionais e comportamentais associadas}

O TC é caracterizado por comportamentos difusos envolvendo hostilidade, crueldade e agressividade, cuja origem ocorre durante a infância e ou adolescência. O TC possui prevalência estimada ao longo da vida de $12 \%$ em meninos e $7 \%$ em meninas, associando-se com elevado risco para problemas legais, prejuízos na saúde física e psicológica, mortalidade prematura, dentre outras dificuldades (Kim-Cohen, Caspi, Moffitt, Harrington, Milne, \& Poulton, 2003). No TC, existe uma alta heterogeneidade nos sintomas apresentados; nesse sentido, profissionais que utilizam o DSM-V para o diagnóstico de TC devem, a partir de agora, também avaliar crianças e adolescentes quanto à presença de, no mínimo, dois dos seguintes itens: 1) ausência de remorso ou culpa; 2) insensibilidade e ausência de empatia; 3) despreocupação com o desempenho (frieza e descaso quanto à performance na escola ou mesmo no trabalho); e 4) afeto superficial ou deficiente. No que tange às dificuldades associadas, diversos estudos indicaram que a presença de traços psicopáticos são importantes na diferenciação entre variadas manifestaçóes do TC em crianças e adolescentes (Forth \& Book, 2010; Frick et al., 2014).

Estudos indicam a adoção de estilos parentais positivos não é, necessariamente, suficiente para atenuar os problemas de conduta exibidos por jovens com EPSL (Clark, 2015; Pasalich, Dadds, Hawes, \& Brennan, 2011; para uma revisão mais aprofundada, ver Hauck-Filho \& Teixeira, 2014). Crianças com altos traços frios e insensíveis envolvem-se com comportamentos agressivos e violentos com maior frequência, tanto concorrentemente como preditivamente (Frick \& Dickens, 2006; Roose, Bijttebier, Decoene, Claes, \& Frick, 2010). De modo similar, investigaçôes longitudinais mostram que as EPSL são estáveis ao longo do tempo (Frick, 2009). Por exemplo, a avaliação dos pais quanto as EPSL de seus filhos, avaliados aos $10 \mathrm{e}$ aos 14 anos, correlacionaram-se fortemente $(r=0,71)$ (Frick, Kimonis, Dandreaux, \& Farrell, 2003). Ainda no que tange à avaliação dos pais em relação as EPSL, outro estudo indicou uma correlaçáo moderada entre as avaliaçóes realizadas aos oito e aos 16 anos $(r=0,50)$ (Obradovic, Pardini, Long, \& Loeber, 2007). No que diz respeito à literatura da psicopatologia do desenvolvimento, a presença de EPSL é consistente com as descriçôes de personalidade de infratores classificados como persistentes, o que denota maior risco de psicopatia na idade adulta (Moffitt, 2003).

Uma revisão recente e abrangente acerca de pesquisas sobre as EPSL e problemas comportamentais forneceu evidência substancial para a associação entre violência e EPSL (Frick et al., 2014). Incluindo 70 estudos transversais e 48 longitudinais, os achados indicaram que, para ambos os sexos, as EPSL foram significativamente associadas a medidas de comportamento antissocial e agressivo em crianças e adolescentes. A força da associação variou muito, entre $r=-0,15$ e $r=$ 0,84 , sendo a correlação média de $r=0,33$ (Forth \& Book, 2010). Associaçóes entre traços de psicopatia e agressividade são encontrados mais frequentemente entre meninos, sobretudo porque os adolescentes com tais traços tendem a ter atitudes que apoiam o uso da violência para atender às suas necessidades, possuem menor empatia e não sentem remorso por suas ações, sendo ainda atraídos por situaçóes de alto risco. Em adição, quando ocorre uma combinaçáo com elevada impulsividade, aumentam-se as probabilidades de uso de violência (Forth \& Book, 2010).

\section{Perfil neuropsicológico de crianças e adolescentes com EPSL}

Compreender o funcionamento neuropsicológico no contexto dos problemas de conduta - e, especificamente, entre indivíduos com EPSL - é importante por várias razóes. Em primeiro lugar, estudar a relação entre problemas de conduta, EPSL e funçôes cognitivas elucida aspectos etiológicos envolvidos nas dificuldades emocionais e comportamentais. Em relação às funçôes 
executivas (FE), estudos sugeriram haver maior inteligência verbal (Loney, Frick, Ellis, \& McCoy, 1998) e melhor habilidade de resolução de problemas sociais (Waschbusch, Walsh, Andrade, King, \& Carrey, 2007) entre crianças com problemas de conduta e EPSL, quando comparadas com pares que possuíam apenas problemas de conduta. Outra investigação apontou para uma relação negativa entre EPSL e habilidades verbais e não-verbais, embora estas não permaneceram significativas após considerar a influência de sintomas de TC e hiperatividade (Fontaine, Barker, Salekin, \& Viding, 2008). Loney e colegas (1998) compararam crianças com problemas comportamentais com e sem níveis elevados de EPSL, apontando que crianças com problemas de conduta sem traços EPSL tiveram desempenho diminuído em testes de inteligência verbal quando comparados a um grupo controle, enquanto aquelas crianças com problemas de conduta com EPSL não apresentaram tal déficit. Mais recentemente, Tye, Bedford, Asherson, Ashwood, Azadi, Bolton e McLoughlin (2017) compararam grupos de meninos com níveis clinicamente significativos de autismo, transtorno de déficit de atenção e hiperatividade (TDAH), autismo mais TDAH, e um grupo controle. Todos possuíam um quociente de inteligência acima de 70 e interromperam o uso de medicação para TDAH 48 horas antes do estudo. Os resultados mostraram que, dentre os participantes com autismo, EPSL foram associadas com performance superior na amplitude N2 (medida por meio de eletroencefalografia) quando comparados com o grupo controle, sugerindo melhor habilidade no monitoramento de conflitos e, assim, certa "vantagem cognitiva" associada com as EPSL. De fato, EPSL podem ser vantajosas em determinados contextos, sobretudo quando frieza emocional é requerida (por ex., cirurgiōes, bombeiros). Com efeito, um estudo nacional indicou que traços psicopáticos em adultos se associaram significativamente com traços adaptativos de personalidade (menor neuroticismo, maior extroversão e maior abertura à mudança; Monteiro, Goveira, Patrick, Carvalho, Medeiros, Pimentel, \& Gouveia, 2015). Logo, as EPSL não representam, necessariamente, riscos causais para agressividade e criminalidade; para tal, é preciso haver comprometimento significativo em diversas esferas, como no funcionamento acadêmico e nas interaçôes sociais. Salekin (2006) sugeriu que indivíduos com marcados déficits na esfera emocional (e.g., empatia afetiva e capacidade de remorso), porém com boas habilidades intelectuais, podem ser mais capazes de planejar e executar atos antissociais. Todavia, até o momento, existem poucas investigaçóes comparando o funcionamento cognitivo de crianças e adolescentes com problemas de conduta com e sem EPSL (Jones \& Wendt, 2015).

Platje, Huijbregts, van Goozen, Popma, Cima e Swaab (2018) exploraram diferenças em relação ao funcionamento executivo, sensibilidade à punição e à recompensa entre meninos adolescentes recrutados da comunidade (amostra não-clínica). Participantes com EPSL e elevados níveis de problemas de conduta tiveram mais problemas nas $\mathrm{FE}$, sobretudo em relação à metacognição e regulação comportamental, embora apresentaram níveis similares de sensibilidade à punição e à recompensa quando comparados com adolescentes com altos problemas de conduta, mas com baixas EPSL. Em estudo prévio, Frick, Cornell, Barry, Bodin e Dane (2003) compararam grupos de crianças com problemas de conduta com e sem EPSL, encontrando déficits no processamento da punição entre crianças com EPSL; já entre crianças com TC, porém sem EPSL, os autores encontraram maior viés de atribuição de hostilidade. Assim, as EPSL poderiam indicar certa imunidade aos esforços corretivos e punitivos de pais e professores, enquanto elevada sintomatologia de TC seria mais fortemente associada a um processamento deficiente de informaçôes. De modo semelhante, Dadds et al. (2006) relataram que as EPSL foram unicamente associadas a déficits no reconhecimento de expressóes de medo, enquanto problemas de conduta sem a concomitante presença de EPSL foram correlacionados a uma maior hipersensibilidade à hostilidade.

Diferenças no tocante à reatividade emocional também foram observadas em investigaçóes prévias. Por exemplo, Loney, Frick, Clements, Ellis e Kerlin (2003) demonstraram uma taxa de reconhecimento de palavras emocionais negativas mais lenta entre adolescentes com TC e EPSL quando comparados com adolescentes com TC, porém com baixas EPSLs, que demonstraram um reconhecimento mais rápido para as mesmas palavras. Logo, tais achados sublinham que o TC, isolado, seria marcado por saliência expressiva de emoçóes negativas, ao passo que EPSL confeririam menor responsividade ao mesmo tipo de emoçóes (Dadds et al., 2006). Ademais, comprometimentos na habilidade de reconhecer expressóes emocionais de medo têm sido demonstrados entre crianças e adolescentes com EPSL, sendo que tais déficits são robustos não apenas no tocante às expressóes emocionais faciais, como também em estudos avaliando postural corporal e expressóes vocais (Blair et al., 2005; Blair, Colledge, Murray, \& Mitchell, 2001).

Em adição, Dadds et al. (2011) testaram a hipótese de que crianças e adolescentes com TC combinado 
com EPSL poderiam apresentar déficits na manutenção de contato visual. Constatou-se que, durante períodos de conversação sobre emoçóes positivas e negativas, crianças com EPSL demonstraram níveis mais baixos de contato visual com seus pais em comparação com o crianças com TC isolado. Os resultados deste estudo elucidaram mecanismos envolvidos no desenvolvimento de dificuldades comportamentais, uma vez que um baixo contato visual poderia desencadear uma menor vinculação entre os membros da família, e, por conseguinte, resultar em acentuado prejuízo no desenvolvimento socioemocional de crianças com EPSL (Dadds et al., 2011). De modo importante, Blair (2005) propôs uma dissociação do conceito de empatia, apresentando os subtipos afetivo e cognitivo. A empatia afetiva permite que um indivíduo experimente a sensação de outra pessoa, enquanto a empatia cognitiva facilita o entendimento dos pensamentos, sem que haja um compartilhamento de sentimentos comuns (Singer, 2006). Mais recentemente, Vachon e Lynam (2016) sugeriram que o componente afetivo da empatia poderia ser subdividido entre empatia afetiva ressonante e dissonante. Embora estudos empíricos testando o papel da empatia afetiva ressonante (definida como uma resposta emocional congruente e expressa em termos de preocupação empática, simpatia, piedade e compaixão) e dissonante (marcada por dissonância afetiva e por respostas emocionais contraditórias, como a obtenção de obter prazer as custas do sofrimento alheio, ou raiva quando da felicidade alheia) sejam ainda raros, é possível criar hipóteses de que a presença de EPSL pode ser mais fortemente ligada à empatia dissonante (Vachon \& Lynam, 2016). Outros autores apoiam a separação entre tomada de perspectiva (ou Teoria da Mente [TM]) e a capacidade de entender e compartilhar as emoçóes alheias (Jones, Happé, Gilbert, Burnett, \& Viding, 2010). Em estudo pioneiro, Jones et al. (2010) compararam crianças com TC e EPSL, crianças apenas com TC e crianças autistas, notando que crianças com EPSL tiveram déficits somente no componente afetivo da empatia, revelando intactas habilidades ligadas à empatia cognitiva e em tarefas da TM. Crianças autistas apresentaram déficits em tarefas ligadas à TM, embora os componentes da empatia afetiva tenham se mostrado intactos. De fato, altas habilidades em tarefas ligadas à TM podem facilitar o comportamento manipulativo no contexto de EPSL. Com efeito, Sutton, Smith e Swettenham (1999) argumentaram que crianças que perpetram comportamentos de bullying manipulam os demais com destreza ímpar, porque dispóem de proficiência acerca de comportamentos e palavras que podem ferir seus pares.
Assim, Happé e Frith (1996) sugeriram que as crianças com TC poderiam desenvolver um tipo específico de TM - "teoria das mentes desagradáveis"- em decorrência, sobretudo, de influências negativas em contextos aversivos, evidenciando estratégias defensivas em contextos abusivos.

\section{Mensuração e tratamento de crianças $e$ adolescentes com EPSL}

Uma das abordagens mais utilizadas para a mensuração das EPSL é a criminológica (DeLisi, 2009), na qual as medidas mais comuns - também referidas como "padrão ouro" - são as Escalas Hare, que possuem uma versão para adolescentes: The Psychopathy Checklist: Youth Version (PCL: YV; Forth, Kosson, \& Hare, 2003). Utilizado amplamente em ambientes correcionais, o PCL:YV (Forth et al., 2003) consiste em 20 itens, que são avaliados por profissionais treinados extensivamente no uso de entrevistas e revisão de registros. Cada item é pontuado em uma escala de três pontos, variando de zero (não se aplica) até 2 (definitivamente se aplica), no qual escores mais elevados denotam maiores níveis de traços psicopáticos (Hauck-Filho et al. 2009). Quatro fatores foram encontrados por Forth et al. (2003), a saber: Interpessoal, incluindo manejo de impressões, grandiosidade, mentira patológica, tendência a ser enganador e manipulador; Afetivo, incluindo a ausência de remorso, afeto superficial, frieza/falta de empatia, não aceitaçáo de responsabilidade; Estilo de vida, no qual incluem-se comportamentos como a busca por estímulos, orientação parasitária, falta de objetivos, impulsividade e irresponsabilidade; e Antissocial, abarcando um fraco controle da raiva, versatilidade criminal, delinquência, problemas comportamentais precoces e revogação de liberdade condicional. O PCL:YV já foi traduzido para o português (Brasil), bem como o seu manual (Gauer, Vasconcellos, \& Werlang, 2006).

Já o Antisocial Process Screen Device (APSD; Frick $\&$ Hare, 2001) é uma medida formada por 20 itens, que são pontuados em uma escala de três pontos, variando de zero (não se aplica) a 2 (definitivamente se aplica). Quanto mais elevado o escore total, maior é a presença de traços psicopáticos. Existem versóes do tipo autorrelato, bem como opçóes nas quais pais e professores aferem a presença ou não dos 20 itens que compóem o APSD. De acordo com Frick e Hare (2001), o APSD é indicado para indivíduos com idades entre 6 até 13 anos, sendo formado pelos seguintes fatores: 1 Narcisismo, no qual o indivíduo se percebe como mais importante do que os demais, vangloria-se, é vigarista, 
pode ser encantador/sedutor, enganador, apresenta raiva em resposta à correção e apresenta emoções rasas; 2 EPSL, no qual características como baixa empatia, ausência de culpa, pouca preocupação com desempenho escolar e dificuldades em manter promessas são incluídas; e 3 Impulsividade, caracterizada por açóes realizadas sem pensar, tendência a culpabilizar os outros por erros próprios, tendência ao tédio, pouco planejamento e envolvimento em atividades de risco. No Brasil, não foram localizados estudos de validação da medida, apenas uma adaptação para a população infanto-juvenil da cidade de Curitiba-PR (Watanabe, 2013).

Uma abordagem alternativa foca-se na mensuração contínua das EPSL (em oposição à abordagem categórica). Tal abordagem foi a base da inclusão das EPSL no escopo do DSM-V (APA, 2013; Marcus, 2017). Segundo o DSM-V (APA, 2013), o especificador EPSL deve estar presente por pelo menos 12 meses, sendo validado não apenas por meio de autorrelato, mas também através da obtenção de informações com informantes familiarizados com a conduta do sujeito, como pais, professores, amigos e colegas. Em relação às medidas de rastreio de traços psicopáticos, é importante destacar que estas não capturam o constructo da psicopatia de modo aprofundado. Assim, medidas dedicadas a crianças e adolescentes, porém ainda não validadas no Brasil, incluem o Youth Psychopathic Traits Inventory (YPTI; Andershed et al., 2002) e o Child Psychopathy Scale (CPS; Lynam, 1997). Tais medidas se fundamentaram amplamente nas Escalas Hare, sendo que versôes incluem autorrelato, relato de pais e professores. O YPTI é formado por 50 itens organizados em uma escala de 4 pontos, variando de 0 (não se aplica) a 4 (se aplica muito bem). Quanto mais elevado o escore total, maior é a presença de traços psicopáticos. Usualmente, a medida é composta por três fatores: Interpessoal, incluindo desonestidade, mentira, manipulação e grandiosidade; Afetivo, marcado por frieza, falta de remorso e insensibilidade; e Estilo de Vida, incluindo impulsividade, busca por sensaçôes fortes e irresponsabilidade. Em respeito ao CPS, medida composta por 50 itens no formato Sim/Não, Lynam (1997) indicou para a presença dos seguintes fatores, em ambas as apresentaçôes do CPS (e.g., autorrelato e versão para pais/cuidadores): Afetivo/Interpessoal, incluindo manipulação, frieza, ausência de culpa e afeto superficial; Antissocial, marcado por pobre planejamento, comportamento descontrolado, tendência ao tédio e estilo de vida parasitário; e Impulsivo/Irresponsável marcado por busca por sensaçóes, irresponsabilidade e impulsividade. Novamente, escores mais elevados denotam maior ocorrência de traços psicopáticos.

Recentemente, houve a adaptação transcultural da versão de autorrelato para adolescentes do Inventário de Traços Frios e Insensíveis (Inventory of Callous-Unemotional Traits [ICU]; Frick, 2004) para o contexto brasileiro (Rigatti et al., 2018). O ICU foi desenvolvido com base na medida APSD (Frick \& Hare, 2001), sendo formado por 24 itens, dispostos em uma escala de 4 pontos, variando de 0 (náo se aplica) a 3 (definitivamente se aplica). Ainda que existam distintas soluçôes fatoriais, comumente o ICU é organizado sob os seguintes fatores: Insensibilidade, marcado por falta de empatia, ausência de remorso e emoçóes rasas; Indiferença, incluindo baixa expressão de comportamentos pró-sociais, ausência de culpa e preocupaçáo com o desempenho; e Emoçóes limitadas, compreendendo um pobre repertório de expressão de emoçôes em variados contextos (Kimonis et al., 2008). Na literatura internacional, existem cinco versões do ICU: versão de autorrelato para adolescentes, versão para pais, versão para professores, versão para pais (crianças em idade pré-escolar) e versão para professores (crianças em idade pré-escolar) (Kimonis et al., 2008). Em todas as apresentações, escores mais elevados indicam maior presença de traços psicopáticos.

Crianças com TC e EPSL apresentam resposta menos favorável ao tratamento quando comparadas com crianças apenas com TC, sendo que uma hipótese central prevê que os as EPSL seriam moderadores importantes em estratégias interventivas, focando em recompensas e punições (Waschbusch et al., 2016). Em suma, assume-se que crianças e adolescentes com potencial para satisfazer critérios de TC não formam um grupo homogêneo, sendo que o papel de traços psicopáticos - ou EPSL - deve ser minuciosamente avaliado. Todavia, a compreensão da heterogeneidade sintomatológica no TC é relativamente recente. Por conseguinte, ainda são iniciais os estudos que busquem avaliar a efetividade de variadas intervençóes psicológicas.

Pesquisas envolvendo terapia comportamental sugerem que crianças com TC e EPSL não apresentam respostas uniformes à intervenção psicológica, diferindo em resposta a aspectos particulares. Especificamente, há evidências de que crianças com altos problemas de conduta e EPSL possam ter resposta positiva em dimensôes de recompensa em terapias comportamentais, embora apresentem menor resposta (ou até mesmo resposta negativa) em relação aos aspectos punitivos terapia comportamental (Haas, Waschbusch, Pelham, King, Andrade, \& Carrey, 2011; Hawes \& Dadds, 2005; Kimonis \& Armstrong, 2012). Ademais, estudos 
de neuroimagem sugerem que crianças com EPSL têm déficits no sistema noradrenérgico e na amígdala, o que parece impactar negativamente a aprendizagem instrumental na medida em que prejudicam a capacidade de formar associaçóes entre estímulos e reforços (Blair, 2005). Logo, parece plausível supor que crianças com EPSL são menos responsivas à terapia cognitivo-comportamental, porque diferem nos modos como aprendem e respondem à recompensa e punição.

Existem ainda muitos fatores que determinam como as crianças respondem a tratamentos baseados no manejo de contingências (Marcus, 2017). Um aspecto que influencia a resposta diante de contingências diz respeito ao conhecimento - ou náo - dos critérios que precisam ser alcançados para obter-se recompensa e evitar punições. Nos programas comportamentais, há pelo menos duas abordagens que fornecem informaçóes sobre os critérios de comportamento alvo: critérios fixos, nos quais o comportamento alvo e os critérios são selecionados e comunicados a priori; e critérios randomizados, nos quais o comportamento alvo é selecionado e comunicado ao indivíduo a priori (Waschbusch et al., 2016). Uma diferença central entre essas duas abordagens diz respeito à previsibilidade. Em abordagens fixas, os critérios do comportamento alvo são previsíveis. Se, por um lado, proporcionar às crianças metas e critérios de tratamento previsíveis provavelmente maximiza a motivação para alcançar o objetivo do tratamento, por outro, a motivação pode diminuir quando o critério acerca do comportamento desejado é alcançado ou quando fica claro ao indivíduo que o objetivo desejado não poderá ser atingido. Conforme Waschbusch et al. (2016), existem razôes teóricas e empíricas pelas quais os critérios-alvo fixos versus aleatórios podem ser relevantes no tratamento de indivíduos com EPSL. Considerando o exemplo de um programa comportamental para uma criança que frequentemente agride aos colegas de escola. Tanto em programas como critérios fixos como nos aleatórios, seria informado que o objetivo do tratamento seria o de reduzir as agressões. Em uma abordagem de critérios fixos, a criança também receberia metas específicas que trariam recompensas ou evitariam punições (por exemplo, se você ficar uma semana sem se envolver em brigas, poderá comprar um livro). Numa abordagem de critérios aleatórios, o número de semanas sem agressão seria determinado aleatoriamente (sorteio, por exemplo). Em ambas as abordagens, as crianças recebem entáo o resultado apropriado (recompensam se satisfizerem os critérios e a falta de recompensa ou punição se não o fizerem). Teoricamente, essa distinção é importante, porque uma das características principais das
EPSL é a falta de cuidado com o desempenho individual (APA, 2013), indicando que a falta de motivação é um componente central a ser trabalhado. Waschbusch et al. (2016) mostraram que crianças com TC e EPSL tiveram comportamentos menos positivos na medida em que se familiarizavam com os procedimentos de cada condição de tratamento. Logo, na medida que experiência com cada condição de tratamento é adquirida, os participantes buscam obter recompensas e evitar punições, sugerindo que critérios previsíveis possam impactar de modo negativo na motivação durante o tratamento. Assim, respostas positivas ao tratamento podem ser maximizadas ao adotar-se critérios aleatórios (Waschbusch et al., 2016). Todavia, é importante novamente lembrar que estudos investigando a eficácia e a efetividade de tais intervenções encontram-se em estágios relativamente iniciais, havendo um amplo espaço para pesquisadores desenvolverem e testarem novos protocolos. O papel dos pais e/ou responsáveis é igualmente importante para o desenvolvimento e manutenção de problemas relacionados às EPSL, motivo pelo qual estudos futuros acerca de eficácia e efetividade de tratamentos devem incluir um exame das práticas parentais e suas relaçóes com problemas emocionais e comportamentais de crianças e adolescentes (Waller et al., 2017).

\section{CONSIDERAÇÓES FINAIS}

No presente manuscrito, foram expostos resultados de pesquisas empíricas que trazem evidências sobre o perfil de crianças e adolescentes com EPSL - incluindo funcionamento neuropsicológico e dificuldades associadas -, bem como foram revisitados estudos que possam ser úteis no processo de prevenção e intervenção psicológica. Em síntese, buscou-se responder às questões relativas a relevância teórica e clínica dos traços frios e insensíveis, suas formas de identificação e implicações para a pesquisa e prática em Psicologia. Evidenciou-se que, embora tenham sido detectadas maiores níveis de inteligência verbal e melhores habilidades de resolução de problemas sociais entre crianças com EPSL (Loney et al., 1998; Waschbusch et al., 2007), existem evidências claras no tocante a déficits no reconhecimento de emoções como medo, tristeza e punição em indivíduos com TC e EPSL (Blair et al., 2005; Tye et al., 2017). Diferenças em termos da função e estrutura cerebral indicam que fatores neuropsicológicos parecem estar associados ao comportamento antissocial no contexto do TC e EPSL, destacando a importância de se subdividir as crianças com problemas de conduta de 
início precoce naqueles com e sem EPSL (Jones \& Wendt, 2015).

Embora contribuições individuais das subdimensões psicopáticas sejam amplamente exploradas, pesquisadores vêm ressaltando especificamente o poder diferencial das EPSL, sobretudo na população infanto-juvenil (Fanti et al., 2018). Com efeito, o termo psicopatia, quando utilizado indiscriminadamente, carrega um forte estigma. De modo similar, o uso do conceito de psicopatia em crianças e adolescentes tem sido marcado por controvérsias. Para muitos profissionais e leigos, a psicopatia pode significar uma condição não passível de tratamento (Marcus, 2017). No entanto, ignorar os sinais precoces das EPSL pode implicar expressivo sofrimento em estágios de desenvolvimento futuros. Portanto, faz-se necessária uma acurada compreensão da complexa interação dos vários tipos de fatores que podem explicar a emergência de traços psicopáticos em crianças e adolescentes. A carência de investigações nacionais acerca da prevalência de problemas comportamentais em crianças e adolescentes (incluindo as EPSL) e de suas dificuldades emocionais associadas aponta para a importância da condução de estudos futuros. De modo importante, é preciso aferir se diferentes estruturas fatoriais reportadas no contexto internacional são significativas para descrever as dimensões da psicopatia entre crianças e adolescentes no Brasil. Uma das maiores críticas quanto ao uso do conceito de psicopatia em indivíduos ainda em desenvolvimento baseia-se na concepção de que crianças ou adolescentes ainda estão processo de maturação. É bem verdade que algumas das características associadas com a psicopatia se referem claramente àquelas que tendem a ser infladas durante o início da adolescência, declinando no início da adultez. Todavia, isso não significa que a busca de um diagnóstico seja inútil.

É sabido que o uso de pontos de corte para a identificação de psicopatia tem sido inconsistente mesmo em adultos (Cauffman, Skeem, Dmitrieva, \& Cavanagh, 2016; Marcus, 2017). Por exemplo, Walters, Ermer, Knight e Kiehl (2015) avaliaram 445 detentos de instituições de segurança máxima, que participaram de um estudo que utilizou medidas de traços psicopáticos e ressonância magnética estrutural para avaliar indicadores de concentração de substância cinzenta (GMC, nos participantes adultos) e de volume de substância cinzenta (GMV, em participantes adolescentes). Os dados foram submetidos à análise taxométrica utilizando três procedimentos: mean above minus below a cut (MAMBAC), covariância máxima (MAXCOV) e análise fatorial Latent Mode (L-Mode). Os resultados mostraram evidência suportando uma estrutura latente e contínua tanto nos adultos como nos adolescentes, bem como através das medidas (GMV, GMC, PCL-R e PCL: YV) e procedimentos taxométricos utilizados (MAMBAC, MAXCOV e L-Mode). A estrutura latente contínua também se manteve quando os indicadores biológicos e comportamentais foram incluídos na mesma análise (Walters et al., 2015). Em relação ao sexo feminino, Guay, Knight, Ruscio e Hare (2018) utilizaram procedimentos taxométricos para testar a estrutura fatorial do PCL-R em 1218 mulheres infratoras. Os resultados das várias estratégias analíticas utilizadas (e.g., MAMBAC, Maximum Eigenvalue [MAXEIG]) e L-Mode) obtiveram soluções distintas. Por exemplo, os procedimentos L-Mode e MAXEIG sugeriram evidências de dimensionalidade, ao passo que os achados utilizando o procedimento MAMBAC sugeriram uma estrutura taxônica. Todavia, para os autores, parece haver suporte robusto que a psicopatia em mulheres - tal qual medida pelo PCL-R - pode ser conceituada através de escores extremos em certos traços de personalidade, e não enquanto uma classe arbitrária. Tais achados fornecem certo suporte para uma visão emergente de que a psicopatia é um construto quantitativo, no qual as pessoas diferem em grau, e não tanto como um construto qualitativo, que atribui categorias distintas as pessoas (Guay et al., 2018; Walters et al., 2015). Enquanto nos modelos dimensionais os indivíduos psicopáticos são conceituados como variantes extremas, nos modelos categóricos ou taxônicos eles são concebidos como qualitativamente diferentes da população geral. Análises taxométricas sugeriram que as EPSL em crianças e adolescentes - mensuradas através de relato dos pais na medida ICU (Frick, 2004; Roose et al., 2010) - também refletem melhor uma estrutura dimensional ao invés de uma categórica/taxônica (Herpers, Klip, Rommelse, Taylor, Greven, \& Buitelaar, 2017). A investigação de Herpers et al. (2017) contou com a participação de 1833 jovens, com idades entre 8 e 18 anos $(M=$ $12,05, D P=2,80)$, encaminhados para uma clínica psiquiátrica de crianças e adolescentes na Holanda. Novamente, as análises taxométricas utilizaram as técnicas MAMBAC, MAXCOV e L-Mode, indicando para a presença de uma estrutura taxônica apenas no caso da técnica MAMBAC (Herpers et al., 2017).

Assim, o uso de medidas e escalas não podem determinar uma boa avaliação sem um aprofundado processo de avaliação psicológica, com entrevistas 
e acompanhamento clínico. Em adição, sobressai-se a necessidade de intervenções positivas que possam auxiliar crianças e adolescentes que apresentam EPSL, ao mesmo tempo em que pais e professores devem receber orientação e auxílio. Fatores ambientais também devem ser levados em conta, uma vez que práticas parentais positivas - incluindo responsividade e afetividade - podem atenuar o desenvolvimento de EPSL, promovendo segurança, empatia e prosocialidade (Gard, Dotterer, \& Hyde, 2018; Waller et al., 2017). Intimamente atrelada as considerações acerca de formas de diagnóstico e intervenção situa-se a questão da formação de profissionais, que devem ser continuamente atualizados acerca de modos de prevenir, identificar e tratar problemas emocionais e comportamentais de crianças e adolescentes.

Finalmente, o presente manuscrito não buscou esgotar as implicações das EPSL na prática psicológica. Embora haja um consenso na literatura quanto à importância de cautelosa avaliação dos traços psicopáticos quando busca-se delinear estratégias de prevenção e intervenção, profissionais devem ter em mente que traços psicopáticos são normológicos na população geral, o que implica cautela adicional antes de aferir diagnóstico. De modo igualmente importante, mensurar a presença de EPSL pode ser relevante não apenas para aferir o diagnóstico de TC, mas também parece ser útil em indivíduos com Transtorno de Oposição Desafiante e TDAH (Herpers, Rommelse, Bons, Buitelaar, \& Scheepers, 2012). Quando deparados com crianças e adolescentes com acentuadas dificuldades na manifestação de comportamentos prossociais e empáticos, ou em casos de elevado uso de agressividade e baixa manifestação de remorso e culpa, pais e professores devem buscar obter orientações junto de profissionais altamente capacitados, de modo que seja possível a realização de uma avaliação completa, séria e baseada em evidências.

\section{REFERÊNCIAS}

Associação Americana de Psiquiatria - APA (2013). Manual diagnóstico e estatístico de transtornos mentais (DSM-V). Porto Alegre, RS: ArtMed.

Blair, R. J. (2005). Responding to the emotions of others: Dissociating forms of empathy through the study of typical and psychiatric populations. Consciousness \& Cognition, 14, 698-718.
Blair, R. J., Budhani, S., Colledge, E., \& Scott, S. (2005). Deafness to fear in boys with psychopathic tendencies. Journal of Child Psychology and Psychiatry, 46, 327-336.

Blair, R. J., Colledge, E., Murray, L., \& Mitchell, D. (2001). A selective impairment in the processing of sad and fearful expressions in children with psychopathic tendencies. Journal of Abnormal Child Psychology, 29, 491-498.

Cauffman, E., Skeem, J., Dmitrieva, J., \& Cavanagh, C. (2016). Comparing the stability of psychopathy scores in adolescents versus adults: How often is "Fledgling Psychopathy" misdiagnosed? Psychology, Public Policy, and Law, 22(1), 77-91.

Clark, J. E. (2015). Positive Parenting, Conduct Problems, and Callous-Unemotional Traits (Dissertação de Mestrado, Instituto de Psicologia, Universidade de Nova Orleans). Recuperado de https://scholarworks. uno.edu/td/2063

Dadds, M. R., Jambrak, J., Pasalich, D., Hawes, D. J., \& Brennan, J. (2011). Impaired attention to the eyes of attachment figures and the developmental origins of psychopathy: Eye contact and origins of psychopathy. Journal of Child Psychology and Psychiatry, 52(3), 238-245. doi:10.1111/j.1469-7610.2010.02323.x.

Dadds, M. R., Perry, Y., Hawes, D. J., Merz, S., Riddell, A. C., Haines, D. J., ... \& Abeygunawardane, A. I. (2006). Attention to the eyes and fearrecognition deficits in child psychopathy. British Journal of Psychiatry, 189, 280-281. doi:1192/bjp. bp. 105.018150

DeLisi, M. (2009). Psychopathy is the unified theory of crime. Youth Violence and Juvenile Justice, 7(3), 256-273.

Fanti, K. A., Kyranides, M. N., Lordos, A., Colins, O. F., \& Andershed, H. (2018). Unique and interactive associations of callous-unemotional traits, impulsivity and grandiosity with child and adolescent conduct disorder symptoms. Journal of Psychopathology and Behavioral Assessment, 40(1), 40-49.

Fontaine, N., Barker, E. D., Salekin, R. T., \& Viding, E. (2008). Dimensions of psychopathy and their relationships to cognitive functioning in children. Journal of Clinical Child \& Adolescent Psychology, 37(3), 690-696.

Forth, A., \& Book, A. (2010). Psychopathy in youth: A valid construct? Em H. Herve, \& J. Yuille (Orgs.), The psychopath: Theory, research, and practice (pp. 369-387). Mahwah, USA: Lawrence Erlbaum Associates. 
Forth, A., Kosson, D., \& Hare, R. (2003). The psychopathy checklist: Youth version. Toronto: MultiHealth Systems.

Frick, P. (2004). Inventory of callous unemotional traits (Unpublished rating scale). Nova Orelans: Editora da University of New Orleans.

Frick, P. (2009). Extending the construct of psychopathy to youths: Implications for understanding, diagnosing, and treating antisocial children and adolescents. Canadian Journal of Psychiatry, 54, 803-812.

Frick, P. J., \& Hare, R. (2001). The antisocial process screen device (APSD). Toronto: Multi-Health Systems.

Frick, P. J., \& Marsee, M. A. (2018). Psychopathy and developmental pathways to antisocial behavior in youth. Em C. J. Patrick (Org.), Handbook of Psychopathy ( ${ }^{\text {a }}$ ed., pp. 456-478). Nova Iorque, USA: Guilford.

Frick, P. J., Cornell, A. H., Barry, C. T., Bodin, S., \& Dane, H. E. (2003). Callous-unemotional traits and conduct problems in the prediction of conduct problem severity, aggression, and self-report of delinquency. Journal of Abnormal Child Psychology, 31(4), 457-470. doi:10.1023/A:1023899703866

Frick, P. J., Ray, J. V., Thornton, L. C., \& Kahn, R. E. (2014). Can callous-unemotional traits enhance the understanding, diagnosis, and treatment of serious conduct problems in children and adolescents? A comprehensive review. Psychological Bulletin, 140(1), 1-57. doi:10.1037/a0033076

Frick, P., Kimonis, E., Dandreaux, D., \& Farrell, R. (2003). The 4-year stability of psychopathic traits in non-referred youth. Behavioral Sciences and the Law, 21, 713-736. doi:10.1002/bsl.568

Frick, R., \& Dickens, C. (2006). Current perspectives on conduct disorder. Current Psychiatry Reports, 8, 59-72.

Gard, A. M., Dotterer, H. L., \& Hyde, L. W. (2018, no prelo). Genetic influences on antisocial behavior: Recent advances and future directions. Current Opinion in Psychology. doi:10.1016/j. copsyc.2018.07.013

Gauer, G. J. C., Vasconcellos, S. J. L., \& Werlang, B. G. (2006). Inventário de Psicopatia de Hare: Versão Jovens (PCL:YV).Toronto: Multi-Health Systems Inc.

Gomes, C. C., \& Almeida, R. M. M. (2010). Psicopatia em homens e mulheres. Arquivos Brasileiros de Psicologia, 62(1), 13-21.

Guay, J. P., Knight, R. A., Ruscio, J., \& Hare, R. D. (2018). A taxometric investigation of psychopathy in women. Psychiatry Research, 261, 565-573. doi: 10.1016/j.psychres.2018.01.015

Haas, S. M., Waschbusch, D. A., Pelham, W. E., King, S., Andrade, B. F., \& Carrey, N. J. (2011). Treatment response in CP/ADHD children with callous/unemotional traits. Journal of Abnormal Child Psychology, 39(4), 541-552.

Happé, F., \& Frith, U. (1996). Theory of mind and social impairment in children with conduct disorder. British Journal of Developmental Psychology, 14(4), 385-398.

Hauck-Filho, N., \& Teixeira, M. A. (2014). Uma perspectiva desenvolvimental da psicopatia: traços callous unemotional em crianças e adolescentes. Em J. C. Borsa, \& D. R. Bandeira (Orgs.), $O$ comportamento agressivo na infância: Compreensão, contextualização, avaliação e intervenção (pp. 100115). São Paulo: Casa do Psicólogo/Pearson.

Hauck-Filho, N., Teixeira, M. A. P., \& Dias, A. C. G. (2009). Psicopatia: o construto e sua avaliação. Avaliação Psicológica, 8(3), 337-346.

Hawes, D. J., \& Dadds, M. R. (2005). The treatment of conduct problems in children with callous-unemotional traits. Journal of Consulting and Clinical Psychology, 73(4), 737-741. doi:10.1037/0022-006X.73.4.737

Herpers, P. C. M., Klip, H., Rommelse, N. N. J., Taylor, M. J., Greven, C. U., \& Buitelaar, J. K. (2017). Taxometric analyses and predictive accuracy of callous-unemotional traits regarding quality of life and behavior problems in non-conduct disorder diagnoses. Psychiatry Research, 253, 351-359. doi: 10.1016/j.psychres.2017.04.004

Herpers, P. C. M., Rommelse, N. N. J., Bons, D. M. A., Buitelaar, J. K., \& Scheepers, F. E. (2012). Callousunemotional traits as a cross-disorders construct. Social Psychiatry and Psychiatric Epidemiology, 47(12), 2045-2064. doi: 10.1007/s00127-012-0513-x

Jones, A. P., \& Wendt, G. W. (2015). Neuropsychology of Psychopathic Traits in Children. Em M. DeLisi, \& M. Vaughn (Orgs.). The Routledge International Handbook of Biosocial Criminology (pp. 218-235). Nova Iorque, USA: Routledge.

Jones, A. P., Happé, F., Gilbert, F., Burnett, S., \& Viding, E. (2010). Feeling, caring, knowing: Different types of empathy deficit in boys with psychopathic tendencies and autism spectrum disorder. Journal of Child Psychology and Psychiatry, 51(11), 1188-1197. doi:10.1111/j.1469-7610.2010.02280.x

Kim-Cohen, J., Caspi, A., Moffitt, T. E., Harrington, H., Milne, B. J., \& Poulton, R. (2003). Prior 
juvenile diagnoses in adults with mental disorder: Developmental follow-back of a prospectivelongitudinal cohort. Archives of General Psychiatry, 60(7), 709-717. doi:10.1001/archpsyc.60.7.709

Kimonis, E. R., \& Armstrong, K. (2012). Adapting parent-child interaction therapy to treat severe conduct problems with callous-unemotional traits: A case study. Clinical Case Studies, 11(3), 234-252. doi:10.1177/1534650112448835

Kimonis, E. R., Frick, P. J., Skeem, J. L., Marsee, M. A., Cruise, K., Munoz, L. C., ... \& Morris, A. S. (2008). Assessing callous-unemotional traits in adolescent offenders: Validation of the Inventory of Callous-Unemotional Traits. International Journal of Law and Psychiatry, 31(3), 241-252.

Loney, B. R., Frick, P. J., Clements, C. B., Ellis, M. L., \& Kerlin, K. (2003). Callous-unemotional traits, impulsivity, and emotional processing in adolescents with antisocial behavior problems. Journal of Clinical Child \& Adolescent Psychology, 32(1), 66-80. doi:10.1207/S15374424JCCP3201 07

Loney, B. R., Frick, P. J., Ellis, M., \& McCoy, M. G. (1998). Intelligence, callous-unemotional traits, and antisocial behavior. Journal of Psychopathology \& Behavioral Assessment, 20(3), 231-247. doi:10.1023/A:1023015318156

Lynam, D. (1997). Pursuing the psychopath: Capturing the fledgling psychopath in a nomological net. Journal of Abnormal Psychology, 106, 425-438.

Marcus, R. F. (2017). The development of aggression and violence in adolescence. Nova Iorque, USA: Palgrave.

Moffitt, T. E. (2003). Life-course persistent and adolescence- limited antisocial behavior: A research review and a research agenda. Em B. B. Lahey, T. E. Moffitt, \& A. Caspi (Orgs.), Causes of conduct disorder and juvenile delinquency (pp. 49-75). Nova Iorque, USA: Guilford.

Monteiro, R. P., Goveira, R. S., Patrick, C. J., Carvalho, H. W., Medeiros, E. D., Pimentel, C. E., \& Gouveia, V. V. (2015). A psicopatia no contexto dos cinco grandes fatores da personalidade. Psico (PUCRS), 46(4), 461-471.

Obradovic, J., Pardini, D., Long, J., \& Loeber, R. (2007). Measuring interpersonal callousness in boys from childhood to adolescence. An examination of longitudinal invariance and temporal stability. Journal of Clinical Child and Adolescent Psychology, 36, 276-292. doi:10.1080/15374410701441633

Pasalich, D. S., Dadds, M. R., Hawes, D. J., \& Brennan, J. (2011). Do callous unemotional traits moderate the relative importance of parental coercion versus warmth in child conduct problems? An observational study. Journal of Child Psychology and Psychiatry, 52(12), 1308-1315. doi: 10.1111/j.1469-7610.2011.02435.x

Platje, E., Huijbregts, S. C. J., van Goozen, S. H. M., Popma, A., Cima, M., \& Swaab, H. J. T. (2018, no prelo). Executive functioning, reward/punishment sensitivity, and conduct problems in boys with callous-unemotional traits. International Journal of Offender Therapy and Comparative Criminology. doi:10.1177/0306624X18758897

Rigatti, R., DeSouza, D. A., Salum, G., Alves, P. F. O., Bottan, G., \& Heldt, E. (2018). Adaptação transcultural do Inventory of Callous-Unemotional Traits para avaliação de traços de insensibilidade e afetividade restrita de adolescentes no Brasil. Revista Gaúcha de Enfermagem, 38(3), 1-7. doi:10.1590/1983-1447.2017.03.64754

Roose, A., Bijttebier, P., Decoene, S., Claes, L., \& Frick, P. J. (2010). Assessing the affective features of psychopathy in adolescence: A further validation of the Inventory of Callous and Unemotional Traits. Assessment, 17(1), 44-57. doi: 10.1177/1073191109344153

Salekin, R. T. (2006). Psychopathy in children and adolescents: Key issues in conceptualization and assessment. Em C. J. Patrick (Org.), Handbook of psychopathy (pp. 389-414). Nova Iorque, USA: Guilford.

Singer, T. (2006). The neuronal basis and ontogeny of empathy and mind reading: Review of literature and implications for future research. Neuroscience and Biobehavioral Reviews, 30(6), 855-863. doi:10.1016/j.neubiorev.2006.06.011

Sutton, J., Smith, P. K., \& Swettenham, J. (1999). Social cognition and bullying: Social inadequacy or skilled manipulation? British Journal of Developmental Psychology, 17(3), 435-450. doi:10.1348/026151099165384

Tye, C., Bedford, R., Asherson, P., Ashwood, K. L., Azadi, B., Bolton, P., \& McLoughlin, G. (2017). Callous-unemotional traits moderate executive function in children with ASD and ADHD: A pilot event-related potential study. Developmental Cognitive Neuroscience, 26, 84-90. doi:10.1016/j. den.2017.06.002

Vachon, D. D., \& Lynam, D. R. (2016). Fixing the problem with empathy: Development and validation of the Affective and Cognitive Measure of Empathy. Assessment, 23(2), 135-149. doi: $10.1177 / 1073191114567941$ 
Waller, R., Shaw, D. S., Neiderhiser, J. M., Ganiban, J. M., Natsuaki, M. N., Reiss, D., Hyde, L. W. (2017). Toward an understanding of the role of the environment in the development of early callous behavior: Early CU behavior and the environment. Journal of Personality, 85(1), 90-103. doi:10.1111/ jopy. 12221

Walters, G. D., Ermer, E., Knight, R. A., \& Kiehl, K. A. (2015). Paralimbic biomarkers in taxometric analyses of psychopathy: Does changing the indicators change the conclusion? Personality Disorders: Theory, Research, and Treatment, 6(1), 41-52. doi: 10.1037/per0000097

Waschbusch, D. A., Bernstein, M. D., RobbMazzant, J., Willoughby, M. T., Haas, S. M., Coles, E. K., \& Pelham, W. E. (2016). A case study examining fixed versus randomized criteria for treating a child with conduct problems and callous-unemotional traits. Evidence-Based Practice in Child and Adolescent Mental Health, 1(2-3), 73-85. doi:10.10 80/23794925.2016.1227946

Waschbusch, D. A., Walsh, T. M., Andrade, B. F., King, S., \& Carrey, N. J. (2007). Social problem solving, conduct problems, and callous-unemotional traits in children. Child Psychiatry and Human Development, 37(4), 293-305.

Watanabe, A. A. (2013). Adaptação e padronização do APSD: Antisocial Process Screening Device para a população de Curitiba (Dissertação de Mestrado, Instituto de Psicologia, Universidade Tuiuti do Paraná, Curitiba). Recuperado de http:// tede.utp.br/tde_busca/arquivo.php? codArquivo $=53$ 


\title{
Percepçáo de professores dos problemas de comportamento em duas amostras clínicas com TDAH: Brasil e Espanha
}

\author{
Teachers' perception of behavioral problems in two clinical samples with ADHD: Brazil and Spain
}

\author{
Ana Flávia Lima Teles da Hora ${ }^{1}$ \\ Concepción López Soler ${ }^{2}$ \\ Simone Souza da Costa Silva ${ }^{3}$ \\ Universidade Federal do Pará-Brasil
}

\begin{abstract}
Resumo
Considerando a díade professor-aluno no contexto escolar, a figura desse profissional tem sido estimada como uma fonte de informação válida na avaliação comportamental do aluno. Trata-se de uma investigaçáo documental do tipo exploratória-descritiva, retrospectiva e transversal, em que se recorreu a análise de prontuários de crianças e adolescentes entre os anos de 2013 e 2014 diagnosticados com TDAH em duas unidades clínicas de psicologia situadas no Brasil e Espanha. Encontraram-se diferenças significativas apenas em duas síndromes: Problemas de Sociabilidade e Problemas de Atenção. A contribuição deste estudo foi comparar a percepção de professores residentes em diferentes países, e constatar que, independentemente das diferenças culturais, foram encontrados comportamentos similares nos indivíduos com o diagnóstico de TDAH.
\end{abstract}

Palavras--chave: Professores; TDAH; Problemas de comportamento; TRF.

\begin{abstract}
Considering teacher-student dyadic interactions, the figure of this professional has been estimated as a valid source of information in the behavioral evaluation of the student. This is an exploratory-descriptive, retrospective and cross-sectional documentary investigation, in which the analysis of medical records of children and adolescents between the years of 2013 and 2014 diagnosed with ADHD in two clinical psychology units located in Brazil and Spain . In the total analysis of TRF scores, significant differences were found only in two syndromes: Sociability Problems and Attention Problems. The contribution of this study was to compare the perception of teachers from different countries and verify that regardless of cultural differences, some behaviors were similarly in individuals with the diagnosis of ADHD.
\end{abstract}

Keywords: Teachers; ADHD; Behavior problems; TRF.

O comportamento é considerado anormal à medida que interfere no curso habitual do desenvolvimento da criança, causando prejuízos na aquisição das competências sociais, afetivas e instrumentais (Dumas, 2011; Whitbourne \& Halgin, 2015). Segundo o relatório da Organização Mundial de Saúde (World Health Organization, 2002), muitas das perturbaçóes comportamentais observadas em adultos provavelmente tiveram início na infância.
A OMS (World Health Organization, 2002) reconhece que de $10 \%$ a $20 \%$ das crianças apresentam um ou mais problemas mentais. Conforme se observa na revisão sistemática (Polanczyk, Salum, Sugaya, Caye, \& Rohde, 2015) de 41 estudos realizados em 27 países a nível mundial, $13,4 \%$ da população infanto-juvenil é afetada por algum transtorno mental que interfere negativamente no desenvolvimento do indivíduo ao longo da vida.

\footnotetext{
${ }^{1}$ Psicóloga. Doutora e Mestre em Teoria e Pesquisa do Comportamento pela Universidade Federal do Pará (UFPA) com período de Doutorado Sanduíche como bolsista CAPES na Universidad de Murcia e no Hospital Clínico Universitário Virgen de la Arrrixaca - Espanha (2014-2015). Desenvolve trabalhos relacionados às áreas de Psicologia do Desenvolvimento, Transtornos do Neurodesenvolvimento: Transtorno do Espectro Autista (TEA) e Transtorno de Déficit de Atenção/Hiperatividade (TDAH). Atualmente é professora e pesquisadora na Universidade Ceuma. ${ }^{2}$ Doutora em Psicologia pela Universidade de Brasília (2006 e pós doutora em Ciências da Reabilitaçáo pela Universidade de Dortmund Alemanha (2012). Professora e diretora adjunta do Núcleo de Teoria e Pesquisa do Comportamento (NTPC/UFPA) onde ocupa o cargo de Diretora Academica da Unidade além de atuar no Programa de Teoria e Pesquisa do Comportamento (PPGTPC) e na faculdade de psicologia. Nos últimos anos desenvolveu pesquisas com famílias ribeirinhas e coordenou grupo de pesquisa que investigou os impactos gerados pelo Programa Bolsa Família (PBF).

${ }^{3}$ Doutora em Psicologia, e professora titular na Universidade de Múrcia, Espanha. É responsável pela Unidade de Psicologia Infanto-juvenil do Hospital Universitário de Investigação na Infância e Adolescência - Psicologia Clínica (GUIIA-PC) do Departamento de Personalidade, Avaliação e Tratamento Psicológicos da Faculdade de Psicologia da Universidade de Múrcia
} 
Partindo da perspectiva de que o comportamento se expressa de diferentes maneiras em conformidade com as demandas do ambiente, os sistemas de classificação de saúde, o Manual Diagnóstico e Estatístico de Transtornos Mentais- DSM (American Psychiatric Association, 2013) e a Classificaçáo Internacional de Doenças - CID (Organização Mundial da Saúde, 1993), reconhecem a escola como um meio de influência na aprendizagem e modelação dos comportamentos das crianças. Assim sendo, delimitam o contexto escolar como um dos ambientes onde os sintomas dos transtornos irão se manifestar com significância clínica.

É na escola que as crianças empregam um longo período de tempo de suas vidas sob tutoria de professores, formando uma díade que influenciará no desenvolvimento global desde a mais tenra infância. Como agentes educadores de novas informaçóes, os professores transmitem a cultura, atuam como facilitadores no desenvolvimento das competências sociais, auxiliam na construção de solução de problemas, contribuem com o desenvolvimento do controle das emoçôes, ajudam mediando situaçóes conflituosas, além de muitas vezes suprir o afeto não correspondido pela família (Bierman, 2011; Farmer, McAuliffe Lines, \& Hamm, 2011; Jiménez, 2008; Kindermann, 2011).

Considerando a díade professor-aluno no contexto escolar, a figura desse profissional tem sido estimada na literatura científica, como uma fonte de informação válida na avaliação comportamental do aluno e, consequentemente, no processo do estabelecimento do diagnóstico (Efstratopoulou, Janssen, \& Simons, 2012; Guttmannova, Szanyi, \& Cali, 2008). Afinal, é no ambiente estruturado de atividades programadas que os comportamentos destoantes dos parâmetros da normalidade tenderão a ficar em evidência. (Bierman, 2011; Curtis Pisecco, Hamilton, \& Moore , 2006; Farmer et al., 2011; Roig, 2011; Rudasill, Reio, Stipanovic, \& Taylor, 2010; Sointu, Savolainen, Lappalainen, \& Epstein, 2012).

A exemplo disso, com o objetivo de avaliar os comportamentos internalizantes, externalizantes e outros problemas de conduta, um estudo (Efstratopoulou et al., 2012) realizado na Grécia com uma amostra composta de pais, professores de educação física e 841 estudantes de 6 a 11 anos, utilizou três instrumentos, sendo eles o MBC (Motor Behavior Checklist for Children), CBCL (Child Behavior Checklist for Parents), e o TRF (Teacher Report Inform). O estudo constatou que os escores das crianças convergiram mais com os dos professores, uma vez comparados com as pontuaçóes dos pais, sugerindo que os professores observam os comportamentos dos escolares de maneira mais sistemática (Efstratopoulou et al., 2012).

Um estudo realizado na Espanha (Bernedo, Salas, García-Martín, \& Fuentes, 2012) utilizou o instrumento TRF para averiguar a partir do relato dos professores os problemas de comportamento em crianças e adolescentes adotados. Com uma amostra de 97 crianças e adolescentes, na faixa etária entre 5 e 17 anos, os pesquisadores constataram que as crianças e adolescentes que tinham sofrido abuso físico ou sexual apresentavam mais problemas de comportamento em ambos os gêneros, uma vez comparados as crianças que náo sofreram tais abusos.

Também considerando o professor como um avaliador dos comportamentos dos alunos, no Brasil, realizou-se um estudo a fim de se investigar os problemas de comportamento mais evidentes nos alunos da $1^{\mathrm{a}}$ a $4^{\mathrm{a}}$ série de uma escola por meio do TRF (Pedrini $\&$ Frizzo, 2010). Os resultados sinalizaram que os professores indicaram maior manifestação dos problemas externalizantes que os internalizantes.

O TRF 6-18 (Teacher Report Form) para as idades de 6 a 18 anos, é um instrumento que integra o sistema psicométrico ASEBA (Achenbach System of Empirically Based Assessment; Achenbach), que possibilita a avaliação de um amplo espectro de problemas de comportamento em escolares a partir da perspectiva do professor (Achenbach et al., 2008; Azevêdo, 2012; Bordin et al., 2013). Os problemas de comportamento agrupam os sintomas internalizantes e externalizantes (Achenbach \& Rescorla, 2001). Os internalizantes compreendem os comportamentos de ordem privada que se manifestam no próprio indivíduo, tais como, os sintomas depressivos, queixas somáticas, ansiedade, timidez, e isolamento social (Achenbach \& Rescorla, 2001; American Psychiatric Association, 2013; Soler, Alcántara, Fernández, Castro, \& López Pina, 2010). Por outro lado, os externalizantes dirigem-se ao meio externo por meio de condutas desafiadores, antissociais, agressivas, hostis, disruptivas e impulsivas (Achenbach \& Rescorla, 2001; American Psychiatric Association, 2013; López Soler et al., 2009).

Entre os transtornos mentais que apresentam maior incidência comórbida com os problemas de comportamento está o Transtorno de Déficit de Atenção e Hiperatividade (Jacob et al., 2014; López Soler et al., 2009; Rivera, Martínez, \& Pérez, 2005; Roessner et al., 2007). O TDAH é um transtorno do neurodesenvolvimento que envolve padróes de comportamentos disfuncionais de desatenção, hiperatividade e impulsividade inconsistentes com o nível de desenvolvimento 
da criança, causando prejuízos na vida pessoal, acadêmica e social que podem persistir até a vida adulta (American Psychiatric Association, 2013; Bauermeister, 2014; Whitbourne \& Halgin, 2015).

O TDAH é um dos transtornos crônicos mais comumente diagnosticado na idade escolar e nos serviços de atenção primária (Barkley, 2008; Bauermeister, 2014; Cardo et al., 2011). A literatura sinaliza que a sintomatologia clínica do TDAH pode evoluir de acordo com a idade do indivíduo (Faraone, Biederman, \& Mick, 2006; Serrano-troncoso, Guidi, \& Alda-Díez, 2013). No contexto escolar por exemplo, uma revisão sistemática de 18 estudos longitudinais e prospectivos publicados no período de 1990 a 2006 (D’Abreu \& Marturano, 2010), sinalizou que as crianças com o diagnóstico de TDAH estáo mais vulneráveis a instabilidade ambiental, a problemas de comportamento e a pobre desempenho escolar.

Em relação ao TDAH e os problemas de comportamento no contexto escolar, são escassos na literatura científica estudos transculturais envolvendo professores como principal fonte de informaçáo da conduta dos alunos, especialmente, estudos comparando o Brasil e a Espanha, países com cultura e características geográficas distintas. Estudos transculturais propiciam a discriminação da topografia dos comportamentos das pessoas que vivenciam culturas distintas (American Psychiatric Association, 2013a; Olatundun, 2009; Whitbourne \& Halgin, 2015), permitindo identificar diferenças e semelhanças entre contextos o que contribui para a compreensão do papel da cultura sobre o fenômeno investigado (Olatundun, 2009).

Compreendendo a importância dos estudos transculturais, a presente pesquisa tem como objetivo identificar as semelhanças e diferenças na percepção de professores brasileiros e espanhóis no que tange aos problemas de comportamentos apresentados no TRF/618 de estudantes de duas amostras clínicas. Os objetivos específicos foram: a) Verificar se haverá diferença significativa em relação as Escalas de Internalização e Externalização; b) Averiguar se haverá diferença significativa nos escores dos professores de ambas as nacionalidades no que corresponde as oito síndromes avaliadas pelo TRF.

\section{MÉTODO}

Trata-se de uma investigação documental do tipo exploratória-descritiva, retrospectiva e transversal, em que se recorreu a análise de prontuários de crianças e adolescentes entre os anos de 2013 e 2014 diagnosticados com TDAH em duas unidades clínicas de psicologia: A Unidade Clínica da Infância e Adolescência do Hospital Universitário Virgen de la Arrixaca, vinculado à Universidad de Murcia na Espanha; e na Unidade de Psicologia do Serviço de Crescimento e Desenvolvimento CAMINHAR voltada para o atendimento infantil do Hospital Universitário Bettina Ferro de Souza, incorporado a Universidade Federal do Pará, no Brasil.

\section{Participantes}

Foram revisados minuciosamente 751 prontuários na Espanha e 805 no Brasil. Destes, foram selecionados 13 na Unidade Hospitalar de Murcia e 24 na Unidade do Bettina. Com o cuidado de uniformizar a amostra, a seleçáo dos prontuários baseou-se nos seguintes critérios de inclusão: o paciente de 6 a 18 anos devem apresentar o diagnóstico fechado de TDAH; o instrumento TRF/6-18 anos deve estar devidamente respondido pelo professor; o professor respondente deveria conhecer o escolar por pelo menos 2 meses, conforme se determina no manual do instrumento (Achenbach \& Rescorla, 2001).

Por sua vez, foram excluídos os prontuários que não registravam o diagnóstico de TDAH; prontuários sem o TRF/6-18; pacientes com TDAH e outras comorbidades; TRF/6-18 com mais de 8 itens em branco conforme consta no manual (Achenbach \& Rescorla, 2001), como também, prontuários de pacientes que apresentavam apenas a sintomatologia do transtorno, mas não cumpriam a todos os critérios estabelecidos no DSM-IV ou CID-10. A amostra total foi de $N=37$ prontuários de crianças e adolescentes. Na Tabela 1 observa-se a caracterização sociodemográficas da amostra.

\section{Tabela 1.}

Caracterização sociodemográfica dos escolares

\begin{tabular}{cccc}
\hline & $\begin{array}{c}\text { Brasil } \\
\mathbf{N}\end{array}$ & $\begin{array}{c}\text { Espanha } \\
\mathbf{N}\end{array}$ & $\mathbf{\%}$ \\
\hline Sexo & & & \\
Feminino & 4 & 1 & $13,5 \%$ \\
Masculino & 20 & 12 & $86,5 \%$ \\
Total & 24 & 13 & $100 \%$ \\
& & & \\
Faixa etária & & & \\
6-10 anos & 18 & 12 & $81 \%$ \\
11-14 anos & 5 & 2 & $19 \%$ \\
Total & 23 & 14 & $100 \%$ \\
\hline
\end{tabular}


${ }^{*} \mathrm{~N}=$ participantes.

\section{Instrumento}

O TRF/6-18 é um instrumento destinado ao professor, compondo uma lista de 113 itens que avaliam os problemas de comportamentos/emocionais e habilidades sociais, cujas respostas variam entre 0 (zero) que equivale a comportamento ausente; 1 (um) comportamento às vezes presente; e 2 (dois) comportamento frequentemente presente (Achenbach \& Rescorla, 2001). Os 113 itens geram escores em três escalas amplas que englobam oito síndromes, sendo elas: Ansiedade/Depressão; Retraimento/Depressão; Queixas somáticas; Problemas de sociabilidade; Problemas de pensamento; Problemas de atenção; Violação de regras; e Comportamento agressivo. As três primeiras síndromes (Ansiedade/Depressão; Retraimento/Depressão; Queixas somáticas) compõem a escala maior intitulada de Escala de Internalização, as duas últimas (violação de regras e comportamento agressivo) compóem a Escala de Externalização, e as duas síndromes (Problemas de pensamento e Problemas de atenção) integram a escala ampla de Outros Problemas (Achenbach \& Rescorla, 2001).

\section{Implicaçôes éticas}

Com o compromisso de manter o caráter confidencial e sigiloso dos dados, solicitou-se a autorização do Comitê de Ética do Hospital Virgen de la Arrixaca
(CEIC Virgen de la Arrixaca), do qual se recebeu o parecer favorável (DICTAMEN FAVORABLE) na Ata 08/15 para a coleta de dados. Repetiu-se o mesmo procedimento no Hospital Bettina Ferro de Souza, onde submeteu-se a solicitação de autorização no Comitê de Ética do Núcleo em Medicina Tropical da UFPA, obtendo-se assim a liberação por meio do Protocolo CAAE 45316515.3.0000.5172.

\section{Análise dos dados}

$\mathrm{Na}$ análise descritiva foram elaboradas tabelas contendo valores absolutos e relativos. Foram aplicados os testes Shapiro-Wilk e o de Levene para testar os pressupostos de Normalidade, seguidos do teste $t$ de Student e Análise de Variância (ANOVA) para a comparação das médias, considerando o nível de significância $\square=$ 0,05 . Para a construçáo do banco de dados utilizou-se o programa estatístico SPSS 22.0 (StatisticalPackage for Social Science) na versão 22.0. E as respostas do TRF foram avaliadas por meio do software Assessment Data Manager (ADM 7.2b).

\section{RESULTADOS}

$\mathrm{Na}$ análise total dos escores do TRF foram considerados satisfatórios os testes Shapiro-Wilk e o de Levene. Na Tabela 2 observa-se a caracterização dos escores apresentados pelos professores brasileiros e espanhóis por meio do Test $\mathrm{T}$ independente e ANOVA.

Tabela 2.

Escores do TRF por pais

\begin{tabular}{lllll}
\hline Síndromes/Escalas & $\begin{array}{l}\text { Brasil } \\
(\mathrm{N}=24)\end{array}$ & $\begin{array}{l}\text { Espanha } \\
(\mathrm{N}=13)\end{array}$ & $\mathrm{F}$ & $\mathrm{P}$ \\
\cline { 2 - 3 } & Média (DP) & Média (DP) & & \\
\hline Ansiedade/Depressão & $5,83(4,371)$ & $6,08(3,883)$ & 0,028 & 0,868 \\
\hline Retraimento/Depressão & $4,83(3,144)$ & $4,31(3,301)$ & 0,228 & 0,636 \\
\hline Queixas Somáticas & $1,71(1,829)$ & $2,08(1,935)$ & 0,329 & 0,570 \\
\hline Problemas de Sociabilidade & $4,38(3,512)$ & $7,08(4,192)$ & 4,357 & $0,044^{*}$ \\
\hline Problemas de Pensamento & $2,63(2,763)$ & $3,23(2,127)$ & 0,471 & 0,497 \\
\hline Problemas de Atenção & $23,25(8,674)$ & $31,54(9,980)$ & 6,930 & $0,013^{*}$ \\
\hline Violação de Regras & $3,33(3,679)$ & $3,69(3,594)$ & 0,097 & 0,757 \\
\hline Comportamento Agressivo & $10,67(10,120)$ & $14,08(9,287)$ & 1,012 & 0,321 \\
\hline Escala de Internalização & $12,38(7,282)$ & $12,46(7,468)$ & 0,001 & 0,973 \\
\hline Escala de Externalização & $14,00(13,322)$ & $17,77(11,439)$ & 0,742 & 0,395
\end{tabular}

${ }^{*} \mathrm{p}<0,05$ (Teste $\mathrm{t}$ de Student) 
Em termos gerais, embora a amostra espanhola $(\mathrm{N}=13)$ fosse menor a brasileira $(\mathrm{N}=24)$, mesmo náo alcançando um nível de significância, verificou-se que na maioria das síndromes (ver Tabela 2), os escores obtidos pelos professores espanhóis em relação aos problemas de comportamento elencados no TRF, foram superiores ao dos brasileiros.

As síndromes e Escalas (ver Tabela 2) que apresentaram maiores escores coincidentemente em ambos os países foram: Ansiedade/Depressão, Retraimento/ Depressão, Problemas de Sociabilidade, Problemas de Atenção, Comportamentos Agressivo, Escala de Internalização e Externalização. Ao passo que, os que sinalizaram os menores escores foram: Queixas Somáticas, Problemas de Pensamento e Violação de Regras. Tais dados possivelmente sugerem que os professores dos dois países, percebem um repertório comportamental semelhante nos alunos com o diagnóstico de TDAH.

Em relação a variável país (ver Tabela 2), encontraram-se diferenças significativas apenas em duas síndromes: Problemas de Sociabilidade e Problemas de Atenção. Na síndrome de Problemas de sociabilidade, os escores dos professores espanhóis $(\mathrm{M}=7,08, \mathrm{DP}=4,192)$ sobressaíram-se significativamente ao dos brasileiros $(\mathrm{M}=4,38 \mathrm{DP}=3,512), \mathrm{t}=2,087, \mathrm{p}<0,05$. Este resultado indica maior tendência dos professores espanhóis observarem comportamentos aversivos no contexto social, e dificuldades no desenvolvimento das habilidades sociais por parte dos alunos com TDAH.

Por sua vez, na síndrome de Problemas de Atenção (ver Tabela 2), a média apresentada pelos professores espanhóis $(M=31,54 \mathrm{DP}=9,980)$ foi significativamente superior à média dos brasileiros $(\mathrm{M}=23,25 \mathrm{DP}=8,674)$, $t=2,632, p<0,05$, sugerindo que os professores espanhóis examinam com mais frequência os problemas de atenção dos estudantes em atividades que demandam o sustento da atenção, uma vez comparados aos professores brasileiros.

\section{DISCUSSÃO}

Estudos transculturais são relevantes na compreensão das expressóes comportamentais dos indivíduos em diferentes contextos ambientais (Cole, 2003; Olatundun, 2009; Valsiner, 2012). Apesar da importância desses estudos, a escassez de investigaçóes científica tendo os professores como informantes, se constitui um dos principais entraves na análise dos resultados. Com o objetivo de preencher essa lacuna, o presente estudo comparou os problemas de comportamento em escolares com o diagnóstico de TDAH sob a perspectiva de professores brasileiros e espanhóis.

A análise exploratória-documental do instrumento TRF/6-18 anos das duas amostras clínicas independentes permitiu verificar alguns padróes comportamentais apontados por outros estudos que utilizaram diferentes instrumentos de rastreamento, como também, sintomas percebidos com diferenças significativas nos dados da amostra espanhola em comparaçáo aos escores obtidos com os professores brasileiros.

Os resultados sinalizaram que tanto nas escalas amplas de Internalização e Externalização, quanto nas síndromes que integram tais escalas (Ansiedade/ Depressão, Retraimento/Depressão e Comportamentos agressivo), os escores foram relativamente similares entre o Brasil e a Espanha, não alcançando, portanto, nível de significância. Tais resultados corroboram com o estudo realizado em Porto Rico (Rivera et al., 2005) cujo professores foram um dos informantes, apontou que os problemas internalizantes e externalizantes são evidentes em alunos com TDAH (Rivera et al., 2005). Como também, com a pesquisa desenvolvida no Irã (Eimani-oshnari, Amiri-majd, \& Babakhany, 2014), que sinalou altos escores de problemas de comportamento nas crianças com TDAH, tendo também os professores como um dos principais informantes dos comportamentos das 55 crianças de 7 a 12 anos.

Um outro dado a se salientar, foi que embora não se tenha alcançado diferença significativa entre as Escalas de Externalização e Internalização, os escores da Escala de Externalização foram superiores em ambos os países. Este dado é coerente com a literatura ao apontar que os problemas externalizantes são mais sobressalentes nos indivíduos com TDAH (Bennett, Marini, Berzenski, Carmody, \& Lewis, 2012; Jacob et al., 2014; López Soler et al., 2009; Roessner, Becker, Rothenberger, Rohde, \& Banaschewski , 2007; Tureck ,Matson, May, A, \& Turygin , 2013).

Os problemas externalizantes evidentes nos dois países, refletem a violência e agressividade interpessoal tanto na relação professor-aluno quanto na relação entre pares, comportamentos antissociais, indisciplina, hostilidade, rebeldia, indiferença à figura do professor, irritabilidade, mentira, inquietação psicomotora, entre outros (Achenbach \& Rescorla, 2001; Pedrini \& Frizzo, 2010; Trianes Torres, Sánchez, \& Muñoz Sánchez, 2001). Alguns pesquisadores sinalizam que são os comportamentos mais frequentemente percebidos pelos professores devido aos conflitos e prejuízos que podem causar no ambiente escolar, uma vez comparados aos problemas internalizantes que são de 
ordem privada (Alves et al., 2008; Bauermeister, 2014; Bolsoni-Silva, Marturano, Pereira, \& Manfrinato, 2006; Efstratopoulou et al., 2012; Pedrini \& Frizzo, 2010; Trianes Torres et al., 2001).

Os resultados apontaram diferenças significativas nas síndromes de Problemas de Sociabilidade e Problemas de Atenção em que escores dos professores espanhóis sobrepujaram ao dos brasileiros. Essa discrepância possivelmente está relacionada ao contexto escolar de ambos os países. No Brasil, por exemplo, o baixo nível salarial dos professores, as longas jornadas de trabalho para uma melhor remuneração, a defasagem das condiçôes de trabalho, o estresse ocupacional, distúrbios de voz, entre outras variáveis, podem interferir na observaçáo acurada dos professores em relação aos comportamentos dos alunos (Canova \& Porto, 2010; Dieguez, 2007; Gasparini, Barreto, \& Assunção, 2005; Giannini, Latorre, \& Ferreira, 2012; Koga et al., 2015).

Em relação aos problemas de sociabilidade, considera-se que a competência social é imprescindível no processo de adaptação da criança nas interaçôes afetivas com os outros, o valores sociais, autocontrole, planejamento, tomada de decisóes, autoimagem e competência cultural (Alves et al., 2008; Fernández-Daza \& Fernández-Parra, 2013). A literatura aponta que o êxito e a motivação escolar estão relacionados às habilidades sociais e emocionais, visto que, a criança apresentará dificuldades na resolução de problemas das atividades escolares se não tiver uma boa relaçáo com seus pares, e se não souber autorregular as suas emoçôes (Bauermeister, 2014; Zins, Bloodworth, Weissberg, \& Walberg, 2007).

Problemas de sociabilidade podem estar relacionados a exclusão social. A exemplo disso, um estudo realizado na Espanha (Mata, Conrado, \& Calero, 2016) com 126 adolescentes de 13 a 17 anos, por meio de instrumentos de socialização e problemas interpessoais, constatou que os adolescentes que viviam em ambientes com risco de exclusão social apresentaram mais problemas de comportamento e pobre repertório de habilidades sociais.

Por sua vez, no Brasil, um estudo (Alves et al., 2008) avaliou a influência do treino das habilidades sociais na relação díade professor-aluno utilizando o TRF e o YSR (Yulf Self Report). A amostra foi composta de 113 alunos e 4 professores. Os pesquisadores averiguaram que antes e após o treinamento, os professores não identificaram problemas na faixa clínica por parte dos alunos. Enquanto que, os alunos antes do treinamento se percebiam pior do que os professores os viam, avaliação que mudou após o treinamento. Os pesquisadores apontaram que possivelmente a desmotivação por parte dos professores com as precárias condiçóes de trabalho, podem ter influenciado nos resultados dos testes, que discordavam da verbalização dos próprios professores em relaçáo ao comportamento dos alunos (Alves et al., 2008).

No que tange a síndrome de Problemas de Atenção, a diferença nos escores possivelmente estiveram relacionadas ao estilo de vida dos professores brasileiros, a sobrecarga de papéis, a pobre infraestrutura do ambiente de trabalho, e ao excesso de alunos em sala de aula (Dieguez, 2007; Gasparini et al., 2005; Pedrini $\&$ Frizzo, 2010). Uma vez que, para se identificar os problemas de atenção nos alunos, será necessária mais proximidade e ambiente mais estruturado de avaliação.

Com base no que já foi mencionado, observa-se como os problemas de comportamento podem interferir no desenvolvimento da criança no contexto da sala de aula, ainda mais quando esta apresenta o diagnóstico de TDAH, transtorno que compromete o funcionamento das funçôes executivas, repercutindo no comprometimento da memória de trabalho, na autorregulação das emoçóes, na capacidade de planejamento, na perseverança da resoluçáo de problemas e na motivação de permanecer na escola (Abad-mas et al., 2011; Vélez-van-Meerbeke et al., 2013).

\section{CONSIDERAÇÓES FINAIS}

A principal contribuição deste estudo foi comparar a percepçáo de professores residentes em diferentes países, e constatar que independente das características geográficas e diferenças culturais, vários comportamentos foram identificados de maneira similar nos indivíduos com o diagnóstico de TDAH. Fato que sinaliza um determinado padrão comportamental em relaçáo a comorbidade de problemas de comportamento com o TDAH, conforme aponta a literatura científica. Demonstrando assim, que os professores são observadores e informantes válidos no que tange ao comportamento dos alunos no ambiente escolar.

Não obstante, algumas limitaçôes necessitam ser apontadas: Primeiro, as amostras clínicas em ambos os países não representam a população escolar geral do Brasil e da Espanha. Segundo, realizar estudo intercultural demanda tempo e trâmites burocráticos das unidades de pesquisas, variáveis que interferem diretamente na coleta de dados. Terceiro, a amostra do estudo foi predominantemente masculina, por isso não se analisou o efeito do gênero na incidência dos problemas de comportamentos. De igual modo, devido a 
desigualdade na faixa-etária entre crianças e adolescentes não se realizaram comparações estatísticas entre os grupos. Sugere-se para futuras pesquisas a comparação do nível de concordância entre pais e professores, como também, a verificação do efeito do gênero nos problemas de comportamento.

\section{REFERÊNCIAS}

Abad-mas, L., Ruiz-andrés, R., Moreno-madrid, F., Sirera-conca, M. Á., Cornesse, M., Delgado-mejía, I. D., \& Etchepareborda, M. C. (2011). Entrenamiento de funciones ejecutivas en el trastorno por déficit de atención / hiperactividad. Revista de Neurología, 52(Supl 1), 77-83.

Achenbach, T. M., Becker, A., Döpfner, M., Heiervang, E., Roessner, V., Steinhausen, H. C., \& Rothenberger, A. (2008). Multicultural assessment of child and adolescent psychopathology with ASEBA and SDQ instruments: Research findings, applications, and future directions. Journal of Child Psychology and Psychiatry and Allied Disciplines, 49(3), 251-275. http://doi.org/10.1111/j.1469-7610.2007.01867.x

Achenbach, T. M., \& Rescorla, L. . (2001). Manual for the ASEBA school-age forms \& profiles. Burlington: Research Centre for Children, Youth and Families, University of Vermont.

Alves, D., Maria, S., Ferreira, A. E., Silvares, M., Neste, R., Sociais, H., ... Report, Y. S. (2008). Influência do Treino em Habilidades Sociais na relação professor-aluno: uma contribuição psicopedagógica para professores. Revista ACOALFAplp: Acolhendo a Alfabetização Nos Paises de Lingua Portuguesa, 3(5), 68-90.

American Psychiatric Association. (2013). Diagnostic and statistical manual of mental disorders. (Am. Psychi). Washington: Am. Psychiatr. Publ. 4th ed., text rev.

Azevêdo, P. V. B. e. (2012). Prevalência de Problemas de Saúde Mental em População de Crianças e Adolescentes Indígenas Karajá da Amazônia Brasileira. Tese de Doutorado. Program de Ciências da Saúde. Universidade Federal de Goiás. Goiás, Brasil.

Barkley, R. A. (2008). Transtorno do Déficit de Atenção/Hiperatividade: Manual para Diagnóstico e Tratamento. Porto Alegre: Artmed.

Bauermeister, J. J. (2014). Hiperactivo, Impulsivo, Distraido ¿Me conoces? (3a). New York: The Guilford Press.

Bennett, D. S., Marini, V. A., Berzenski, S. R., Carmody, D. P., \& Lewis, M. (2012). Externalizing problems in late childhood as a function of prenatal cocaine exposure and environmental risk. Journal of pediatric psychology, 38(3), 296-308. doi:10.1093/jpepsy/ jss117sh

Bernedo, I. M., Salas, M. D., García-Martín, M. A., \& Fuentes, M. J. (2012). Teacher assessment of behavior problems in foster care children. Children and Youth Services Review, 34(4), 615-621. http:// doi.org/10.1016/j.childyouth.2011.12.003

Bierman, K. L. (2011). The promise and potential of studying the "invisible hand" of teacher influence on peer relations and student outcomes: A commentary. Journal of Applied Developmental Psychology, 32(5), 297-303. http://doi.org/10.1016/j. appdev.2011.04.004

Bolsoni-Silva, A. T., Marturano, E. M., Pereira, V. A., \& Manfrinato, J. W. S. (2006). Habilidades Sociais e Problemas de Comportamento de PréEscolares : Comparando Avaliações de Mães e de Professoras Preschooler's Social Skills and Behavior Problems: Comparison between Mother and Teacher Assessments. Psicologia: Reflexão E Crítica, 19(3), 460-469. Retrieved from http://dx.doi. org/10.1590/S0102-79722006000300015

Bordin, I. A., Rocha, M. M., Paula, C. S., Teixeira, M. C. T. V, Achenbach, T. M., Rescorla, L. A., \& Silvares, E. F. M. (2013). Child Behavior Checklist ( CBCL ), Youth Self- Report ( YSR ) and Teacher's Report Form (TRF): an overview of the development of the original and Brazilian. Cad Saucide Publica, 29(1), $13-28$.

Canova, K. R., \& Porto, J. B. (2010). O impacto dos valores organizacionais no estresse ocupacional: um estudo com professores de ensino médio. Revista de Administração Mackenzie (Online), 11(5), 4-31. http://doi.org/10.1590/ S1678-69712010000500002

Cardo, E., Servera, M., Vidal, C., Azua, B., Redondo, M., \& Riutort, L. (2011). Influencia de los diferentes criterios diagnósticos y la cultura en la prevalencia del trastorno por déficit de atención / hiperactividad. Rev Neurol, 52(Supl 1), 109-117.

Cole, M. (2003). Psicología cultural (2a). Madrid: Morata.

Curtis, D. F., Pisecco, S., Hamilton, R. J., \& Moore, D. W. (2006). Teacher perceptions of classroom interventions for children with ADHD: A crosscultural comparison of teachers in the United States and New Zealand. School Psychology Quarterly, 21(2), 171-196. http://doi.org/10.1521/ scpq.2006.21.2.171 
D’Abreu, L. C. F., \& Marturano, E. M. (2010). Associação entre comportamentos externalizantes e baixo desempenho escolar: uma revisão de estudos prospectivos e longitudinais. Estudos de Psicologia, 15(1), 43-51.

Dieguez, F. (2007). Professores, elo frágil da educação. Estudos Avançados, 21(60), 105-115. http://doi. org/10.1590/S0103-40142007000200008

Dumas, J. E. (2011). Psicopatologia da infância e da adolescência $\left(3^{\mathrm{a}}\right)$. Porto Alegre: Artmed.

Efstratopoulou, M., Janssen, R., \& Simons, J. (2012). Agreement among physical educators, teachers and parents on children's behaviors: A multitrait-multimethod design approach. Research in Developmental Disabilities, 33(5), 1343-1351. http://doi.org/10.1016/j.ridd.2012.03.015

Eimani-oshnari, M., Amiri-majd, M., \& Babakhany, V. (2014). A Comparison of emotional and behavioral problems in children with ADHD at home and school. J Anal Res Clin Med, 2(2), 64-70. http:// doi.org/10.5681/jarcm.2014.011

Faraone, S. V, Biederman, J., \& Mick, E. (2006). The age-dependent decline of attention deficit hyperactivity disorder: a meta-analysis of follow-up studies. Psychological Medicine, 36, 159-165. http:// doi.org/10.1017/S003329170500471X

Farmer, T. W., McAuliffe Lines, M., \& Hamm, J. V. (2011). Revealing the invisible hand: The role of teachers in children's peer experiences. Journal of Applied Developmental Psychology, 32(5), 247-256. http://doi.org/10.1016/j.appdev.2011.04.006

Fernández-Daza, M. P., \& Fernández-Parra, A. (2013). Problemas de comportamiento y competencias psicosociales en niños y adolescentes institucionalizados. Universitas Psychologica, 12(3), 1. http://doi.org/10.11144/Javeriana.UPSY12-3. pccp

Gasparini, S. M., Barreto, S. M., \& Assunção, A. A. (2005). O professor, as condiçóes de trabalho e os efeitos sobre sua saúde. Educação E Pesquisa, 31(2), 189-199. http://doi.org/10.1590/ S1517-97022005000200003

Giannini, S. P. P., Latorre, M. do R. D. de O., \& Ferreira, L. P. (2012). Distúrbio de voz e estresse no trabalho docente: um estudo caso-controle Voice disorders related to job stress in teaching: a case-control study. Cadernos de Saúde Pública, 28(11), 2115-2124. http://doi.org/10.1590/ S0102-311X2012001100011

Guttmannova, K., Szanyi, J. M., \& Cali, P. W. (2008). Internalizing and Externalizing Behavior
Problem Scores. Educational and Psychological Measurement, 68(4), 676-694. http://doi. org/10.1177/0013164407310127

Jacob, C., Gross-Lesch, S., Jans, T., Geissler, J., Reif, A., Dempfle, A., \& Lesch, K. P. (2014). Internalizing and externalizing behavior in adult ADHD. $A D H D$ Atten Def Hyp Disord, 6, 101-110. http://doi. org/10.1007/s12402-014-0128-z

Jiménez, E. P. (2008). El papel del profesorado en la actualidad. Su función docente y social. Foro de Educación, 1(10), 325-345. http://doi.org/ISSN: 1698-7799

Kindermann, T. A. (2011). Commentary: The invisible hand of the teacher. Journal of Applied Developmental Psychology, 32(5), 304-308. http:// doi.org/10.1016/j.appdev.2011.04.005

Koga, G. K. C., Melanda, F. N., Santos, H. G. dos, Sant'Anna, F. L., González, A. D., Mesas, A. E., \& Andrade, S. M. de. (2015). Fatores associados a piores níveis na escala de Burnout em professores da educação básica. Cadernos Saúde Coletiva, 23(3), 268-275. http://doi.org/10.1590/1414-462X201500030121

Kostelnik, M. ., Gregory, K. ., Soderman, A. ., \& Whiren, A. . (2012). Guia de aprendizagem e desenvolvimento social da criança (7a edição). São Paulo: Cengage Learning.

López Soler, C., Castro Sáez, M., Alcántara López, M. V., Fernández Fernández, V., López Pina, J. A., LópezSoler, C., ... López Pina, J. A. (2009). Prevalencia y características de los síntomas externalizantes en la infancia. Diferencias de género. Psicothema, 21(3), 353-358. Retrieved from http://dialnet.unirioja. es/servlet/articulo? codigo $=3024951$ \&orden $=2193$ 84\&info=linklnhttp://dialnet.unirioja.es/servlet/ extart? codigo $=3024951$

Mata, S., Conrado, M., \& Calero, M. . (2016). Sociabilidad y problemas de conducta en Adolescentes con riesgo de exclusión social. Behavioral Psychology/ Psicología Conductual, 24(1), 127-139.

Olatundun, I. O. (2009). What is Cross-cultural Research? International Journal of Psychological Studies, 1(2), 82-96. http://doi.org/10.5539/ijps. v1n2p82

Organização Mundial da Saúde. (1993). Classificação de transtornos mentais e de comportamento da CID-10: descriçôes clínicas e diretrizes diagnósticas. (Editora Artes Médicas, Ed.). Porto Alegre.

Pedrini, J. R., \& Frizzo, G. B. (2010). Avaliação de indicadores de problemas de comportamento infantil relatados por pais e professores. Aletheia, (33), 1-11. 
Polanczyk, G. V., Salum, G. A., Sugaya, L. S., Caye, A., \& Rohde, L. A. (2015). Annual research review: A meta-analysis of the worldwide prevalence of mental disorders in children and adolescents. Journal of Child Psychology and Psychiatry and Allied Disciplines, 56(3), 345-365. http://doi.org/10.1111/jcpp.12381

Rivera, O., Martínez, A., \& Pérez, J. (2005). Comparación de la sintomatología internalizante y externalizante en un grupo de niños y nińas con y sin trastorno de déficit de atención con hiperactividad. Revista Puertorirqueña de Psicología, 16, 27-50.

Roessner, V., Becker, A., Rothenberger, A., Rohde, L., \& Banaschewski, T. (2007). A cross-cultural comparison between samples of Brazilian and German children with ADHD / HD using the Child Behavior Checklist. Eur Arch Psychiatry Clin Neurosci, 257, 352-359. http://doi.org/10.1007/ s00406-007-0738-y

Rudasill, K. M., Reio, T. G., Stipanovic, N., \& Taylor, J. E. (2010). A longitudinal study of student-teacher relationship quality, difficult temperament, and risky behavior from childhood to early adolescence. Journal of School Psychology, 48(5), 389-412. http:// doi.org/10.1016/j.jsp.2010.05.001

Serrano-troncoso, E., Guidi, M., \& Alda-Díez, J. A. (2013). ¿ Es el tratamiento psicológico eficaz para el trastorno por déficit de atención con hiperactividad ( TDAH )? Revisión sobre los tratamientos no farmacológicos en niños y adolescentes con TDAH. Actas Esp Psiquiatr 41(1), 44-51.

Sointu, E. T., Savolainen, H., Lappalainen, K., \& Epstein, M. H. (2012). Parent, Teacher and Student Cross Informant Agreement of Behavioral and Emotional Strengths: Students With and Without Special Education Support. Journal of Child and Family Studies, 21(4), 682-690. http://doi. org/10.1007/s10826-011-9520-x

Soler, C. L., Alcántara, M. V., Fernández, V., Castro, M., \& López Pina, J. a. (2010). Características y prevalencia de los problemas de ansiedad, depresión y quejas somáticas en una muestra clínica infantil de 8 a 12 años, mediante el CBCL (Child Behavior Checklist). Anales de Psicologia, 26(2), 325-334. http://doi.org/10.6018/analesps.26.2.109301

Trianes Torres, V., Sánchez, A. S., \& Muñoz Sánchez, Á. (2001). Educar la convivencia como prevención de violencia interpersonal: perspectivas de los profesores. Revista Interuniversitaria de Formación Del Profesorado, (11), 73-93. Retrieved from http:// www.redalyc.org/pdf/274/27404106.pdf
Tureck, K., Matson, J. L., May, A., \& Turygin, N. (2013, feb.). Externalizing and tantrum behaviours in children with ASD and ADHD compared to children with ADHD. Developmental Neurorehabilitation, 16, 52-57. http://doi.org/10.3109/17518423.2012.71 9245

Valsiner, J. (2012). Fundamentos da psicologia cultural: mundos da mente, mundos da vida. Porto Alegre: Artmed.

Vélez-van-Meerbeke, a., Zamora, I. P., Guzmán, G., Figueroa, B., López Cabra, C. a., \& Talero-Gutiérrez, C. (2013). Evaluación de la función ejecutiva en una población escolar con síntomas de déficit de atención e hiperactividad. Neurologia, 28(6), 348-355. http:// doi.org/10.1016/j.nrl.2012.06.011

Whitbourne, S. ., \& Halgin, R. . (2015). Psicopatologia: perspectivas clínicas dos transtornos psicológicos. Porto Alegre: AMGH.

World Health Organization. (2002). Relatório mundial da saúde - Saúde mental: nova concepção, nova esperança.

Zins, J. E., Bloodworth, M. R., Weissberg, R. P., \& Walberg, H. J. (2007). The Scientific Base Linking Social and Emotional Learning to School Success. Journal of Educational and Psychological Consultation, 17(2-3), 191-210.

\section{Endereço para correspondência:}

Programa de Pós-Graduação em Psicologia

Universidade Federal do Pará

Rua Augusto Corrêa, 01

Campus Universitário do Guamá

Belém, PA

CEP 66.075.110

Ana Flávia Lima Teles Da Hora

anaflaviadahora@hotmail.com

Recebido em 19/09/2018

Aceito em 29/10/2018 